Cochrane Database of Systematic Reviews

\title{
Interventions for treating people with symptoms of bladder pain syndrome: a network meta-analysis (Review)
}

Imamura M, Scott NW, Wallace SA, Ogah JA, Ford AA, Dubos YA, Brazzelli M

Imamura M, Scott NW, Wallace SA, Ogah JA, Ford AA, Dubos YA, Brazzelli M.

Interventions for treating people with symptoms of bladder pain syndrome: a network meta-analysis.

Cochrane Database of Systematic Reviews 2020, Issue 7. Art. No.: CD013325.

DOI: 10.1002/14651858.CD013325.pub2.

www.cochranelibrary.com

Interventions for treating people with symptoms of bladder pain syndrome: a network meta-analysis (Review) 
HEADER 1

ABSTRACT

PLAIN LANGUAGE SUMMARY

SUMMARY OF FINDINGS

BACKGROUND

Figure 1.

OBJECTIVES

METHODS

RESULTS

Figure 2.

Figure 3.

Figure 4.

Figure 5.

Figure 6.

Figure 7.

Figure 8.

Figure 9.

Figure 10.

Figure 11.

Figure 12.

Figure 13.

Figure 14.

DISCUSSION

AUTHORS' CONCLUSIONS

ACKNOWLEDGEMENTS

REFERENCES

CHARACTERISTICS OF STUDIES

ADDITIONAL TABLES

APPENDICES

HISTORY

CONTRIBUTIONS OF AUTHORS

DECLARATIONS OF INTEREST

SOURCES OF SUPPORT

DIFFERENCES BETWEEN PROTOCOL AND REVIEW

\section{TABLE OF CONTENTS}


[Intervention Review]

\section{Interventions for treating people with symptoms of bladder pain syndrome: a network meta-analysis}

Mari Imamura1 ${ }^{\text {, Neil W Scott }}{ }^{2}$, Sheila A Wallace ${ }^{3}$, Joseph A Ogah ${ }^{4}$, Abigail A Ford ${ }^{5}$, Yann A Dubos ${ }^{6}$, Miriam Brazzelli

1Health Services Research Unit, University of Aberdeen, Aberdeen, UK. 2Medical Statistics Team, University of Aberdeen, Aberdeen, UK. ${ }^{3}$ Evidence Synthesis Group, Population Health Sciences Institute, Faculty of Medical Sciences, Newcastle University, Newcastle upon Tyne, UK. ${ }^{4}$ Obstetrics and Gynaecology, University Hospitals of Morecambe Bay NHS Foundation Trust, Barrow in Furness, UK. ${ }^{5}$ Department of Urogynaecology, Imperial Healthcare Trust, St Mary's Hospital, London, UK. ${ }^{6} \mathrm{c} / \mathrm{o}$ Health Services Research Unit, University of Aberdeen, Aberdeen, UK

Contact address: Miriam Brazzelli, m.brazzelli@abdn.ac.uk.

Editorial group: Cochrane Incontinence Group.

Publication status and date: New, published in Issue 7, 2020.

Citation: Imamura M, Scott NW, Wallace SA, Ogah JA, Ford AA, Dubos YA, Brazzelli M. Interventions for treating people with symptoms of bladder pain syndrome: a network meta-analysis. Cochrane Database of Systematic Reviews 2020, Issue 7. Art. No.: CD013325. DOI: 10.1002/14651858.CD013325.pub2.

Copyright @ 2020 The Cochrane Collaboration. Published by John Wiley \& Sons, Ltd.

\section{A B S T R A C T}

\section{Background}

Bladder pain syndrome (BPS), which includes the condition of interstitial cystitis, is a poorly understood clinical condition for which patients present with varying symptoms. Management of BPS is challenging for both patients and practitioners. At present, there is no universally accepted diagnosis and diverse causes have been proposed. This is reflected in wide-ranging treatment options, used alone or in combination, with limited evidence. A network meta-analysis (NMA) simultaneously comparing multiple treatments may help to determine the best treatment options for patients with BPS.

\section{Objectives}

To conduct a network meta-analysis to assess the effects of interventions for treating people with symptoms of bladder pain syndrome (BPS).

\section{Search methods}

We searched the Cochrane Incontinence Specialised Register, which contains trials identified from the Cochrane Central Register of Controlled Trials (CENTRAL, in the Cochrane Library), MEDLINE, MEDLINE In-Process, MEDLINE Epub Ahead of Print, ClinicalTrials.gov, the World Health Organization International Clinical Trials Registry Platform (WHO ICTRP) and handsearched journals and conference proceedings (searched 11 May 2018) and the reference lists of relevant articles. We conducted a further search on 5 June 2019, which yielded four small studies that were screened for eligibility but were not incorporated into the review.

\section{Selection criteria}

We included randomised controlled trials (RCTs) and quasi-RCTs of interventions for treating adults with BPS. All types of interventions (including conservative, pharmacological and surgical) were eligible.

\section{Data collection and analysis}

We assessed the risk of bias of included studies using Cochrane's 'Risk of bias' tool. Primary outcomes were the number of people cured or improved, pain, frequency and nocturia. For each outcome, random-effects NMA models were fitted using WinBUGS 1.4. We monitored median odds ratios (ORs) for binary outcomes and mean differences (MDs) for continuous outcomes with $95 \%$ credible intervals (Crls). We 
compared results of the NMA with direct evidence from pairwise meta-analysis of head-to-head trials. We used the CINeMA tool to assess the certainty of evidence for selected treatment categories.

\section{Main results}

We included 81 RCTs involving 4674 people with a median of 38 participants (range 10 to 369 ) per RCT. Most trials compared treatment against control; few trials compared two active treatments. There were 65 different active treatments, and some comparisons were informed by direct evidence from only one trial. To simplify, treatments were grouped into 31 treatment categories by mode of action. Most studies were judged to have unclear or high risk of bias for most domains, particularly for selection and detection bias. Overall, the NMA suggested that six (proportion cured/improved), one (pain), one (frequency) and zero (nocturia) treatment categories were effective compared with control, but there was great uncertainty around estimates of effect.

Due to the large number of intervention comparisons in this review, we focus on three interventions: antidepressants, pentosan polysulfate (PPS) and neuromuscular blockade. We selected these interventions on the basis that they are given 'strong recommendations' in the EAU Guidelines for management of BPS (EAU Guidelines 2019).

We found very low-certainty evidence suggesting that antidepressants were associated with greater likelihood of cure or improvement compared with control (OR 5.91, 95\% Crl 1.12 to 37.56), but it was uncertain whether they reduced pain (MD -1.27, 95\% Crl -3.25 to 0.71; low-certainty evidence), daytime frequency (MD -2.41, 95\% Crl -6.85 to 2.05; very low-certainty evidence) or nocturia (MD $0.01,95 \% \mathrm{Crl}$ -2.53 to 2.50 ; very low-certainty evidence).

There was no evidence that PPS had improved cure/improvement rates (OR $0.14,95 \% \mathrm{Crl} 0.40$ to 3.35 ; very low-certainty evidence) or reduced pain (MD $0.42,95 \% \mathrm{Crl}-1.04$ to 1.91 ; low-certainty evidence), frequency (MD $-0.37,95 \% \mathrm{Crl}-5.00$ to 3.44 ; very low-certainty evidence) or nocturia (MD -1.20, $95 \% \mathrm{Crl}-3.62$ to 1.28 ; very low-certainty evidence).

There was evidence that neuromuscular blockade resulted in greater cure or improvement (OR 5.80, 95\% $\mathrm{Crl} 2.08$ to 18.30 ) but no evidence that it improved pain (MD - $0.33,95 \% \mathrm{Crl}-1.71$ to 1.03 ), frequency (MD -0.91, 95\% Crl-3.24, 1.29) or nocturia (MD -0.04, 95\% Crl-1.35 to 1.27 ). The certainty of this evidence was always very low.

\section{Authors' conclusions}

We are uncertain whether some treatments may be effective in treating patients with BPS because the certainty of evidence was generally low or very low. Data were available for a relatively large number of trials, but most had small sample sizes and effects of treatments often could not be estimated with precision. An NMA was successfully conducted, but limited numbers of small trials for each treatment category hampered our ability to fully exploit the advantages of this analysis. Larger, more focused trials are needed to improve the current evidence base.

\section{PLAIN LANGUAGE SUMMARY}

\section{Treatments for people with bladder pain syndrome}

\section{What is bladder pain syndrome?}

Bladder pain syndrome (BPS; also called painful bladder syndrome or interstitial cystitis) is a long-term painful condition that affects the bladder. 'Syndrome' refers to a collection of symptoms. In BPS, these symptoms include: intense pain in the pelvis (felt below the bellybutton); sudden strong urges to urinate; needing to urinate more often than usual; and waking up several times during the night to urinate.

BPS is more common in women. We do not know what causes it or how to cure it. Symptoms sometimes come and go in phases. BPS can significantly affect lifestyle, work, emotional health and relationships.

\section{Treatments for BPS}

Lifestyle changes are usually tried first, then medicines and supportive therapies. Surgery may be needed as a last resort.

Medicines used include pentosan polysulfate sodium - which may help to restore the inner surface of the bladder - anti-inflammatories, antidepressants and antihistamines. Medicines that block the connection between nerves and muscles can be injected into the bladder muscle to try to relax it ('neuromuscular blockade'). Supportive therapies and treatments include behavioural therapy, physiotherapy, bladder re-training, psychological therapy and transcutaneous electrical nerve stimulation (TENS).

\section{Review question}

In this Cochrane Review, we wanted to find out which treatments work best to treat BPS.

\section{What did we do?}


We searched for studies that looked at any type of treatment for BPS. We looked for randomised controlled studies, in which the treatment people receive is randomly decided, because these studies usually give the most reliable evidence about treatments.

\section{Search date}

We included evidence published up to 11 May 2018. We conducted a further search on 5 June 2019, which yielded four small studies that were screened for eligibility but were not incorporated into the review.

\section{What we found}

We found 81 studies involving 4674 people with BPS. The biggest study included 369 people, and the smallest study included 10 people. Most studies lasted around three months; only six studies lasted 12 months or longer. Twenty-four studies were funded by pharmaceutical companies.

We found 65 treatments for BPS, which we grouped into 31 categories based on how the treatments worked. In most studies, a treatment for BPS was compared with a placebo (or dummy) treatment. We compared all treatments with each other using a mathematical method called network meta-analysis.

\section{What are the results of our review?}

After 12 months, antidepressants or neuromuscular blockade (and some other treatments) may improve symptoms of BPS more than placebo, but we are not certain about this result. We did not find enough evidence to know if pentosan polysulfate sodium improves symptoms.

We are uncertain whether 12 months of treatment with antidepressants, neuromuscular blockade or pentosan polysulfate sodium reduced pain (as measured on a scale); the number of times people had to urinate during the day; or the number of times people had to get up to urinate during the night.

\section{Our confidence in the results}

We are uncertain about our results because we did not find enough reliable evidence. Although we obtained results from 81 studies, most of these studies were small and did not include enough people for us to be certain of their results. Some of the studies (30\%) were conducted by pharmaceutical companies, and this may have affected how the studies were designed, conducted and reported. Our results may change when results from more, and larger, studies become available.

\section{Conclusions}

We did not find enough reliable evidence about how well medicines, behavioural therapy, physiotherapy and neuromuscular blockade worked to treat all, or any, of the symptoms of BPS. 


\section{SUMMARY OF FINDINGS}

\section{Summary of findings 1 . Interventions for treating people with symptoms of bladder pain syndrome}

Interventions for treating people with symptoms of bladder pain syndrome

Patient or population: people with bladder pain syndrome

Settings: hospital setting

Intervention: antidepressants, pentosan polysulfate (PPS), neuromuscular blockade

Comparison: control treatment

\begin{tabular}{|c|c|c|c|c|c|}
\hline \multirow[t]{2}{*}{ Outcomes } & \multicolumn{4}{|c|}{$\begin{array}{l}\text { Effects and } 95 \% \text { credible intervals (NMA) and confidence intervals (pairwise) in the effects. Main compara- } \\
\text { tor is control treatment }\end{array}$} & \multirow[t]{2}{*}{ Comments } \\
\hline & $\begin{array}{l}\text { Risk with con- } \\
\text { trol treatment* }\end{array}$ & $\begin{array}{l}\text { Risk with antidepres- } \\
\text { sants }{ }^{\star \star}\end{array}$ & Risk with PPS ${ }^{\star \star}$ & $\begin{array}{l}\text { Risk with neuromuscular } \\
\text { blockade }\end{array}$ & \\
\hline \multirow{2}{*}{$\begin{array}{l}\text { Cure or improve- } \\
\text { ment: median odds } \\
\text { ratio ( } 95 \% \text { credible } \\
\text { interval) }\end{array}$} & \multirow{2}{*}{$\begin{array}{l}26.2 \% \text { (303 to } \\
1156)\end{array}$} & OR 5.91 (1.12 to 37.56$)$ & OR 1.14 (0.40 to 3.35$)$ & OR 5.80 (2.08 to 18.30$)$ & \multirow{2}{*}{$\begin{array}{l}\text { Follow-up: } 12 \text { months or } \\
\text { nearest time point available } \\
\text { to } 12 \text { months }\end{array}$} \\
\hline & & $\begin{array}{l}\oplus \odot \odot \ominus \\
\text { Very low } a\end{array}$ & $\begin{array}{l}\oplus \ominus \ominus \ominus \\
\text { Very low } b\end{array}$ & $\begin{array}{l}\oplus \ominus \ominus \ominus \\
\text { Very low } c\end{array}$ & \\
\hline \multirow[t]{2}{*}{$\begin{array}{l}\text { Pain score: mean } \\
\text { differences vs con- } \\
\text { trol (95\% credible in- } \\
\text { terval) }\end{array}$} & \multirow[t]{2}{*}{$\begin{array}{l}\text { Mean pain score } \\
\text { at follow-up } \\
\text { ranged across } \\
\text { control groups } \\
\text { from } 2.6 \text { to } 9.4\end{array}$} & $\begin{array}{l}\text { Mean pain score in the in- } \\
\text { tervention groups was } \mathbf{1 . 2 7} \\
\text { lower ( } 3.25 \text { lower to } 0.71 \\
\text { higher) }\end{array}$ & $\begin{array}{l}\text { Mean pain score in the in- } \\
\text { tervention groups was } \mathbf{0 . 4 2} \\
\text { higher (1.04 lower to } 1.91 \\
\text { higher) }\end{array}$ & $\begin{array}{l}\text { Mean pain score in the inter- } \\
\text { vention groups was } \mathbf{0 . 3 3} \text { low- } \\
\text { er ( } 1.71 \text { lower to } 1.03 \text { higher) }\end{array}$ & \multirow{2}{*}{$\begin{array}{l}\text { Scale ranged from } 0 \text { to } 10 \text {. } \\
\text { Less pain indicated by lower } \\
\text { values } \\
\text { MCID = } 2.5 \text { points } \\
\text { Follow-up: } 12 \text { months or } \\
\text { nearest time point available } \\
\text { to } 12 \text { months }\end{array}$} \\
\hline & & $\begin{array}{l}\oplus \oplus \ominus \ominus \\
\text { Low }\end{array}$ & $\begin{array}{l}\oplus \ominus \ominus \ominus \\
\text { Very low } e\end{array}$ & $\begin{array}{l}\oplus \ominus \ominus \ominus \\
\text { Very low } c\end{array}$ & \\
\hline \multirow{3}{*}{$\begin{array}{l}\text { Daytime frequen- } \\
\text { cy (number of day- } \\
\text { time voids): mean } \\
\text { differences vs con- } \\
\text { trol (95\% credible in- } \\
\text { terval) }\end{array}$} & $\begin{array}{l}\text { Mean daytime } \\
\text { frequency ranged } \\
\text { across control }\end{array}$ & $\begin{array}{l}\text { Mean number of daytime } \\
\text { voids in the intervention } \\
\text { groups was }\end{array}$ & $\begin{array}{l}\text { Mean number of daytime } \\
\text { voids in the intervention } \\
\text { groups was }\end{array}$ & $\begin{array}{l}\text { Mean number of daytime } \\
\text { voids in the intervention } \\
\text { groups was }\end{array}$ & \multirow{3}{*}{$\begin{array}{l}\text { Lower scores indicate better } \\
\text { outcome } \\
\text { MCID = } 2 \text { points } \\
\text { Follow-up: } 12 \text { months or } \\
\text { nearest time point available } \\
\text { to } 12 \text { months }\end{array}$} \\
\hline & 8.2 to 14.8 & $\begin{array}{l}2.41 \text { lower }(6.85 \text { lower to } \\
2.05 \text { higher) }\end{array}$ & $\begin{array}{l}\mathbf{0 . 3 7} \text { lower }(5.00 \text { lower to } \\
3.44 \text { higher) }\end{array}$ & $\begin{array}{l}0.91 \text { lower ( } 3.24 \text { lower to } 1.29 \\
\text { higher) }\end{array}$ & \\
\hline & & $\begin{array}{l}\oplus \ominus \ominus \ominus \\
\text { Very low } f\end{array}$ & $\begin{array}{l}\oplus \ominus \ominus \ominus \\
\text { Very low } d\end{array}$ & $\begin{array}{l}\oplus \ominus \ominus \ominus \\
\text { Very low } g\end{array}$ & \\
\hline
\end{tabular}




\begin{tabular}{|c|c|c|c|c|c|}
\hline \multirow{3}{*}{ 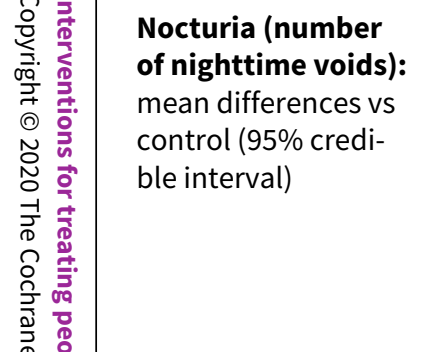 } & \multirow{3}{*}{$\begin{array}{l}\text { Mean nocturia } \\
\text { ranged across } \\
\text { control groups } \\
\text { from } \\
1.0 \text { to } 5.8\end{array}$} & $\begin{array}{l}\text { Mean number of nighttime } \\
\text { voids in the intervention } \\
\text { groups was }\end{array}$ & $\begin{array}{l}\text { Mean number of nighttime } \\
\text { voids in the intervention } \\
\text { groups was }\end{array}$ & $\begin{array}{l}\text { Mean number of nighttime } \\
\text { voids in the intervention } \\
\text { groups was }\end{array}$ & \multirow{3}{*}{$\begin{array}{l}\text { Lower scores indicate better } \\
\text { outcome } \\
\text { MCID = } 1 \text { point } \\
\text { Follow-up: } 12 \text { months or } \\
\text { nearest time point available } \\
\text { to } 12 \text { months }\end{array}$} \\
\hline & & $\begin{array}{l}0.01 \text { higher ( } 2.53 \text { lower to } \\
2.50 \text { higher) }\end{array}$ & $\begin{array}{l}1.20 \text { lower ( } 3.62 \text { lower to } \\
1.28 \text { higher) }\end{array}$ & $\begin{array}{l}\mathbf{0 . 0 4} \text { lower ( } 1.35 \text { lower to } 1.27 \\
\text { higher) }\end{array}$ & \\
\hline & & $\begin{array}{l}\oplus \ominus \ominus \ominus \\
\text { Very low } h\end{array}$ & $\begin{array}{l}\oplus \ominus \ominus \ominus \\
\text { Very low } i\end{array}$ & $\begin{array}{l}\oplus \ominus \ominus \ominus \\
\text { Very low } e\end{array}$ & \\
\hline
\end{tabular}

* The risk in the control group (and its 95\% confidence interval) is based on a meta-analysis of proportions from the studies included in this review for this group.

${ }^{\star \star}$ Risks in the antidepressant, PPS and neuromuscular blockade groups (and their $95 \%$ credible interval) are based on the assumed risk in the control group and the relative effects of the interventions (and their $95 \%$ credible interval).

Note: In GRADE assessments, 'within-study bias' was determined using the following domains from the 'risk of bias' assessments: sequence generation, allocation concealment and blinding of outcome assessor. Studies were classified as 'low risk of bias' if all key domains were judged to be at low risk, 'unclear risk of bias' if one or more key domains were judged to be at unclear risk, and 'high risk of bias' if one or more key domains were judged to be at high risk. We conducted GRADE assessments using the CINeMA 2017 web application.

MCID: minimal clinically important difference; NMA: network meta-analysis; OR: odds ratio; PPS: pentosan polysulfate.

GRADE Working Group grades of evidence.

High certainty: we are very confident that the true effect lies close to that of the estimate of the effect.

Moderate certainty: we are moderately confident in the effect estimate; the true effect is likely to be close to the estimate of the effect, but there is a possibility that it is substantially different.

Low certainty: our confidence in the effect estimate is limited; the true effect may be substantially different from the estimate of the effect.

Very low certainty: we have very little confidence in the effect estimate; the true effect is likely to be substantially different from the estimate of effect.

aDowngraded due to within-study bias, heterogeneity and incoherence, based on 2 studies.

bDowngraded due to within-study bias and imprecision, based on 6 studies.

cDowngraded due to within-study bias and heterogeneity, based on 6 studies.

$d$ Downgraded due to within-study bias and imprecision, based on 2 studies.

eDowngraded due to within-study bias and heterogeneity, based on 4 studies.

fDowngraded due to within-study bias, imprecision and heterogeneity, based on 1 study.

gDowngraded due to within-study bias, imprecision and heterogeneity, based on 5 studies.

howngraded due to within-study bias and imprecision, based on 1 study.

iDowngraded due to within-study bias and heterogeneity, based on 2 studies. 


\section{B A C K G R O U N D}

\section{Description of the condition}

Bladder pain syndrome (BPS), which includes the condition of interstitial cystitis, is a chronic condition that most often affects women and is characterised by pain in the bladder and/or pelvis and other urinary symptoms, such as urgency and frequency (Hanno 2017). The causes of BPS remain poorly understood, and no single causative trigger or validated diagnostic markers have been identified. Thus, diagnosis primarily relies on reported symptoms and the exclusion of any other identifiable causes (Hanno 2017).

During a major international meeting in 1987, and later in 1990, the National Institute of Diabetes and Digestive and Kidney Diseases (NIDDK) developed diagnostic criteria for interstitial cystitis based on objective cystoscopic and urodynamic evaluation (NIDDK 2017). Such evaluation involves putting the patient under local or general anaesthesia and catheterising the urinary bladder, and so is associated with substantial risks and costs. The NIDDK criteria have helped inform the selection of homogeneous patient populations for research purposes but have proven too strict for use in routine clinical practice (Hanno 1999). Consequently, the International Continence Society (ICS) proposed a broader term - 'painful bladder syndrome' (Abrams 2002). The European Society for Study of Interstitial Cystitis/Bladder Pain Syndrome (ESSIC) used the term, 'bladder pain syndrome (BPS)', defined as "chronic pelvic pain, pressure or discomfort of greater than six months duration perceived to be related to the urinary bladder accompanied by at least one other urinary symptom like persistent urge to void or urinary frequency. Confusable diseases as the cause of the symptoms must be excluded" (van de Merwe 2008). This definition was accepted by the International Consultation on Incontinence in 2010 (Hanno 2010). As patients tend to refer to it as interstitial cystitis, the name 'interstitial cystitis' may be used in parallel with BPS (e.g. 'IC/BPS'). In this Cochrane Review, we will refer to the condition as BPS, although we will also consider some older literature using the original terminology.

Lack of a universally accepted clinical diagnosis of BPS makes epidemiological studies of the condition problematic. Prevalence estimates vary widely depending on diagnostic criteria and how prevalence estimates were derived (i.e. self-report, physician diagnoses and/or symptom-based surveys). One estimate is that BPS is experienced by 100 to 200 per 100,000 women, with a male prevalence of $10 \%$ to $20 \%$ of the estimate for females (Hanno 2017), although it is accepted that BPS is more common than is suggested by empirical studies (Hanno 2017). BPS may negatively impact quality of life and the psychological state of people with the condition, with some experiencing depression, anxiety, distress and sexual dysfunction (Cox 2016).

Although not consistently present (particularly in non-ulcerative BPS), the main pathological feature of BPS is inflammation of the bladder. This leads to vasodilation, enhanced vascular permeability and degradation of the mucosal glycosaminoglycan coating of the urothelium. When inflammation is present, it can spread to deeper tissues of the bladder, and, in some cases, Hunner's lesions may appear in the bladder wall. This is often referred to as ulcerative BPS. It is thought that this abnormal inflammation of the bladder underlies the symptoms of pain (Grover 2011; Logadottir 2014).
To date, no definitive consensus has been reached on how or why BPS develops.

\section{Description of the intervention}

Treatment options for BPS are varied (Hanno 2017). Current clinical guidelines emphasise that an individualised treatment plan is likely to lead to better patient outcomes (Cox 2016). Usually, the initial treatment of BPS comprises patient education and support, dietary manipulation, stress reduction, non-prescription analgesics and pelvic floor relaxation techniques. When the conservative approach fails, or symptoms are severe and conservative management is unlikely to succeed, pharmacological interventions including analgesics, antidepressants, antibiotics and immune modulators may be used orally or intravesically (directly into the bladder). As a last approach, surgery, including botulinum toxin A injections or removal of the bladder, may be considered (Hanno 2017). Some evidence indicates that BPS with Hunner's lesions may have a different clinical response to certain treatment as compared with non-lesion disease; however, this has not yet been formalised (Hanno 2017).

\section{How the intervention might work}

Conservative interventions including dietary and lifestyle changes, behavioural modifications (e.g. patient education, bladder retraining) and psychological therapies (e.g. stress management techniques) can be beneficial in reducing the symptoms associated with BPS. Women with BPS may also have pelvic floor dysfunction, and physical therapy techniques such as pelvic floor muscle training and soft tissue massage can be effective in helping to relax the pelvic floor muscles.

Pharmacological treatments address the many theories of pathogenesis, including the following.

- Analgesics, such as non-steroidal anti-inflammatory drugs (NSAIDs), target the main symptom of pain.

- Antidepressants are often used to manage pain in chronic conditions, including BPS.

- Antibiotics are known to decrease the markers of bladder inflammation, thus reducing pain.

- Immune modulators, such as bacillus Calmette-Guerin (BCG), are believed to work immunologically, on the basis of an autoimmune cause for interstitial cystitis.

- Steroids are known to have an anti-inflammatory effect.

Surgery should be considered only when all other treatments have failed (Hanno 2017). People should be informed of all aspects of surgery and should understand the consequences and potential side effects of these interventions. Surgical interventions can work in the following ways.

- Botulinum toxin A injections inhibit the release of chemical transmitters from nerve fibres and the urothelium.

- A total cystectomy (removal of the bladder) can be performed for extreme cases. This approach also requires subsequent urinary diversion to expel urine from the body.

Some therapies for treating BPS are emerging. These include:

- hyperbaric oxygen, which involves breathing pure oxygen in a pressurised chamber; 
- monoclonal antibodies, which inhibit nerve growth factors and act as potential analgesics;

- cannabinoids, which could help relieve the symptoms of BPS; and
- intravesical liposomes, which could potentially protect against inflammation.

The algorithm for diagnosis and treatment proposed at the Sixth International Consultation on Incontinence in 2016 is presented in Figure 1 (Hanno 2017). 
Figure 1. Algorithm for diagnosis and treatment: 2016 International Consultation on Incontinence. Taken from Hanno 2017, and reproduced with permission from Abrams 2017.

\section{BLADDER PAIN SYNDROME}
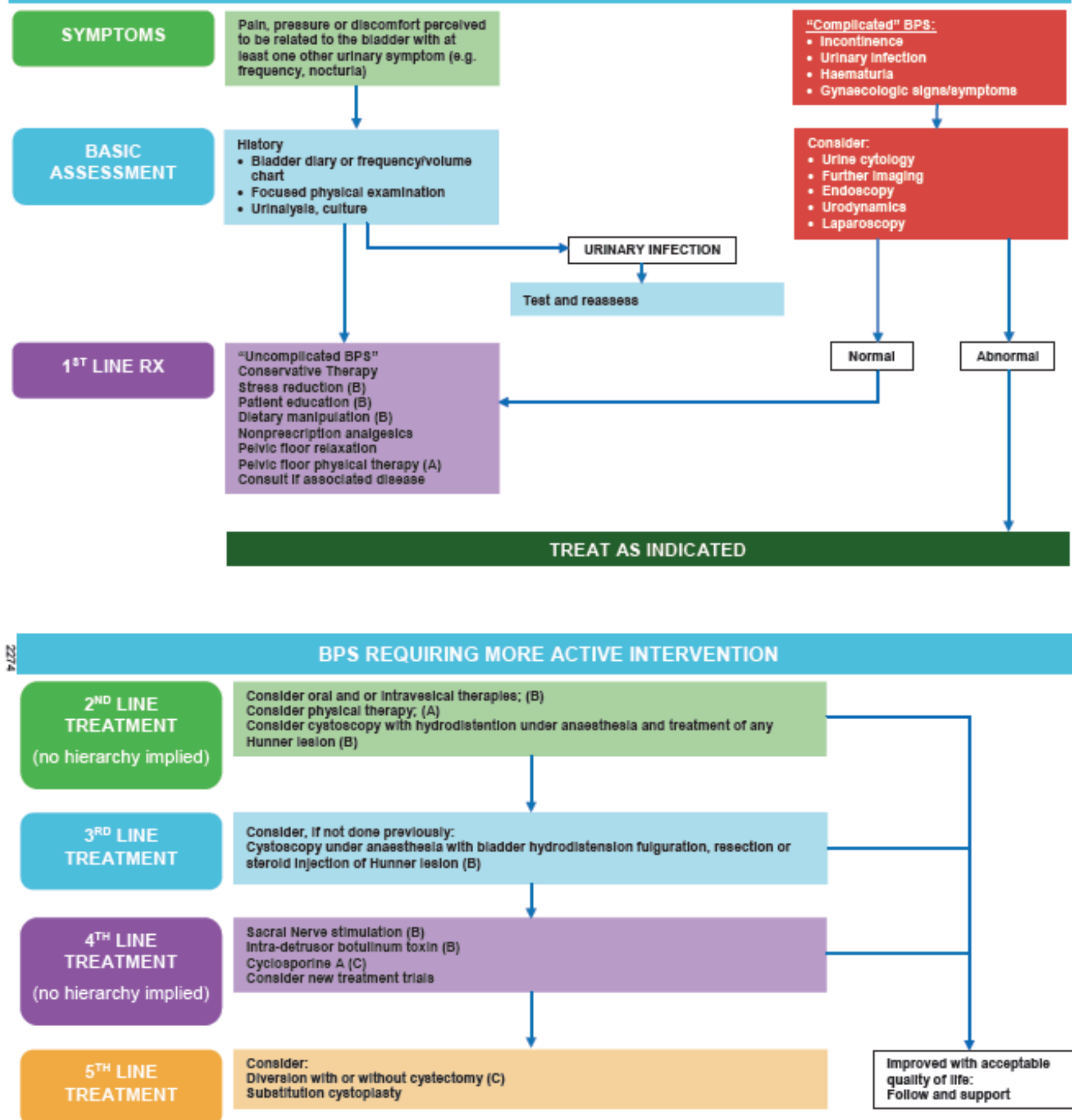

BPS REQUIRING MORE ACTIVE INTERVENTION

Consider oral and or intravesical theraples; (B)

Consider physical therapy, (A)
Consider cyatoscopy with hydrodistention under anaesthesla and treatment of any Hunner lealon (B)

Consider, if not done previlously:

Cystoscopy under anaesthesla with bladder hydrodlstension fulguration, resection or sterold Injection of Hunner lesion (B)

Intra-detrusor botulinum toxin $(B)$

Cyclosporine A (C)

Consider new treatment trials<smiles>C=CC=CC</smiles>

AMENT

Consider:

Diveralon with or without cyatectomy (C)

subatitution cystoplasty

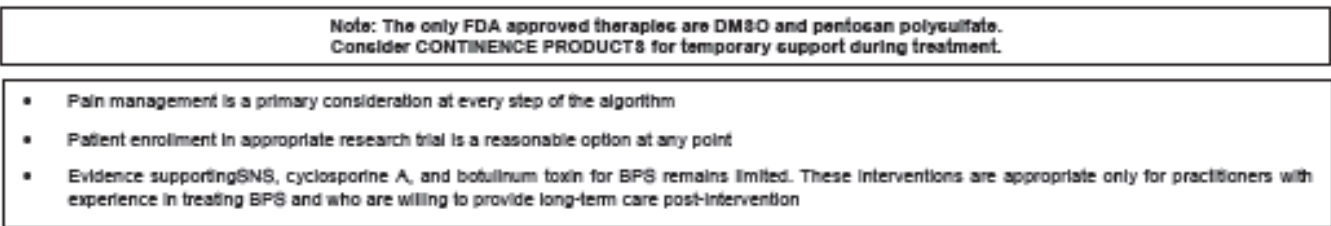




\section{Why it is important to do this review}

BPS is a condition with an unknown cause. More information is needed about the effects and safety of available treatment options and therapies. Currently, several small trials are assessing a wide range of treatment options, but the number of large trials comparing one treatment versus another is limited (there is one existing Cochrane Review on intravesical treatments for BPS (Dawson 2007)). A Cochrane Review increasing coverage to all clinical interventions by any route of administration, including both direct and indirect comparisons, will help to provide valuable information to inform clinical practice. A systematic review using network meta-analysis (NMA) is the most appropriate method in this clinical context, as it can simultaneously incorporate evidence for the effectiveness of many different treatments within a single analysis.

\section{O B J E C T IVES}

To conduct a network meta-analysis to assess the effects of interventions for treating people with symptoms of bladder pain syndrome (BPS).

\section{METHODS}

\section{Criteria for considering studies for this review}

\section{Types of studies}

We included parallel-group and cross-over randomised controlled trials (RCTs) and quasi-RCTs (e.g. alternate allocation) of interventions for treating BPS.

\section{Types of participants}

Allowing for the many terminologies that have been used for this condition, we included trials in which adults were specified as having BPS, interstitial cystitis or painful bladder syndrome. We accepted the classification of diagnoses as defined by trial investigators, and we regarded as eligible a clinical diagnosis of BPS that did or did not meet NIDDK criteria (NIDDK 2017). We excluded studies of adults with urethral syndrome.

\section{Types of interventions}

We included trials of any intervention that aimed to cure or improve symptoms of BPS, covering both emerging and more traditional modes of treatment. All types of interventions were eligible, including conservative, pharmacological and surgical therapies.

Conservative therapies include behavioural therapies (e.g. bladder training), psychological therapies (e.g. stress management techniques), complementary therapies (e.g. acupuncture) and physical therapy (e.g. pelvic floor muscle training, non-invasive electrical stimulation). We considered pharmacological treatments regardless of their routes of administration (which are likely to be oral, subcutaneous, intramuscular, intravenous or intravesical). Examples of relevant interventions are shown in Table 1.

Valid comparators were placebo, no treatment and another intervention.

We excluded trials:

- comparing two or more regimens of the same treatment (e.g. varying doses of pentosan polysulfate); or
- comparing two or more treatments with the same mechanism or mode of action (e.g. sacral nerve stimulation versus pudendal nerve stimulation, both of which are neuromodulation).

\section{Types of outcome measures}

We used the following definitions of outcomes. If a particular outcome was reported by using different definitions across different studies, then, depending on the quantity of data available, we decided either to restrict inclusion to the primary (or most common) definition or to include multiple definitions selected according to the hierarchies proposed below. In the event that a study reported any other measure not included in our proposed list, we added this measure to the bottom of the hierarchy and extracted the data.

\section{Primary outcomes}

- Proportion of participants whose symptoms were cured or improved: self-reported measures are preferred, such as the Global Response Assessment. We used objective measures (e.g. number of participants who experienced pain score reduction) as a proxy if self-reported measures were unavailable. We used the number cured if this was reported. If cure was not reported, we used the number improved, as defined by trial investigators

- Pain score: we used the following hierarchy to select one outcome measure per study: visual analogue scale (VAS); numerical rating scale (NRS); McGill Pain Questionnaire (Melzack 1975; Melzack 1987); Short Form Health Survey (SF-36)/RAND-36 (if a score for the pain-specific item is available) (Hays 1993; McHorney 1993; Ware 1992); and the number of participants with pain reduction

- Daytime frequency (number of voids): we considered the following terms to be equivalent to daytime frequency: frequency; daily frequency; frequency per day; and daytime frequency. We excluded 24-hour frequency

- Nocturia (number of nighttime voids)

\section{Secondary outcomes}

- Subjective symptom measures (combining frequency, nocturia and pain): we used the following hierarchy to select one outcome measure per study: O'Leary-Sant Interstitial Cystitis Symptom Index (ICSI) (O'Leary 1997); Pelvic Pain and Urgency/ Frequency Questionnaire (PUF) (Parsons 2002); University of Wisconsin Interstitial Cystitis Scale (UW-IC Scale) (Goin 1998); and King's Health Questionnaire (KHQ), Part III (Kelleher 1997)

- Quality of life (including symptom bother): we used the following hierarchy to select one outcome measure per study: O'Leary-Sant Interstitial Cystitis Problem Index (ICPI) (O'Leary 1997); Pelvic Pain and Urgency/Frequency Questionnaire (PUF), bother score (Parsons 2002); King's Health Questionnaire (KHQ) (Kelleher 1997); Short Form Health Survey (SF)-36 and SF-12, Mental component (McHorney 1993; Ware 1992; Ware 1996); and SF-36 and SF-12, Physical component (McHorney 1993; Ware 1992; Ware 1996)

- Functional bladder capacity: this is defined using the following terms for the purpose of this review: functional bladder capacity; functional bladder volume; bladder capacity; maximum bladder capacity; and maximum tolerable bladder capacity. We excluded volume at first or strong desire to void, (mean) voided volume, (maximum) cystometric bladder capacity and urodynamic capacity 
- Adverse events: the category of adverse events was accepted as reported by study authors

\section{Timing of outcome assessment}

The primary time point for outcome assessment is 12 months or the nearest time point available to 12 months.

\section{Main outcomes for 'Summary of findings' tables}

We included the following outcomes in our 'Summary of findings' table, in order of priority.

- Proportion of participants whose symptoms were cured or improved.

- Pain score (VAS (0 to 10)).

- Daytime frequency.

- Nocturia.

We used minimal clinically important difference (MCID) to rate the certainty of evidence for the primary outcomes in the 'Summary of findings' table. As there is no agreed MCID in the literature for BPS, we considered MCID to be as follows based on expert opinion: for cure or improvement, risk reduction of $25 \%$ (odds ratio (OR) 0.8 to 1.25); for pain, 2.5 points; for daytime frequency, 2 points; and for nocturia, 1 point

\section{Search methods for identification of studies}

We did not impose any language or other limitations on any of the searches described below.

\section{Electronic searches}

We performed searches that drew on the search strategy developed for Cochrane Incontinence. We identified relevant trials from the Cochrane Incontinence Specialised Register. For details of the search methods used to build the Specialised Register, please see the Group's webpages, where details of the Register's development (from inception) and the most recent searches performed to populate the Register can be found. To summarise, the Register contains trials identified from the Cochrane Central Register of Controlled Trials (CENTRAL), in the Cochrane Library; MEDLINE; MEDLINE In-Process; MEDLINE Epub Ahead of Print; ClinicalTrials.gov; WHO ICTRP; and the UK Clinical Research Network Portfolio (now replaced by Be Part of Research), and from handsearching of journals and conference proceedings. Many of the trials in the Cochrane Incontinence Specialised Register are also contained in CENTRAL.

The terms that we used to search the Cochrane Incontinence Specialised Register are given in Appendix 1.

The most recent search of the Cochrane Incontinence Specialised Register was fully incorporated into this review on 11 May 2018. A further search was conducted on 5 June 2019, which was screened for eligibility but was not incorporated into the review.

\section{Searching other resources}

We identified relevant studies from an existing Cochrane Review on intravesical treatments for BPS (date of last search: 30 May 2006) (Dawson 2007). We also screened the reference lists of the included studies for other relevant trials.

\section{Data collection and analysis}

\section{Selection of studies}

One review author (SW) established the selection of studies from the relevant Cochrane Review on intravesical treatments for BPS (Dawson 2007), which a second review author (MI) checked. Two review authors ( $\mathrm{JO}$ and $\mathrm{AF}$ ) independently screened the titles and abstracts of all citations identified by the literature searches. The same two review authors evaluated full-text copies of all potentially relevant reports. We resolved any discrepancies or inconsistencies by recourse to a third review author (SW, MI, NS or MB).

We obtained translations of eligible studies when resources allowed, including any available translated information obtained by Dawson 2007. If translations were not obtained, we added these studies to Studies awaiting classification and discussed the implications of any missing information under Overall completeness and applicability of evidence.

\section{Data extraction and management}

We exported study characteristics and outcome data of individual studies from the relevant Cochrane Review, and one review author (MI or YAD) checked them against individual trial reports (Dawson 2007). From additional studies identified by updated literature searches, one review author (MI or YAD) performed data extraction using a pre-piloted data form, which another review author (MI or YAD) checked. We resolved any discrepancies or inconsistencies by recourse to a third review author (SW, NS or MB).

We collected information on study design and setting, participant characteristics (including disease diagnosis), study eligibility criteria, details of the intervention(s) given, outcomes assessed and the source of study funding for each included study. When multiple publications of the same study were identified, we extracted the most complete data across all known publications.

For binary outcomes, we extracted the total number of participants in each treatment arm and the number with the event. For continuous outcomes, we extracted mean scores (i.e. mean scores at follow-up or mean change scores from baseline) for each arm along with standard deviation (SD) and the number of participants. If both final scores and change scores were available, we used final scores in the analysis.

\section{Assessment of risk of bias in included studies}

We used the original risk of bias assessments made by review authors of the relevant Cochrane Review (Dawson 2007). In that review, judgements were made for the following criteria.

- Adequacy of randomisation and description of allocated groups before treatment and blinding to allocation.

- Adherence to prescribed treatment once allocated.

- Adequacy of follow-up and accounting for participants excluded/withdrawing from trial.

- Analysis of participants based on allocated treatment group and adequacy of presented data.

Each study was judged to be at 'low', 'high' or 'unclear' risk of bias.

Two review authors (JO and AF) independently updated these assessments using Cochrane's 'Risk of bias' tool (Higgins 
2011a), resolving any discrepancies by discussion. The updated assessments addressed the following domains.

- Random sequence generation (selection bias).

- Allocation concealment (selection bias).

- Blinding of participants and personnel (performance bias).

- Blinding of outcome assessor (detection bias).

- Incomplete outcome data (attrition bias).

- Free of selective reporting (reporting bias).

- Other sources of bias.

Assessment of two domains, detection bias and attrition bias, was modified further and these domains were assessed on an outcome-specific basis. One review author (MI) performed these assessments, which were checked by another review author (SW).

For detection bias, we grouped outcomes into subjective and objective outcomes. We defined the following as subjective outcomes.

- Proportion of participants whose symptoms were cured or improved.

- Pain score.

- Daytime frequency.

- Nocturia.

- Subjective symptom measures (combining frequency, nocturia and pain).

- Quality of life (QoL) (including symptom bother).

- Adverse events.

We defined functional bladder capacity as an objective outcome.

For attrition bias, we assessed individual outcomes separately.

\section{Measures of treatment effect}

For binary outcomes, we used odds ratios (ORs) as the measure of treatment effect. For continuous outcomes, we used mean differences (MDs) in final scores or in change scores.

We re-scaled visual analogue scale (VAS) pain scores so that zero represented no pain and 10 maximum pain.

\section{Unit of analysis issues}

We included only patient randomised trials in this review, and the unit of analysis was the individual participant.

For cross-over trials, we intended to use data from paired analyses when available. In cross-over studies, when paired analyses were not reported, we used data from the first trial period if these were presented separately, as detailed in the Cochrane Handbook for Systematic Reviews of Interventions, Section 16.4.5 (Higgins 2011b). We excluded cross-over studies from the analysis if only data for the first and second periods combined were available.

If two or more arms of a multi-arm trial belonged to the same treatment category, we combined data using standard pooling formulae (Higgins 2011b).

\section{Dealing with missing data}

We employed a number of approaches to calculate or estimate SDs when these were not reported. The standard methods described in the Cochrane Handbook for Systematic Reviews of Interventions were preferred (Higgins 2011c). If standard errors (SEs) were reported, we derived the SD using the appropriate standard formula, as detailed in the Cochrane Handbook for Systematic Reviews of Interventions, Section 7.7.3.2 (Higgins 2011b). If necessary, we calculated SDs from a $90 \%$ or $95 \%$ confidence interval $(\mathrm{Cl})$ for a mean difference or from the $\mathrm{P}$ value for a t-test (Higgins 2011b), or we imputed the SD using the average of other studies in the review.

\section{Assessment of heterogeneity}

We assessed the presence of statistical heterogeneity by visually inspecting forest plots for pairwise meta-analyses and by calculating the $I^{2}$ statistic (Higgins 2003). $I^{2}$ values above $50 \%$ were considered to represent important heterogeneity. For network meta-analyses, we also investigated consistency between direct and indirect evidence (see Data synthesis).

\section{Assessment of reporting biases}

If there had been more than 10 trials per comparison in an outcome, we had planned to examine funnel plots to assess reporting bias.

\section{Data synthesis}

We divided interventions into treatment categories, each of which was further classified as a conservative, pharmacological or surgical intervention. The total number of treatment categories that could be included in each analysis depended on the number of studies that provided usable data for the outcomes of interest. If considered clinically appropriate (e.g. if treatment B is considered a routine therapy or procedure), we 'cancelled' treatments (e.g. a trial of $A+B$ versus $B$ become $A$ versus control). If this was not considered appropriate, we used a combination of therapies as a single treatment category (e.g. "chondroitin sulfate plus hyaluronic acid"). We combined different doses of the same treatment as a single category, provided this was considered clinically appropriate.

We performed two approaches to meta-analysis. The primary method was network meta-analysis, but we also conducted standard pairwise meta-analyses and compared the results with those from the network meta-analysis.

\section{Network meta-analysis}

Network meta-analysis is an analytical approach that allows a large number of treatments to be evaluated within a single analysis, and allows the effect size between any two treatments to be estimated using evidence from the entire network. If we found a large number of treatment combinations, we planned to report only the effects of each active treatment versus control.

We followed the recommendations in the National Institute for Health and Care Excellence Decision Support Unit Technical Support Documents 2 (NICE DSU TSD 2) (Dias 2016). Network meta-analysis models were fitted using WinBUGS 1.4 and were used to conduct synthesis of trial data (Lunn 2000). We used a binomial likelihood for binary outcomes and the normal likelihood for continuous outcomes. We used random-effects models due 
to expected heterogeneity between treatments and outcome measures. Three chains were used and parameters were fitted using vague normal prior distributions.

For binary outcomes, we used Programme 1(c) from the NICE DSU TSD 2 (Dias 2016). We monitored ORs for all treatments in the network against control and presented results using 95\% credible intervals $(\mathrm{Crl})$. ORs greater than 1 were associated with a favourable effect of treatment versus control. We monitored only effects of active treatments versus control. Treatments were described as effective if $95 \%$ Crls from the NMA did not contain 1 (binary outcome) or 0 (continuous outcomes).

For continuous outcomes, the effect size was the mean difference (MD) between groups. We monitored only contrasts between active treatments and control. For each outcome, high scores represent poorer patient outcomes than lower scores. Therefore, effect sizes less than zero will mean that treatment is favoured over control. We used a shared parameter model (Programme 8(a) from the NICE DSU TSD 2) to simultaneously incorporate two data formats (Dias 2016).

- Final score arm-based data.

- Contrast-based differences in change from baseline.

For the network meta-analysis, there is an additional assumption of transitivity, also known as consistency or coherence, which assumes that included participants should be eligible to be randomised to any treatment within the network. Violations of this assumption can be investigated by examining the consistency between direct and indirect evidence when there are closed loops in the network that allow this. We intended to use the methods described in the NICE DSU TSD 4 to compare closed loops within the network (Dias 2014), and we used CINeMA software as the primary way to examine direct and indirect evidence (CINeMA 2017).

We produced network diagrams for each outcome using the networkplot command in Stata (Stata 2017). Lines between treatment categories mean that direct evidence exists between a pair of treatments. The thickness of the line is proportionate to the number of included studies.

When data allowed, we planned to undertake network metaanalyses for all outcomes specified in the review. For cross-over trials that provided usable data, we used data from the first period only if they did not provide information to approximate a paired analysis.

\section{Pairwise meta-analyses}

We compared results of the network meta-analysis with direct evidence from head-to-head trials using standard Cochrane methods. For each outcome, we performed a separate pairwise meta-analysis for each treatment category versus control. We conducted meta-analyses using the metan command in Stata (Stata 2017). We did not conduct meta-analyses between pairs of active treatments. The number of trials contributing to the pairwise meta-analyses may be smaller than the number included in the corresponding network meta-analysis because only trials with a control group were included.

For binary outcomes, we pooled ORs for each treatment versus control. We used the Mantel-Haenszel approach to meta-analysis using random-effects models in Stata as the primary analysis
(Stata 2017). For continuous outcomes, the effect size was the mean difference between treatment and control. As for network meta-analyses, we used a mixture of change score and final score data within the same analysis (see the Cochrane Handbook for Systematic Reviews of Interventions, Section 9.4.5.2; Deeks 2011). We combined studies using the inverse variance weighted approach and presented results using 95\% confidence intervals (Cls).

\section{Subgroup analysis and investigation of heterogeneity}

We did not conduct subgroup analyses.

\section{Sensitivity analysis}

We did not conduct sensitivity analyses.

\section{Summarising findings and assessing certainty of the evidence}

We assessed the overall certainty (quality) of evidence for the primary outcomes using the GRADE approach (Guyatt 2008; Guyatt 2011; Schünemann 2011). We applied the GRADE approach modified for network meta-analysis (Salanti 2014), using the CINeMA 2017 web application. We rated the certainty of each outcome as 'high', 'moderate', 'low' or 'very low', taking into account six criteria: within-study bias (study limitations), acrossstudies bias (e.g. publication bias), indirectness, imprecision, heterogeneity and incoherence (among direct, indirect and mixed evidence).

Two review authors (MI and NS) worked together to conduct the GRADE assessment, reaching consensus for how each outcome should be rated. We followed the guidance provided in the latest draft version of the Cochrane Handbook for Systematic Reviews of Interventions, in the chapter on network meta-analysis, to develop our own 'Summary of findings' table (Chaimani 2017).

Due to the large number of intervention comparisons in this review, we present one 'Summary of findings' table with three interventions: antidepressants (including amitriptyline), pentosan polysulfate and neuromuscular blockade (injection of botulinum toxin type A). We selected these interventions on the basis that they are given 'strong recommendations' in the EAU Guidelines for management of BPS (EAU Guidelines 2019).

\section{RE S U L T S}

\section{Description of studies}

\section{Results of the search}

The initial search of the list of included studies of an existing Cochrane Review yielded 12 reports of nine studies that were eligible for this current review (Dawson 2007).

The literature search produced 431 records in total, which were screened. The full text of 160 articles was obtained for further assessment, of which 129 reports of 81 studies were included and the available data fully incorporated into this review. Sixteen reports of 14 studies did not meet the eligibility criteria and were excluded, the reasons for which are given in the Characteristics of excluded studies table. Additionally, we identified 15 reports of 13 ongoing studies; the details of these can be found in the Characteristics of ongoing studies table. 
The further updated literature search (conducted on 5 June 2019) identified 45 records, which were screened. Of these, 15 reports of 14 studies were eligible for inclusion in this review (five reports of four new studies; three additional reports of three already included studies; and seven study registrations of seven ongoing studies). All four new studies were small (ranging from 15 to 42 participants) (Aboyan 2018; Bosch 2018; Cervigni 2018; Oh-Oka 2017). Only one of these studies covered one of the comparisons included in our NMA (hyaluronic acid alone compared with hyaluronic acid in combination with chondroitin sulphate) (Aboyan 2018). Due to resource constraints, these were not fully incorporated into the review, but brief details of each can be viewed in the Characteristics of studies awaiting classification table.

The flow of literature through the assessment process is shown in the PRISMA diagram (Figure 2). 
Figure 2. PRISMA study flow diagram.

12 reports of 9
studies included
in the published
Cochrane review
(Dawson 2007)

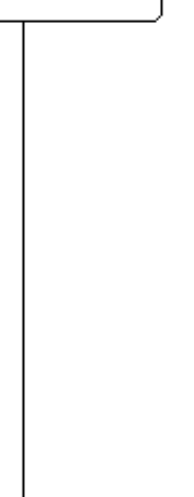

430 records identified through searching the Cochrane Incontinence Specialised Register

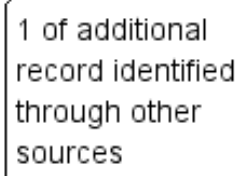

1 of additional record identified through other sources

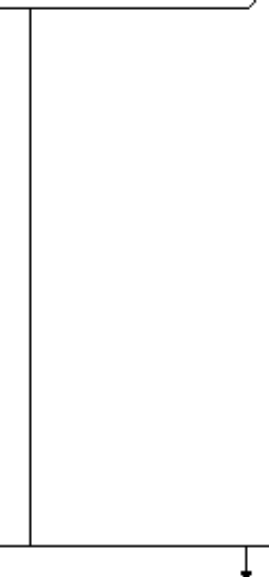

45 records identified by an updated search of the Cochrane Incontinence Specialised Register on 5 June 2019 were screened. There were 15 reports of 14 eligible studies: 5 reports of 4 new studies; 3 additional reports of 3 already included studies; and 7 trials registrations of 7 ongoing studies. Please note: these studies have not been fully incorporated into the review. For further details please see: Characteristics of studies awaiting classification.

431 records after duplicates removed

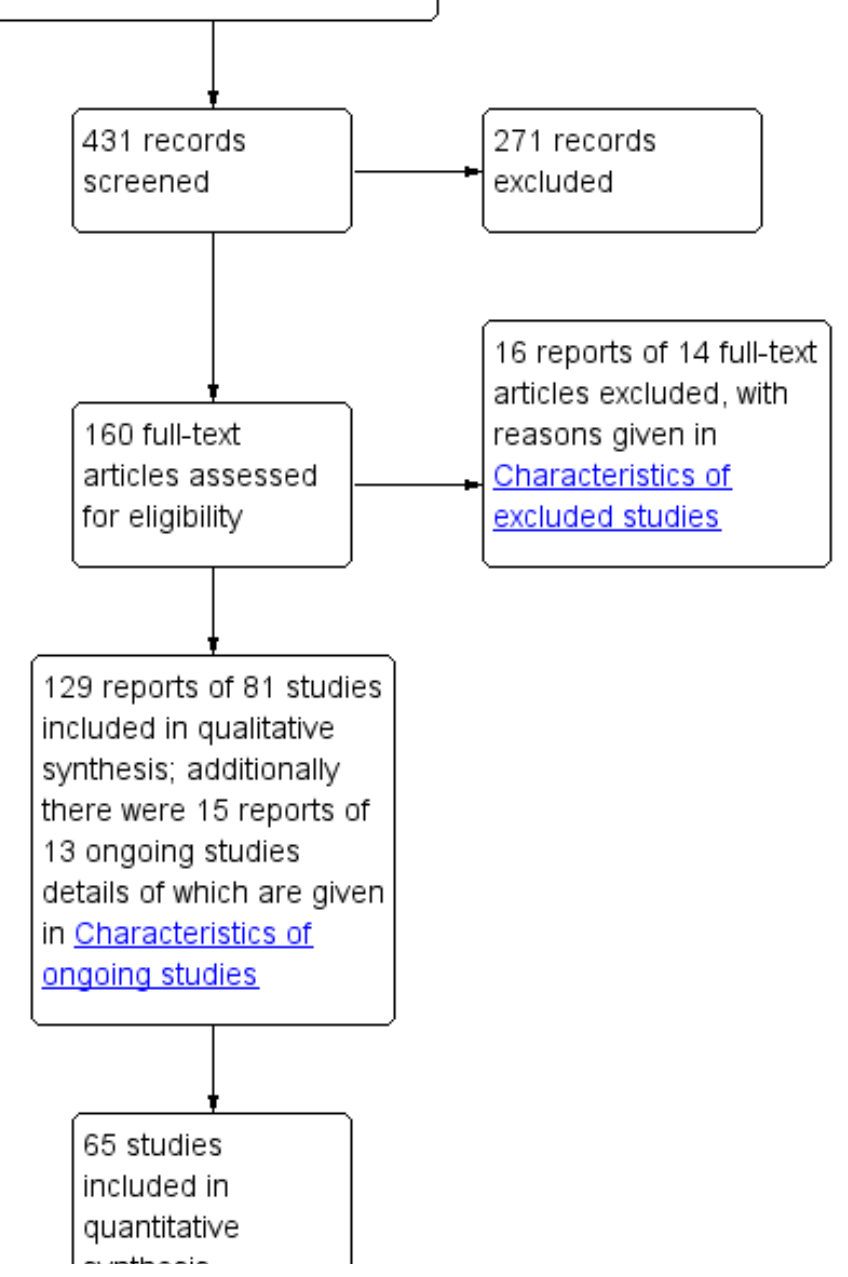


Figure 2. (Continued)

$$
\begin{aligned}
& \text { quantitative } \\
& \text { synthesis } \\
& \text { (pairwise } \\
& \text { meta-analysis) } \\
& \text { and } 57 \text { studies } \\
& \text { included in the } \\
& \text { network } \\
& \text { meta-analysis }
\end{aligned}
$$

\section{Included studies}

The 81 RCTs identified by the literature searches were published between 1988 and 2017 (Carty 2017; Chuang 2017; Nomiya 2017; Perez-Marrero 1988; Wang 2017a). Of these, 61 (75\%) were available as full-text publications (Bade 1997; Barbalias 2000; Bosch 2014; Carrico 2008; Cartledge 2000; Carty 2017; Cervigni 2014; Chen 2005; Chen 2014; Chuang 2017; Davis 2008; De Ridder 2013; ElHefnawy 2015; Evans 2011; FitzGerald 2009; FitzGerald 2012; Foster 2010; Geirsson 1993; Gottsch 2011; Gulpinar 2015; Ham 2012; Hsieh 2012; Irani 2004; Kanter 2016; Korting 1999; Kuo 2009; Kuo 2016; Lazzeri 1996; Lazzeri 2000; Leadership 201 Trial 2016; Lee 2014; Lu 2015; Manning 2014; Matsumoto 2013; Mayer 2005; Mulholland 1990; Nguan 2005; Nickel 2009; Nickel 2010; Nickel 2012a; Nickel 2012b; Nickel 2015; Nickel 2016; O'Reilly 2004; Parsons 2012; Payne 2005; Payne 2014; Peeker 2000; Perez-Marrero 1988; Peters 1997; Sairanen 2005; Sairanen 2009; Sant 2003; Souza 2012; Thilagarajah 2001; van Ophoven 2004; van Ophoven 2006; Wang 2017a; Warren 2000; Yang 2011; Zakaria 2016), and the remaining 20 (25\%) were available as conference abstracts only (Ahmadnia 2011; Dimitrakov 2001; Gulpinar 2013; Hanno 2015; Herati 2011; Ismail 2016; Kasyan 2012; Kim 2012; Kim 2015; Lee 2016; Mirkin 2012; Mirkin 2015; Moldwin 2015; Nomiya 2017; Oliver 2013; Pinto 2016; Shirvan 2015; Singh 2003; Taha 2007; Yassin 2011).

The Characteristics of included studies tables provide further details of the included studies.

\section{Design}

Six of the identified studies were randomised cross-over trials (Cartledge 2000; Geirsson 1993; Nguan 2005; Parsons 2012; Peeker 2000; Perez-Marrero 1988). The other 75 studies were parallel RCTs.

\section{Sample size}

The included studies enrolled a total of 4674 participants. A majority of studies had a small sample size, but 34 studies (42\%) included 50 or more participants (Carty 2017; Cervigni 2014; Chuang 2017; Evans 2011; FitzGerald 2012; Foster 2010; Gulpinar 2013; Hanno 2015; Hsieh 2012; Korting 1999; Kuo 2009; Kuo 2016; Leadership 201 Trial 2016; Lee 2014; Lee 2016; Manning 2014; Mayer 2005; Mirkin 2015; Moldwin 2015; Mulholland 1990; Nickel 2009; Nickel 2010; Nickel 2012a; Nickel 2012b; Nickel 2015; Nickel 2016; O'Reilly 2004; Payne 2005; Sairanen 2005; Sairanen 2009; Sant 2003; van Ophoven 2004; Warren 2000; Yang 2011). Sample sizes ranged from 10 in Oliver 2013 to 369 in Nickel 2015, with a median size of 38.

\section{Setting}

Of the included studies, 29 studies (36\%) were conducted in several centres (multi-centre) (Cervigni 2014; Chen 2005; Chen
2014; Chuang 2017; De Ridder 2013; Evans 2011; FitzGerald 2009; FitzGerald 2012; Foster 2010; Irani 2004; Kim 2015; Kuo 2016; Leadership 201 Trial 2016; Manning 2014; Mayer 2005; Mulholland 1990; Nguan 2005; Nickel 2009; Nickel 2010; Nickel 2012a; Nickel 2012b; Nickel 2015; Parsons 2012; Payne 2005; Sairanen 2005; Sant 2003; Wang 2017a; Warren 2000; Yang 2011). Thirteen (16\%) were small-scale, single-centre trials (Bade 1997; Bosch 2014; Carrico 2008; Carty 2017; Davis 2008; El-Hefnawy 2015; Gottsch 2011; Lu 2015; Payne 2014; Perez-Marrero 1988; Peters 1997; Souza 2012; van Ophoven 2004). Thirty-nine (48\%) did not provide information on the number of centres involved (Ahmadnia 2011; Barbalias 2000; Cartledge 2000; Dimitrakov 2001; Geirsson 1993; Gulpinar 2013; Gulpinar 2015; Ham 2012; Hanno 2015; Herati 2011; Hsieh 2012; Ismail 2016; Kanter 2016; Kasyan 2012; Kim 2012; Korting 1999; Kuo 2009; Lazzeri 1996; Lazzeri 2000; Lee 2014; Lee 2016; Matsumoto 2013; Mirkin 2012; Mirkin 2015; Moldwin 2015; Nickel 2016; Nomiya 2017; O'Reilly 2004; Oliver 2013; Peeker 2000; Pinto 2016; Sairanen 2009; Shirvan 2015; Singh 2003; Taha 2007; Thilagarajah 2001; van Ophoven 2006; Yassin 2011; Zakaria 2016).

Included studies were conducted in various countries. The USA was the country where most studies were conducted (25 studies) (Bosch 2014; Carrico 2008; Carty 2017; Davis 2008; Evans 2011; FitzGerald 2009; FitzGerald 2012; Foster 2010; Gottsch 2011; Hanno 2015; Herati 2011; Kanter 2016; Korting 1999; Mayer 2005; Moldwin 2015; Mulholland 1990; Nickel 2012a; Oliver 2013; Parsons 2012; Payne 2005; Payne 2014; Peeker 2000; Peters 1997; Sant 2003; Warren 2000). Nineteen studies were conducted in 11 other Western countries, including Canada (Chen 2005; Nguan 2005; Perez-Marrero 1988); Australia (Manning 2014; O'Reilly 2004); Belgium (De Ridder 2013); Finland (Sairanen 2005); Germany (van Ophoven 2004; van Ophoven 2006); Greece (Barbalias 2000); Italy (Cervigni 2014; Lazzeri 1996; Lazzeri 2000); Portugal (Pinto 2016); Sweden (Geirsson 1993); the Netherlands (Bade 1997); and the UK (Cartledge 2000; Singh 2003; Thilagarajah 2001). Eighteen studies were conducted in six different Asian countries, including China (Chen 2014; Lu 2015); Japan (Matsumoto 2013; Nomiya 2017); Korea (Ham 2012; Kim 2012; Kim 2015); Taiwan (Chuang 2017; Hsieh 2012; Kuo 2009; Kuo 2016; Lee 2014; Lee 2016); Iran (Ahmadnia 2011; Irani 2004; Shirvan 2015); and Turkey (Gulpinar 2013; Gulpinar 2015). Four studies were conducted in Egypt (El-Hefnawy 2015; Taha 2007; Yassin 2011; Zakaria 2016); three in Iran (Ahmadnia 2011; Irani 2004; Shirvan 2015); and one in Brazil (Souza 2012), and three studies were conducted in Russia (Kasyan 2012; Mirkin 2012; Mirkin 2015). Seven studies involved more than one country (Leadership 201 Trial 2016; Nickel 2009; Nickel 2010; Nickel 2012b; Nickel 2015; Wang 2017a; Yang 2011). For four studies, the country in which the study was conducted is unclear (Dimitrakov 2001; Ismail 2016; Nickel 2016; Sairanen 2009). 


\section{Participants}

Participants enrolled in the included studies presented with various clinical diagnoses including interstitial cystitis (IC); painful bladder syndrome (PBS); bladder pain syndrome (BPS); painful bladder disease (PBD); chronic urogenital pain (Carty 2017); severe bladder pain (Lazzeri 1996); or hypersensitive disorder and severe pain (Lazzeri 2000). One study included patients with IC/PBS, as well as patients with chronic prostatitis (CP)/chronic pelvic pain syndrome (CPPS) (not eligible for this evidence synthesis) (FitzGerald 2009).

Study participants were female in 29 studies and were predominantly (> 75\%) female in 34 studies (Bosch 2014; Cartledge 2000; Chen 2005; Chuang 2017; De Ridder 2013; Evans 2011; Foster 2010; Ismail 2016; Kuo 2016; Lazzeri 1996; Matsumoto 2013; Mayer 2005; Mulholland 1990; Nickel 2009; Nickel 2010; Nickel 2012b; Nickel 2015; Nickel 2016; Nomiya 2017; Oliver 2013; Payne 2005; Payne 2014; Peeker 2000; Perez-Marrero 1988; Sairanen 2005; Sairanen 2009; Sant 2003; Souza 2012; Thilagarajah 2001; van Ophoven 2004; Wang 2017a; Warren 2000; Yang 2011; Yassin 2011). Two studies included slightly more women than men (51\% to 63\%) (FitzGerald 2009; Lazzeri 2000), and one study included only men (Zakaria 2016). The other 15 studies did not report participants' gender.

The reported mean or median age of participants in each study lay between 30 and 44 years in 12 studies (Carrico 2008; Cartledge 2000; Chen 2014; Davis 2008; El-Hefnawy 2015; FitzGerald 2009; FitzGerald 2012; Foster 2010; Geirsson 1993; Lazzeri 2000; Mirkin 2012; Thilagarajah 2001); between 45 and 64 years in 45 studies (Bade 1997; Barbalias 2000; Bosch 2014; Carty 2017; Cervigni 2014; Chen 2005; Chuang 2017; Gottsch 2011; Gulpinar 2013; Gulpinar 2015; Ham 2012; Hsieh 2012; Irani 2004; Kanter 2016; Kim 2012; Kim 2015; Korting 1999; Kuo 2016; Lazzeri 1996; Leadership 201 Trial 2016; Lee 2014; Lu 2015; Manning 2014; Mayer 2005; Mulholland 1990; Nickel 2009; Nickel 2010; Nickel 2012a; Nickel 2012b; Nickel 2015; Nickel 2016; Payne 2005; Payne 2014; Peeker 2000; PerezMarrero 1988; Peters 1997; Pinto 2016; Sairanen 2005; Sairanen 2009; Sant 2003; Souza 2012; van Ophoven 2004; Wang 2017a; Warren 2000; Yang 2011); and 65 years or older in four studies (Matsumoto 2013; Nomiya 2017; Oliver 2013; van Ophoven 2006). Mean or median age of participants was not reported in the remaining 20 studies.

\section{Study funding sources}

Twenty-four included studies (30\%) were sponsored by pharmaceutical companies that manufactured the products being studied (Bosch 2014; Cervigni 2014; Chuang 2017; Davis 2008; De Ridder 2013; Evans 2011; Leadership 201 Trial 2016; Mirkin 2012; Moldwin 2015; Mulholland 1990; Nickel 2009; Nickel 2010; Nickel 2012a; Nickel 2012b; Nickel 2015; Nickel 2016; Parsons 2012; Payne 2005; Payne 2014; Peeker 2000; Peters 1997; Pinto 2016; van Ophoven 2004; Wang 2017a), and 19 included studies (23\%) were independent or were publicly funded (e.g. from research councils, government, individual hospitals) (Carrico 2008; Chen 2014; Dimitrakov 2001; Geirsson 1993; Herati 2011; Kanter 2016; Kim 2012; Kuo 2016; Lee 2014; Matsumoto 2013; Mayer 2005; Nguan 2005; Nomiya 2017; Sairanen 2005; Sant 2003; Taha 2007; van Ophoven 2006; Warren 2000; Yang 2011). Four studies (5\%) stated that no research funding was received (Kasyan 2012; Lee 2016; Oliver 2013; Yassin 2011). The other 34 studies (42\%) did not specify the source of funding (Ahmadnia 2011; Bade 1997; Barbalias 2000;
Cartledge 2000; Carty 2017; Chen 2005; El-Hefnawy 2015; FitzGerald 2009; FitzGerald 2012; Foster 2010; Gottsch 2011; Gulpinar 2013; Gulpinar 2015; Ham 2012; Hanno 2015; Hsieh 2012; Irani 2004; Ismail 2016; Kim 2015; Korting 1999; Kuo 2009; Lazzeri 1996; Lazzeri 2000; Lu 2015; Manning 2014; Mirkin 2015; O'Reilly 2004; PerezMarrero 1988; Sairanen 2009; Shirvan 2015; Singh 2003; Souza 2012; Thilagarajah 2001; Zakaria 2016).

\section{Interventions}

The included studies assessed 65 different active treatments, given alone or in combination. We grouped these treatments into treatment categories by mode of action, based on treatment descriptions for BPS from the 6th $\mathrm{ICl}$ wherever possible (Hanno 2017). The analysis included 31 active treatment categories, which are shown in Table 2. No studies were identified using our search strategies for the interventions listed in Table 3. A majority of the treatment categories in the analysis were pharmacological therapies, and a relatively small number of treatment categories were related to conservative therapies and surgical interventions.

For trials that compared two or more varieties of the same treatment against control, trial arms comparing the same treatment were combined. For example, Chen 2005 comparing resiniferatoxin (RTX) $0.05 \mathrm{microMol} / \mathrm{L}$, RTX $0.1 \mathrm{microMol} / \mathrm{L}$ and placebo, and Payne 2005 comparing RTX 0.01 microMol/L, RTX 0.05 microMol/L, RTX $0.10 \mathrm{microMol} / \mathrm{L}$ and control, were both analysed as 'RTX (calcium channel agonist) versus control'; and Chuang 2017 comparing liposomal-formulated onabotulinumtoxinA (lipotoxin), onabotulinumtoxinA in normal saline and normal saline was analysed as 'onabotulinumtoxinA (neuromuscular blockade) versus control'. One trial comprising four intervention groups using a factorial design (antihistamines, PPS, PPS + antihistamines and control) was analysed as a four-intervention arm trial (Sant 2003).

\section{Outcomes}

No common single outcome was assessed by all included trials. Outcomes that were conceptually similar such as pain were measured by different scales or tools, and a clear definition often was not provided. Continuous outcomes (e.g. pain, daytime frequency, nocturia) were reported as mean scores at last follow-up or as mean changes from baseline. Considerable efforts were made to standardise the reported outcomes to incorporate them into the analysis. A sizeable number of studies provided no usable outcome data.

\section{Length of follow-up}

A majority of studies provided short follow-up. Only six studies (7\%) had follow-up of 12 months or longer (Irani 2004; Kuo 2009; Lu 2015; Mayer 2005; Peters 1997; Taha 2007). Follow-up time ranged from 0 months in Mirkin 2012, Nickel 2009 and Souza 2012 to 27 months in Peters 1997, with a median of three months.

\section{Excluded studies}

Sixteen reports of 14 studies were excluded after full-text screening. For example, we excluded studies that enrolled participants with urethral syndrome (Choa 1983; Costantini 2003), as well as studies that compared different regimens of the same treatment (Lai 2013; Lubeck 2001; Nickel 2005; Peters 2007). Further details are provided in the Characteristics of excluded studies table. 


\section{Risk of bias in included studies}

Summaries of 'Risk of bias' judgements for the included studies are presented in Figure 3 and Figure 4. 
Figure 3. Risk of bias summary: review authors' judgements about each risk of bias item for each included study.

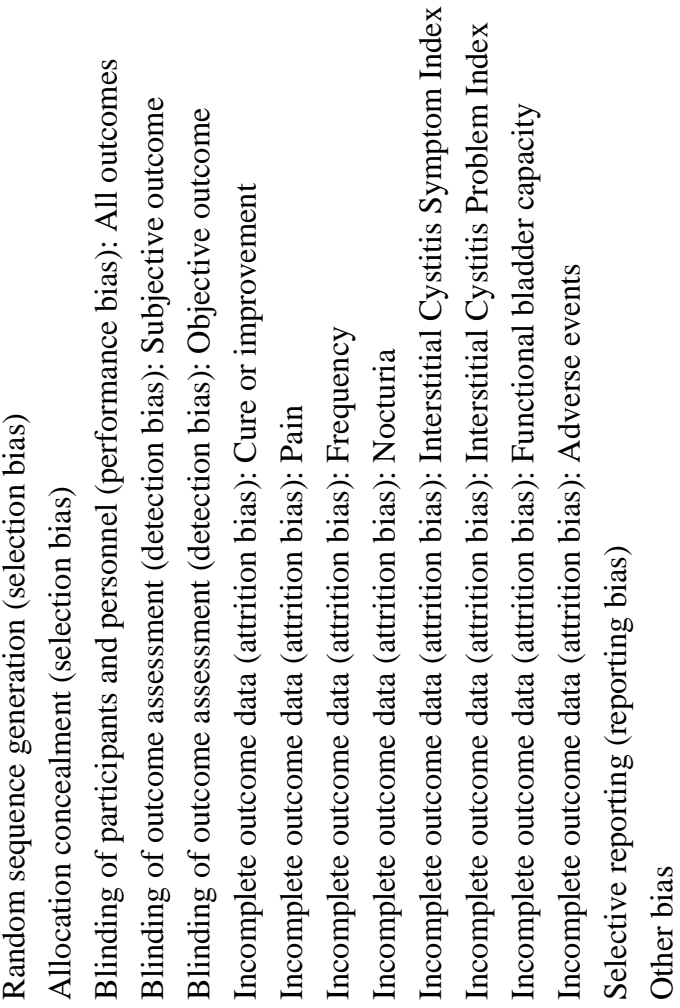

Ahmadnia 2011

Bade 1997

Barbalias 2000

Bosch 2014

Carrico 2008

Cartledge 2000

Carty 2017

Cervigni 2014

Chen 2005

Chen 2014

Chuang 2017

Davis 2008

De Ridder 2013

Dimitrakov 2001

El-Hefnawy 2015

Evans 2011

FitzGerald 2009

FitzGerald 2012

Foster 2010

Geirsson 1993

Gottsch 2011

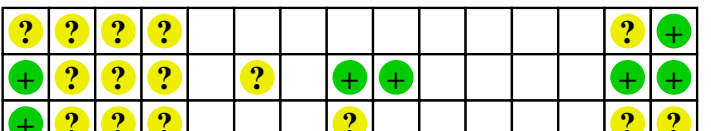

Aulninar 2012

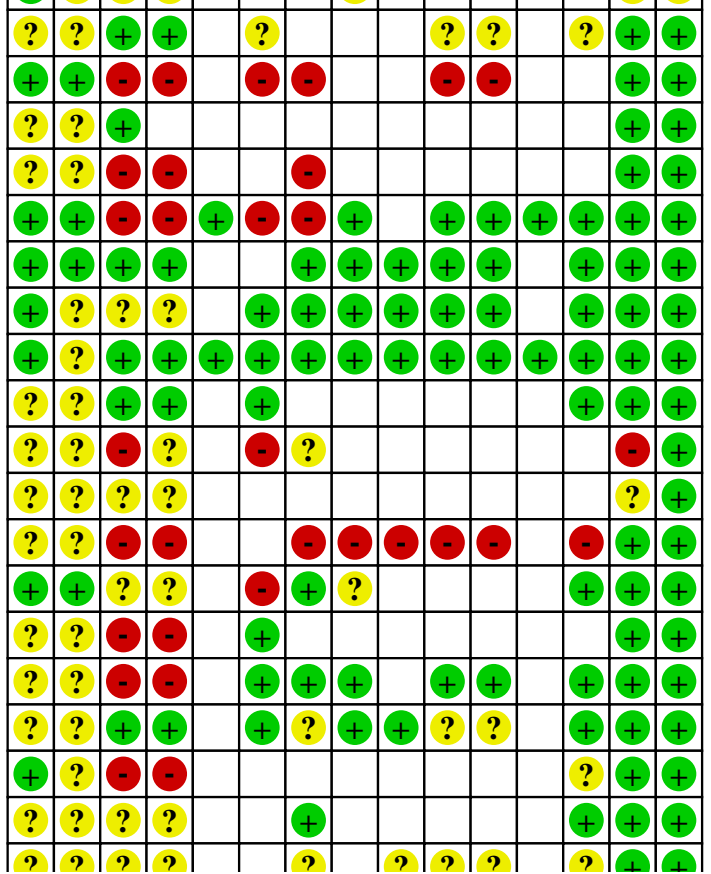


Figure 3. (Continued)

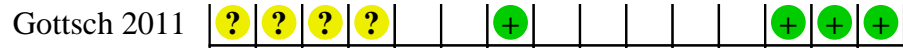

Gulpinar 2013

Gulpinar 2015

Ham 2012

Hanno 2015

Herati 2011

Hsieh 2012

Irani 2004

Ismail 2016

Kanter 2016

Kasyan 2012

Kim 2012

Kim 2015

Korting 1999

Kuo 2009

Kuo 2016

Lazzeri 1996

Lazzeri 2000

Leadership 201 Trial 2016

Lee 2014

Lee 2016

Lu 2015

Manning 2014

Matsumoto 2013

Mayer 2005

Mirkin 2012

Mirkin 2015

Moldwin 2015

Mulholland 1990

Nguan 2005

Nickel 2009

Nickel 2010

Nickel 2012a

Nickel 2012b

Nickel 2015

Nickel 2016

Nomiya 2017

O'Reilly 2004

Oliver 2013

Parsons 2012

Payne 2005

Payne 2014

Peeker 2000

Perez-Marrero 1988

Peters 1997

Pinto 2016

\begin{tabular}{|l|l|l|l|l|}
\hline$?$ & $?$ & $?$ & $?$ \\
\hline$?$ & $?$ & $?$ & $?$ \\
\hline & $?$ & $?$ & 9 \\
\hline
\end{tabular}

$+4$

\begin{tabular}{|l|l|l|l|l|}
\hline$?$ & $?$ & $?$ & $?$ & + \\
\hline
\end{tabular}

\begin{tabular}{ll|l|l|}
\hline$?$ & $?$ & $?$ & $?$
\end{tabular}

\begin{tabular}{ll|l|l|}
+ & $?$ & $?$ & $?$ \\
\hline & $?$ & & \\
\hline
\end{tabular}

\begin{tabular}{lllll}
$?$ & $?$ & - & - \\
\hline & + & + & & \\
\hline
\end{tabular}

\begin{tabular}{llllllll}
\hline$?$ & + & + & + & + & + & + & +
\end{tabular}

\begin{tabular}{ll|l|l|l}
$?$ & $?$ & $?$ & $?$
\end{tabular}

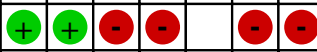

\begin{tabular}{|l|l|l|l|l|l|l|l|l|l|l|l|l|l|l|}
\hline$?$ & $?$ & $?$ & $?$ & & & $?$ & & & $?$ & $?$ & & $?$ & + & + \\
\hline
\end{tabular}

\begin{tabular}{l|l|l|l|}
\hline$?$ & $?$ & $?$ & $?$
\end{tabular}

\begin{tabular}{lll|l|l|l|l}
$?$ & $?$ & - & - & & & $?$
\end{tabular}

\begin{tabular}{lllllllll}
\hline+ & + & + & & - & & + & +
\end{tabular}

\begin{tabular}{lllllllllllllllll}
\hline$?$ & $?$ & $\odot$ & - & + & + & + & + & + & + & + & + & + & + \\
\hline
\end{tabular}

\begin{tabular}{|c|cccccccccccccc}
\hline & + & + & + & + & + & + & + & + & + & + & + & + & + & + \\
\hline
\end{tabular}

\begin{tabular}{lll|l}
\hline$?$ & $?$ & + & +
\end{tabular}

\begin{tabular}{|l|l|l|l|l|l|l|l|l|}
\hline$?$ & $?$ & - & - & & & $?$ & $?$ & $?$ \\
\hline
\end{tabular}

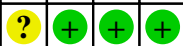

$\begin{array}{llllll}+ & + & + & + & +\end{array}$

\begin{tabular}{|lllll|l|l|l|l|l|l|l|l|l|l|}
\hline$?$ & $?$ & $?$ & $?$ & & & $?$ & & & $?$ & $?$ & & & + & + \\
\hline
\end{tabular}

\begin{tabular}{|lllll|l|l|l|l|l|l|l|l|l|l|}
\hline ? & ? & ? & ? & & + & + & + & & & & & + & ? & + \\
\hline
\end{tabular}

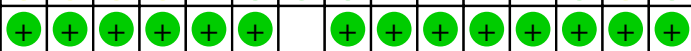

\begin{tabular}{|lllll|l|l|l|l|l|l|l|l|l|l|}
\hline+ & + & ? & ? & & & ? & & & ? & ? & & ? & + & + \\
\hline
\end{tabular}

\begin{tabular}{lllllllllllllllll}
\hline$?$ & $?$ & $?$ & $?$ & + & + & + & + & & + & + & + & + & + & + \\
\hline
\end{tabular}

\begin{tabular}{lllllll|llll|l|l|l|l|l|}
\hline$?$ & $?$ & $?$ & $?$ & & & $?$ & $?$ & & & & & $?$ & + & + \\
\hline
\end{tabular}

\begin{tabular}{ll|l|l|l|}
$?$ & $?$ & $?$ & $?$
\end{tabular}

\begin{tabular}{|l|l|l|l|l|l|l|l|l|l|l|l|l|l|}
\hline & $?$ & $?$ & $?$ & & & & & & & & & $?$ & $?$
\end{tabular}

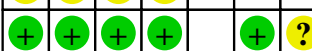

\begin{tabular}{lllllllllllllllll}
\hline & $?$ & $?$ & $?$ & & & + & & & & & & & + & + \\
\hline
\end{tabular}

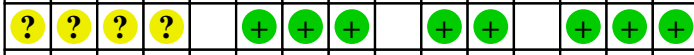

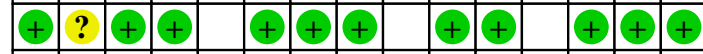

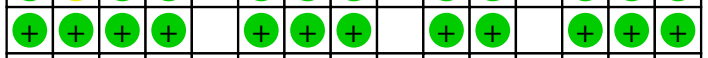

$+? ?$

\begin{tabular}{llllllll}
\hline+ & $?$ & + & + & & + & + & +
\end{tabular}

\begin{tabular}{l|l|l|l|}
\hline$?$ & $?$ & $?$ & $?$
\end{tabular}

\begin{tabular}{lllllllllllll}
\hline & $?$ & $?$ & $?$ & & + & - & - & - & + & + & +
\end{tabular}

\begin{tabular}{|llllllllllll|l|l|l|}
\hline$?$ & $?$ & + & + & & & + & + & & + & + & & & + & + \\
\hline
\end{tabular}

\begin{tabular}{l|l|l|l|}
$?$ & $?$ & - & $?$
\end{tabular}

\begin{tabular}{ll|l|l|l}
\hline$?$ & + & + & +
\end{tabular}

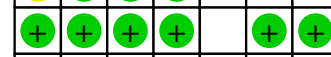

$+?$ ? $\quad ?$

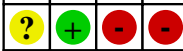

\begin{tabular}{|l|l|l|l|l|l|}
\hline$?$ & $?$ & - & - & & + \\
\hline
\end{tabular}

\begin{tabular}{|l|l|l|l|l|l|l|}
\hline$?$ & $?$ & + & + & & $?$ & $?$ \\
\hline
\end{tabular}

\begin{tabular}{|l|l|l|l|}
\hline$?$ & $?$ & $?$ & $?$ \\
\hline
\end{tabular}

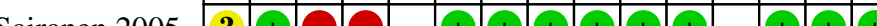


Figure 3. (Continued)

Pinto 2016

Sairanen 2005

Sairanen 2009

Sant 2003

Shirvan 2015

Singh 2003

Souza 2012

Taha 2007

Thilagarajah 2001 van Ophoven 2004 van Ophoven 2006

Wang 2017a

Warren 2000

Yang 2011

Yassin 2011

Zakaria 2016

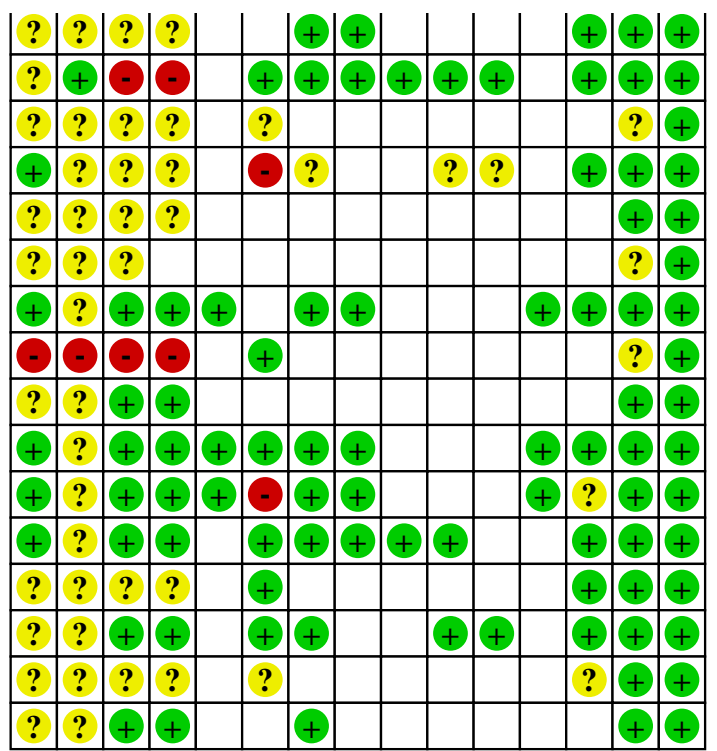

Figure 4. Risk of bias graph: review authors' judgements about each risk of bias item presented as percentages across all included studies.

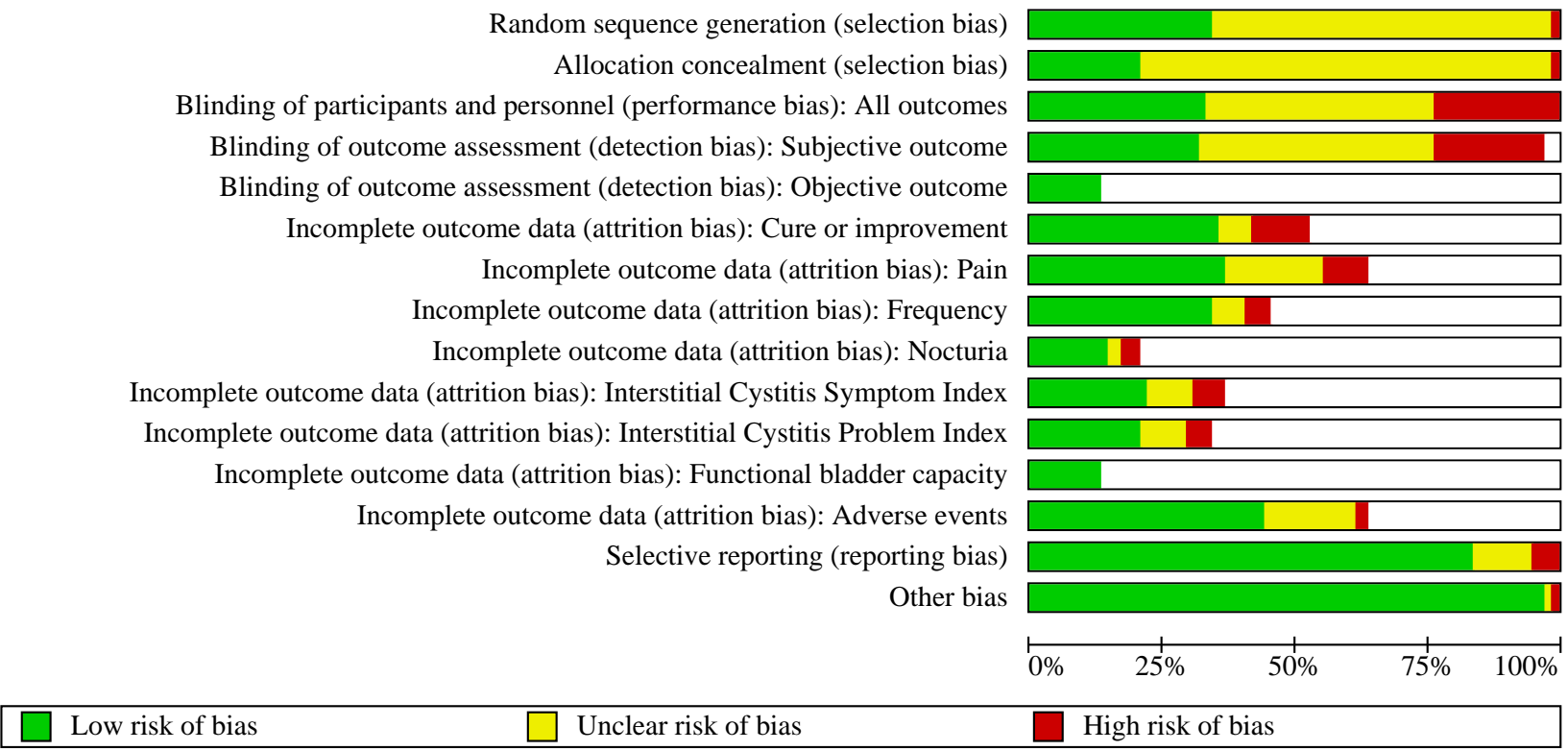

\section{Allocation}

Twelve studies (15\%) were considered to have adequate random sequence generation and appropriate allocation concealment, indicating an overall low risk of selection bias (Carrico 2008; Cervigni 2014; Chen 2005; Evans 2011; Kanter 2016; Korting 1999; Kuo 2016; Manning 2014; Matsumoto 2013; Mulholland 1990; Nickel 2012a; Payne 2005). Seventeen studies (21\%) had adequate random sequence generation but it was unclear whether they assured allocation concealment (Bade 1997; Barbalias 2000; Chen 2014; Chuang 2017; Davis 2008; Geirsson 1993; Herati 2011; Nguan
2005; Nickel 2010; Nickel 2012b; Nickel 2015; Payne 2014; Sant 2003; Souza 2012; van Ophoven 2004; van Ophoven 2006; Wang 2017a), and five studies (6\%) had adequate allocation concealment but it was unclear how the random sequence was generated (Irani 2004; Leadership 201 Trial 2016; Parsons 2012; Peeker 2000; Sairanen 2005). In one study that used alternate allocation, both random sequence generation and allocation concealment were considered inadequate, indicating an overall high risk of selection bias (Taha 2007). The other 46 studies (57\%) did not provide sufficient information on which to assess the risk of selection bias. 


\section{Blinding}

\section{Performance bias}

Twenty-seven studies (33\%), most of which were placebo- or sham-controlled trials, reported adequate methods for blinding participants and personnel to treatment allocation and were considered to have low risk of performance bias (Bosch 2014; Cartledge 2000; Chen 2005; Chuang 2017; Davis 2008; Foster 2010; Irani 2004; Korting 1999; Kuo 2016; Lazzeri 1996; Leadership 201 Trial 2016; Manning 2014; Mulholland 1990; Nickel 2010; Nickel 2012a; Nickel 2015; O'Reilly 2004; Parsons 2012; Payne 2005; Peters 1997; Souza 2012; Thilagarajah 2001; van Ophoven 2004; van Ophoven 2006; Wang 2017a; Yang 2011; Zakaria 2016).

In 19 studies (23\%), it was assumed that blinding of both patients and personnel was not done and the risk of performance bias was considered to be high. These included 13 studies using behavioural, physical or surgical interventions when blinding was not feasible due to the nature of the interventions (Carrico 2008; Carty 2017; El-Hefnawy 2015; FitzGerald 2009; FitzGerald 2012; Geirsson 1993; Hsieh 2012; Kanter 2016; Kim 2015; Kuo 2009; Lee 2014; Oliver 2013; Taha 2007). The other six studies reported some noticeable difference between the intervention and the comparator, such as the garlic-like taste or an odour of dimethyl sulfoxide (DMSO) on the participant's breath (Cervigni 2014; Peeker 2000; PerezMarrero 1988); a light warm or burning sensation after instillation of resiniferatoxin solution (Lazzeri 2000); the use of vials of different sizes (De Ridder 2013); or the use of an 'open-label' study design (Lazzeri 2000).

In the remaining 35 studies (43\%), blinding was not mentioned, or the term 'blinding' was mentioned (e.g. 'double-blind study') but the method used for blinding was not described (e.g. placebo was unspecified). We judged these studies to be at unclear risk of bias.

\section{Detection bias}

For blinding subjective outcome assessment, 26 studies (32\%) reported adequate methods for blinding assessors of subjective outcomes and were judged to be at low risk of bias (Bosch 2014; Chen 2005; Chuang 2017; Davis 2008; Foster 2010; Irani 2004; Korting 1999; Kuo 2016; Lazzeri 1996; Leadership 201 Trial 2016; Manning 2014; Mulholland 1990; Nickel 2010; Nickel 2012a; Nickel 2015; O'Reilly 2004; Parsons 2012; Payne 2005; Peters 1997; Souza 2012; Thilagarajah 2001; van Ophoven 2004; van Ophoven 2006; Wang 2017a; Yang 2011; Zakaria 2016). Seventeen studies were judged to be at high risk because the participants either were not or could not be blinded to the intervention (Carrico 2008; Carty 2017; Cervigni 2014; El-Hefnawy 2015; FitzGerald 2009; FitzGerald 2012; Geirsson 1993; Hsieh 2012; Kanter 2016; Kim 2015; Kuo 2009; Lazzeri 2000; Lee 2014; Peeker 2000; Perez-Marrero 1988; Sairanen 2005; Taha 2007). The risk of detection bias was unclear in the remaining 36 studies (44\%) as the blinding of study participants was not explicitly stated. Risk of bias was not applicable in two studies that did not report any usable subjective outcome data (Cartledge 2000; Singh 2003).

For blinding objective outcome assessment, we assessed 11 studies $(14 \%)$ that reported functional bladder capacity as being at low risk of bias, as bladder capacity was measured in terms of urine volume $(\mathrm{mL})$ and therefore was unlikely to be affected by lack of blinding (Cervigni 2014; Chuang 2017; Ham 2012; Irani 2004; Kuo 2009; Kuo 2016; Manning 2014; Mayer 2005; Souza 2012; van Ophoven 2004; van Ophoven 2006). Risk of bias was not applicable in the remaining 70 studies (86\%), which did not report this outcome.

\section{Incomplete outcome data}

We assessed the risk of attrition bias based on differential dropout rates. We judged that there was high risk of attrition bias when the number of participants lost at follow-up differed between treatment groups by $10 \%$ or more.

For the outcome of cure or improvement, as reported in 43 studies (53\%), risk of attrition bias was considered to be low in 29 studies (36\%) (Chen 2014; Chuang 2017; Davis 2008; FitzGerald 2009; FitzGerald 2012; Foster 2010; Gulpinar 2015; Irani 2004; Kuo 2009; Kuo 2016; Lazzeri 1996; Lu 2015; Manning 2014; Mayer 2005; Mulholland 1990; Nickel 2009; Nickel 2010; Nickel 2012a; Nickel 2015; Nomiya 2017; Payne 2005; Payne 2014; Perez-Marrero 1988; Sairanen 2005; Taha 2007; van Ophoven 2004; Wang 2017a; Warren 2000; Yang 2011); high in nine studies (\%) (Carrico 2008; Cervigni 2014; De Ridder 2013; Evans 2011; Kanter 2016; Korting 1999; Nickel 2012b; Sant 2003; van Ophoven 2006); and unclear in five studies (6\%) (Bade 1997; Bosch 2014; Peters 1997; Sairanen 2009; Yassin 2011).

For the outcome of pain, as reported in 51 studies (63\%), risk of attrition bias was considered to be low in 30 studies (11\%) (Chen 2005; Chen 2014; Chuang 2017; Evans 2011; FitzGerald 2012; Gottsch 2011; Ham 2012; Irani 2004; Kuo 2009; Kuo 2016; Lazzeri 1996; Leadership 201 Trial 2016; Lee 2014; Lu 2015; Mayer 2005; Nguan 2005; Nickel 2009; Nickel 2010; Nickel 2012a; Nickel 2015; Nickel 2016; O'Reilly 2004; Payne 2005; Pinto 2016; Sairanen 2005; Souza 2012; van Ophoven 2004; van Ophoven 2006; Wang 2017a; Yang 2011); high in seven studies (9\%) (Carrico 2008; Carty 2017; Cervigni 2014; El-Hefnawy 2015; Kanter 2016; Nickel 2012b; Nomiya 2017); and unclear in 14 studies (17\%) (De Ridder 2013; Foster 2010; Gulpinar 2013; Hanno 2015; Kasyan 2012; Kim 2015; Lazzeri 2000; Lee 2016; Matsumoto 2013; Mirkin 2012; Mirkin 2015; Mulholland 1990; Peters 1997; Sant 2003).

For the outcome of daytime frequency, as reported in 40 studies (49\%), risk of attrition bias was considered to be low in 29 studies (36\%) (Bade 1997; Cervigni 2014; Chen 2005; Chen 2014; Chuang 2017; Evans 2011; FitzGerald 2012; Foster 2010; Gulpinar 2015; Ham 2012; Irani 2004; Korting 1999; Kuo 2009; Kuo 2016; Leadership 201 Trial 2016; Lu 2015; Manning 2014; Mayer 2005; Nickel 2009; Nickel 2010; Nickel 2012a; Nickel 2015; O'Reilly 2004; Pinto 2016; Sairanen 2005; Souza 2012; van Ophoven 2004; van Ophoven 2006; Wang 2017a); high in four studies (5\%) (El-Hefnawy 2015; Hsieh 2012; Nickel 2012b; Nomiya 2017); and unclear in seven studies (9\%) (Barbalias 2000; Gulpinar 2013; Lazzeri 2000; Matsumoto 2013; Mirkin 2012; Mirkin 2015; Sant 2003).

For the outcome of nocturia, as reported in 18 studies (22\%), risk of attrition bias was considered to be low in 13 studies (16\%) (Bade 1997; Chen 2005; Chen 2014; Chuang 2017; Foster 2010; Ham 2012; Korting 1999; Kuo 2009; Kuo 2016; Lu 2015; Manning 2014; Sairanen 2005; Wang 2017a); high in three studies (4\%) (El-Hefnawy 2015; Hsieh 2012; Nomiya 2017); and unclear in two studies (2\%) (Gulpinar 2013; Lazzeri 2000).

For the outcome of ICSI, as reported in 31 studies (38\%), risk of attrition bias was considered to be low in 18 studies (22\%) (Cervigni 2014; Chen 2005; Chen 2014; Chuang 2017; FitzGerald 2012; Kuo 
2009; Kuo 2016; Leadership 201 Trial 2016; Lee 2014; Manning 2014; Mayer 2005; Nickel 2009; Nickel 2010; Nickel 2012a; O'Reilly 2004; Sairanen 2005; Wang 2017a; Yang 2011); high in five studies (6\%) (Carrico 2008; El-Hefnawy 2015; Kanter 2016; Nickel 2012b; Nomiya 2017); and unclear in eight studies (10\%) (Bosch 2014; De Ridder 2013; Foster 2010; Gulpinar 2013; Kasyan 2012; Lee 2016; Matsumoto 2013; Sant 2003).

For the outcome of ICPI, as reported in 28 studies (35\%), risk of attrition bias was considered to be low in 17 studies (21\%) (Cervigni 2014; Chen 2005; Chen 2014; Chuang 2017; FitzGerald 2012; Kuo 2009; Kuo 2016; Leadership 201 Trial 2016; Lee 2014; Manning 2014; Mayer 2005; Nickel 2009; Nickel 2010; Nickel 2012a; O'Reilly 2004; Sairanen 2005; Yang 2011); high in four studies (5\%) (Carrico 2008; El-Hefnawy 2015; Kanter 2016; Nomiya 2017); and unclear in seven studies (9\%) (Bosch 2014; Foster 2010; Gulpinar 2013; Kasyan 2012; Lee 2016; Matsumoto 2013; Sant 2003).

For the outcome of functional bladder capacity, as reported in 11 studies (14\%), risk of attrition bias was considered to be low in all 11 studies (Cervigni 2014; Chuang 2017; Ham 2012; Irani 2004; Kuo 2009; Kuo 2016; Manning 2014; Mayer 2005; Souza 2012; van Ophoven 2004; van Ophoven 2006).

For the outcome of adverse events, as reported in 52 studies (64\%), risk of attrition bias was considered to be low in 35 studies (43\%) (Cervigni 2014; Chen 2005; Chen 2014; Chuang 2017; Davis 2008; Evans 2011; FitzGerald 2012; Foster 2010; Gottsch 2011; Gulpinar 2015; Ham 2012; Irani 2004; Kuo 2009; Kuo 2016; Lazzeri 1996; Leadership 201 Trial 2016; Lu 2015; Manning 2014; Mayer 2005; Nickel 2009; Nickel 2010; Nickel 2012a; Nickel 2012b; Nickel 2015; Nickel 2016; Nomiya 2017; Payne 2014; Pinto 2016; Sairanen 2005; Sant 2003; Souza 2012; van Ophoven 2004; Wang 2017a; Warren 2000; Yang 2011); high in two studies (2\%) (El-Hefnawy 2015; Korting 1999); and unclear in 15 studies (19\%) (Bosch 2014; Dimitrakov 2001; Geirsson 1993; Gulpinar 2013; Hanno 2015; Ismail 2016; Kasyan 2012; Lazzeri 2000; Matsumoto 2013; Mirkin 2012; Moldwin 2015; Mulholland 1990; Peters 1997; van Ophoven 2006; Yassin 2011).

\section{Selective reporting}

We considered that there was low risk of reporting bias when the results of all outcomes specified in the methods were reported. Studies were considered at high risk of bias when outcomes specified in the methods were missing or were partially reported in the results, or when outcomes not specified in the methods were reported in the results. Risk of reporting bias was considered to be high in five studies (6\%) (due to limited information available) (Barbalias 2000; De Ridder 2013; Herati 2011; Payne 2014; Peeker 2000); unclear in eight studies (10\%) (Ahmadnia 2011; Dimitrakov 2001; Hanno 2015; Lu 2015; Moldwin 2015; Sairanen 2009; Singh 2003; Taha 2007); and low in the remaining 68 studies (84\%).

\section{Other potential sources of bias}

In one cross-over study (Peeker 2000), participants were randomly allocated to a treatment, and if they did not improve, they were crossed over to the other treatment. The analysis was conducted at the end of the study period; therefore, treatment effects in this study could have been estimated after most (if not all) of the participants had received both treatments. As such, we judged this study to be at high risk of other bias. No other potential sources of bias were identified in the other studies.

\section{Effects of interventions}

See: Summary of findings 1 Interventions for treating people with symptoms of bladder pain syndrome

We included 81 randomised controlled trials (RCTs) with a total of 4674 participants and a median of 38 participants (range 10 to 369). Most trials compared treatment against control; few trials compared two active treatments. There were 65 different active treatments, and some comparisons were informed by direct evidence from only one trial.

Data from one study could not be included in the statistical analyses as participants with interstitial cystitis (IC)/painful bladder syndrome (PBS) were a subgroup of the study population (including chronic prostatitis (CP)/chronic pelvic pain syndrome (CPPS)), but randomisation was not stratified according to clinical diagnosis (FitzGerald 2009).

For some outcomes, certain treatments were not part of a connected network and therefore could not be evaluated against control within the network meta-analysis (NMA). This occurred, for example, when a pair of active treatments were included only in a particular head-to-head trial but not in any other trials in the review.

As reported in the Methods, we present one 'Summary of findings' table with three interventions: antidepressants (including amitriptyline), pentosan polysulfate and neuromuscular blockade (injection of botulinum toxin type A). GRADE ratings for the other interventions can be found in Table 4, Table 5, Table 6 and Table 7.

\section{Primary outcomes}

\section{Proportion of participants whose symptoms were cured or improved}

Figure 5 shows the network diagram with the number of trials assessing each pair of treatments in the network for the proportion of participants cured or improved. A majority of trials compared an active treatment versus control. All trials were contained within a connected network; therefore an NMA was conducted. 
Figure 5. Network diagram for the proportion of participants whose symptoms were cured or improved. The thickness of each line is proportionate to the number of included studies.

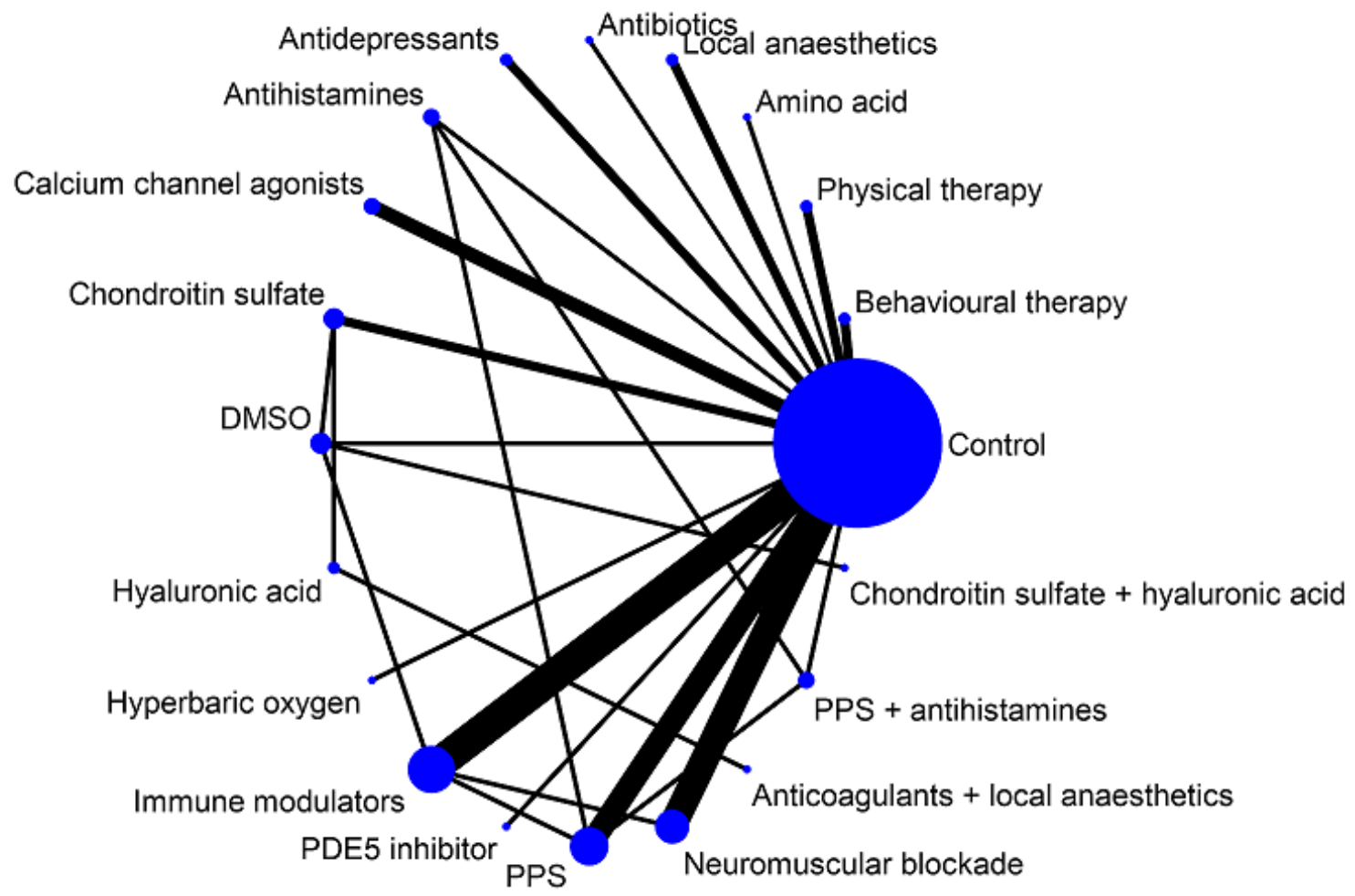

Forty-three trials with usable data for the cure outcome were identified, forming a network of 20 treatment categories: control, two types of conservative therapy, 13 types of pharmacological treatments, one surgical intervention and three combination therapies of two different pharmacological interventions. Most trials had two treatment arms, but one trial included four treatment arms (Sant 2003). Trials were generally small; only five trials provided data for over 100 participants.

After the initial NMA models were run in WinBUGS, the diagnostic plots suggested that results for hyperbaric oxygen ( $\mathrm{HBO}$ ) were unstable and the model failed to converge. This treatment was assessed in only one trial in which three participants in the HBO group were cured or improved compared with none in the control group (van Ophoven 2006). As such, the lack of convergence is likely to be related to the zero cell count. For this trial, we followed the advice of the National Institute for Health and Care Excellence Decision Support Unit Technical Support Documents 2 (NICE DSU TSD 2) and added 1 to the denominator and 0.5 to the numerator in each group (Dias 2016). No adjustment was necessary for the other trial that had a zero cell count, as this was one of several studies that compared neuromuscular blockade with control (Payne 2014). The results for all other treatments showed good convergence.

Figure 6 and Table 4 show results of the final NMA for each of the 19 active treatment categories versus control. Median odds ratios (ORs) from the NMA were above 1 for 18 treatment categories, indicating favourable cure rates versus control, but the $95 \%$ credible intervals (Crls) were wide, reflecting the small number and size of available trials. Very low-certainty evidence suggests that the following treatment categories were effective versus control: behavioural therapy (OR 9.42, 95\% Crl 1.01 to 110.83), physical therapy (OR 6.78, 95\% Crl 1.08 to 46.85), antidepressants (OR 5.91, $95 \% \mathrm{Crl} 1.12$ to 37.56 ), immune modulators (OR 2.74, 95\% Crl 1.16 to 6.57), phosphodiesterase-5 (PDE5) inhibitors (OR 24.53, 95\% Crl 1.21 to 1255.14 ) and neuromuscular blockade (OR 5.80, 95\% $\mathrm{Crl} 2.08$ to 18.30$)$. 
Figure 6. Meta-analysis results for proportion of participants whose symptoms were cured or improved. For each treatment category, the unbroken horizontal line represents the odds ratio $(95 \% \mathrm{Crl})$ versus control from the network meta-analysis, and the dotted line represents the odds ratio $(95 \% \mathrm{Cl})$ versus control from the pairwise meta-analysis (if applicable). The number of studies included in each analysis is also shown. Intervals less than 0.3 and greater than $\mathbf{4 0}$ have been truncated.

Behavioural therapy
Physical therapy
Amino acid
Local anaesthetics
Antibiotics
Antidepressants
Antihistamines
Calcium channel agonists
Chondroitin sulfate
DMSO
Hyaluronic acid
Hyperbaric oxygen
Immune modulators
PDE5 inhibitor
PPS
Neuromuscular blockade
Anticoagulants + local anaesthetics
PPS + antihistamines
Chondroitin sulfate + hyaluronic acid

Chondroitin sulfate + hyaluronic acid

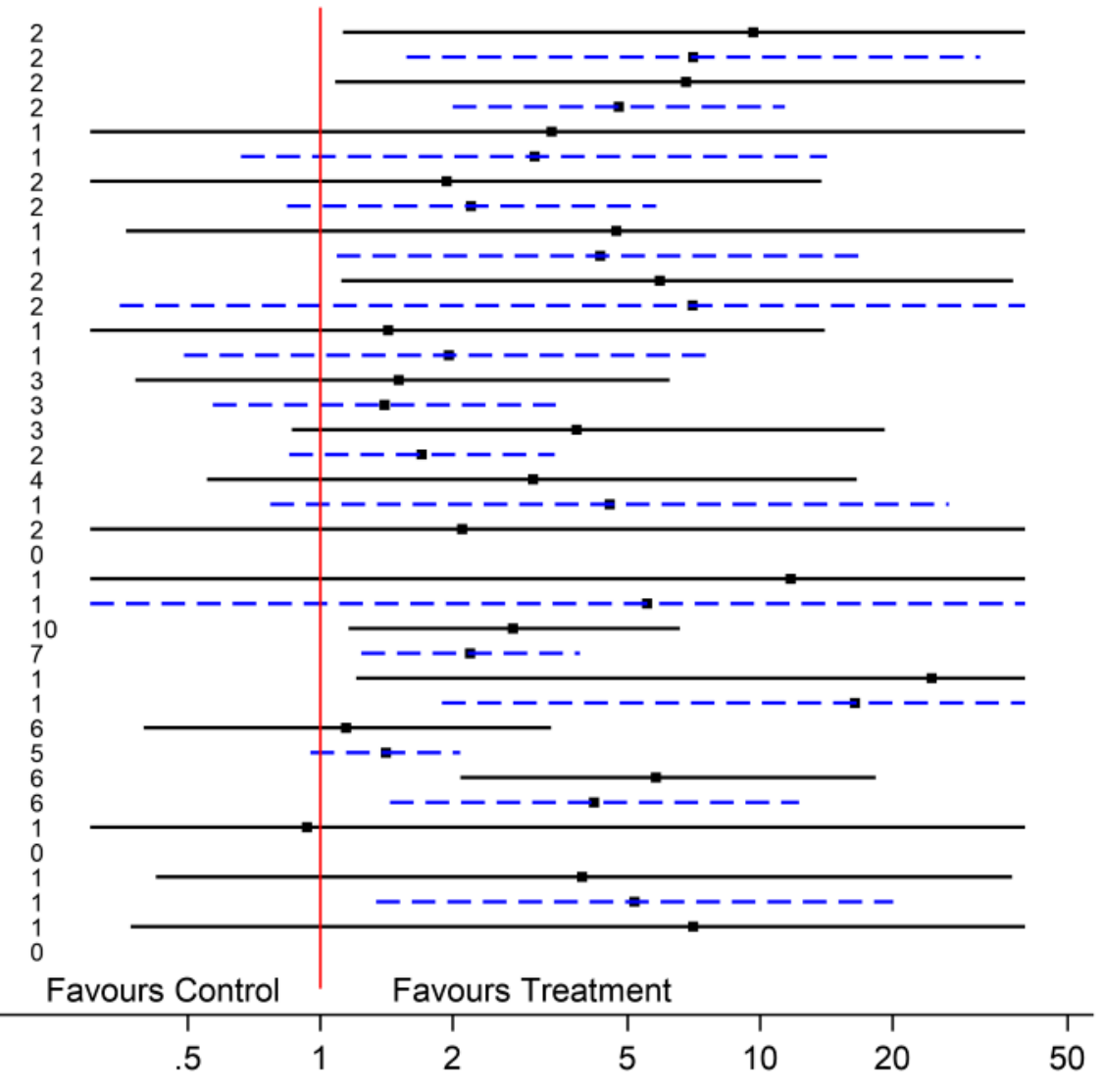

A comparison of results of the network and pairwise meta-analyses is provided in Figure 6 and Table 4. The results were generally consistent, although in both sets of analyses, there was a wide range of uncertainty about the true effects of treatment. The pairwise results suggested benefits for two additional treatments: antibiotics and pentosan polysulfate (PPS) plus antihistamines (Table 6; Figure 4).

We assessed the heterogeneity and consistency assumptions of the NMA. Three of the nine pairwise comparisons containing more than one study were associated with an $\mathrm{I}^{2}$ statistic greater than $50 \%$, suggesting important heterogeneity. There were relatively few closed loops within the network by which to assess the consistency assumption, but a global test based on a random-effects designby-treatment interaction model in CINeMA suggested evidence of inconsistency $(P=0.02)$ that was primarily associated with the results for chondroitin sulfate versus control. Overall, however, results of the NMA and the pairwise meta-analysis seemed to be consistent, considering the wide $\mathrm{Crls}$ and confidence intervals (Cls).

\section{Pain score}

We were able to include a variety of continuous pain scales in the analyses. Scores were re-scaled so that 0 represented no pain and 10 the worst possible pain. No categorical measures of pain were included in the analyses.

Figure 7 shows the network diagram for the pain outcome. Most comparisons in the network were against control. One trial comparing hyaluronic acid with anticoagulants plus local anaesthetics was disconnected from the rest of the network and therefore could not be included in the NMA (Lu 2015). Of the 51 studies comprising 25 active treatment categories that could be included, 28 had final score data for pain. For the remaining 23 studies, change score data had to be used. 
Figure 7. Network diagram for pain score. The thickness of each line is proportionate to the number of included studies.

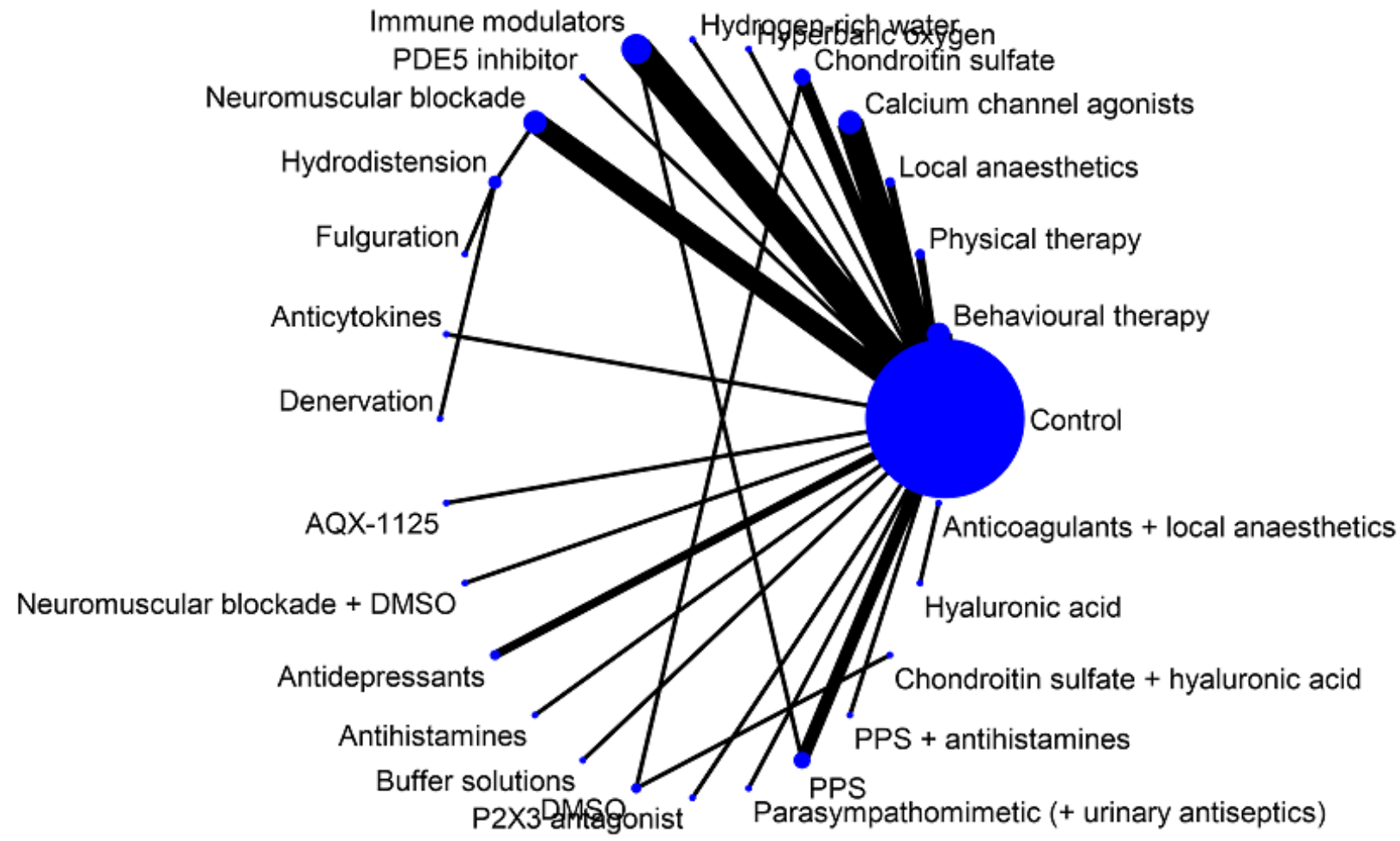

Results for the NMA are shown in Figure 8 and Table 5. Moderatecertainty evidence shows that physical therapy reduced pain compared with control by around 4 points on a 0 to 10 scale (mean difference (MD) $-3.92,95 \% \mathrm{Cl}-5.80$ to -1.94$)$. However, this comparison contained two studies with very heterogeneous results. One study showed an extreme effect, with mean (standard deviation (SD)) pain scores of $2.6(0.13)$ and $9.4(0.21)$ in the treatment and control groups, respectively, at four months' followup (Zakaria 2016). The other study showed a more modest effect (mean pain scores of 3.8 and 4.3, respectively) (FitzGerald 2012). Due to this heterogeneity, caution should be applied when interpreting these results. There is no clear evidence that any other treatment categories were effective. 
Figure 8. Meta-analysis results for pain score. For each treatment category, the unbroken horizontal line represents the mean difference $(95 \% \mathrm{Crl})$ in VAS $(0-10)$ versus control from the network meta-analysis, and the dotted line represents the mean difference $(95 \% \mathrm{Cl})$ versus control from the pairwise meta-analysis (if applicable). The number of studies included in each analysis is also shown.

Behavioural therapy
Physical therapy
Local anaesthetics
Calcium channel agonists
Chondroitin sulfate
Hyperbaric oxygen
Hydrogen-rich water
Immune modulators
PDE5 inhibitor
Neuromuscular blockade
Hydrodistension
Fulguration
Anticytokines
Denervation
AQX-1125
Neuromuscular blockade + DMSO
Antidepressants
Antihistamines
Buffer solutions
DMSO
P2X3 antagonist
Parasympathomimetic (+ urinary antiseptics)
PPS
PPS + antihistamines
Chondroitin sulfate + hyaluronic acid

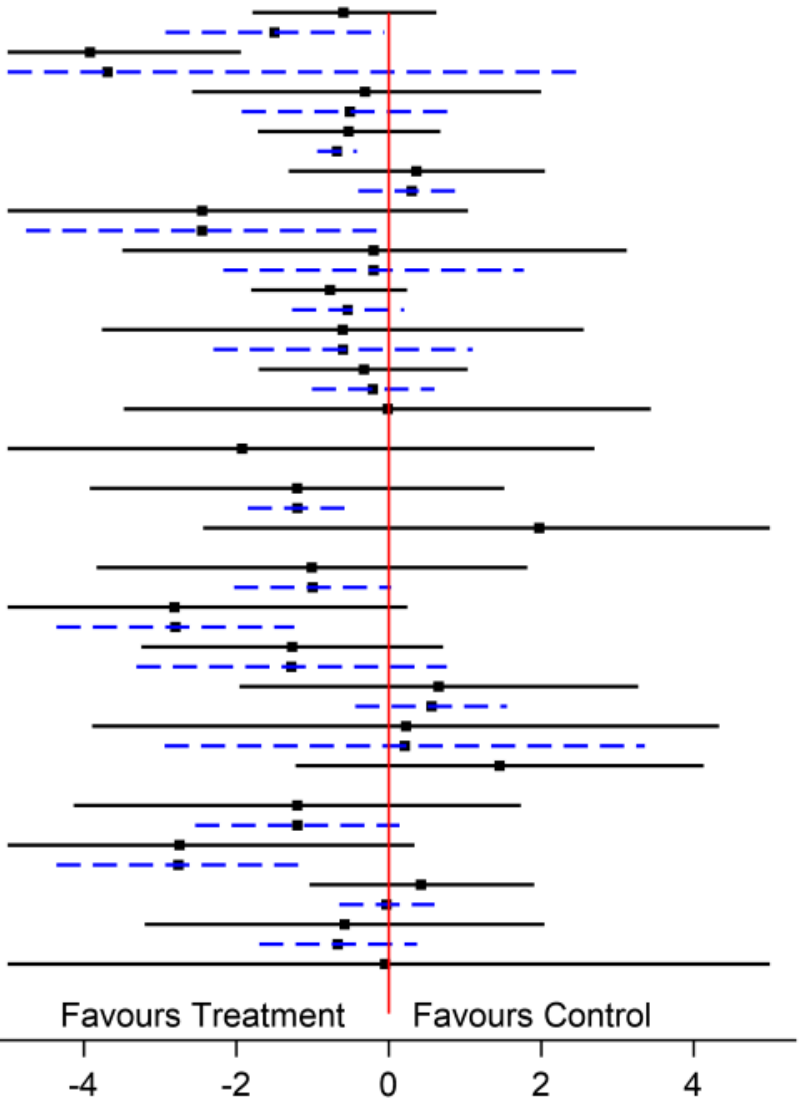

The pairwise meta-analyses generally provided similar effect sizes to the NMA, but Cls tended to be narrower (Figure 8; Table 5). There was important heterogeneity $\left(I^{2}>50 \%\right)$ for four of nine pairwise comparisons with at least two studies. There were no concerns about the consistency of the NMA itself ( $P$ value for interaction $=$ 0.18 ), but it was difficult to assess this assumption as there was only a small number of closed loops within the network, which meant that few comparisons between direct and indirect effect estimates could be made (the primary way that consistency in an NMA can be addressed).

\section{Daytime frequency (number of voids)}

The network diagram for the frequency outcome is shown in Figure 9. Fourteen treatment categories are included in this network, but 23 of the 27 trials compared a single treatment against control, resulting in a network that was nearly completely "starshaped", which meant that there were few closed loops within the network, which makes it difficult to assess consistency in results of the NMA. Six treatments could not be included as they are not connected to the rest of the network. These include denervation and hydrodistension (compared only in El-Hefnawy 2015); dimethyl sulfoxide (DMSO) and chondroitin sulfate plus hyaluronic acid (compared only in Cervigni 2014); and hyaluronic acid and anticoagulants plus local anaesthetics (compared only in Lu 2015). Eighteen studies in the network contributed final score data, and six studies contributed change score data. 
Figure 9. Network diagram for daytime frequency (number of daytime voids). The thickness of each line is proportionate to the number of included studies.

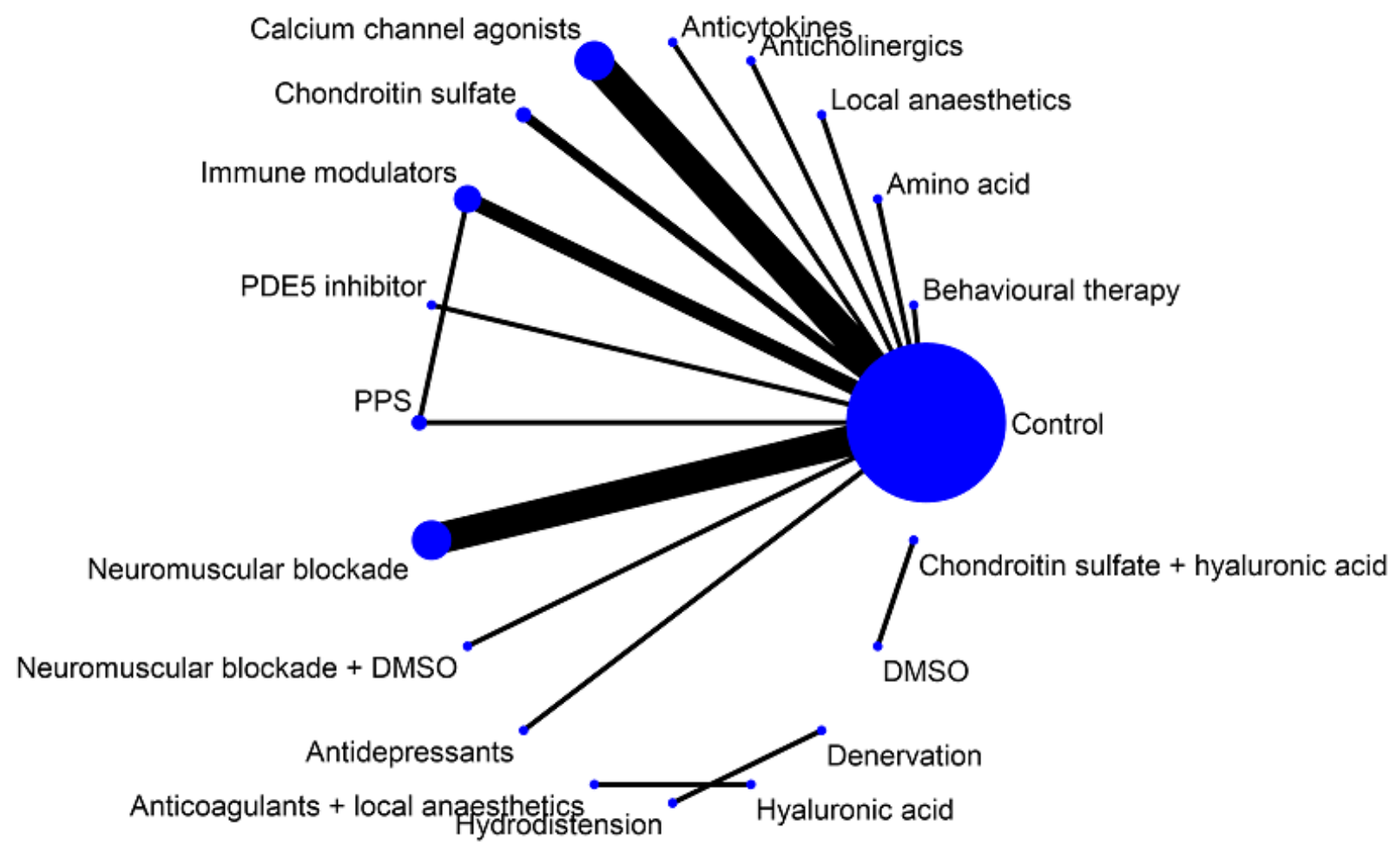

The NMA results are presented in Figure 10 and Table 6. reduction of around nine voids per day compared with control (MD These yielded moderate-certainty evidence that the combination of neuromuscular blockade plus DMSO was associated with a $-8.97,95 \% \mathrm{Crl}-15.23$ to -2.81 ). 
Figure 10. Meta-analysis results for daytime frequency (number of daytime voids). For each treatment category, the unbroken horizontal line represents the mean difference $(95 \% \mathrm{Crl})$ in number of daytime voids versus control from the network meta-analysis, and the dotted line represents the mean difference $(95 \% \mathrm{Cl})$ versus control from the pairwise meta-analysis (if applicable). The number of studies included in each analysis is also shown.

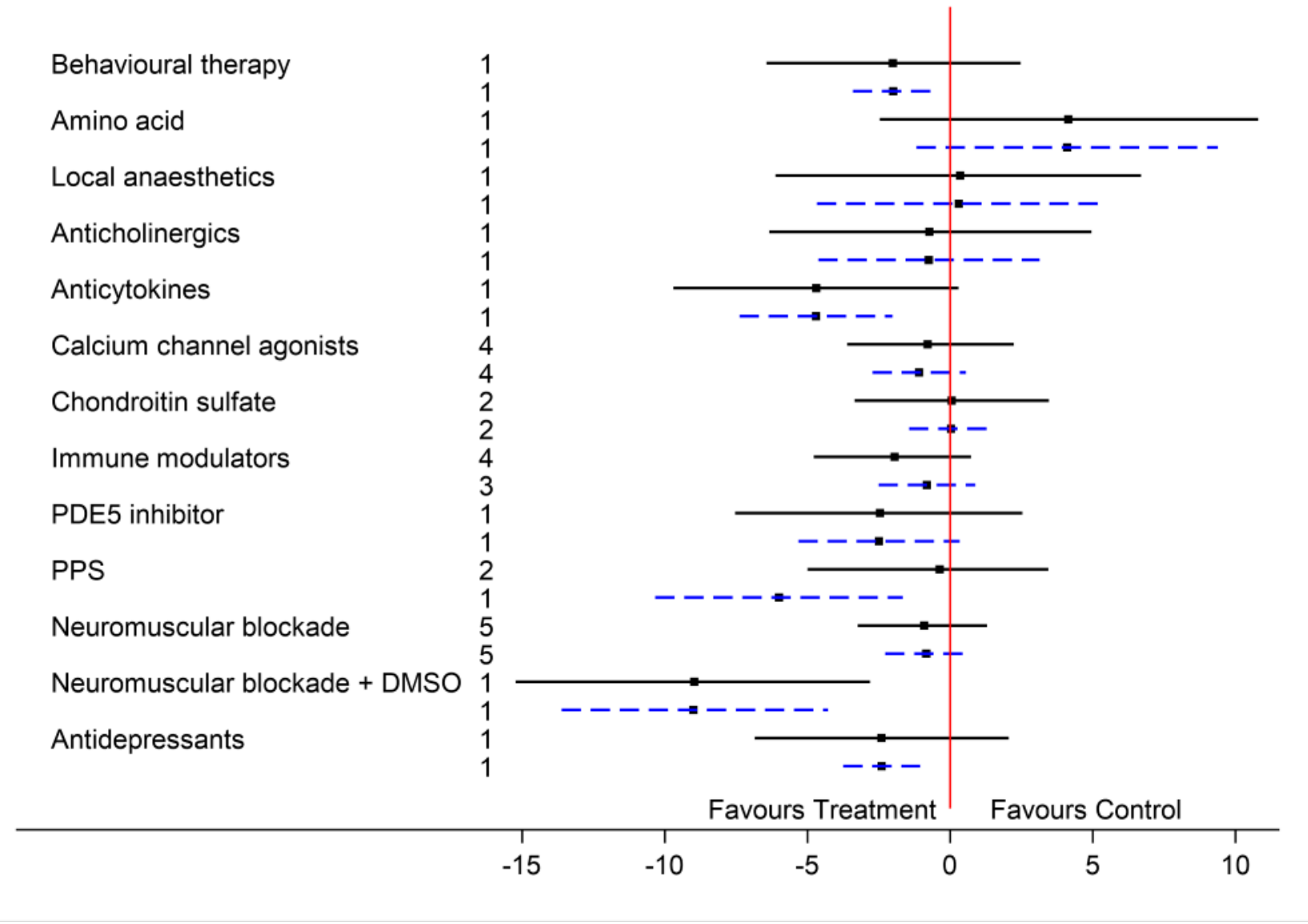

The pairwise meta-analyses generally yielded similar results but also suggested benefits for four additional treatment categories (behavioural therapy, anticytokines, PPS and antidepressants) (Figure 10; Table 6). There was evidence of heterogeneity $\left(\mathrm{I}^{2}>\right.$ $50 \%$ ) for one of the four pairwise comparisons with at least two studies. There were some concerns about consistency within the only closed loop within the network involving immune modulators, PPS and control ( $P$ value for interaction $=0.007$ ).

\section{Nocturia (number of nighttime voids)}

Figure 11 shows the network diagram for nocturia. Again, there were relatively few closed loops, resulting in a network that was almost star-shaped, with all treatments compared only with control, except for one comparison of PPS and immune modulators. Once again, the denervation and hydrodistension treatment categories could not be included, as they were not connected to the rest of the network (El-Hefnawy 2015). Thirteen studies in the network contributed final score data, and three studies contributed change score data. 
Figure 11. Network diagram for nocturia (number of nighttime voids). The thickness of each line is proportionate to the number of included studies.

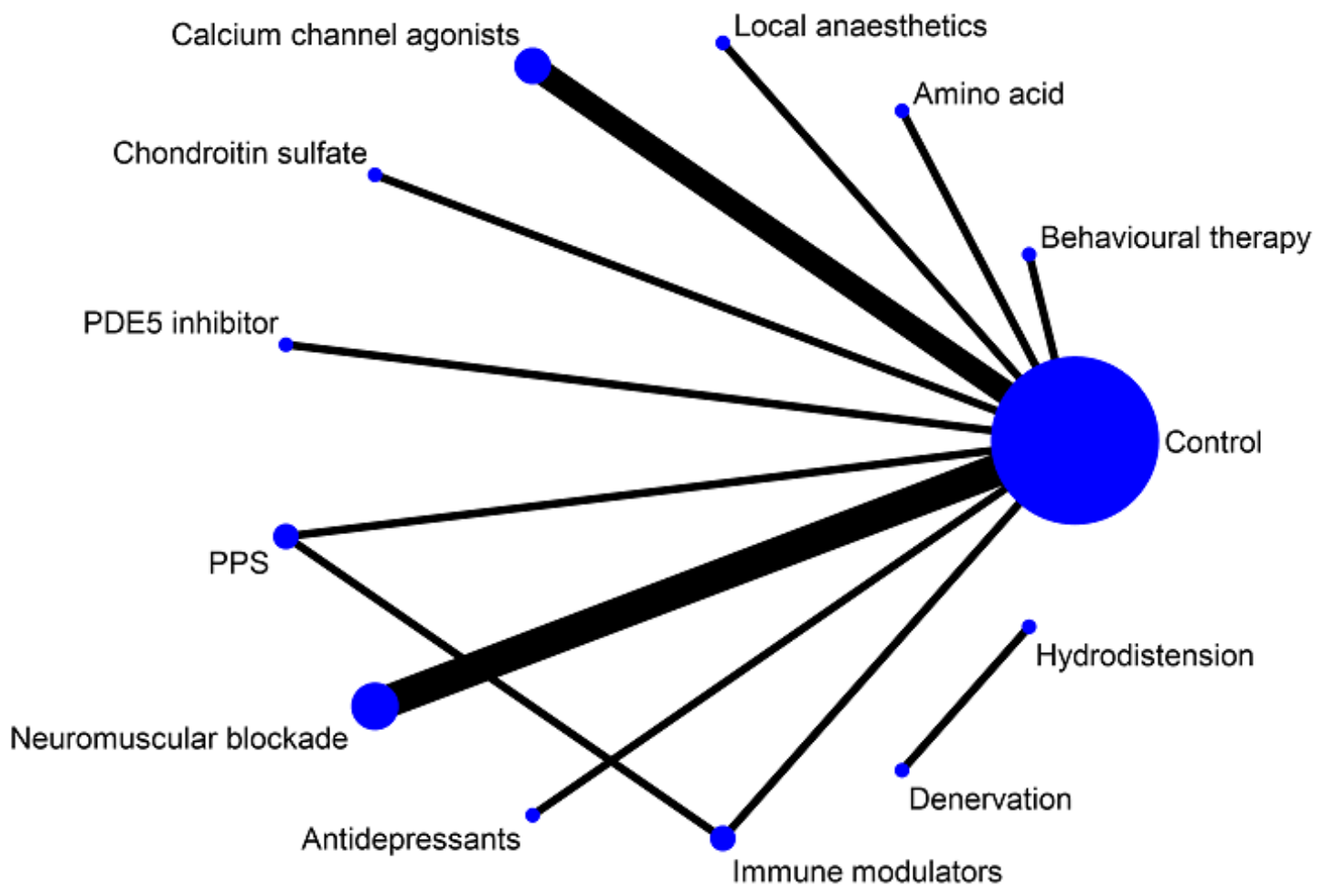

The NMA results did not yield any treatment categories with a 95\% Crl excluding zero, so there was no clear evidence that any treatments were beneficial in reducing nocturia (Figure 12; Table 7). The advantage of an NMA in this situation may not be particularly large due to the star-shaped network. However the corresponding pairwise meta-analyses suggested favourable results for behavioural therapy, PDE5 inhibitors and PPS (Figure 12; Table 7). One of the two comparisons with at least two studies was associated with important heterogeneity $\left(1^{2}>50 \%\right)$. There was again only a single closed loop within the network, but there were no concerns about inconsistency ( $P$ value for interaction $=0.10$ ). 
Figure 12. Meta-analysis results for nocturia (number of nighttime voids). For each treatment category, the unbroken horizontal line represents the mean difference $(95 \% \mathrm{Crl})$ in number of nighttime voids versus control from the network meta-analysis, and the dotted line represents the mean difference $(95 \% \mathrm{Cl})$ versus control from the pairwise meta-analysis (if applicable). The number of studies included in each analysis is also shown.

$\begin{array}{ll}\text { Behavioural therapy } & 1 \\ \text { Amino acid } & 1 \\ & 1 \\ \text { Local anaesthetics } & 1 \\ & 1 \\ \text { Calcium channel agonists } & 1 \\ \text { Chondroitin sulfate } & 3 \\ & 3 \\ \text { PDE5 inhibitor } & 1 \\ \text { PPS } & 1 \\ & 1 \\ \text { Neuromuscular blockade } & 1 \\ & 2 \\ \text { Antidepressants } & 1 \\ \text { Immune modulators } & 4 \\ & 1 \\ \end{array}$

\section{Secondary outcomes}

\section{Subjective symptom measures (combining frequency, nocturia} and pain)

Although studies reported symptoms in a variety of ways, we included only data for the Interstitial Cystitis Symptom Index (ICSI) subscale because this was the most commonly reported subjective measure across trials. On the ICSI subscale, 0 represented the lowest possible and 20 the highest possible severity of symptoms. We did not include studies that reported the ICSI and Interstitial Cystitis Problem Index (ICPI) Scales combined.
The network diagram for the ICSI outcome is shown in Figure 13. Compared with other outcomes, the number of connections between treatments was relatively high, although most treatments were compared to control. Eighteen studies contributed final score data, and 12 studies (including Sant 2003, a four-arm trial) contributed change score data. Evidence from the NMA suggests that PDE5 inhibitors reduced symptoms by around 6 points on a 0 to 20 scale (MD $-6.02,95 \% \mathrm{Crl}-9.05$ to -2.93 ) (Table 8). 
Figure 13. Network diagram for subjective symptom measures (combining frequency, nocturia and pain) - ICSI. The thickness of each line is proportionate to the number of included studies.

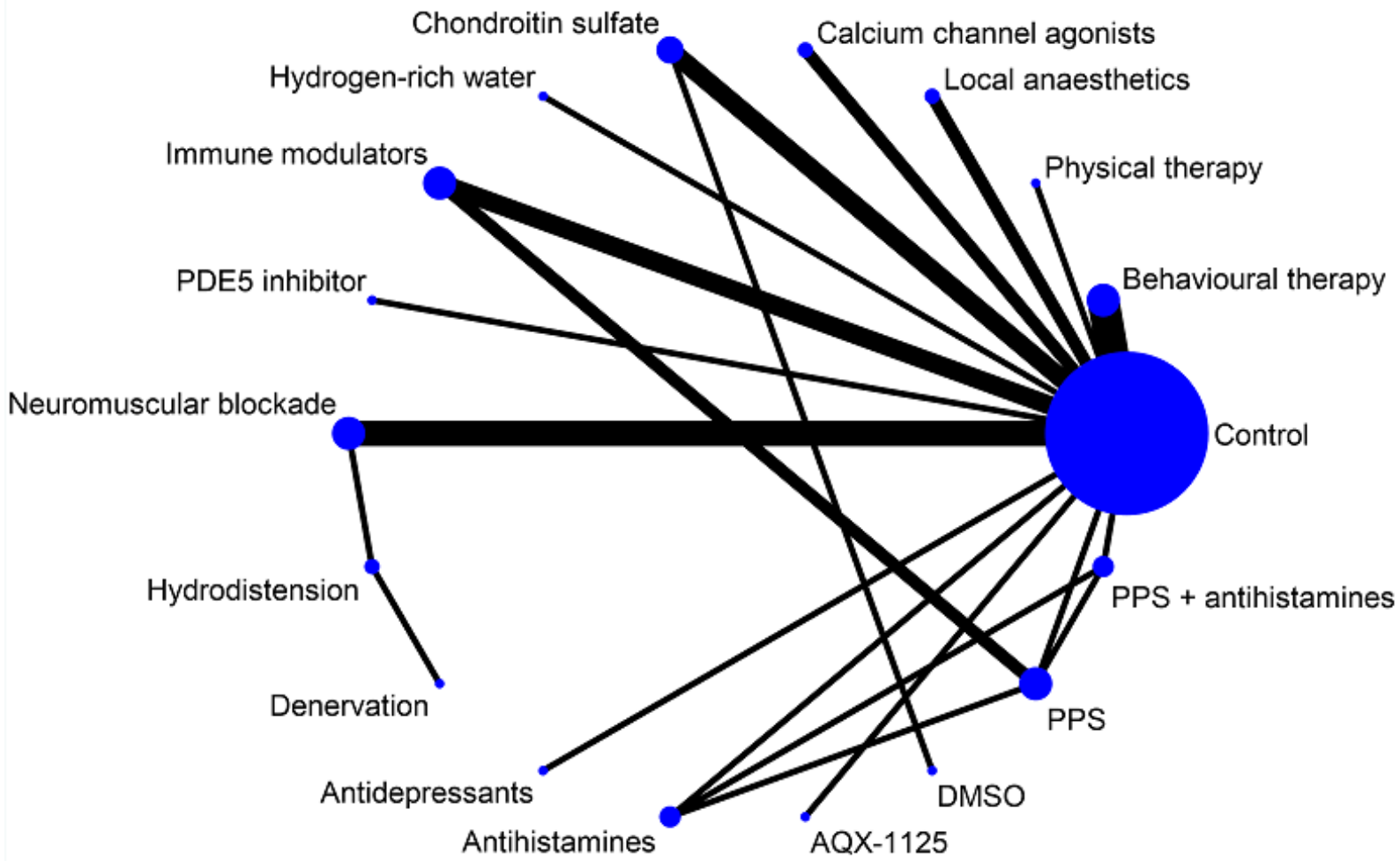

The pairwise meta-analyses also suggested benefits for antidepressants and for AQX-1125 (Table 8).

\section{Quality of life (including symptom bother)}

We included only studies that had reported the ICPI subscale because it was the most commonly reported quality of life measure across trials. In ICPI, scores of 0 represented the highest possible quality of life and scores of 16 the lowest possible quality of life.

The network diagram for the ICPI diagram was the same as that for ICSI but with a slightly reduced number of trials involved (Figure 14). Eighteen studies contributed final score data, and 10 studies contributed change score data. 
Figure 14. Network diagram for quality of life - ICSI. The thickness of each line is proportionate to the number of included studies.

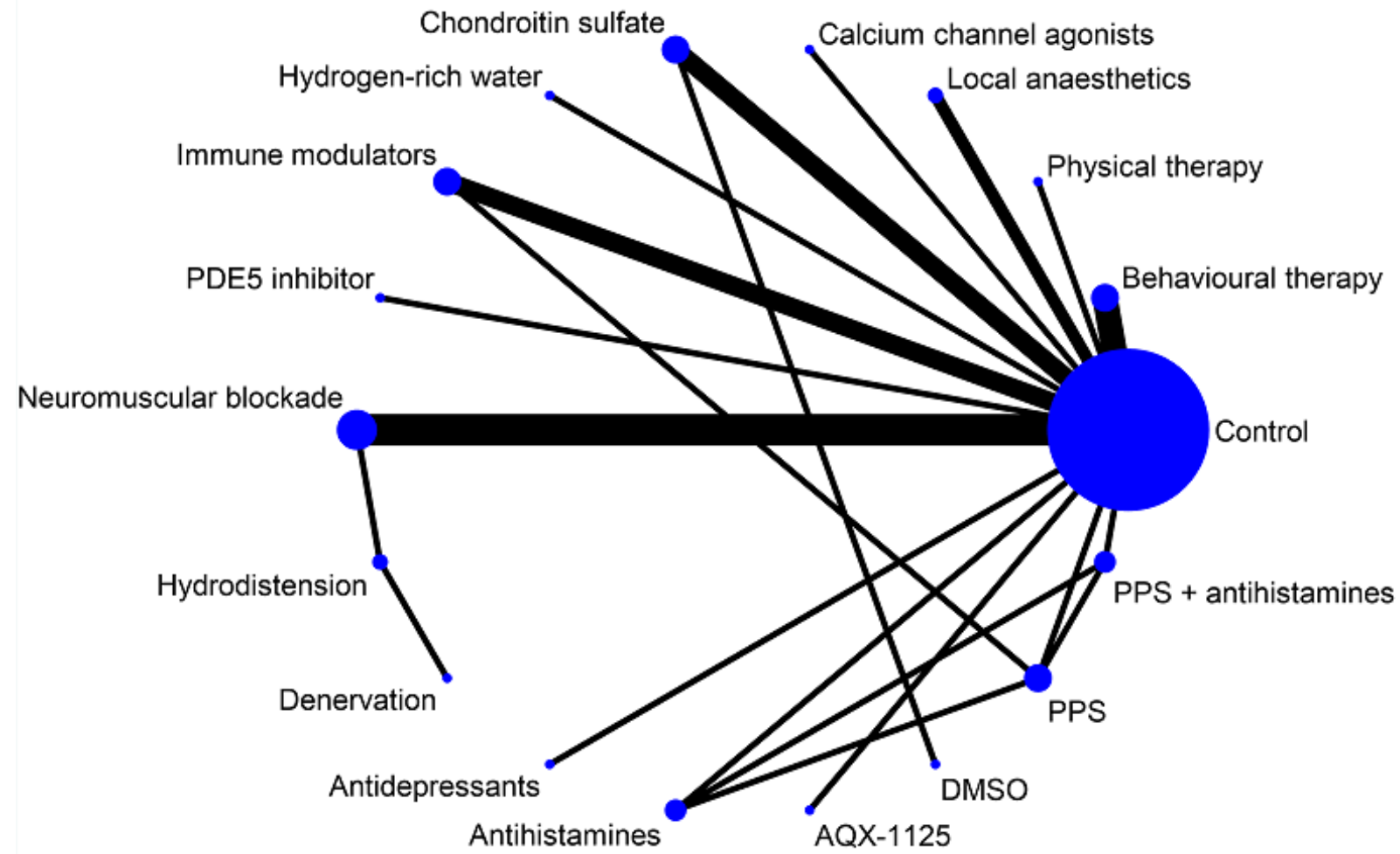

There was no clear evidence from the NMA suggesting that any treatment category was effective in reducing quality of life as measured by this scale (Table 9). The corresponding pairwise metaanalyses suggested benefits for four additional treatments: local anaesthetics; PDE5 inhibitors; antidepressants; and AQX-1125.

\section{Functional bladder capacity (descriptive statistics)}

Limited data were available for the outcome of functional bladder capacity, and no meta-analyses were performed because of variation in the way this outcome was reported across studies (Table 10). In general, differences in mean between groups, or changes in mean from baseline in each group, appear small and were in the range of $30 \mathrm{~mL}$ or less. Although not empirically tested, it has been suggested that an increase in bladder capacity of 30 $\mathrm{mL}$ may not be clinically relevant (Hanno 2017). A slightly larger difference between groups (from about 40 to $60 \mathrm{~mL}$ in terms of MD) was observed in one trial comparing immune modulator (bacillus Calmette-Guérin (BCG)) and control (Irani 2004), as well as in two further trials comparing neuromuscular blockade versus control (Kuo 2009; Manning 2014), but reported $P$ values $(0.165,0.05$ and 0.27 , respectively) indicate that there is no evidence of a difference between treatment groups.

\section{Adverse events}

Table 11 shows the number of participants experiencing at least one adverse event. Classifications and definitions of adverse events were described as reported by trial investigators and were not directly comparable across studies. In many cases, trial authors grouped adverse events under the broad categories of 'adverse events' or 'serious adverse events' without specifying the types of events. Due to variation in the way in which adverse events were reported, we were unable to conduct meta-analyses.

Although a large number of participants experienced one or more adverse event in most trials, these events were reported to be primarily mild to moderate in severity, and the treatments under study were reported to be reasonably well tolerated, with similar percentages of participants between groups experiencing undesirable effects.

Some trials reported relatively more adverse events with intervention than with control. Warren 2000 reported that adverse events occurred in $80 \%$ (20 out of 25 ) of participants taking antibiotics compared with $40 \%$ (10 of 25) taking placebo, with nausea and/or vomiting the most common event category. This led to discontinuation of 10 courses of antibiotics due to perceived adverse events, compared with two in the placebo group (reported $P$ value of 0.018 ). van Ophoven 2004 reported a higher incidence 
of anticholinergic side effects, particularly mouth dryness, in the group taking an antidepressant (amitriptyline) compared with the placebo group ( $92 \%$ ( 22 of 24 ) versus $21 \%$ (5 of 24$)$ ), although the reported events were not considered by trialists to be severe (grade 3 or higher). Kuo 2016 reported significantly more adverse events in the group that received botulinum toxin A compared with the control group (dysuria was the most common adverse event), although these adverse events were judged to be manageable and acceptable. In Sairanen 2005, there were more adverse events in the immune modulator (cyclosporin A) group than in the PPS group ( $94 \%$ (30 of 32 ) versus $56 \%$ (18 of 32 )), but withdrawals were reported to be similar in both study arms. In five trials comparing calcium channel agonists (e.g. capsaicin, resiniferatoxin) versus control, pain during instillation was commonly reported among participants in the intervention group (Chen 2005; Ham 2012; Lazzeri 1996; Lazzeri 2000; Payne 2005).

The number of participants experiencing serious adverse events is shown in Table 12. Definitions of serious adverse events were those reported by trial investigators. Overall, serious adverse events appear uncommon ( $\leq 3 \%$ within the study group). In trials where a greater number of serious adverse events were reported (possibly due to different definitions used), overall event rates appear similar between study arms.

For example, in one trial comparing immune modulators (BCG) and placebo (Mayer 2005), rates of 'severe' events (defined as grade 3 on the Common Toxicity Criteria) were 50\% (64 of 129) in the treatment group and $48 \%$ (63 of 132 ) in the placebo group. This study also reported a total of 32 'serious' adverse events in 21 participants, although the number in each group was not reported. Two of these were associated with the study drug (BCG hypersensitivity reaction in one patient in the BCG group, and prostatitis and urinary tract infection (UTI) in one patient in the placebo group).

Nickel 2009 reported that 'severe' adverse events were experienced by $8 \%$ ( 4 of 50 ) and 10\% (5 of 52) of participants receiving local anaesthetic (PSD597, intravesical alkalised lidocaine) and placebo, respectively. The most common event was bladder pain, which usually resolved within a day of instillation.

Evans 2011 reported 'serious' adverse events in 7\% (2 of 29) of participants treated with immune modulator and in 20\% (4 of 20) of those who received placebo. Events associated with immune modulator treatment included 'vertigo' and 'drug exposure during pregnancy', and 'cholelithiasis', 'ovarian mass', 'urosepsis/urinary tract infection' and 'transient ischaemic attack' were associated with placebo.

\section{DISCUSSION}

\section{Summary of main results}

Results of the network meta-analysis (NMA) suggest that the following treatment categories appear effective versus control for treatment of bladder pain syndrome (BPS), although a degree of caution is required in interpreting these results because of the small number of studies and the wide credible intervals.

\section{Primary outcomes (level of certainty)}

- Proportion cured or improved: behavioural therapy (very low), physical therapy (very low), antidepressants (very low), immune modulators (very low), phosphodiesterase-5 (PDE5) inhibitors (very low) and neuromuscular blockade (very low)

- Pain: physical therapy (moderate)

- Frequency: neuromuscular blockade plus dimethyl sulfoxide (DMSO) (moderate)

- Nocturia: no evidence from the NMA that any treatment category was effective

\section{Secondary outcomes}

- Interstitial Cystitis Symptom Index (ICSI): PDE5 inhibitors

- Interstitial Cystitis Problem Index (ICPI): no evidence from the NMA that any treatment category was effective

Because relatively few trials compared two non-control treatments, the benefit of using an NMA approach for some outcomes may have been relatively small, and this method may have produced results that were more conservative than the corresponding pairwise meta-analysis results. The results of these were generally consistent with the NMA, but as confidence intervals $(\mathrm{Cls})$ tended to be slightly narrower, a wider range of treatments had $\mathrm{Cls}$ that excluded the null effect.

For the proportion of participants who were cured or improved, the point estimate for the odds ratios (ORs) for treatment versus control was generally above two, suggesting large effects that could perhaps be considered clinically important. However, credible intervals (Crls) were very wide, reflecting that only a small number of studies were available for each comparison, and that sample sizes for included studies were generally small. For most treatments, the $\mathrm{Crl}$ also included values that were within the range specified as unlikely to be clinically important for our review $(0.8$ to 1.25). Similar findings were observed for continuous outcomes.

A descriptive analysis based on limited available data for assessment of functional bladder capacity suggests a relatively small difference between study arms. This difference is unlikely to be clinically relevant.

In general, treatments under investigation were reported to be reasonably well tolerated, and adverse events were usually reported to be mild or moderate in severity. Serious adverse events appear relatively uncommon for all interventions under investigation. As information on adverse events is limited, and given that adverse events were reported in various ways, we could not meta-analyse results or assess certainty of the evidence.

\section{Overall completeness and applicability of evidence}

This review included 81 randomised controlled trials (RCTs) involving a total of 4674 participants. A majority of studies were parallel-arm trials with a small sample size (median 38) and short follow-up (median three months). Six studies were crossover RCTs. The included studies evaluated 31 active treatment categories (grouped by mode of action). The most commonly evaluated treatment categories were immune modulators (e.g. bacille Calmette-Guérin (BCG), tanezumab) in 15 studies (Bosch 2014; Dimitrakov 2001; Evans 2011; Irani 2004; Mayer 2005; Nickel 2016; Oliver 2013; Peeker 2000; Peters 1997; Sairanen 2005; Sairanen 2009; Shirvan 2015; Taha 2007; Wang 2017a; Yang 2011); neuromuscular blockade in 13 studies (e.g. onabotulinumtoxinA) (Ahmadnia 2011; Chuang 2017; Gottsch 2011; Ismail 2016; Kasyan 2012; Kuo 2009; Kuo 2016; Manning 2014; Mirkin 2012; Payne 2014; 
Pinto 2016; Taha 2007; Yassin 2011); calcium channel agonists in seven studies (e.g. capsaicin, resiniferatoxin (RTX)) (Chen 2005; Ham 2012; Kim 2012; Lazzeri 1996; Lazzeri 2000; Nickel 2012b; Payne 2005); DMSO in six studies (Cervigni 2014; De Ridder 2013; Peeker 2000; Perez-Marrero 1988; Sairanen 2009; Singh 2003); and pentosan polysulfate (PPS) in six studies (Bade 1997; Davis 2008; Mulholland 1990; Nickel 2015; Sairanen 2005; Sant 2003). However, most treatment categories were assessed only in single trials. Study participants had various diagnoses including interstitial cystitis (IC), bladder pain syndrome (BPS), painful bladder syndrome (PBS) and painful bladder disease (PBD). It is worth noting that although there is significant overlap, these clinical diagnoses are not identical. This reflects the fact that the aetiology of BPS and validated diagnostic criteria have yet to be established.

We did not impose any language or other limitations on the literature search, which should help ensure overall completeness of the evidence. A further updated search of the Cochrane Incontinence Specialised Register was undertaken on 5 June 2019. Of the 45 records retrieved by the search, 15 reports of 14 studies appeared to meet the inclusion criteria for this evidence synthesis: five reports of four new studies; three additional reports of three already included studies; and seven trial registrations of seven ongoing studies. The four new studies were all small (ranging from 15 to 42 participants) (Aboyan 2018; Bosch 2018; Cervigni 2018; Oh-Oka 2017). Only one of these studies covered one of the comparisons included in our NMA (hyaluronic acid alone compared with hyaluronic acid in combination with chondroitin sulphate) (Aboyan 2018). Further details are given in the Characteristics of studies awaiting classification table. None of these study reports have been incorporated into the current evidence synthesis.

A strength of this work is that we have been able to assess all treatments for BPS, including many different conservative, pharmacological and surgical interventions, within a single analysis. NMA is a relatively new method that is well suited to this type of evidence synthesis, wherein a large number of trials evaluate a large number of treatments. Its key advantage is that it can incorporate both direct and indirect evidence between each pair of treatments.

Nevertheless, the limited number of small trials available for each treatment category hindered our ability to fully exploit the advantages of NMA. This was compounded by the fact that most treatments were compared with placebo or control, sometimes resulting in a so-called 'star-shaped' network. Consequently, Crls tended to be wide, indicating great uncertainty in effect estimates. There were also some differences in results of the pairwise metaanalyses. These more conservative results from NMA are not unexpected when the network is mainly star-shaped and there are few connections between pairs of non-control treatments (Filippini 2013).

We did not compare pairs of active treatments directly because there were too many combinations of treatments and the degree of uncertainty was considerable. A small number of treatments could not be assessed because they were disconnected from the rest of the network. We also decided not to use the NMA to rank treatments. It was difficult to assess the consistency assumption of the NMA due to the small number of closed loops within most networks, which meant that we were generally unable to compare the evidence from direct and indirect estimates of effect to check that these were consistent.
A further methodological challenge was that definitions of treatments and reported outcomes were heterogeneous across trials. We grouped treatments into broad categories, and within these there was often variation in types of treatments and how these were delivered. Some trials evaluated two treatments delivered in combination, and incorporating these into the analyses was sometimes challenging. Finally, we included a range of therapies that may be considered either first- or secondline treatments but did not consider this in our analyses. The populations of included participants in each trial may have differed in terms of symptom severity. An assumption of the NMA is that included patients could be randomised to any of the treatments, but in practice this may not have been the case.

No common single outcome was assessed by all included trials. Outcomes that were conceptually similar were measured in different ways. For example, pain was reported as measured by different scales or assessment tools. Continuous outcomes were reported as mean scores at last follow-up or as mean changes from baseline, and very few studies reported data in both formats. Outcome definitions were often unclear or ambiguous, and standard deviations (SDs) and denominators were not always provided. Considerable additional work was required to make extracted data suitable for the statistical analyses. Despite this additional effort, a sizeable number of studies often provided no usable data.

For the small number of cross-over trials that provided usable data, we used data from the first period only, as none provided information to approximate a paired analysis. This may have introduced bias and loss of precision, but the impact is likely to be small.

Although Cochrane recommends using final scores rather than change scores for continuous outcomes, roughly half of the included studies reported only change scores. We were successful in incorporating both types in the meta-analyses, but this complicated the analysis. We were able to utilise National Institute for Health and Care Excellence Decision Support Unit (NICE DSU) programmes that allowed data as both change and final scores, as well as multi-arm trials, to be used.

Another limitation of this work is that no subgroup analyses nor sensitivity analyses were carried out. Due to the multi-factorial aetiology of BPS, which is yet to be established, heterogeneity of the trial populations was anticipated, but we were not able to identify specific sources of heterogeneity worthy of further exploration. Future updates of this review could consider subgroup analyses or network meta-regression, if possible, and could consider a sensitivity analysis to explore the effect of including studies with high risk of bias.

Clinical characteristics of study participants included BPS with Hunner's lesions (classic diagnosis of IC). However, in most of the included studies, results were not reported separately for this subgroup. Therefore, we are not in a position to comment on the applicability of findings to patients with or without Hunner's lesions, who may show different responses to treatment.

\section{Quality of the evidence}

We assessed the overall certainty (quality) of evidence for the primary outcomes using the GRADE approach as modified for 
network meta-analysis (Salanti 2014), via the CINeMA 2017 web application. The overall certainty of evidence was moderate at best, and was low or very low for most outcomes. Evidence level was most often downgraded for within-study risk of bias, imprecision and heterogeneity. The quality of reporting was insufficient in most trial reports included in the review, and this may have contributed to downgrading of the certainty of evidence. However, these assessments may be conservative, as they were dependent on the choice of minimal clinically important difference (MCID) and subjective judgements in interpreting CINeMA guidance to enable GRADE assessment.

\section{Potential biases in the review process}

Although two review authors independently assessed the eligibility of published trial reports for inclusion in this review, data extraction and risk of bias assessment were carried out by one review author and were checked by another review author. The GRADE assessment of the certainty of evidence was conducted by two review authors working together, not independently, reaching consensus in discussion. This was a pragmatic decision due to resource constraints and may carry some risk of bias.

\section{Agreements and disagreements with other studies or reviews}

To the best of our knowledge, this review represents the first comprehensive assessment of published evidence for all interventions for BPS evaluated in RCTs. A narrative systematic review on interventions for BPS and IC published in 2016 identified the lack of high-level evidence in this area, as well as clinical and methodological heterogeneity in published studies (Pazin 2016), which is in line with the findings of the current review.

Recent systematic reviews of RCT evidence focused on individual interventions including PPS and onabotulinumtoxinA (Lee 2019; van Ophoven 2019). Other recent systematic reviews incorporating non-randomised evidence also focused on specific interventions such as cyclosporin A (Wang 2016); intravesical therapy (Barua 2016); intravesical hyaluronic acid with chondroitin sulfate (Pyo 2016); hydrodistension (Olson 2018); sacral modulation (El-Azab 2019; Wang 2017b); and complementary therapy (Verghese 2016). These reviews found only limited efficacy and pointed to a small evidence base and diversity in study populations, interventions and outcome measures, as well as insufficient descriptions of study methods used, which hindered further assessment to identify effective treatment options for BPS.

\section{AUTHORS' CONCLUSIONS}

\section{Implications for practice}

This review includes evidence from direct and indirect comparisons of existing treatments for BPS. These range from conservative treatments to surgical interventions. Very lowcertainty evidence suggests that behavioural therapy, physical therapy, antidepressants, immune modulators, PDE5 inhibitors and neuromuscular blockade may be effective in treating some, if not all, of the symptoms of BPS. However, due to limitations of the current evidence base, it is difficult to identify treatments that are superior to others.

Until further evidence for therapies for managing and treating pelvic floor dysfunction becomes available, developing a multi- disciplinary model of care, which involves not only the clinicians who traditionally treat BPS but also other professionals (including physical therapists, psychotherapists, pain management specialists and clinicians from other specialties) when non-bladder symptoms or disorders, as well as patient support groups, are part of the clinical picture, seems to be the best way forward.

\section{Implications for research}

An attempt to harmonise definitions and measurement tools across research groups would be useful, as would the use of tools that capture patient-reported outcomes. In particular, a definition of pain and the way to measure it should be clearly reported in future studies.

It is worth noting that BPS remains an unclear and controversial condition with unknown aetiology and no accepted diagnostic markers. Future research designed to better understand this clinical condition and consequently manage patients more effectively is clearly needed. In particular, there is a need to understand the pathophysiological processes involved in BPS and how these interrelate with chronic pelvic pain syndromes, and to identify both systemic and bladder-specific biomarkers (e.g. nerve growth factors, angiogenic growth factors, cytokines chemokine profiles). Better clinical phenotyping of BPS patients would allow health professionals to tailor specific treatments to individual patients. For trials that focus on BPS patients, it would be helpful to analyse data from patients with Hunner's lesion and from those with non-lesion disease separately, as these two groups of patients may respond differently to treatment.

According to the 6th International Consultation on Incontinence (Hanno 2017), as well as the US Food and Drug Administration (FDA) Bone, Reproductive and Urologic Drugs Advisory Committee (BRUDAC) 2018 criteria for IC/BPS (Nickel 2018), future research should cover the following clinical areas.

- Pathology of BPS.

- Biomarker development.

- Immunology of BPS.

- Neurological aspects, with particular attention to the relationship of BPS and overactive bladder.

- The relationship of bladder pain syndrome to chronic pelvic pain syndrome (non-bacterial prostatitis).

- Expanded definitions of bladder pain developed with the patient.

- Input, to include burning, pressure and discomfort.

- Validated patient-reported outcome instruments as recommended when the efficacy of drugs for treatment of patients with symptoms of BPS is assessed.

- Development of a simple, non-invasive diagnostic test for BPS.

- Development of a multi-disciplinary care model.

In addition, patient-relevant outcomes should be used in future trials for assessing interventions for BPS. Large, high-quality trials assessing specific interventions or comparisons of interventions with longer follow-up are needed. Current small trials testing numerous different interventions may be considered as research waste if they do not yield clinically useful knowledge. It is clear that researchers need to perform sample size calculations to ensure 
that studies have appropriate statistical power to answer research questions.

\section{ACKNOWLEDGEMENTS}

We are grateful to Kerry Dwan, Andy Elders, Sarah Hodgkinson, Jane Meijlink, Tess Moore and Luke Vale for valuable comments on drafts of the review; and thank Andrew Elders, Lynn Hampson, Carmel MA Ramage and Luke Vale for valuable comments on drafts of the protocol.
The review authors are grateful to Lara Kemp for secretarial support, Suzanne Freeman (Complex Review Support Unit, University of Leicester) for advice on methodological aspects of the network meta-analysis, Wanwuri Akor for kind assistance with double-screening the updated but unincorporated search of 5 June 2019, Christopher Harding (British Association of Urological Surgeons) for comments on the 'Background' section and advice on the MCID for our outcomes (at 7 August 2019) and for suggestions on which interventions to include in the SoF table, and Suzanne Biers (British Association of Urological Surgeons) for advice on clinical aspects of the review (at 22 December 2019). 


\section{R E F E R E N C E S}

\section{References to studies included in this review}

\section{Ahmadnia 2011 \{published data only\}}

Ahmadnia H, Shamsa A, Daloee MK, Ghanbarizadeh SR, Imanee MM, Rezayat AA. The effect of botulinum A toxin in treatment of painful bladder syndrome (Abstract number UP-358). Journal of Endourology 2012;26(Suppl 1):A396. [srincont64225]

* Ahmadnia H, Shamsa A, Khoje Daloee M, Ghanbarizadeh S. The effect of botulinum toxin $A$ in treatment of painful bladder syndrome (Abstract number UP-01.110). Urology 2011;78(3 Suppl 1):S221-2. [sr-incont64236]

\section{Bade 1997 \{published data only\}}

Bade JJ, Laseur M, Nieuwenburg A, van der Weele LT, Mensink HJ. A placebo-controlled study of intravesical pentosan polysulphate for the treatment of interstitial cystitis. British Journal of Urology 1997;79(2):168-71. [sr-incont4756]

\section{Barbalias 2000 \{published data only\}}

Barbalias GA, Liatsikos EN, Athanasopoulos A, Nikiforidis G. Interstitial cystitis: bladder training with intravesical oxybutynin. Journal of Urology 2000;163(6):1818-22. [srincont11700]

\section{Bosch 2014 \{published data only\}}

Bosch P. A randomized, double-blind, placebo controlled trial of adalimumab in the treatment of interstitial cystitis/bladder pain syndrome (Abstract number PD9-11). Journal of Urology 2014;191(4 Suppl 1):e216. [sr-incont67459]

* Bosch PC. A randomized, double-blind, placebo controlled trial of adalimumab for interstitial cystitis/bladder pain syndrome. Journal of Urology 2014;191(1):77-82. [NCT01295814] [sr-incont50404]

Bosch PC. Examination of the significant placebo effect in the treatment of interstitial cystitis/bladder pain syndrome. Urology 2014;84(2):321-6. [sr-incont62612]

\section{Carrico 2008 \{published data only\}}

Carrico DJ, Peters KM, Diokno AC. Guided imagery for women with interstitial cystitis: results of a prospective, randomized controlled pilot study. Journal of Alternative \& Complementary Medicine 2008;14(1):53-60. [sr-incont27092]

\section{Cartledge 2000 \{published data only\}}

Cartledge J, Davies A-M, Eardley I. A randomised double blind placebo controlled crossover trial of the efficacy of l-arginine in the treatment of interstitial cystitis (Abstract number 279). In: Proceedings of the International Continence Society (ICS), 29th Annual Meeting, 1999 Aug 23-26, Denver, Colorado. 1999:322. [sr-incont9924]

* Cartledge JJ, Davies AM, Eardley I. A randomized double-blind placebo-controlled crossover trial of the efficacy of L-arginine in the treatment of interstitial cystitis. BJU International 2000;85(4):421-6. [sr-incont11749]

\section{Carty 2017 \{published data only\}}

Carty J, Lumley MA, NCT02286115. Life-stress interview for women with chronic urogenital pain conditions. clinicaltrials.gov/show/NCT02286115 (first received 7 November 2014). [NCT02286115] [sr-incont68863]

* Carty J, Ziadni M, Lumley M, Holmes H, Tomakowsky J, Schubiner $\mathrm{H}$, et al. The effects of a stress and emotion interview for women with urogenital pain: a randomized trial (Abstract number Poster \#M41). Neurourology and Urodynamics 2017;36(S1):S52. [NCT02286115] [sr-incont75239]

Carty J. The Effects of a Life-Stress Interview for Women With Chronic Urogenital Pain: A Randomized Trial [PhD thesis]. Detroit, MI: Wayne State University, 2016. [NCT02286115] [srincont77800]

\section{Cervigni 2014 \{published data only\}}

Cervigni M, Sommariva M, Porru D, Ostardo E, Tenaglia R, Giammo A, et al. A randomized, open-label, multicentre study of efficacy and safety of intravesical hyaluronic acid and chondroitin sulfate (HA 1.6\% and CS $2 \%$ ) vs dimethyl sulfoxide (DMSO 50\%) in women with bladder pain syndrome/interstitial cystitis (BPS/IC) (Abstract). European Urology Supplement 2014;13(1):e464. [sr-incont67479]

* Cervigni M, Sommariva M, Porru D, Ostardo E, Tenaglia R, Giammo A, et al. A randomized, open-label, multicentre study of efficacy and safety of intravesical hyaluronic acid and chondroitin sulfate (HA 1.6\% and CS $2 \%$ ) vs. dimethyl sulfoxide (DMSO 50\%) in women with bladder pain syndrome/interstitial cystitis (BPS/IC) (Abstract number 14). Neurourology and Urodynamics 2014;33(6):665-6. [sr-incont64735]

Cervigni M, Sommariva M, Tenaglia R, Porru D, Ostardo E, Giammo A, et al. A randomized, open-label, multicenter study of the efficacy and safety of intravesical hyaluronic acid and chondroitin sulfate versus dimethyl sulfoxide in women with bladder pain syndrome/interstitial cystitis. Neurourology and Urodynamics 2017;36(4):1178-86. [EudraCT2010-021556-25] [srincont73574]

\section{Chen 2005 \{published data only\}}

Chen TY, Corcos J, Camel M, Ponsot Y, Tu le M. Prospective, randomized, double-blind study of safety and tolerability of intravesical resiniferatoxin (RTX) in interstitial cystitis (IC). International Urogynecology Journal 2005;16(4):293-7. [srincont21168]

\section{Chen 2014 \{published data only\}}

* Chen H, Wang F, Chen W, Ye Xt, Zhou Q, Shao F, et al. Efficacy of daily low-dose sildenafil for treating interstitial cystitis: results of a randomized, double-blind, placebo-controlled trial treatment of interstitial cystitis/painful bladder syndrome with low-dose sildenafil. Urology 2014;84(1):51-6. [sr-incont63933]

Chen HD. Efficacy of daily low-dose sildenafil for treating interstitial cystitis: results of randomized, double-blind, placebo-controlled trial. chictr.org.cn/showproj.aspx?proj=5629 
(first received 17 May 2013). [ChiCTR-TRC-13003938] [srincont68873]

\section{Chuang 2017 \{published data only\}}

Chuang YC, Kuo HC. A prospective multicenter doubleblind randomized trial of bladder instillation of liposome formulation onabotulinumtoxinA for interstitial cystitis/ bladder pain syndrome. Journal of Urology 2017;198(2):376-82. [NCT02247557] [sr-incont74522]

\section{Davis 2008 \{published data only\}}

Davis EL, El Khoudary SR, Talbott EO, Davis J, Regan LJ. Safety and efficacy of the use of intravesical and oral pentosan polysulfate sodium for interstitial cystitis: a randomized doubleblind clinical trial. Journal of Urology 2008;179(1):177-85. [srincont26269]

\section{De Ridder 2013 \{published data only\}}

* De Ridder D, Klockaerts K, Plancke H, Ost D, Van der Aa F. A prospective randomised controlled multicentre trial comparing intravesical DMSO and chondroitin sulphate 2 for painful bladder syndrome/interstitial cystitis (Abstract number 120). Neurourology and Urodynamics 2013;32(6):691-2. [srincont49212]

Tutolo M, Ammirati E, Castagna G, Klockaerts K, Plancke H, Ost $\mathrm{D}$, et al. A prospective randomized controlled multicentre trial comparing intravesical DMSO and chondroitin sulphate $2 \%$ for painful bladder syndrome/interstitial cystitis. International Brazilian Journal of Urology 2017;43(1):134-41. [sr-incont74273]

\section{Dimitrakov 2001 \{published data only\}}

Dimitrakov J, Tchitalov J, Zlatanov T, Dikov D, Rawadi G. Recombinant human nerve growth factor in the treatment of interstitial cystitis: preliminary results. Urology 2001;57(Suppl 6A):118-9. [sr-incont14750]

\section{El-Hefnawy 2015 \{published data only\}}

El-Hefnawy AS, Makharita MY, Abed A, Amr YM, Salah ElBadry M, Shaaban AA. Anesthetic bladder hydrodistention is superior to superior hypogastric plexus neurolysis in treatment of interstitial cystitis-bladder pain syndrome: a prospective randomized trial. Urology 2015;85(5):1039-44. [sr-incont66895]

\section{Evans 2011 \{published data only\}}

Evans RJ, Moldwin RM, Cossons N, Darekar A, Mills IW, Scholfield D. Proof of concept trial of tanezumab for the treatment of symptoms associated with interstitial cystitis. Journal of Urology 2011;185(5):1716-21. [NCT00601484] [srincont41532]

\section{FitzGerald 2009 \{published data only\}}

* FitzGerald MP, Anderson RU, Potts J, Payne CK, Peters KM, Clemens JQ, et al. Randomized multicenter feasibility trial of myofascial physical therapy for the treatment of urological chronic pelvic pain syndromes. Journal of Urology 2009;182(2):570-80. [NCT00434343] [sr-incont31887]

FitzGerald MP, Anderson RU, Potts J, Payne CK, Peters KM, Clemens JQ, et al. Randomized multicenter feasibility trial of myofascial physical therapy for the treatment of urological chronic pelvic pain syndromes. Journal of Urology 2013;189(1 Suppl):S75-85. [NCT00434343] [sr-incont46791]

FitzGerald 2012 \{published data only\}

FitzGerald MP, Payne CK, Lukacz ES, Yang CC, Peters KM, Chai TC, et al. Randomized multicenter clinical trial of myofascial physical therapy in women with interstitial cystitis/ painful bladder syndrome and pelvic floor tenderness. Journal of Urology 2012;187(6):2113-8. [NCT00733603] [sr-incont44631]

Foster 2010 \{published data only\}

* Foster HE Jr, Hanno PM, Nickel JC, Payne CK, Mayer RD, Burks DA, et al. Effect of amitriptyline on symptoms in treatment naive patients with interstitial cystitis/painful bladder syndrome. Journal of Urology 2010;183(5):1853-8. [NCT00124306] [sr-incont39619]

Yang W, Propert KJ, Landis JR. Estimating the efficacy of an interstitial cystitis/painful bladder syndrome medication in a randomized trial with both non-adherence and loss to followup. Statistics in Medicine 2014;33(20):3547-55. [sr-incont62584]

\section{Geirsson 1993 \{published data only\}}

Geirsson G, Wang YH, Lindstrom S, Fall M. Traditional acupuncture and electrical stimulation of the posterior tibial nerve. A trial in chronic interstitial cystitis. Scandinavian Journal of Urology and Nephrology 1993;27(1):67-70. [sr-incont125]

\section{Gottsch 2011 \{published data only\}}

Gottsch HP, Miller JL, Yang CC, Berger RE. A pilot study of botulinum toxin for interstitial cystitis/painful bladder syndrome. Neurourology and Urodynamics 2011;30(1):93-6. [srincont41053]

\section{Gulpinar 2013 \{published data only\}}

Gulpinar O, Kayis A, Guclu AG, Suer E, Arikan N. Clinical comparison of intravesical hyaluronic acid and hyaluronic acid-chondroitin sulphate therapy for patients with painful bladder syndrome/interstitial cystitis (Abstract number 561). In: Proceedings of the 43rd Annual Meeting of the International Continence Society (ICS), 2013 Aug 26-30, Barcelona, Spain. 2013. [sr-incont69711]

\section{Gulpinar 2015 \{published data only\}}

Gulpinar O, Esen B, Kayis A, Gokce MI, Suer E. Clinical comparison of intravesical hyaluronic acid and chondroitin sulfate therapies in the treatment of bladder pain syndrome/ interstitial cystitis. Neurourology and Urodynamics 2018;37(1):257-62. [sr-incont76583]

* Gulpinar O, Kayis A, Akinci A, Esen B, Suer E, Gokce MI. Clinical comparison of intravesical hyaluronic acid and chondroitin sulphate therapy for bladder pain syndrome/interstitial cystitis (Abstract number 24). Neurourology and Urodynamics 2015;34(S3):S50-1. [sr-incont68762]

\section{Ham 2012 \{published data only\}}

Ham BK, Kim JH, Oh MM, Lee JG, Bae JH. Effects of combination treatment of intravesical resiniferatoxin instillation and hydrodistention in patients with refractory painful bladder syndrome/interstitial cystitis: a pilot study. International Neurourology Journal 2012;16(1):41-6. [sr-incont44726] 
Hanno 2015 \{published data only\}

Hanno P, Kitt M, Moldwin R, Ford A, Butera P, McCarthy B. A multicenter study evaluating the safety and efficacy of af-219, a p2x3 antagonist, in women with interstitial cystitis/bladder pain syndrome (IC/BPS) (Abstract number: Podium \#4). Neurourology and Urodynamics 2015;34(S1):S77-8. [sr-incont68570]

\section{Herati 2011 \{published data only\}}

Herati A, Shorter B, Sadek M, Levey H, Okhunov Z, Moldwin R. The effects of caffeine on the symptoms of interstitial cystitis/ painful bladder syndrome: a randomized, placebo-controlled double blind study (Abstract number 808). Journal of Urology 2011;185(4S Suppl):e325. [sr-incont63347]

\section{Hsieh 2012 \{published data only\}}

Hsieh CH, Chang WC, Huang MC, Su TH, Li YT, Chang ST, et al. Hydrodistention plus bladder training versus hydrodistention for the treatment of interstitial cystitis. Taiwanese Journal of Obstetrics \& Gynecology 2012;51(4):591-5. [sr-incont46833]

\section{Irani 2004 \{published data only\}}

Irani D, Heidari M, Khezri A. The efficacy and safety of intravesical Bacillus-Calmette-Guerin in the treatment of female patients with interstitial cystitis: a double-blinded prospective placebo controlled study. Urology Journal 2004;1(2):90-3. [srincont27869]

\section{Ismail 2016 \{published data only\}}

* Ismail A, Lo H, Lo M. A prospective randomized controlled trial of botulinum toxin type A (BoNT-A) for the treatment of interstitial cystitis/bladder pain syndrome (IC/BPS) (Abstract number MP22-21). Journal of Endourology 2016;30(Suppl 2):A194-5. [sr-incont75871]

Ismail AF, Lo MC, Lo HL. Assessment of efficacy of intravesical bont-A for the treatment of interstitial cystitis/bladder pain syndrome (IC/BPS). A prospective randomised single blinded placebo-controlled clinical trial (Abstract number POD-11). BJU International 2016;118(Suppl S4):8. [sr-incont75016]

Lo W, Lo MC. Assessment of efficacy of intravesical BoNT-A for the treatment of interstitial cystitis/bladder pain syndrome (IC/BPS): a prospective randomised single-blinded placebocontrolled clinical trial (Abstract number C-NURO-1074). International Journal of Urology 2016;23(Suppl S1):28. [srincont73747]

\section{Kanter 2016 \{published data only\}}

Kanter G, Komesu Y, Qaedan F, Rogers R. Mindfulness-based stress reduction as a novel treatment for interstitial cystitis/ bladder pain syndrome: a randomized controlled trial. American Journal of Obstetrics and Gynecology 2016;214(4 Suppl 1):S457-8. [NCT02457182] [sr-incont72771]

* Kanter G, Komesu YM, Qaedan F, Jeppson PC, Dunivan GC, Cichowski SB, et al. Mindfulness-based stress reduction as a novel treatment for interstitial cystitis/bladder pain syndrome: a randomized controlled trial. International Urogynecology Journal 2016;27(11):1705-11. [NCT02457182] [sr-incont72139]

Kanter G, NCT02457182. Mindfulness-based therapy for interstitial cystitis/bladder pain syndrome. clinicaltrials.gov/
show/NCT02457182 (first received 29 May 2015). [NCT02457182] [sr-incont68822]

Kasyan 2012 \{published data only\}

* Kasyan G, Pushkar D. Randomized controlled trial for efficacy of botulinum toxin type $A$ in treatment of patients suffering bladder pain syndrome/interstitial cystitis with Hunner's lesions: preliminary results (Abstract). Journal of Urology 2012;187(4 Suppl 1):e335-6. [NCT01437579] [sr-incont64386]

Zaitcev AV, Kasyan GR, Tsibulya O, Pushkar DY. A randomised controlled trial to evaluate the efficacy of botulinum toxin type $A$ in the treatment of patients suffering bladder pain syndrome/ interstitial cystitis with Hunner's lesions: preliminary results (Abstract). European Urology Supplement 2012;11(1):e271-1a. [NCT01437579] [sr-incont64283]

\section{Kim 2012 \{published data only\}}

Kim JH, Ham BG, Park JY, Jang HA, Choi H, et al. Effects of combination treatment of intravesical resiniferatoxin instillation and hydrodistention in patients with refractory painful bladder syndrome/interstitial cystitis: a pilot study (Abstract number 527). In: Proceedings of the 42nd Annual Meeting of the International Continence (ICS), 2012 Oct 15 to 19, Beijing, China. 2012. [sr-incont50605]

\section{Kim 2015 \{published data only\}}

* Kim JH, Jee S, Kim S, Choo M, Lee K, Kim J, et al. The effect of hydrodistention versus transurethral fulguration of bladder in interstitial cystitis/bladder pain syndrome (IC/BPS) patients: prospective, multicenter, randomized clinical trial (Abstract number: Poster \#M31). Neurourology and Urodynamics 2015;34(S1):S31. [sr-incont68508]

Kim JH, Kim SW, Jee SH, Lee KS, Choo MS, Kim JC, et al. Prospective, multicenter, randomized clinical trial comparing the effect of hydrodistention and transurethral fulguration of bladder in interstitial cystitis/bladder pain syndrome patients (Abstract number PD20-10). Journal of Urology 2015;193(4 Suppl 1):e401. [sr-incont71161]

\section{Korting 1999 \{published data only\}}

Korting GE, Smith SD, Wheeler MA, Weiss RM, Foster HE Jr. A randomized double-blind trial of oral L-arginine for treatment of interstitial cystitis. Journal of Urology 1999;161(2):558-65. [srincont8258]

\section{Kuo 2009 \{published data only\}}

Kuo HC, Chancellor MB. Comparison of intravesical botulinum toxin type A injections plus hydrodistention with hydrodistention alone for the treatment of refractory interstitial cystitis/painful bladder syndrome. BJU International 2009;104(5):657-61. [sr-incont32065]

\section{Kuo 2016 \{published data only\}}

Jhang J-F, Tseng H-L, Kuo H-C, Kuo Y-C, Tsai Y-C. Intravesical botulinum toxin $A$ single injections can reduce bladder pain in treatment of interstitial cystitis/bladder pain syndrome refractory to conventional treatment - a prospective, multicenter, randomized, double-blind, placebo-controlled clinical trial (Abstract number PD20-02). Journal of Urology 2015;193(4 Suppl 1):e397-8. [NCT01969773] [sr-incont77801] 
* Kuo H-C, Jiang Y-H, Tsai Y-C, Kuo Y-C. Intravesical botulinum toxin-A injections reduce bladder pain of interstitial cystitis/ bladder pain syndrome refractory to conventional treatment - a prospective, multicenter, randomized, double-blind, placebo-controlled clinical trial. Neurourology and Urodynamics 2016;35(5):609-14. [NCT01969773] [sr-incont72758]

Kuo H-C, NCT01969773. Intravesical botulinum toxin A injections in treatment of interstitial cystitis refractory to conventional treatment [Intravesical botulinum toxin A injection in treatment of interstitial cystitis refractory to conventional treatment - a prospective, multicenter, randomized, double-blind, placebo-controlled clinical trial]. clinicaltrials.gov/show/NCT01969773 (first received 25 October 2013). [NCT01969773] [sr-incont68847]

Kuo Y, Lee C, Jiang Y, Kuo H. Therapeutic effects of intravesical onabotulinumtoxinA injection on IC/BPS refractory to conventional treatment - a randomized, double blind, placebo controlled study (Abstract number 560). In: Proceedings of the 44th Annual Meeting of the International Continence Society (ICS), 2014 Oct 20-24, Rio de Janeiro, Brazil. 2014. [NCT01969773] [sr-incont69715]

Lee C-L, Jiang Y-H, Jhang J-F, Kuo H-C. The efficacy of intravesical onabotulinumtoxin-A injection in the treatment of interstitial cystitis/bladder pain syndrome: a randomized, double-blind, placebo controlled study (Abstract number 578). European Urology Supplement 2014;13(1):e578-8b. [srincont67344]

\section{Lazzeri 1996 \{published data only\}}

Lazzeri M. Intravesical capsaicin for treatment of severe bladder pain: a randomized placebo controlled study. Journal of Urology 1996;156(3):947-52. [sr-incont18355]

\section{Lazzeri 2000 \{published data only\}}

Lazzeri M, Beneforti P, Spinelli M, Zanollo A, Barbagli G, Turini D. Intravesical resiniferatoxin for the treatment of hypersensitive disorder: a randomized placebo controlled study. Journal of Urology 2000;164(3 Pt 1):676-9. [sr-incont11649]

\section{Leadership 201 Trial 2016 \{published data only\}}

Nickel JC, Egerdie B, Davis E, Evans R, Biagi H, Shrewsbury S. Efficacy and safety of a novel, oral SH2-containing inositol-5'phosphatase 1 activator, AQX-1125, in subjects with moderate to severe interstitial cystitis/bladder pain syndrome (Abstract number POD-03.01). Canadian Urological Association Journal 2016;10(5-6 Suppl 1):S10. [NCT01882543] [sr-incont77334]

* Nickel JC, Egerdie B, Davis E, Evans R, Mackenzie L, Shrewsbury SB. A phase II study of the efficacy and safety of the novel oral SHIP1 activator AQX-1125 in subjects with moderate to severe interstitial cystitis/bladder pain syndrome [erratum appears in: Journal of Urology 2016;196(6):1826]. Journal of Urology 2016;196(3):747-54. [NCT01882543] [sr-incont73536]

Shrewsbury SB, NCT01882543. Efficacy and safety of AQX-1125 in IC/BPS (LEADERSHIP) [A phase 2 study to evaluate the efficacy and safety of AQX-1125 in subjects with interstitial cystitis/bladder pain syndrome mediated by the Src homology-2-domain-containing inositol 5' phosphatase [SHIP1] pathway]. clinicaltrials.gov/show/NCT01882543 (first received 20 June 2013). [NCT01882543] [sr-incont68828]

\section{Lee 2014 \{published data only\}}

Lee MH, Wu HC, Lin JY, Tan TH, Chan PC, Chen YF. Development and evaluation of an E-health system to care for patients with bladder pain syndrome/interstitial cystitis. International Journal of Urology 2014;21(Suppl S1):62-8. [sr-incont62086]

\section{Lee 2016 \{published data only\}}

* Lee MH, Wu HC, Chen WC, Chen YF. Multidisciplinary selfmanagement telecare system may improve quality of life in patients with interstitial cystitis/bladder pain syndrome (IC/BPS) - a randomized controlled trial (Abstract number 51). Neurourology and Urodynamics 2016;35(S4):S94-5. [srincont73453]

Lee MH, Wu HC, Chen WC. Multidisciplinary self-management telecare system may improve quality of life in patients with interstitial cystitis/bladder pain syndrome (IC/BPS) - a randomized controlled study (Abstract number 429). European Urology Supplement 2017;16(3):e755-6. [sr-incont77823]

\section{Lu 2015 \{published data only\}}

Lu G-L, Wang D-W, Shao Y, Xu D. Comparative study on intravesical hyaluronic acid instillation and heparinlidocaine instillation for the treatment of interstitial cystitis. Journal of Shanghai Jiaotong University (Medical Science) 2015;35(11):1757-61. [sr-incont70945]

\section{Manning 2014 \{published data only\}}

* Manning J, Dwyer P, Rosamilia A, Colyvas K, Murray C, Fitzgerald E. A multicentre, prospective, randomised, double-blind study to measure the treatment effectiveness of abobotulinum A (AboBTXA) among women with refractory interstitial cystitis/bladder pain syndrome. International Urogynecology Journal 2014;25(5):593-9. [ACTRN12612000216819] [sr-incont60617]

Manning J. Botulinum toxin A (BTXA) versus hydrodistension for refractory interstitial cystitis/painful bladder syndrome (IC/PBS) - a multicentre, prospective, randomized, double blind study. anzctr.org.au/ACTRN12612000216819.aspx (first received 13 February 2012). [ACTRN12612000216819] [sr-incont68877]

\section{Matsumoto 2013 \{published data only\}}

* Matsumoto S, Ueda T, Kakizaki H. Does the supplementation with hydrogen-rich water improve the problems of pain in patients with interstitial cystitis? (Abstract number 570). International Urogynecology Journal and Pelvic Floor Dysfunction 2011;22(Suppl 2):S691. [sr-incont65162]

Matsumoto S, Ueda T, Kakizaki H. Does the supplementation with hydrogen-rich water improve the problems of pain in patients with interstitial cystitis? (Abstract number 570). Proceedings of the Joint Meeting of the International Continence Society (ICS) and the International Urogynecological Association, 2010 Aug 23-27, Toronto, Canada 2010. [UMIN000001253] [sr-incont40183]

* Matsumoto S, Ueda T, Kakizaki H. Effect of supplementation with hydrogen-rich water in patients with interstitial cystitis/ 
painful bladder syndrome. Urology 2013;81(2):226-30. [srincont47640]

\section{Mayer 2005 \{published data only\}}

Leiby BE, Sammel MD, Ten Have TR, Lynch KG. Identification of multivariate responders/non-responders using Bayesian growth curve latent class models. Journal of the Royal Statistical Society Series C Applied Statistics 2009;58(4):505-24. [sr-incont72268]

* Mayer R, Propert KJ, Peters KM, Payne CK, Zhang Y, Burks D, et al. A randomized controlled trial of intravesical bacillus Calmette-Guerin for treatment refractory interstitial cystitis. Journal of Urology 2005;173(4):1186-91. [sr-incont20181]

Nickel JC, Tripp D, Teal V, Propert KJ, Burks D, Foster HE, et al. Sexual function is a determinant of poor quality of life for women with treatment refractory interstitial cystitis. Journal of Urology 2007;177(5):1832-6. [sr-incont23119]

Propert KJ, Mayer R, Nickel JC, Payne CK, Peters KM, Teal V, et al. Did patients with interstitial cystitis who failed to respond to initial treatment with bacillus Calmette-Guerin or placebo in a randomized clinical trial benefit from a second course of open label bacillus Calmette-Guerin? Journal of Urology 2007;178(3 Pt 1):886-90. [sr-incont23911]

Propert KJ, Mayer R, Nickel JC, Payne CK, Peters KM, Teal V, et al. Followup of patients with interstitial cystitis responsive to treatment with intravesical bacillus Calmette-Guerin or placebo. Journal of Urology 2008;179(2):552-5. [sr-incont26448]

\section{Mirkin 2012 \{published data only\}}

Mirkin Y, Bedretdinova D, Eizenakh I, Smirnov G, Romikh V, Malinina O. First clinical experience of intravesical electromotive botulinum toxin administration for painful bladder syndrome treatment (Abstract number 516). In: Proceedings of the 42nd Annual Meeting of the International Continence (ICS), 2012 Oct 15 to 19, Beijing, China. 2012. [srincont50604]

\section{Mirkin 2015 \{published data only\}}

Mirkin YB, Karapetyan A, Shumoff S, Mirkina K. Intravesical administration of hyaluronic acid with tacrolimus for treatment of bladder pain (Abstract number 269). European Urology Supplement 2015;14(2):e269. [sr-incont69555]

\section{Moldwin 2015 \{published data only\}}

Moldwin R, Kitt M, Mangel J, Beyer R, Hanno P, Butera P, et al. A phase 2 study in women with interstitial cystitis/ bladder pain syndrome (IC/BPS) of the novel P2X3 antagonist AF-219 (Abstract number 23). Neurourology and Urodynamics 2015;34(S3):S50. [NCT01569438] [sr-incont68763]

\section{Mulholland 1990 \{published data only\}}

Mulholland SG, Hanno P, Parsons CL, Sant GR, Staskin DR. Pentosan polysulfate sodium for therapy of interstitial cystitis. A double-blind placebo-controlled clinical study. Urology 1990;35(6):552-8. [sr-incont3406]

\section{Nguan 2005 \{published data only\}}

Nguan C, Franciosi LG, Butterfield NN, Macleod BA, Jens M, Fenster HN. A prospective, double-blind, randomized cross- over study evaluating changes in urinary $\mathrm{pH}$ for relieving the symptoms of interstitial cystitis. BJU International 2005;95(1):91-4. [sr-incont20240]

\section{Nickel 2009 \{published data only\}}

Nickel JC, Moldwin R, Lee S, Davis EL, Henry RA, Wyllie MG. Intravesical alkalinized lidocaine (PSD597) offers sustained relief from symptoms of interstitial cystitis and painful bladder syndrome. BJU International 2009;107(7):910-8. [srincont31168]

\section{Nickel 2010 \{published data only\}}

Nickel JC, Egerdie RB, Steinhoff G, Palmer B, Hanno P. A multicenter, randomized, double-blind, parallel group pilot evaluation of the efficacy and safety of intravesical sodium chondroitin sulfate versus vehicle control in patients with interstitial cystitis/painful bladder syndrome. Urology 2010;76(4):804-9. [sr-incont40346]

\section{Nickel 2012a \{published data only\}}

Nickel JC, Hanno P, Kumar K, Thomas H. Second multicenter, randomized, double-blind, parallel-group evaluation of effectiveness and safety of intravesical sodium chondroitin sulfate compared with inactive vehicle control in subjects with interstitial cystitis/bladder pain syndrome. Urology 2012;79(6):1220-5. [sr-incont44642]

\section{Nickel 2012b \{published data only\}}

Drug company. A phase 2, 12 week, multicenter, randomized, double-blind, placebo- controlled, parallel group, proof of concept study evaluating the efficacy and safety of PD 0299685 for the treatment of symptoms associated with interstitial cystitis/painful bladder syndrome. clinicaltrialsregister.eu/ ctr-search/search?query=eudract_number:2008-002421-37 (first received 29 July 2008). [EUCTR2008-002421-37-DE] [NCT00739739] [sr-incont68886]

NCT00739739, Drug company. An effectiveness and safety study of PD 0299685 for the treatment of symptoms associated with interstitial cystitis [A phase 2, 12 week, multicenter, randomized, double-blind, placebo-controlled, parallel group, proof of concept study evaluating the efficacy and safety of PD 0299685 for the treatment of symptoms associated with interstitial cystitis/painful bladder syndrome]. clinicaltrials.gov/show/NCT00739739 (first received 22 August 2008). [EUCTR2008-002421-37-DE] [NCT00739739] [srincont63831]

* Nickel JC, Crossland A, Davis E, Haab F, Mills IW, Rovner E, et al. Investigation of a $\mathrm{Ca}(2+)$ channel alpha2delta ligand for the treatment of interstitial cystitis: results of a randomized, double-blind, placebo controlled phase II trial. Journal of Urology 2012;188(3):817-23. [EUCTR2008-002421-37-DE] [NCT00739739] [sr-incont45123]

\section{Nickel 2015 \{published data only\}}

Nickel JC, Herschorn S, Whitmore KE, Forrest JB, Hu P, Friedman AJ, et al. Pentosan polysulfate sodium for treatment of interstitial cystitis/bladder pain syndrome: insights from a randomized, double-blind, placebo controlled study. Journal of Urology 2015;193(3):857-62. [NCT00086684] [sr-incont66885] 


\section{Nickel 2016 \{published data only\}}

Drug company. A phase $2 b$, randomized, double-blind, placebocontrolled, dose ranging study evaluating the efficacy and safety of tanezumab for the treatment of moderate to severe pain associated with interstitial cystitis/ painful bladder syndrome (IC/PBS). clinicaltrialsregister.eu/ctr-search/search? query=eudract_number:2009-014597-17 (first received 28 October 2009). [EUCTR2009-014597-17-SE] [NCT00999518] [srincont68885]

NCT00999518, Drug company. A study to investigate tanezumab in patients with interstitial cystitis/painful bladder syndrome [A phase $2 \mathrm{~b}$, randomized, double-blind, placebo-controlled, dose ranging study evaluating the efficacy and safety of tanezumab for the treatment of moderate to severe pain associated with interstitial cystitis/painful bladder syndrome (IC/PBS)]. clinicaltrials.gov/show/NCT00999518 (first received 21 October 2009). [EUCTR2009-014597-17-SE] [NCT00999518] [sr-incont68827]

Nickel JC, Krieger J, Mills I, Crook T, Jorga A, Atkinson G, et al. Tanezumab reduces pain in women with interstitial cystitis/ bladder pain syndrome (Abstract number PD20-01). Journal of Urology 2015;193(4 Suppl 1):e397. [EUCTR2009-014597-17-SE] [NCT00999518] [sr-incont71162]

* Nickel JC, Mills IW, Crook TJ, Jorga A, Smith MD, Atkinson G, et al. Tanezumab reduces pain in women with interstitial cystitis/bladder pain syndrome and patients with nonurological associated somatic syndromes. Journal of Urology 2016;195(4 Pt 1):942-8. [EUCTR2009-014597-17-SE] [NCT00999518] [srincont74140]

\section{Nomiya 2017 \{published data only\}}

* Nomiya A, Niimi A, Akiyama Y, Tabata M, Enomoto Y, Igawa Y, et al. A randomized control trial on intravesical instillation of heparin alone versus a cocktail of heparin plus alkalized lidocaine for refractory interstitial cystitis (Abstract number 551). Neurourology and Urodynamics 2017;36(Suppl S3):S461-2. [UMIN000026714] [sr-incont77706]

Nomiya A. RCT study of bladder instillation therapy in patients with refractory interstitial cystitis. upload.umin.ac.jp/cgi-openbin/ctr_e/ctr_view.cgi?recptno=R000024393 (first received 27 March 2017). [UMIN000026714] [sr-incont76236]

\section{O'Reilly 2004 \{published data only\}}

O'Reilly BA, Dwyer PL, Hawthorne G, Cleaver S, Thomas E, Rosamilia A, et al. Transdermal posterior tibial nerve laser therapy is not effective in women with interstitial cystitis. Journal of Urology 2004;172(5 Pt 1):1880-3. [sr-incont19425]

\section{Oliver 2013 \{published data only\}}

Oliver J, Klutke C. Triamcinolone injection vs. fulguration for treatment of Hunner's ulcer-type interstitial cystitis: preliminary results of a prospective randomized trial (Abstract number 555). In: Proceedings of the 43rd Annual Meeting of the International Continence Society (ICS), 2013 Aug 26-30, Barcelona, Spain. 2013. [sr-incont69712]

\section{Parsons 2012 \{published data only\}}

Parsons CL, Zupkas P, Proctor J, Koziol J, Franklin A, Giesing D, et al. Alkalinized lidocaine and heparin provide immediate relief of pain and urgency in patients with interstitial cystitis. Journal of Sexual Medicine 2012;9(1):207-12. [sr-incont42957]

\section{Payne 2005 \{published data only\}}

Payne C, Mosbaugh P, Forrest J, Evans R, Frumkin L. Phase II safety and efficacy study of single dose of intravesical resiniferatoxin (RTX) in patients with interstitial cystitis (Abstract). Neurourology and Urodynamics 2004;23(5/6):606-7. [sr-incont19028]

* Payne CK, Mosbaugh PG, Forrest JB, Evans RJ, Whitmore KE, Antoci JP, et al. Intravesical resiniferatoxin for the treatment of interstitial cystitis: a randomized, double-blind, placebo controlled trial. Journal of Urology 2005;173(5):1590-4. [srincont20737]

\section{Payne 2014 \{published data only\}}

Payne C, Comiter C. A randomized, double-blinded, doseranging study of botulinum toxin bladder injections in the treatment of interstitial cystitis/bladder pain syndrome (Abstract number 761). In: Proceedings of the 44th Annual Meeting of the International Continence Society (ICS), 2014 Oct 20-24, Rio de Janeiro, Brazil. 2014. [sr-incont69714]

\section{Peeker 2000 \{published data only\}}

Peeker R, Haghsheno MA, Holmang S, Fall M. Intravesical bacillus Calmette-Guerin and dimethyl sulfoxide for treatment of classic and nonulcer interstitial cystitis: a prospective, randomized double-blind study. Journal of Urology 2000;164(6):1912-6. [sr-incont11822]

\section{Perez-Marrero 1988 \{published data only\}}

Perez-Marrero R, Emerson LE, Feltis JT. A controlled study of dimethyl sulfoxide in interstitial cystitis (Abstract number 339). Journal of Urology 1986;135:188A. [sr-incont5163]

* Perez-Marrero R, Emerson LE, Feltis JT. A controlled study of dimethyl sulfoxide in interstitial cystitis [see comments]. Journal of Urology 1988;140(1):36-9. [sr-incont483]

\section{Peters 1997 \{published data only\}}

* Peters K, Diokno A, Steinert B, Yuhico M, Mitchell B, Krohta S, et al. The efficacy of intravesical Tice strain bacillus CalmetteGuerin in the treatment of interstitial cystitis: a double-blind, prospective, placebo controlled trial. Journal of Urology 1997;157(6):2090-4. [sr-incont5641]

Peters KM, Diokno AC, Steinert BW, Gonzalez JA. The efficacy of intravesical bacillus Calmette-Guerin in the treatment of interstitial cystitis: long-term followup. Journal of Urology 1998;159(5):1483-6. [sr-incont5418]

\section{Pinto 2016 \{published data only\}}

Cruz F. Treatment of bladder pain syndrome with onabotulinum toxin A. clinicaltrialsregister.eu/ctr-search/trial/2014-001013-81/ PT/ (first received 3 July 2014). [EudraCT2014-001013-81] [srincont66686] 
* Pinto R, Costa D, Morgado A, Pereira P, Silva J, Cruz F. Efficacy and safety of intra-trigonal injection of OnaBotulinum toxin $A$ in patients with bladder pain syndrome/interstitial cystitis: interim analysis of an exploratory randomized, double blind, placebocontrolled trial (Abstract number 628). In: Proceedings of the International Continence Society (ICS), Annual Meeting, 2016 Sep 13-16, Tokyo, Japan. 2016. [EudraCT2014-001013-81] [srincont73457]

Pinto R, Costa D, Morgado A, Pereira P, Silva J, Cruz F. Results from a randomized, double blind, placebo-controlled trial to evaluate efficacy and safety of intra-trigonal injection of onabotulinum toxin A in patients with bladder pain syndrome/ interstitial cystitis (Abstract number PD01-01). Journal of Urology 2017;197(4 Suppl 1):e46. [EudraCT2014-001013-81] [srincont77574]

\section{Sairanen 2005 \{published data only\}}

Sairanen J, Hotakainen K, Tammela TL, Stenman UH, Ruutu M. Urinary epidermal growth factor and interleukin- 6 levels in patients with painful bladder syndrome/interstitial cystitis treated with cyclosporine or pentosan polysulfate sodium. Urology 2008;71(4):630-3. [sr-incont27136]

Sairanen J, Leppilahti M, Tammela TL, Paananen I, Aaltomaa S, Taari K, et al. Evaluation of health-related quality of life in patients with painful bladder syndrome/interstitial cystitis and the impact of four treatments on it. Scandinavian Journal of Urology and Nephrology 2009;43(3):212-9. [sr-incont31405]

* Sairanen J, Tammela TL, Leppilahti M, Multanen M, Paananen I, Lehtoranta K, et al. Cyclosporine A and pentosan polysulfate sodium for the treatment of interstitial cystitis: a randomized comparative study. Journal of Urology 2005;174(6):2235-8. [sr-incont21247]

Sairanen J, Tammela TL, Leppilahti M, Onali M, Forsell T, Ruutu M. Potassium sensitivity test (PST) as a measurement of treatment efficacy of painful bladder syndrome/interstitial cystitis: a prospective study with cyclosporine $A$ and pentosan polysulfate sodium. Neurourology and Urodynamics 2007;26(2):267-70. [sr-incont23111]

\section{Sairanen 2009 \{published data only\}}

Sairanen J, Leppilahti M, Tammela TL, Paananen I, Aaltomaa S, Taari K, et al. Evaluation of health-related quality of life in patients with painful bladder syndrome/interstitial cystitis and the impact of four treatments on it. Scandinavian Journal of Urology and Nephrology 2009;43(3):212-9. [sr-incont31405]

\section{Sant 2003 \{published data only\}}

Sant GR, Propert KJ, Hanno PM, Burks D, Culkin D, Diokno AC, et al. A pilot clinical trial of oral pentosan polysulfate and oral hydroxyzine in patients with interstitial cystitis.[see comment]. Journal of Urology;170(3):810-5. [sr-incont16524]

\section{Shirvan 2015 \{published data only\}}

Shirvan M. A novel method for treatment of painful bladder syndrome (Abstract number 86). BJU International 2015;115(Suppl 4):44. [sr-incont71164]
Singh 2003 \{published data only\}

Singh M, Edgeley D, Pary B, Ramsden CS, Lingam K. Prospective randomised controlled trial of intravesical dimethylsulphoxide (DMSO) versus cystistat (hyaluronic acid) in the treatment of female patients with interstitial cystitis (IC) (Abstract number 568). In: Proceedings of the International Continence Society (ICS), 33rd Annual Meeting, 2003 Oct 5-9, Florence Italy. 2003:510-1. [sr-incont17162]

\section{Souza 2012 \{published data only\}}

Souza GHB, Maistro EL, Rodrigues M, Carvalho JCT, Fonseca FLA, Lopes AP, et al. Phase II clinical study of an association for the treatment of interstitial cystitis (Cystex). HealthMED 2012;6(2):423-7. [sr-incont61015]

\section{Taha 2007 \{published data only\}}

Taha M, Farahat Y, Bahnasy A, Damhougy M. A randomized controlled trial of bacillus Calmette-Guerin and botulinum toxin-A for the treatment of refractory interstitial cystitis (Abstract number 107). Neurourology and Urodynamics 2007;26(5):735. [sr-incont26669]

\section{Thilagarajah 2001 \{published data only\}}

Thilagarajah R. Oral cimetidine gives effective symptom relief in painful bladder disease: a prospective, randomized, double-blind placebo-controlled trial. BJU International 2001;87(3):207-12. [sr-incont18072]

\section{van Ophoven 2004 \{published data only\}}

van Ophoven A, Hertle L. Safety and efficacy of amitriptyline for the treatment of interstitial cystitis: results of a placebo controlled trial and a prospective long-term observational study (Abstract number 109). Neurourology and Urodynamics 2005;24(5/6):572-3. [sr-incont20989]

* van Ophoven A, Pokupic S, Heinecke A, Hertle L. A prospective, randomized, placebo controlled, double-blind study of amitriptyline for the treatment of interstitial cystitis. Journal of Urology 2004;172(2):533-6. [sr-incont19310]

\section{van Ophoven 2006 \{published data only\}}

van Ophoven A, Rossbach G, Pajonk F, Hertle L. Safety and efficacy of hyperbaric oxygen therapy for the treatment of interstitial cystitis: a randomized, sham controlled, doubleblind trial (erratum published Journal of Urology 2007 Apr;177(4):1588). Journal of Urology 2006;176(4 Pt 1):1442-6. [sr-incont22336]

\section{Wang 2017a \{published data only\}}

NCT01060254, Drug company. A study to evaluate the pain relieving effects, safety, and tolerability of JNJ-42160443 for the relief of bladder pain [A randomized, double-blind, placebocontrolled study to explore the efficacy, safety, and tolerability of JNJ-42160443 in subjects with interstitial cystitis/ painful bladder syndrome]. clinicaltrials.gov/show/NCT01060254 (first received 2 February 2010). [NCT01060254] [sr-incont68834]

* Wang H, Russell LJ, Kelly KM, Wang S, Thipphawong J. Fulranumab in patients with interstitial cystitis/bladder pain syndrome: observations from a randomized, double- 
blind, placebo-controlled study. BMC Urology 2017;17:2.

[NCT01060254] [sr-incont75516]

Warren 2000 \{published data only\}

Warren JW, Horne LM, Hebel JR, Marvel RP, Keay SK, Chai TC. Pilot study of sequential oral antibiotics for the treatment of interstitial cystitis. Journal of Urology 2000;163(6):1685-8. [srincont11701]

\section{Yang 2011 \{published data only\}}

Yang CC, Burks DA, Propert KJ, Mayer RD, Peters KM, Nickel JC, et al. Early termination of a trial of mycophenolate mofetil for treatment of interstitial cystitis/painful bladder syndrome: lessons learned. Journal of Urology 2011;185(3):901-6. [srincont40998]

\section{Yassin 2011 \{published data only\}}

Yassin M, Saffan A, Shaker H, Murad S, Gamal M. Intravesical injection of botulinum $A$ toxin (BTX-A) in the management of painful bladder syndrome/interstitial cystitis (a randomized control study) (Abstract number 766). In: Proceedings of the 41st Annual Meeting of the International Continence Society (ICS), 2011 Aug 29 to Sept 2, Glasgow, Scotland. 2011. [srincont42232]

\section{Zakaria 2016 \{published data only\}}

Zakaria MEM, Ashraf HM, Ahmed A-EM, Mahmoud HMAW. Effect of transcutaneous electrical nerve stimulation on interstitial cystitis/painful bladder syndrome. International Journal of PharmTech Research 2016;9(6):59-65. [sr-incont75112]

\section{References to studies excluded from this review}

\section{Akiyama 2014 \{published data only\}}

Akiyama Y, Nomiya A, Niimi A, Yamada Y, Suzuki M, Fujimura T, et al. A prospective randomized control trial of botulinum toxin $A$ (Botox A) injection for interstitial cystitis (Abstract number 160). In: Proceedings of the 44th Annual Meeting of the International Continence Society (ICS), 2014 Oct 20-24, Rio de Janeiro, Brazil. 2014. [sr-incont69716]

\section{Baert 1975 \{published data only\}}

Baert L. Controlled double-blind trial of flavoxate in painful conditions of the lower urinary tract. Current Medical Research \& Opinion 1975;2(10):631-5. [sr-incont901]

\section{Choa 1983 \{published data only\}}

Choa RG, Abrams PH, Pynsent PB, Ashken MH. A controlled trial of otis urethrotomy. British Journal of Urology 1983;55(6):694-7. [sr-incont671]

\section{Costantini 2003 \{published data only\}}

* Costantini E, Mearini L, Pizzirusso G, Mearini E, Vivacqua C, Porena M. Laser therapy for the urethral syndrome (Abstract). In: Proceedings of the International Continence Society (ICS), 33rd Annual Meeting, 2003 Oct 5-9, Florence Italy. 2003:134-5. [sr-incont17148]

Costantini E, Zucchi A, Del Zingaro M, Mearini L. Treatment of urethral syndrome: a prospective randomized study with
Nd:YAG laser. Urologia Internationalis 2006;76(2):134-8. [srincont21578]

\section{Gallego-Vilar 2013 \{published data only\}}

Gallego-Vilar D, Garcia-Fadrique G, Povo-Martin I, SalvadorMarin M, Gallego-Gomez J. Maintenance of the response to dimethyl sulfoxide treatment using hyperbaric oxygen in interstitial cystitis/painful bladder syndrome: a prospective, randomized, comparative study. Urologia Internationalis 2013;90(4):411-6. [sr-incont48085]

\section{Keay 2007 \{published data only\}}

Keay S, Reeder JE, Koch K, Zhang CO, Grkovic D, Peters K, et al. Prospective evaluation of candidate urine and cell markers in patients with interstitial cystitis enrolled in a randomized clinical trial of Bacillus Calmette Guerin (BCG). World Journal of Urology 2007;25(5):499-504. [sr-incont23856]

\section{Ko 2016 \{published data only\}}

Ko K, Seo S, Jeon S, Lee H, Lee K. Therapeutic effect of transurethral resection and coagulation of Hunner's lesion in female interstitial cystitis/bladder pain syndrome patients (Abstract number OP 71). International Urogynecology Journal and Pelvic Floor Dysfunction 2016;27(1 Suppl):S135-6. [srincont73433]

\section{Lai 2013 \{published data only\}}

Lai MC, Kuo YC, Kuo HC. Intravesical hyaluronic acid for interstitial cystitis/painful bladder syndrome: a comparative randomized assessment of different regimens. International Journal of Urology 2013;20(2):203-7. [sr-incont47645]

Lee 2015 \{published data only\}

Lee SW, Choi YH, Lee SE, Park JH, Kim TH, Sung HH, et al. Therapeutic effect of transurethral resection and coagulation of Hunner's lesion in interstitial cystitis/bladder pain syndrome patients (Abstract number 154). European Urology Supplement 2015;14(2):e154-4a. [sr-incont71536]

\section{Li 2016 \{published data only\}}

Li B, Xu A, Liu C. Comparison of intradetrusor injection of onabotulinum toxin $\mathrm{A}$ and instillation of hyaluronic acid in the treatment of ketamine cystitis (Abstract number: CNURO-1893). International Journal of Urology 2016;23(Suppl S1):28. [sr-incont75064]

\section{Lubeck 2001 \{published data only\}}

Lubeck DPW. Psychometric validation of the O'Leary-Sant Interstitial Cystitis Symptom Index in a clinical trial of pentosan polysulfate sodium. Urology 2001;57(6 Suppl 1):62-6. [srincont13071]

\section{Netto 1980 \{published data only\}}

Netto NR, da Silva RP. Treatment of recurrent cystitis in women by internal urethrotomy or antimicrobial agents. International Urology and Nephrology 1980;12(3):211-5. [sr-incont787]

\section{Nickel 2005 \{published data only\}}

* Nickel JC, Barkin J, Forrest J, Mosbaugh PG, HernandezGraulau J, Kaufman D, et al. Randomized, double-blind, dose- 
ranging study of pentosan polysulfate sodium for interstitial cystitis. Urology 2005;65(4):654-8. [sr-incont20375]

Sand PK, Kaufman DM, Evans RJ, Zhang HF, Alan Fisher DL, Nickel JC. Association between response to pentosan polysulfate sodium therapy for interstitial cystitis and patient questionnaire-based treatment satisfaction. Current Medical Research and Opinion 2008;24(8):2259-64. [sr-incont27743]

\section{Peters 2007 \{published data only\}}

Peters KM, Feber KM, Bennett RC. A prospective, singleblind, randomized crossover trial of sacral vs pudendal nerve stimulation for interstitial cystitis. BJU International 2007;100(4):835-9. [sr-incont23872]

\section{References to studies awaiting assessment}

\section{Aboyan 2018 \{published data only\}}

Aboyan V, Aboyan I, Zin'kovskaya O, Mirkin Y. Comparison of efficacy of intravesical hyaluronic acid alone and in combination with oral chondroitin sulfate in patients with bladder pain syndrome (Abstract number 240). European Urology Supplement 2018;17(2):e341. [sr-incont78063]

\section{Asumpinwong 2018 \{published data only\}}

Asumpinwong C, TCTR20180912004. Short-term outcomes of intravesical heparin therapy for bladder pain syndrome; a single-blinded randomized controlled trial. clinicaltrials.in.th/index.php? tp=regtrials\&menu=trialsearch\&smenu=fulltext\&task=search\&task2=vit (first received 12 September 2018). [TCTR20180912004] [srincont78180]

\section{Bosch 2018 \{published data only\}}

Bosch PC. A randomized, double-blind, placebo-controlled trial of certolizumab pegol in women with refractory interstitial cystitis/bladder pain syndrome. European Urology 2018;74(5):623-30. [NCT02497976] [sr-incont78061]

\section{Carty 2019 \{published data only\}}

Carty JN, Ziadni MS, Holmes HJ, Tomakowsky J, Peters K, Schubiner $\mathrm{H}$, et al. The effects of a life stress emotional awareness and expression interview for women with chronic urogenital pain: a randomized controlled trial. Pain Medicine 2019;20(7):1321-9. [NCT02286115] [sr-incont78020]

\section{Cervigni 2018 \{published data only\}}

Cervigni M, Onesti E, Ceccanti M, Gori MC, Tartaglia G, Campagna $G$, et al. Repetitive transcranial magnetic stimulation for chronic neuropathic pain in patients with bladder pain syndrome/interstitial cystitis. Neurourology and Urodynamics 2018;37(8):2678-87. [sr-incont78021]

\section{El Refaye 2019 \{published data only\}}

El Refaye GE, NCT03844581. Effect of interferential electrical stimulation on pain perception and disability level on interstitial cystitis. clinicaltrials.gov/show/NCT03844581 (first received 18 February 2019). [NCT03844581] [sr-incont78186]

\section{Hsieh 2018 \{published data only\}}

Hsieh T-T, NCT03619486. Low energy shock wave for the treatment of interstitial cystitis/bladder pain syndrome (IC/BPS) [Low energy shock wave for the treatment of interstitial cystitis/ bladder pain syndrome (IC/BPS) - a randomized, double-blind, placebo-controlled, prospective study]. clinicaltrials.gov/show/ NCT03619486 (first received 8 August 2018). [NCT03619486] [srincont78192]

\section{Kenny 2016 \{published data only\}}

Kenny L, O'Sullivan S, Wiseman S, NCT02795026. Trans-perineal trigger point dry needling for chronic pelvic pain [To investigate the use of trans-perineal trigger point dry needling with manual therapy and to compare the outcome with manual therapy treatment for chronic pelvic pain with dyspareunia: a randomized clinical trial]. clinicaltrials.gov/show/NCT02795026 (first received 9 June 2016). [NCT02795026] [sr-incont78193]

Lee 2018 \{published data only\}

Lee MH, Wu HC, Tseng CM, Ko TL, Weng TJ, Chen YF. Health education and symptom flare management using a videobased $\mathrm{m}$-health system for caring women with IC/BPS. Urology 2018;119:62-9. [sr-incont78196]

Moldwin 2018 \{published data only\}

Moldwin RM, Hanno P, Biagi H, Butterfield N. Randomized, placebo-controlled, clinical trial in interstitial cystitis/bladder pain syndrome shows common symptom presentation but higher rates of Hunner lesions in European patients (Abstract

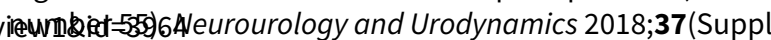
5):S109-10. [EUCTR2016-000906-12] [NCT02858453] [srincont78200]

Moon 2019 \{published data only\}

Moon D, Heo G, KCT0003772. Investigation of efficacy of pentosan polysulfate in IC/BPS with lower urinary tract symptom using portable uroflometry and flow chart. cris.nih.go.kr/cris/en/search/search_result st01.jsp?seq=13703 (first received 3 April 2019). [KCT0003772] [sr-incont78201]

Oh-Oka 2017 \{published data only\}

* Oh-Oka H. Clinical efficacy of 1-year intensive systematic dietary manipulation as complementary and alternative medicine therapies on female patients with interstitial cystitis/bladder pain syndrome. Urology 2017;106:50-4. [srincont78204]

Oh-oka $\mathrm{H}$. Usefulness of long-term dietary manipulation for female patients with painful bladder syndrome/interstitial cystitis (Abstract number 61). Neurourology and Urodynamics 2018;37(Suppl 5):S116-7. [sr-incont78205]

Rahimi 2018 \{published data only\}

Rahimi H, Tafaghodi M, IRCT20130811014330N5. Effectiveness of hyaluronic acid for the treatment of interstitial cystitis [Treatment of interstitial cystitis; clinical effectiveness of hydrodistention with intravesical hyaluronic acid (cystistat ${ }^{\circledR}$ ) over hydrodistention alone]. en.irct.ir/trial/34300 (first received 29 November 2018). [IRCT20130811014330N5] [sr-incont78210] 
Yusefi 2018 \{published data only\}

Yusefi MH, Nojavan F, IRCT20170112031893N2. Evaluation of the effect of topical use of chamomile oil on appeasing of patients with interstitial cystitis [Evaluation of the effect of topical use of chamomile oil on appeasing of patients with interstitial cystitis: a triple randomized placebo-controlled trial]. en.irct.ir/trial/29497 (first received 13 November 2018). [IRCT20170112031893N2] [sr-incont78214]

\section{References to ongoing studies}

\section{Bhat 2018 \{published data only\}}

Bhat G, CTRI/2018/03/012720. Tadalafil for painful bladder [Evaluation of efficacy of low dose tadalafil]. ctri.nic.in/ Clinicaltrials/pmaindet2.php?trialid=24308 (first received 21 March 2018). [CTRI/2018/03/012720] [sr-incont77819]

\section{Bond 2016 \{published data only\}}

Bond J, Pape H, NCT02743962. A pilot study investigating the use of a therapeutic wand in addition to physiotherapy for bladder pain syndrome. clinicaltrials.gov/show/NCT02743962 (first received 19 April 2016). [NCT02743962] [sr-incont72662]

\section{Brucker 2016 \{published data only\}}

Brucker B, NCT02747420. PTNS versus sham efficacy in treatment of BPS [Randomized controlled trial of PTNS versus sham efficacy in treatment of bladder pain syndrome]. clinicaltrials.gov/show/NCT02747420 (first received 21 April 2016). [NCT02747420] [sr-incont72645]

\section{Cardenas-Trowers 2018 \{published data only\}}

Cardenas-Trowers O, Meriwether K, NCT03463915. Clinical trial comparing two bladder instillations for IC/BPS [Randomized controlled trial comparing two different bladder instillation treatments for interstitial cystitis/bladder pain syndrome]. clinicaltrials.gov/show/NCT03463915 (first received 13 March 2018). [NCT03463915] [sr-incont77825]

\section{Cvach 2011 \{published data only\}}

Cvach K. Efficacy of Clorpactin(R) in bladder pain syndrome/ interstitial cystitis: a randomised placebo-controlled trial. anzctr.org.au/ACTRN12611000717954.aspx (first received 8 July 2011). [ACTRN12611000717954] [sr-incont68881]

\section{Drug Company 2005 \{published data only\}}

Drug company. A phase 2, randomized, double-blind, placebocontrolled study of YM672 in the treatment of painful bladder syndrome/interstitial cystitis. clinicaltrialsregister.eu/ctrsearch/search?query=eudract_number:2005-003367-23 (first received 23 November 2005). [EUCTR2005-003367-23-DE] [srincont68888]

\section{Drug Company 2017a \{published data only\}}

Drug company. Exploratory, randomized, doubleblind, placebo-controlled evaluation of efficacy, tolerability, and safety of intravesical instillation of GRT6010 compared to placebo in subjects with bladder pain syndrome. clinicaltrialsregister.eu/ctr-search/ search?query=eudract_number:2016-003940-35 (first received 19 January 2017). [EUCTR2016-003940-35-PL; EUCTR2016-003940-35-DE] [sr-incont76237]

Drug Company 2017b \{published data only\}

Drug company. Phase III study of KRP-116D [A phase III, multicenter, randomized, double-blind, placebo controlled, parallel group study to assess the efficacy and safety of KRP-116D in Japanese patients with interstitial cystisis]. clinicaltrials.jp/user/showCteDetailE.jsp? japicld=JapicCTI-173566 (first received 20 April 2017). [JPRNJapicCTI-173566] [sr-incont76235]

\section{Drug Company 2017c \{published data only\}}

EUCTR2016-004138-12-DE, Drug Company. Study of the effect of ASP6294 for the treatment of bladder pain syndrome/interstitial cystitis in female subjects [A phase $2 \mathrm{a}$, randomized, double-blind, placebo-controlled, parallelgroup, proof of concept study to investigate efficacy, safety, pharmacodynamics and pharmacokinetics of ASP6294 in the treatment of female subjects with bladder pain syndrome/ interstitial cystitis]. clinicaltrialsregister.eu/ctr-search/search? query=eudract_number:2016-004138-12 (first received 10 July 2017). [EUCTR2016-004138-12-DE; NCT03282318] [srincont77820]

* NCT03282318, Drug company. A study to investigate efficacy, safety, pharmacodynamics and pharmacokinetics of ASP6294 in the treatment of female subjects with bladder pain syndrome/ interstitial cystitis. clinicaltrials.gov/show/NCT03282318 (first received 13 September 2017). [EudraCT2016-004138-12] [NCT03282318] [sr-incont77798]

\section{Leadership 301 Trial 2016 \{published data only\}}

Drug company. A randomized study comparing placebo and AQX-1125 in the treatment of subjects with interstitial cystitis/ bladder pain syndrome [A 12-week, randomized, multi-center, double-blind, placebo-controlled, 3 arm, parallel-group, phase 3 trial to evaluate the efficacy and safety of 2 doses of AQX-1125 targeting the SHIP1 pathway in subjects with interstitial cystitis/ bladder pain syndrome followed by 14 or 40 -week extension periods - The LEADERSHIP 301 Trial]. clinicaltrialsregister.eu/ ctr-search/search?query=eudract_number:2016-000906-12 (first received 19 July 2016). [EUCTR2016-000906-12; EUCTR2016-000906-12-CZ; EUCTR2016-000906-12-HU; EUCTR2016-000906-12-DK; NCT02858453] [sr-incont74041]

* NCT02858453, Biagi H, Moldwin R. Efficacy and safety of 2 doses of AQX-1125 in subjects with interstitial cystitis/bladder pain syndrome (LEADERSHIP 301) [The LEADERSHIP 301 Trial: a 12-week, randomized, multi-center, double-blind, placebocontrolled, 3-arm, parallel-group, phase 3 trial to evaluate the efficacy and safety of 2 doses of AQX-1125 targeting the Src homology 2-containing inositol-5'-phosphatase 1 (SHIP1) pathway in subjects with interstitial cystitis/bladder pain syndrome followed by 14 - or 40-week extension periods]. clinicaltrials.gov/show/NCT02858453 (first received 8 August 2016). [EUCTR2016-000906-12; EUCTR2016-000906-12CZ; EUCTR2016-000906-12-HU; EUCTR2016-000906-12-DK; NCT02858453] [sr-incont73365] 
Parsons 2015 \{published data only\}

Parsons CL, Grako K, Osborne N, NCT02591199. Engage 24: evaluation of the safety and effectiveness of URG101 in subjects with interstitial cystitis/bladder pain syndrome [A phase 2a, randomized, double-blind, placebo-controlled multi-center single dose study to evaluate the safety and effectiveness of URG101 compared with the individual components lidocaine and heparin in subjects with interstitial cystitis/bladder pain syndrome]. clinicaltrials.gov/show/NCT02591199 (first received 29 October 2015). [NCT02591199] [sr-incont69697]

\section{Peters 2016 \{published data only\}}

Peters KM, NCT02870738. Bladder directed vs. pelvic floor therapy in IC/BPS [Comparison of bladder directed and pelvic floor therapy in women with interstitial cystitis/bladder pain syndrome]. clinicaltrials.gov/show/NCT02870738 (first received 17 August 2016). [NCT02870738] [sr-incont73361]

\section{Shah 2016 \{published data only\}}

Shah NM, Whitmore K, NCT02787083. A pilot study of the effects of mirabegron on symptoms in patients with interstitial cystitis. clinicaltrials.gov/show/NCT02787083 (first received 19 January 2018). [NCT02787083] [sr-incont73351]

\section{Additional references}

\section{Abrams 2002}

Abrams P, Cardozo L, Fall M, Griffiths D, Rosier P, Ulmsten U, et al. The standardisation of terminology of lower urinary tract function: report from the Standardisation Sub-committee of the International Continence Society. Neurourology and Urodynamics 2002;21(2):167-78.

\section{Abrams 2017}

Abrams P, Cardozo L, Wagg A, Wein A, editor(s). Incontinence. 6th edition. Bristol, UK: ICI-ICS International Continence Society, 2017. [ISBN: 978-0956960733]

\section{Barua 2016}

Barua JM, Arance I, Angulo JC, RiedI CR. A systematic review and meta-analysis on the efficacy of intravesical therapy for bladder pain syndrome/interstitial cystitis. International Urogynecology Journal 2016;27(8):1137-47.

\section{Chaimani 2017}

Chaimani A, Caldwell DM, Li T, Higgins JP, Salanti G. Chapter 11. Undertaking network meta-analyses. In: Higgins JP, Churchill R, Chandler J, Cumpston MS, editor(s). Cochrane Handbook for Systematic Reviews of Interventions version 5.2.0 (updated June 2017). The Cochrane Collaboration, 2017. Available from www.training.cochrane.org/handbook.

\section{CINeMA 2017 [Computer program]}

Institute of Social and Preventive Medicine, University of Bern CINeMA: Confidence in Network Meta-Analysis. Version accessed 17 January 2019. Bern, Switzerland: Institute of Social and Preventive Medicine, University of Bern, 2017. Available at cinema.ispm.ch.

\section{Cox 2016}

Cox A, Golda N, Nadeau G, Curtis Nickel J, Carr L, Corcos J, et al. CUA guideline: diagnosis and treatment of interstitial cystitis/ bladder pain syndrome. Canadian Urological Association Journal 2016;10(5-6):E136-55.

\section{Dawson 2007}

Dawson TE, Jamison J. Intravesical treatments for painful bladder syndrome/interstitial cystitis. Cochrane Database of Systematic Reviews 2007, Issue 4. Art. No: CD006113. [DOI: 10.1002/14651858.CD006113.pub2]

\section{Deeks 2011}

Deeks JJ, Higgins JP, Altman DG, editor(s). Chapter 9. Analysing data and undertaking meta-analyses. In: Higgins JP, Green $S$, editor(s). Cochrane Handbook for Systematic Reviews of Interventions Version 5.1.0 (updated March 2011). The Cochrane Collaboration, 2011. Available from handbook.cochrane.org.

\section{Dias 2014}

Dias S, Welton NJ, Sutton AJ, Caldwell DM, Lu G, Ades AE, NICE Decision Support Unit. NICE DSU Technical Support Document 4: inconsistency in networks of evidence based on randomised controlled trials. www.nicedsu.org.uk (accessed 22 August 2017).

\section{Dias 2016}

Dias S, Welton NJ, Sutton AJ, Ades AE, NICE Decision Support Unit. NICE DSU Technical Support Document 2: a generalised linear modelling framework for pairwise and network metaanalysis of randomised controlled trials. www.nicedsu.org.uk (accessed 22 August 2017).

\section{EAU Guidelines 2019}

Engeler D, Baranowski AP, Berghmans B, Borovicka J, Cottrell AM, Elneil PS, et al. Chronic pelvic pain: European Association of Urology (EAU) clinical guidelines. Available at https://uroweb.org/guideline/chronic-pelvic-pain/\#9 2019.

\section{El-Azab 2019}

El-Azab AS, Siegel SW. Sacral neuromodulation for female pelvic floor disorders. Arab Journal of Urology 2019;17(1):14-22.

\section{EndNote 2018 [Computer program]}

EndNote. Version X8.2. Philadelphia: Clarivate Analytics, 2018.

\section{Filippini 2013}

Filippini G, Del Giovane C, Vacchi L, D'Amico R, Di Pietrantonj C, Beecher D, et al. Immunomodulators and immunosuppressants for multiple sclerosis: a network meta-analysis. Cochrane Database of Systematic Reviews 2013, Issue 6. Art. No: CD008933. [DOI: 10.1002/14651858.CD008933.pub2]

\section{Goin 1998}

Goin JE, Olaleye D, Peters KM, Steinert B, Habicht K, Wynant G. Psychometric analysis of the University of Wisconsin Interstitial Cystitis Scale: implications for use in randomized clinical trials. Journal of Urology 1998;159(3):1085-90. 


\section{Grover 2011}

Grover S, Srivastava A, Lee R, Tewari AK, Te AE. Role of inflammation in bladder function and interstitial cystitis. Therapeutic Advances in Urology 2011;3(1):19-33.

\section{Guyatt 2008}

Guyatt GH, Oxman AD, Vist GE, Kunz R, Falck-Ytter Y, Schünemann HJ, et al. GRADE: what is "quality of evidence" and why is it important to clinicians? BMJ 2008;336(7651):995-8.

\section{Guyatt 2011}

Guyatt G, Oxman AD, Akl EA, Kunz R, Vist G, Brozek J, et al. GRADE guidelines: 1. Introduction - GRADE evidence profiles and summary of findings tables. Journal of Clinical Epidemiology 2011;64(4):383-94.

\section{Hanno 1999}

Hanno PM, Landis JR, Matthews-Cook Y, Kusek J, Nyberg L Jr. The diagnosis of interstitial cystitis revisited: lessons learned from the National Institutes of Health Interstitial Cystitis Database study. Journal of Urology 1999;161(2):553-7.

\section{Hanno 2010}

Hanno P, Lin A, Nordling J, Nyberg L, van Ophoven A, Ueda T, et al. Bladder Pain Syndrome Committee of the International Consultation on Incontinence. Neurourology and Urodynamics 2010;29(1):191-8.

\section{Hanno 2017}

Hanno P, Cervigni M, Dinis P, Lin A, Nickel JC, Nordling J, et al. Bladder pain syndrome. In: Abrams $P$, Cardozo L, Wagg A, Wein A , editors(s). Incontinence: 6 th International Consultation on Incontinence; 2016 September 12-14; Tokyo. Bristol: International Continence Society (ICS) and International Consultation on Urological Diseases (ICUD), 2017:2206-301. [ISBN: 978-0956960733]

\section{Hays 1993}

Hays RD, Sherbourne CD, Mazel RM. The RAND 36-Item Health Survey 1.0. Health Economics 1993;2(3):217-27.

\section{Higgins 2003}

Higgins JP, Thompson SG, Deeks JJ, Altman DG. Measuring inconsistency in meta-analyses. BMJ 2003;327(7414):557-60.

\section{Higgins 2011a}

Higgins JP, Altman DG, Gotzsche PC, Juni P, Moher D, Oxman AD, et al. The Cochrane Collaboration's tool for assessing risk of bias in randomised trials. BMJ 2011;343:d5928.

\section{Higgins 2011b}

Higgins JP, Deeks JJ, editor(s). Chapter 7. Selecting studies and collecting data. In: Higgins JP, Green S, editor(s). Cochrane Handbook for Systematic Reviews of Interventions Version 5.1.0 (updated March 2011). The Cochrane Collaboration, 2011. Available from handbook.cochrane.org.

\section{Higgins 2011c}

Higgins JP, Green S, editor(s). Cochrane Handbook for Systematic Reviews of Interventions Version 5.1.0 (updated
March 2011). The Cochrane Collaboration, 2011. Available from handbook.cochrane.org.

\section{Kelleher 1997}

Kelleher CJ, Cardozo LD, Khullar V, Salvatore S. A new questionnaire to assess the quality of life of urinary incontinent women. British Journal of Obstetrics and Gynaecology 1997;104(12):1374-9.

\section{Lee 2019}

Lee HY, Doo SW, Yang WJ, Song YS, Sun HY, Nho EJ, et al. Efficacy and safety of noninvasive intravesical instillation of onabotulinum toxin-A for overactive bladder and interstitial cystitis/bladder pain syndrome: systematic review and metaanalysis. Urology 2019;125:50-7.

\section{Logadottir 2014}

Logadottir Y, Delbro D, Fall M, Gjertsson I, Jirholt P, Lindholm C, et al. Cytokine expression in patients with bladder pain syndrome/interstitial cystitis ESSIC type 3C. Journal of Urology 2014;192(5):1564-8.

\section{Lunn 2000}

Lunn DJ, Thomas A, Best N, Spiegelhalter D. WinBUGS - a Bayesian modelling framework: concepts, structure, and extensibility. Statistics and Computing 2000;10(4):325-37.

\section{McHorney 1993}

McHorney CA, Ware JE Jr, Raczek AE. The MOS 36-Item ShortForm Health Survey (SF-36): II. Psychometric and clinical tests of validity in measuring physical and mental health constructs. Medical Care 1993;31(3):247-63.

\section{Melzack 1975}

Melzack R. The McGill Pain Questionnaire: major properties and scoring methods. Pain 1975;1(3):277-99.

\section{Melzack 1987}

Melzack R. The short-form McGill Pain Questionnaire. Pain 1987;30(2):191-7.

\section{Nickel 2018}

Nickel JC, Moldwin R. FDA BRUDAC 2018 criteria for interstitial cystitis/bladder pain syndrome clinical trials: future direction for IC/BPS research. Journal of Urology 2018;200(1):39-42.

\section{NIDDK 2017}

National Institute of Diabetes and Digestive and Kidney Diseases (NIDDK). Diagnosis of interstitial cystitis: how do health care professionals diagnose IC? www.niddk.nih.gov/ health-information/urologic-diseases/interstitial-cystitispainful-bladder-syndrome/diagnosis (accessed 26 January 2018).

\section{O'Leary 1997}

O'Leary MP, Sant GR, Fowler FJ Jr, Whitmore KE, SpolarichKroll J. The Interstitial Cystitis Symptom Index and Problem Index. Urology 1997;49(5A Suppl):58-63. 


\section{Olson 2018}

Olson LE, Dyer JE, Haq A, Ockrim J, Greenwell TJ. A systematic review of the literature on cystodistension in bladder pain syndrome. International Urogynecology Journal 2018;29(2):251-7.

\section{Parsons 2002}

Parsons CL, Dell J, Stanford EJ, Bullen M, Kahn BS, Waxell T, et al. Increased prevalence of interstitial cystitis: previously unrecognized urologic and gynecologic cases identified using a new symptom questionnaire and intravesical potassium sensitivity. Urology 2002;60(4):573-8.

\section{Pazin 2016}

Pazin C, de Souza Mitidieri AM, Silva AP, Gurian MB, PoliNeto OB, Rosa-e-Silva JC. Treatment of bladder pain syndrome and interstitial cystitis: a systematic review. International Urogynecology Journal 2016;27(5):697-708.

\section{Pyo 2016}

Pyo JS, Cho WJ. Systematic review and meta-analysis of intravesical hyaluronic acid and hyaluronic acid/ chondroitin sulfate instillation for interstitial cystitis/painful bladder syndrome. Cellular Physiology and Biochemistry 2016;39(4):1618-25.

\section{Salanti 2014}

Salanti G, Del Giovane C, Chaimani A, Caldwell DM, Higgins JP. Evaluating the quality of evidence from a network metaanalysis. PLoS One 2014;9(7):e99682.

\section{Schünemann 2011}

Schünemann HJ, Oxman AD, Higgins JP, Vist GE, Glasziou P, Guyatt GH. Chapter 11. Presenting results and 'Summary of findings' tables. In: Higgins JP, Green S, editor(s). Cochrane Handbook for Systematic Reviews of Interventions Version 5.1.0 (updated March 2011). The Cochrane Collaboration, 2011. Available from handbook.cochrane.org.

\section{Stata 2017 [Computer program]}

Stata. College Station, TX, USA: StataCorp, 2017. Available at www.stata.com.

\section{van de Merwe 2008}

van de Merwe JP, Nordling J, Bouchelouche P, Bouchelouche K, Cervigni M, Daha LK, et al. Diagnostic criteria, classification, and nomenclature for painful bladder syndrome/interstitial cystitis: an ESSIC proposal. European Urology 2008;53(1):60-7.

\section{CHARACTERISTICS OF STUDIES}

Characteristics of included studies [ordered by study ID]

\section{van Ophoven 2019}

van Ophoven A, Vonde K, Koch W, Auerbach G, Maag KP. Efficacy of pentosan polysulfate for the treatment of interstitial cystitis/ bladder pain syndrome: results of a systematic review of randomized controlled trials. Current Medical Research and Opinion 2019;35(9):1495-503.

\section{Verghese 2016}

Verghese TS, Riordain RN, Champaneria R, Latthe PM. Complementary therapies for bladder pain syndrome: a systematic review. International Urogynecology Journal 2016;27(8):1127-36.

\section{Wang 2016}

Wang Z, Zhang L. Treatment effect of cyclosporine A in patients with painful bladder syndrome/interstitial cystitis: a systematic review. Experimental and Therapeutic Medicine 2016;12(1):445-50.

\section{Wang 2017b}

Wang J, Chen Y, Chen J, Zhang G, Wu P. Sacral neuromodulation for refractory bladder pain syndrome/interstitial cystitis: a global systematic review and meta-analysis. Scientific Reports 2017;7(1):11031.

\section{Ware 1992}

Ware JE Jr, Sherbourne CD. The MOS 36-item short-form health survey (SF-36). I. Conceptual framework and item selection. Medical Care 1992;30(6):473-83.

\section{Ware 1996}

Ware J Jr, Kosinski M, Keller SD. A 12-Item Short-Form Health Survey: construction of scales and preliminary tests of reliability and validity. Medical Care 1996;34(3):220-33.

\section{References to other published versions of this review Imamura 2019}

Imamura M, Scott NW, Ogah JA, Ford AA, Wallace SA, Dubos YA, et al. Interventions for treating people with symptoms of bladder pain syndrome: a network meta-analysis. Cochrane Database of Systematic Reviews 2019, Issue 5. Art. No: CD013325. [DOI: 10.1002/14651858.CD013325]

* Indicates the major publication for the study

Ahmadnia 2011

\section{Study characteristics}

$\begin{array}{ll}\text { Methods } & \text { Study design: } \mathrm{RCT} \\ & \text { Study duration (months): } 1\end{array}$


Ahmadnia 2011 (Continued)

\section{Participants}

\section{Number randomised: 24}

Setting: not reported

Country: Iran

Sex: female

Age, years: not reported

Diagnosis: PBS

Inclusion criteria: patients (female) with painful bladder syndrome refractory to conventional oral therapies

Exclusion criteria: not reported
Group A ( $\mathbf{n}=\mathbf{1 2})$ : 200 IU botulinum toxin A into trigone and lateral walls

Group B (n= 12): $\mathrm{NaCl}$

Treatment category in NMA: neuromuscular blockade vs control

\begin{tabular}{|c|c|c|}
\hline Outcomes & \multicolumn{2}{|c|}{ Outcome data in analysis (no usable data) } \\
\hline Funding & \multicolumn{2}{|l|}{ Not reported. } \\
\hline Notes & \multicolumn{2}{|c|}{ Publication status: abstract } \\
\hline \multicolumn{3}{|l|}{ Risk of bias } \\
\hline Bias & Authors' judgement & Support for judgement \\
\hline $\begin{array}{l}\text { Random sequence genera- } \\
\text { tion (selection bias) }\end{array}$ & Unclear risk & Quote: "randomly divided" \\
\hline $\begin{array}{l}\text { Allocation concealment } \\
\text { (selection bias) }\end{array}$ & Unclear risk & No information provided \\
\hline $\begin{array}{l}\text { Blinding of participants } \\
\text { and personnel (perfor- } \\
\text { mance bias) } \\
\text { All outcomes }\end{array}$ & Unclear risk & $\begin{array}{l}\text { Blinding not mentioned. "Under short general anesthesia in the study group } \\
\text { botulinum toxin A ... was used, and in the control group, normal saline was in- } \\
\text { jected through cystoscopic needle submucosally into trigone and lateral walls } \\
\text { of the bladder" }\end{array}$ \\
\hline $\begin{array}{l}\text { Blinding of outcome as- } \\
\text { sessment (detection bias) } \\
\text { Subjective outcome }\end{array}$ & Unclear risk & $\begin{array}{l}\text { Blinding not mentioned. "Under short general anesthesia in the study group } \\
\text { botulinum toxin A ... was used, and in the control group, normal saline was in- } \\
\text { jected through cystoscopic needle submucosally into trigone and lateral walls } \\
\text { of the bladder" }\end{array}$ \\
\hline $\begin{array}{l}\text { Selective reporting (re- } \\
\text { porting bias) }\end{array}$ & Unclear risk & Outcomes not specified in Methods (abstract only) \\
\hline Other bias & Low risk & None detected \\
\hline
\end{tabular}

Bade 1997

\section{Study characteristics}

Study design: RCT
Methods
Interventions for treating people with symptoms of bladder pain syndrome: a network meta-analysis (Review)
Copyright @ 2020 The Cochrane Collaboration. Published by John Wiley \& Sons, Ltd.


Bade 1997 (Continued)

\section{Study duration (months): 3}

$\begin{array}{ll}\text { Participants } & \text { Number randomised: } 20 \\ & \text { Setting: } 1 \text { hospital } \\ \text { Country: the Netherlands } \\ \text { Sex: female } \\ \text { Age, years: mean } 52.8 \text {, range } 24 \text { to } 79 \\ \text { Diagnosis: IC (NIDDK criteria) }\end{array}$

Inclusion criteria: patients with IC

Exclusion criteria: not reported

\begin{tabular}{ll}
\hline Interventions & Group A $(\mathbf{n}=\mathbf{1 0})$ : pentosan polysulfate (PPS) \\
Group B $(\mathbf{n}=\mathbf{1 0})$ : unspecified placebo \\
Three months of twice-weekly instillations; each instillation for as long as tolerable
\end{tabular}

Treatment category in NMA: PPS vs control

\begin{tabular}{|c|c|c|}
\hline \multirow[t]{4}{*}{ Outcomes } & \multicolumn{2}{|c|}{ Outcome data in analysis } \\
\hline & \multicolumn{2}{|c|}{$\begin{array}{l}\text { Cure or improvement: improved subjective symptoms using visual analogue scale ( } 1 \text { point or greater } \\
\text { reduction on the severity scale scoring } 0 \text { to } 5 \text { points): at } 3 \text { months }\end{array}$} \\
\hline & \multicolumn{2}{|l|}{ Frequency: at 3 months } \\
\hline & \multicolumn{2}{|l|}{ Nocturia: at 3 months } \\
\hline Funding & \multicolumn{2}{|l|}{ Not reported } \\
\hline \multirow[t]{2}{*}{ Notes } & \multicolumn{2}{|c|}{ Publication status: full text } \\
\hline & \multicolumn{2}{|c|}{$\begin{array}{l}\text { [Notes from previous versions of the review] Attempted study author contact regarding SD for data, } \\
\text { pain as outcome and who had UTI; received no response }\end{array}$} \\
\hline \multicolumn{3}{|l|}{ Risk of bias } \\
\hline Bias & Authors' judgement & Support for judgement \\
\hline $\begin{array}{l}\text { Random sequence genera- } \\
\text { tion (selection bias) }\end{array}$ & Low risk & $\begin{array}{l}\text { Quote: "assigned randomly using a code... After receiving treatment for } 3 \\
\text { months, the code was broken..." }\end{array}$ \\
\hline \multirow[t]{2}{*}{$\begin{array}{l}\text { Allocation concealment } \\
\text { (selection bias) }\end{array}$} & Unclear risk & $\begin{array}{l}\text { Quote: "assigned randomly using a code... After receiving treatment for } 3 \\
\text { months, the code was broken..." }\end{array}$ \\
\hline & & Comment: unclear if this refers to blinding or allocation concealment \\
\hline $\begin{array}{l}\text { Blinding of participants } \\
\text { and personnel (perfor- } \\
\text { mance bias) } \\
\text { All outcomes }\end{array}$ & Unclear risk & "double-blind, placebo-controlled study". Placebo not described \\
\hline $\begin{array}{l}\text { Blinding of outcome as- } \\
\text { sessment (detection bias) } \\
\text { Subjective outcome }\end{array}$ & Unclear risk & "double-blind, placebo-controlled study". Placebo not described \\
\hline
\end{tabular}


Bade 1997 (Continued)

Incomplete outcome data Unclear risk Number analysed not stated
(attrition bias)

Cure or improvement

\begin{tabular}{lll}
$\begin{array}{l}\text { Incomplete outcome data } \\
\text { (attrition bias) } \\
\text { Frequency }\end{array}$ & Low risk & $\begin{array}{l}9 / 10 \text { (90\%) included in intervention group (1 dropped out due to persisting } \\
\text { symptoms); 10/10 included in control group }\end{array}$ \\
\hline $\begin{array}{l}\text { Incomplete outcome data } \\
\begin{array}{l}\text { (attrition bias) } \\
\text { Nocturia }\end{array}\end{array}$ & Low risk & $\begin{array}{l}9 / 10(90 \%) \text { included in intervention group (1 dropped out due to persisting } \\
\text { symptoms); 10/10 included in control group }\end{array}$ \\
\hline $\begin{array}{l}\text { Selective reporting (re- } \\
\text { porting bias) }\end{array}$ & Low risk & Results included all outcomes specified in the methods section \\
\hline Other bias & Low risk & None detected \\
\hline
\end{tabular}

\section{Barbalias 2000}

\section{Study characteristics}

\begin{tabular}{ll}
\hline Methods & $\begin{array}{l}\text { Study design: RCT } \\
\text { Study duration (months): } 6\end{array}$ \\
\hline
\end{tabular}

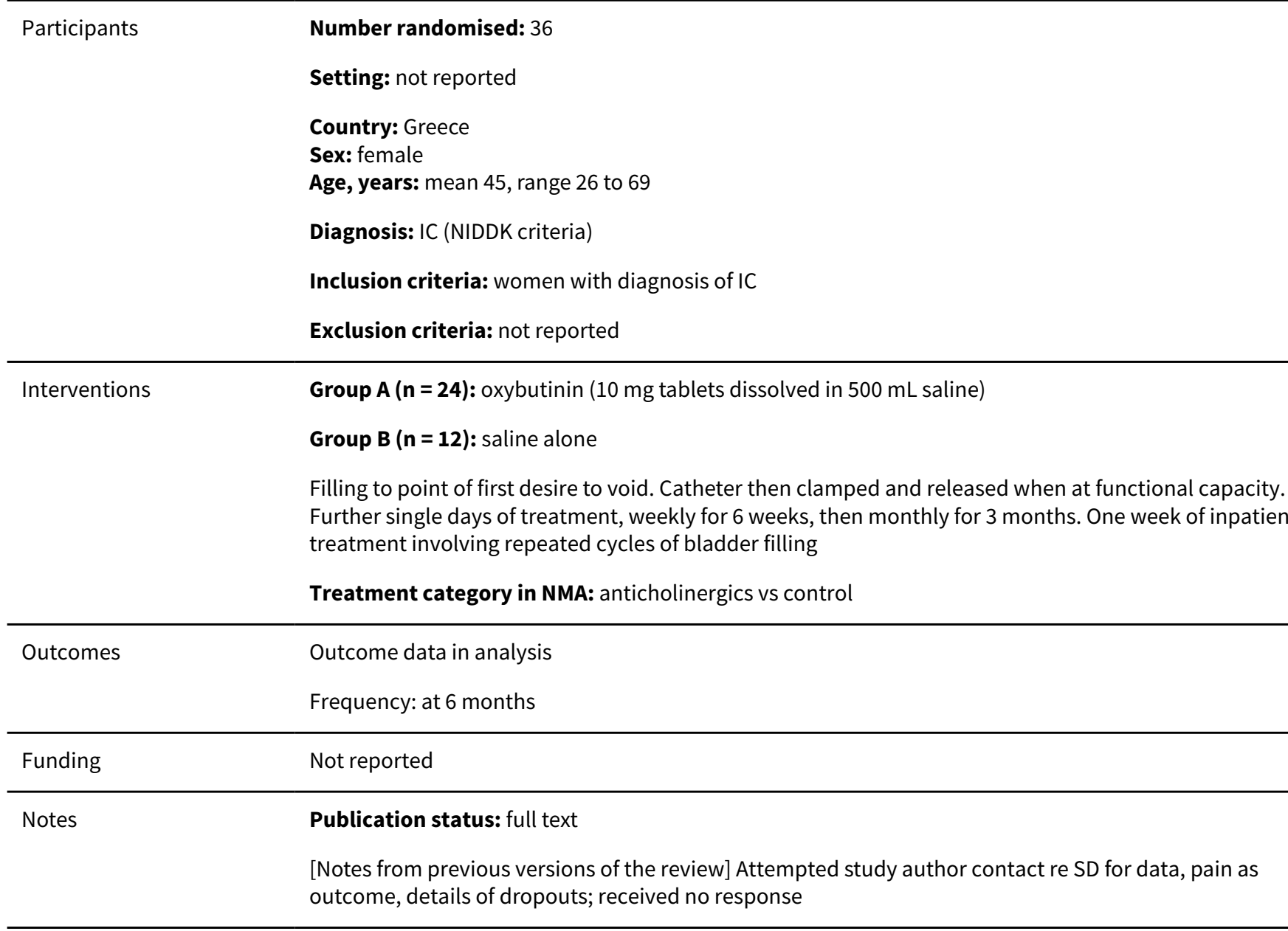


Barbalias 2000 (Continued)

Risk of bias

\begin{tabular}{|c|c|c|}
\hline Bias & Authors' judgement & Support for judgement \\
\hline $\begin{array}{l}\text { Random sequence genera- } \\
\text { tion (selection bias) }\end{array}$ & Low risk & Quote: "in a randomized fashion by computer assigned numbers" \\
\hline $\begin{array}{l}\text { Allocation concealment } \\
\text { (selection bias) }\end{array}$ & Unclear risk & No information provided \\
\hline $\begin{array}{l}\text { Blinding of participants } \\
\text { and personnel (perfor- } \\
\text { mance bias) } \\
\text { All outcomes }\end{array}$ & Unclear risk & $\begin{array}{l}\text { Blinding not mentioned. "In the control group the bladder was filled only with } \\
\text { normal saline and the same protocol guidelines were maintained as in the oxy- } \\
\text { butynin group". Intravesical instillation }\end{array}$ \\
\hline $\begin{array}{l}\text { Blinding of outcome as- } \\
\text { sessment (detection bias) } \\
\text { Subjective outcome }\end{array}$ & Unclear risk & $\begin{array}{l}\text { Blinding not mentioned. "In the control group the bladder was filled only with } \\
\text { normal saline and the same protocol guidelines were maintained as in the oxy- } \\
\text { butynin group". Intravesical instillation }\end{array}$ \\
\hline $\begin{array}{l}\text { Incomplete outcome data } \\
\text { (attrition bias) } \\
\text { Frequency }\end{array}$ & Unclear risk & $\begin{array}{l}\text { Number analysed unclear. } 1 / 24 \text { dropped out from intervention group; } 4 / 12 \\
\text { dropped out from control group; it is not clear how missing data were handled }\end{array}$ \\
\hline $\begin{array}{l}\text { Selective reporting (re- } \\
\text { porting bias) }\end{array}$ & Unclear risk & "Clinical amelioration" (cure) was defined but not fully reported in results \\
\hline Other bias & Unclear risk & None detected \\
\hline
\end{tabular}

Bosch 2014

\section{Study characteristics}

\begin{tabular}{ll}
\hline Methods & Study design: RCT \\
& Study duration (months): 3
\end{tabular}

Participants

\section{Number randomised: 43}

Setting: single centre

Country: USA

Sex: 34 females and 9 males

Age, years: mean 45.2 (SD 14.0) for Group A, mean 46.5 (SD 13.4) for Group B

Diagnosis: IC/BPS, moderate to severe

Inclusion criteria: men and women 18 to 65 years old, previously diagnosed with moderate or severe IC/BPS. Fulfilment of certain criteria including symptoms of urinary urgency, frequency or pain longer than 6 months, urinating at least 7 times a day, total score of 18 or greater on the OSPI and score of 15 or greater on the PUF

Exclusion criteria: microbiologically proven urinary tract infection within 6 weeks at screening or randomisation; gross haematuria; intravesical therapy a month before or during the study; and/or history of malignancy, diabetes, central nervous system demyelinating disease, tuberculosis, hepatitis $\mathrm{B}$, hepatitis $\mathrm{C}$ or human immunodeficiency disease. Female patients must not have been pregnant or lactating and must have used adequate birth control during the study. History and physical examination, comprehensive metabolic chemistry panel, complete blood count, urinalysis and culture, hepatitis B virus serology and a purified protein derivative skin test were also required 
Bosch 2014 (Continued)

Interventions

Group A ( $\mathbf{n}=\mathbf{2 1}$ ): subcutaneous adalimumab. $80 \mathrm{mg}$ loading dose, followed by $40 \mathrm{mg}$ every 2 weeks

Group B (n = 22): subcutaneous placebo

Participants were allowed to continue on current medications except medications listed in the exclusion criteria

Treatment category in NMA: immune modulators vs control

\begin{tabular}{ll}
\hline Outcomes & Outcome data in analysis \\
& Cure or improvement: 'moderately' or 'markedly' improved on GRA: at 12 weeks \\
& ICSI: at 12 weeks \\
ICPI: at 12 weeks \\
Adverse events: at 12 weeks (assumed from paper) \\
\hline Funding & AbbVie (pharma business) \\
\hline Notes & Publication status: full text \\
& The study was terminated early 'after half of the 43 patients demonstrated a dramatic and statistically \\
significant clinical improvement'
\end{tabular}

\section{Risk of bias}

\section{Bias}

Authors' judgement Support for judgement

Random sequence genera- Unclear risk Quote: "randomised"

tion (selection bias)

\begin{tabular}{ll}
\hline $\begin{array}{l}\text { Allocation concealment } \\
\text { (selection bias) }\end{array}$ & Unclear risk \\
& Comment: unclear whether this refers to blinding or allocation concealment \\
\hline
\end{tabular}

$\begin{array}{ll}\begin{array}{l}\text { Blinding of participants } \\ \text { and personnel (perfor- }\end{array} & \text { Low risk } \\ \text { manote "'double blind"; "the study drug and placebo were provided in ready to } \\ \text { use unit dose syringes that were identical" }\end{array}$
mance bias)

All outcomes

Blinding of outcome as- $\quad$ Low risk $\quad$ "double blind", using identical placebo
sessment (detection bias)
Subjective outcome

\begin{tabular}{lll}
\hline $\begin{array}{l}\text { Incomplete outcome data } \\
\text { (attrition bias) } \\
\text { Cure or improvement }\end{array}$ & Unclear risk & $\begin{array}{l}\text { Number analysed unclear. 2/21 dropped out from intervention group (due to } \\
\text { "lack of efficacy"); 2/22 dropped out from placebo group (medical reasons un- } \\
\text { related to trial); it is not clear how missing data were handled }\end{array}$ \\
\hline $\begin{array}{l}\text { Incomplete outcome data } \\
\begin{array}{l}\text { (attrition bias) } \\
\text { Interstitial Cystitis Symp- }\end{array}\end{array}$ & Unclear risk \\
$\begin{array}{l}\text { tom Index } \\
\text { Incomplete outcome data }\end{array}$ & Unclear risk & \\
$\begin{array}{l}\text { (attrition bias) } \\
\text { Interstitial Cystitis Prob- } \\
\text { lem Index }\end{array}$ & \\
\hline
\end{tabular}


Bosch 2014 (Continued)
Incomplete outcome data
Unclear risk
Number analysed not stated
(attrition bias)

Adverse events

\begin{tabular}{lll}
\hline $\begin{array}{l}\text { Selective reporting (re- } \\
\text { porting bias) }\end{array}$ & Low risk & Results included all outcomes specified in the methods section \\
\hline Other bias & Low risk & None detected \\
\hline
\end{tabular}

Carrico 2008

\section{Study characteristics}

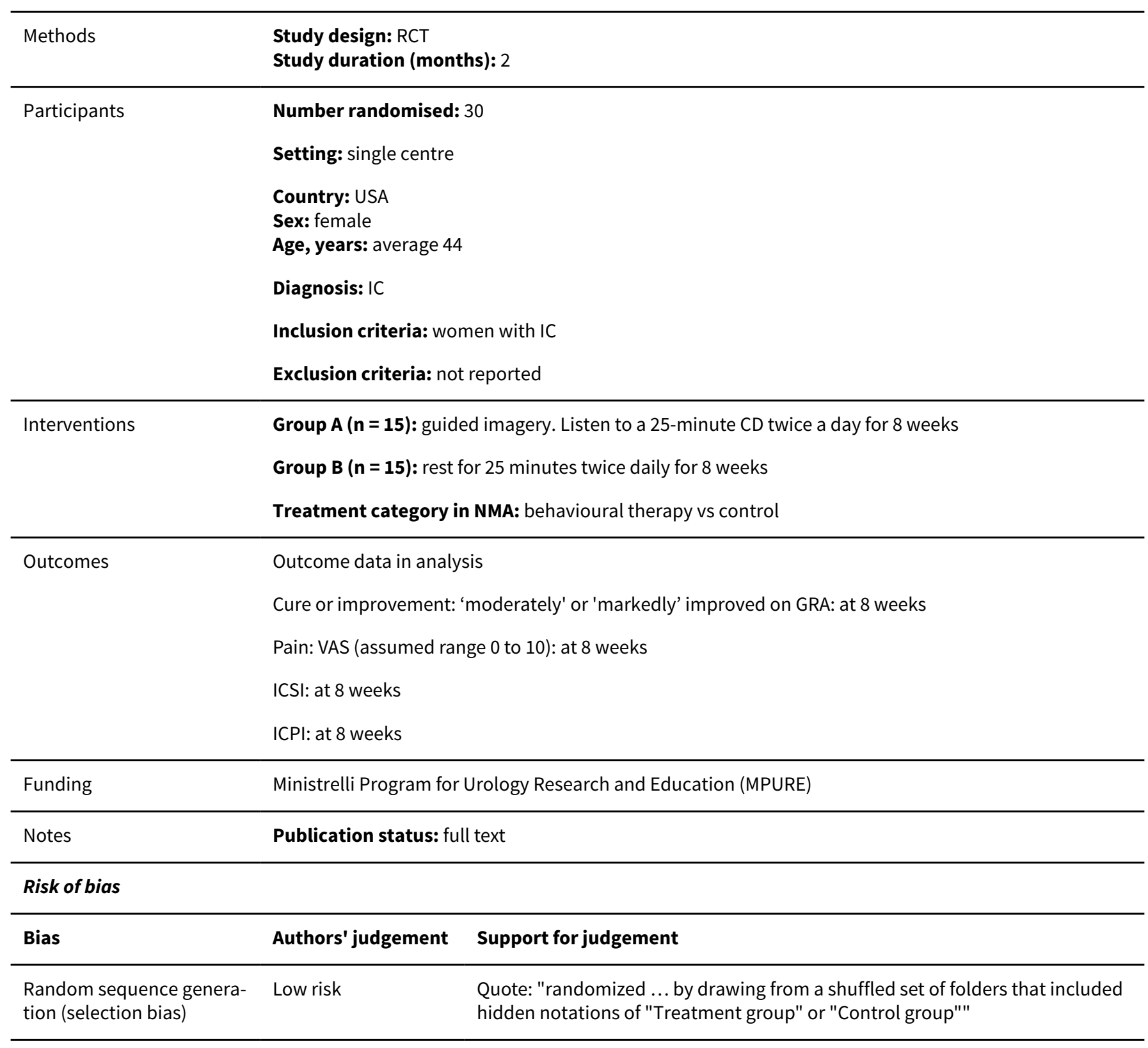


Carrico 2008 (Continued)

Allocation concealment Low risk Quote: "randomized by a blinded research staff member not involved in the (selection bias) study by drawing from a shuffled set of folders that included hidden notations of "Treatment group" or "Control group" "

\begin{tabular}{|c|c|c|}
\hline $\begin{array}{l}\text { Blinding of participants } \\
\text { and personnel (perfor- }\end{array}$ & High risk & $\begin{array}{l}\text { Probably not done. } 25 \text {-minute guided imagery compact disc vs sitting or lying } \\
\text { down for } 25 \text { minutes }\end{array}$ \\
\hline
\end{tabular}

All outcomes

\begin{tabular}{lll}
\hline $\begin{array}{l}\text { Blinding of outcome as- } \\
\text { sessment (detection bias) } \\
\text { Subjective outcome }\end{array}$ & High risk & $\begin{array}{l}\text { Probably not done. 25-minute guided imagery compact disc vs sitting or lyin } \\
\text { down for } 25 \text { minutes }\end{array}$ \\
\hline $\begin{array}{l}\text { Incomplete outcome data } \\
\begin{array}{l}\text { (attrition bias) } \\
\text { Cure or improvement }\end{array}\end{array}$ & High risk & $\begin{array}{l}11 / 15(73 \%) \text { included in intervention group; 14/15 (93\%) included in control } \\
\text { group. } 5 \text { withdrew "for personal reasons (too busy, not able to follow proto- } \\
\text { col)" }\end{array}$ \\
\hline
\end{tabular}

\begin{tabular}{|c|c|c|}
\hline $\begin{array}{l}\text { Incomplete outcome data } \\
\text { (attrition bias) } \\
\text { Pain }\end{array}$ & High risk & $\begin{array}{l}11 / 15(73 \%) \text { included in intervention group; } 14 / 15(93 \%) \text { included in control } \\
\text { group. } 5 \text { withdrew "for personal reasons (too busy, not able to follow proto- } \\
\text { col)" }\end{array}$ \\
\hline $\begin{array}{l}\text { Incomplete outcome data } \\
\text { (attrition bias) } \\
\text { Interstitial Cystitis Symp- } \\
\text { tom Index }\end{array}$ & High risk & $\begin{array}{l}11 / 15(73 \%) \text { included in intervention group; } 14 / 15(93 \%) \text { included in control } \\
\text { group. } 5 \text { withdrew "for personal reasons (too busy, not able to follow proto- } \\
\text { col)" }\end{array}$ \\
\hline $\begin{array}{l}\text { Incomplete outcome data } \\
\text { (attrition bias) } \\
\text { Interstitial Cystitis Prob- } \\
\text { lem Index }\end{array}$ & High risk & $\begin{array}{l}11 / 15(73 \%) \text { included in intervention group; } 14 / 15(93 \%) \text { included in control } \\
\text { group. } 5 \text { withdrew "for personal reasons (too busy, not able to follow proto- } \\
\text { col)" }\end{array}$ \\
\hline $\begin{array}{l}\text { Selective reporting (re- } \\
\text { porting bias) }\end{array}$ & Low risk & Results included all outcomes specified in the methods section \\
\hline Other bias & Low risk & None detected \\
\hline
\end{tabular}

Cartledge 2000

\section{Study characteristics}

\begin{tabular}{ll}
\hline Methods & $\begin{array}{l}\text { Study design: cross-over randomised trial } \\
\text { Study duration (months): } 1\end{array}$
\end{tabular}

Participants Number randomised: 16

Setting: not reported

Country: UK

Sex: 12 females and 4 males

Age, years: mean 51, range 26 to 76

Diagnosis: IC (NIDDK criteria)

Inclusion criteria: male or female with IC by NIDDK criteria

Exclusion criteria: history of diabetes or liver disease 
Cartledge 2000 (Continued) Interventions

Group A: L-arginine, given as capsules containing $400 \mathrm{mg}$ of active compound, at a total dose of 2.4 grams/d

Group B: an inert placebo, in identical capsules

Number in each group not reported

Treatment category in NMA: amino acid vs control

\begin{tabular}{ll}
\hline Outcomes & Outcome data in analysis (no usable data) \\
\hline Funding & Not reported \\
\hline Notes & Publication status: full text
\end{tabular}

\section{Risk of bias}

\begin{tabular}{|c|c|c|}
\hline Bias & Authors' judgement & Support for judgement \\
\hline $\begin{array}{l}\text { Random sequence genera- } \\
\text { tion (selection bias) }\end{array}$ & Unclear risk & Quote: "randomised" \\
\hline $\begin{array}{l}\text { Allocation concealment } \\
\text { (selection bias) }\end{array}$ & Unclear risk & No information provided \\
\hline $\begin{array}{l}\text { Blinding of participants } \\
\text { and personnel (perfor- } \\
\text { mance bias) } \\
\text { All outcomes }\end{array}$ & Low risk & $\begin{array}{l}\text { Quote: "double-blind, placebo-controlled crossover trial"; "an inert placebo, in } \\
\text { identical capsules, was..." }\end{array}$ \\
\hline $\begin{array}{l}\text { Selective reporting (re- } \\
\text { porting bias) }\end{array}$ & Low risk & Results included all outcomes specified in the methods section \\
\hline Other bias & Low risk & None detected \\
\hline
\end{tabular}

\section{Carty 2017}

\section{Study characteristics}

\begin{tabular}{ll}
\hline Methods & $\begin{array}{l}\text { Study design: } \mathrm{RCT} \\
\text { Study duration (months): } 1.5\end{array}$
\end{tabular}

Participants

\section{Number randomised: 70}

Setting: single centre

Country: USA

Sex: female

Age, years: mean 46.03 (SD 15.10) for whole group, mean 44.89 (SD 15.34) for Group A, mean 47.72 (SD 14.88) for Group B

Diagnosis: "chronic urogenital pain"

Inclusion criteria: women with chronic urogenital pain conditions; 18 to 80 years old

Exclusion criteria: patients who (a) had a current psychotic disorder; (b) were unable to communicate in English; (c) were unable to read; (d) were cognitively impaired or had dementia; or (e) were deemed too psychiatrically unstable by their clinician at the Women's Urology Center to meaningfully complete 
Carty 2017 (Continued)

this study. Participants were allowed to engage in the study regardless of current medication use and engagement in other treatment

Interventions

Group A ( $\mathbf{n}=\mathbf{4 5}$ ): 90-minute life stress interview (stress and emotion interview)

Group B ( $\mathbf{n}=\mathbf{2 0})$ : wait-list control (no interview)

Treatment category in NMA: behavioural therapy vs control

\begin{tabular}{ll}
\hline Outcomes & Outcome data in analysis \\
& Pain: Brief Pain Inventory pain severity subscale; average of 4 items ranking pain on a scale ranging \\
& from 0 to 10: at 6 weeks
\end{tabular}

\begin{tabular}{ll}
\hline Funding & Not reported \\
\hline Notes & Publication status: full text
\end{tabular}

Risk of bias

\begin{tabular}{|c|c|c|}
\hline Bias & Authors' judgement & Support for judgement \\
\hline $\begin{array}{l}\text { Random sequence genera- } \\
\text { tion (selection bias) }\end{array}$ & Unclear risk & Quote: "randomized" \\
\hline $\begin{array}{l}\text { Allocation concealment } \\
\text { (selection bias) }\end{array}$ & Unclear risk & No information provided \\
\hline $\begin{array}{l}\text { Blinding of participants } \\
\text { and personnel (perfor- } \\
\text { mance bias) } \\
\text { All outcomes }\end{array}$ & High risk & $\begin{array}{l}\text { Probably not done. Interview vs wait-list } \\
\text { Quote: "both the interviewer and participant were blinded to condition until } \\
\text { baseline measures were completed" }\end{array}$ \\
\hline $\begin{array}{l}\text { Blinding of outcome as- } \\
\text { sessment (detection bias) } \\
\text { Subjective outcome }\end{array}$ & High risk & $\begin{array}{l}\text { Probably not done. Interview vs wait-list } \\
\text { Quote: "both the interviewer and participant were blinded to condition until } \\
\text { baseline measures were completed" }\end{array}$ \\
\hline $\begin{array}{l}\text { Incomplete outcome data } \\
\text { (attrition bias) } \\
\text { Pain }\end{array}$ & High risk & $\begin{array}{l}37 / 45(82 \%) \text { included in intervention group ( } 8 \text { did not receive intervention) and } \\
25 / 25 \text { included in control group. } 4 / 25(16 \%) \text { in control group did not "complete } \\
\text { their follow-up evaluation", but it is unclear how missing data were handled }\end{array}$ \\
\hline $\begin{array}{l}\text { Selective reporting (re- } \\
\text { porting bias) }\end{array}$ & Low risk & Results included all outcomes specified in the methods section \\
\hline Other bias & Low risk & None detected \\
\hline
\end{tabular}

\section{Cervigni 2014}

\section{Study characteristics}

\begin{tabular}{ll}
\hline Methods & $\begin{array}{l}\text { Study design: } \mathrm{RCT} \\
\text { Study duration (months): } 6\end{array}$ \\
\hline Participants & Number randomised: 110 \\
& Setting: 6 centres
\end{tabular}


Cervigni 2014 (Continued)

\section{Country: Italy}

Sex: female

Age, years: mean 50.2, range 18 to 88

Diagnosis: BPS/IC. Diagnosis according to European Society for the Study of IC/PBS (ESSIC) criteria

Inclusion criteria: patients aged 18 years or older with a diagnosis of BPS/IC, unresponsive to first-line non-invasive treatment (e.g. oral drugs considered to be a standard treatment for BPS/IC, such as antidepressants, antiepileptics, antihistaminics, cyclosporin A, pentosan polysulfate) or at first observation. Relevant inclusion criteria included the presence of pain (pelvic, pressure or discomfort) with at least 1 other urinary symptom such as urgency, increased urination frequency for at least 6 months, discomfort or pain during sexual intercourse

Exclusion criteria: pregnant or breastfeeding women, presence of other confusable disease as the main cause of urinary symptoms, those who had undergone previous intravesical treatments. A minimum time of 3 months from last treatment to start of therapy was required for all patients

Interventions

Group A ( $\mathbf{n}=\mathbf{7 4})$ : :AluRil $^{\oplus}$

Group B ( $\mathbf{n} \mathbf{3 6}$ ): DMSO (dimethyl sulfoxide)

Treatment category in NMA: chondroitin sulfate + hyaluronic acid vs DMSO

\begin{tabular}{|c|c|c|}
\hline \multirow[t]{8}{*}{ Outcomes } & \multicolumn{2}{|c|}{ Outcome data in analysis } \\
\hline & \multicolumn{2}{|c|}{ Cure or improvement: at least $50 \%$ VAS reduction in pain from baseline: at 6 months } \\
\hline & \multicolumn{2}{|c|}{ Pain: VAS (range 0 to 100 ): at 3 months } \\
\hline & \multicolumn{2}{|c|}{ Frequency: at 3 months } \\
\hline & \multicolumn{2}{|l|}{ ICSI: at 6 months } \\
\hline & \multicolumn{2}{|l|}{ ICPI: at 6 months } \\
\hline & \multicolumn{2}{|c|}{ Functional bladder capacity: at 3 months } \\
\hline & \multicolumn{2}{|c|}{ Adverse events: at 6 months } \\
\hline Funding & \multicolumn{2}{|c|}{ Sponsored by IBSA Farmaceutici Italia. This assistance was funded by IBSA Institut Biochimique SA } \\
\hline Notes & \multicolumn{2}{|c|}{ Publication status: full text } \\
\hline \multicolumn{3}{|l|}{ Risk of bias } \\
\hline Bias & Authors' judgement & Support for judgement \\
\hline $\begin{array}{l}\text { Random sequence genera- } \\
\text { tion (selection bias) }\end{array}$ & Low risk & $\begin{array}{l}\text { Quote: "a centralized randomization procedure was generated by the Moses- } \\
\text { Oakland algorithm" }\end{array}$ \\
\hline $\begin{array}{l}\text { Allocation concealment } \\
\text { (selection bias) }\end{array}$ & Low risk & Quote: "a centralized randomization procedure" \\
\hline $\begin{array}{l}\text { Blinding of participants } \\
\text { and personnel (perfor- } \\
\text { mance bias) } \\
\text { All outcomes }\end{array}$ & High risk & $\begin{array}{l}\text { "An open-label design"; "due to the garlic-like taste of DMSO after intravesical } \\
\text { administration, which would have been impossible to mask" }\end{array}$ \\
\hline $\begin{array}{l}\text { Blinding of outcome as- } \\
\text { sessment (detection bias) } \\
\text { Subjective outcome }\end{array}$ & High risk & $\begin{array}{l}\text { "An open-label design"; "due to the garlic-like taste of DMSO after intravesical } \\
\text { administration, which would have been impossible to mask" }\end{array}$ \\
\hline
\end{tabular}


Cervigni 2014 (Continued)

Blinding of outcome as- Low risk Outcome measurement is not likely to be influenced by lack of blinding sessment (detection bias)

Objective outcome

\begin{tabular}{lll}
\hline Incomplete outcome data & High risk & Review authors chose to use per-protocol analysis. 66/74 (89\%) included in \\
(attrition bias) & HA/CS (hyaluronic acid + chondroitin sulfate) group; 27/36 (75\%) included in \\
Cure or improvement & DMSO group
\end{tabular}

\begin{tabular}{|c|c|c|}
\hline $\begin{array}{l}\text { Incomplete outcome data } \\
\text { (attrition bias) } \\
\text { Pain }\end{array}$ & High risk & $\begin{array}{l}\text { Review authors chose to use per-protocol analysis. } 66 / 74(89 \%) \text { included in } \\
\text { HA/CS group; } 27 / 36(75 \%) \text { included in DMSO group }\end{array}$ \\
\hline $\begin{array}{l}\text { Incomplete outcome data } \\
\text { (attrition bias) } \\
\text { Frequency }\end{array}$ & Low risk & $59 / 74(80 \%)$ included in HA/CS group; $31 / 36(86 \%)$ included in DMSO group \\
\hline $\begin{array}{l}\text { Incomplete outcome data } \\
\text { (attrition bias) } \\
\text { Interstitial Cystitis Symp- } \\
\text { tom Index }\end{array}$ & Low risk & $73 / 74$ (99\%) included in HA/CS group; $36 / 36(100 \%)$ included in DMSO group \\
\hline $\begin{array}{l}\text { Incomplete outcome data } \\
\text { (attrition bias) } \\
\text { Interstitial Cystitis Prob- } \\
\text { lem Index }\end{array}$ & Low risk & $73 / 74$ (99\%) included in HA/CS group; $36 / 36(100 \%)$ included in DMSO group \\
\hline $\begin{array}{l}\text { Incomplete outcome data } \\
\text { (attrition bias) } \\
\text { Functional bladder capac- } \\
\text { ity }\end{array}$ & Low risk & 44/74 (59\%) included in HA/CS group; 25/36 (69\%) included in DMSO group \\
\hline $\begin{array}{l}\text { Incomplete outcome data } \\
\text { (attrition bias) } \\
\text { Adverse events }\end{array}$ & Low risk & All randomised participants were included in analysis \\
\hline $\begin{array}{l}\text { Selective reporting (re- } \\
\text { porting bias) }\end{array}$ & Low risk & Results included all outcomes specified in the methods section \\
\hline Other bias & Low risk & None detected \\
\hline
\end{tabular}

Chen 2005

\section{Study characteristics}

\begin{tabular}{ll}
\hline Methods & $\begin{array}{l}\text { Study design: RCT } \\
\text { Study duration (months): } 3\end{array}$
\end{tabular}

\section{Participants}

Number randomised: 22

Setting: multi-centre

Country: Canada

Sex: 17 females and 5 males

Age, years: mean 43.7 for Group A, mean 56.6 for Group B; range 18 to 85 for whole group

Diagnosis: IC (NIDDK criteria) 
Chen 2005 (Continued)

Inclusion criteria: patients on medication to control irritative symptoms, provided dosage had not changed within the 30 days leading to the study. No dosage change was permitted during the protocol

Exclusion criteria: pregnant or nursing, or other pathologies of the lower urinary tract (infection, detrusor overactivity and urologic manifestation of neurological disease), ulcerative IC, intravesical therapy or bladder hydrodistension 6 weeks before, current or previous malignancy, known chemical addiction, seizure or major psychiatric disorder, pertinent allergy, significant medical condition

Interventions

Group A ( $\mathbf{n}=\mathbf{1 8})$ : 2 arms combined for this review. Arm 1: resiniferatoxin (RTX) 0.05 microMol/L solution in $10 \%$ ethanol in saline. Arm 2: RTX 0.1 microMol/L in $10 \%$ ethanol in saline

Group B ( $\mathbf{n}=\mathbf{4}):$ : $10 \%$ ethanol in saline (placebo)

All 3 trial arms had the option of 10 minute pre-treatment instillation of $2 \%$ lidocaine. Single-instillation treatment of $50 \mathrm{~mL}$ of solution retained for 30 minutes. Bladder then rinsed with saline

Treatment category in NMA: calcium channel agonists vs control

\begin{tabular}{|c|c|c|}
\hline \multirow{7}{*}{ Outcomes } & \multicolumn{2}{|c|}{ Outcome data in analysis } \\
\hline & \multicolumn{2}{|c|}{ Pain: VAS (assumed range 0 to 10 ): at 12 weeks } \\
\hline & \multicolumn{2}{|l|}{ Frequency: at 12 weeks } \\
\hline & \multicolumn{2}{|l|}{ Nocturia: at 12 weeks } \\
\hline & \multicolumn{2}{|l|}{ ICSI: at 12 weeks } \\
\hline & \multicolumn{2}{|l|}{ ICPI: at 12 weeks } \\
\hline & \multicolumn{2}{|c|}{ Adverse events: at 12 weeks } \\
\hline Funding & \multicolumn{2}{|l|}{ Not reported } \\
\hline Notes & \multicolumn{2}{|c|}{ Publication status: full text } \\
\hline \multicolumn{3}{|l|}{ Risk of bias } \\
\hline Bias & Authors' judgement & Support for judgement \\
\hline $\begin{array}{l}\text { Random sequence genera- } \\
\text { tion (selection bias) }\end{array}$ & Low risk & Quote: "randomized via a computer generated randomization schedule" \\
\hline $\begin{array}{l}\text { Allocation concealment } \\
\text { (selection bias) }\end{array}$ & Low risk & $\begin{array}{l}\text { Quote: "the size of the randomization block was not disclosed. Bliniding infor- } \\
\text { mation was contained in sealed envelopes .... Breaking the blind was permit- } \\
\text { ted only on a case-by-case basis and only in the event of an emergency" }\end{array}$ \\
\hline $\begin{array}{l}\text { Blinding of participants } \\
\text { and personnel (perfor- } \\
\text { mance bias) } \\
\text { All outcomes }\end{array}$ & Low risk & $\begin{array}{l}\text { "double-blind, placebo-controlled study". Solutions used for intervention and } \\
\text { placebo groups "were identical in appearance" }\end{array}$ \\
\hline $\begin{array}{l}\text { Blinding of outcome as- } \\
\text { sessment (detection bias) } \\
\text { Subjective outcome }\end{array}$ & Low risk & $\begin{array}{l}\text { "double-blind, placebo-controlled study". Solutions used for intervention and } \\
\text { placebo groups "were identical in appearance" }\end{array}$ \\
\hline $\begin{array}{l}\text { Incomplete outcome data } \\
\text { (attrition bias) } \\
\text { Pain }\end{array}$ & Low risk & All randomised participants were included in analysis \\
\hline
\end{tabular}


Chen 2005 (Continued)
Incomplete outcome data Low risk
All randomised participants were included in analysis
(attrition bias)

Frequency

Incomplete outcome data Low risk All randomised participants were included in analysis
(attrition bias)
Nocturia

Nocturia

Incomplete outcome data Low risk All randomised participants were included in analysis
(attrition bias)
Interstitial Cystitis Symp-
tom Index

\begin{tabular}{|c|c|c|}
\hline $\begin{array}{l}\text { Incomplete outcome data } \\
\text { (attrition bias) } \\
\text { Interstitial Cystitis Prob- } \\
\text { lem Index }\end{array}$ & Low risk & All randomised participants were included in analysis \\
\hline $\begin{array}{l}\text { Incomplete outcome data } \\
\text { (attrition bias) } \\
\text { Adverse events }\end{array}$ & Low risk & All randomised participants were included in analysis \\
\hline $\begin{array}{l}\text { Selective reporting (re- } \\
\text { porting bias) }\end{array}$ & Low risk & Results included all outcomes specified in the methods section \\
\hline Other bias & Low risk & None detected \\
\hline
\end{tabular}

\section{Chen 2014}

\section{Study characteristics}

\begin{tabular}{ll}
\hline Methods & $\begin{array}{l}\text { Study design: } \mathrm{RCT} \\
\text { Study duration (months): } 6\end{array}$ \\
\hline
\end{tabular}

Participants

Number randomised: 48

Setting: 3 departments of urology

Country: China

Sex: female

Age, years: mean 38.3 (SD 5.4) for Group A, mean 37.8 (SD 4.4) for Group B, range 28 to 55 for whole group

Diagnosis: IC/PBS (NIDDK criteria)

Inclusion criteria: women with IC/PBS

Exclusion criteria: patients with diabetes mellitus, mental disorder, hypertension, hypohepatia or renal insufficiency; receiving any treatment for IC/PBS within 3 months

Interventions

Group A ( $\mathbf{n}=\mathbf{2 4}$ ): sildenafil $25 \mathrm{mg}$ (sildenafil is a phosphodiesterase type 5 (PDE5) inhibitor)

Group B ( $\mathbf{n}=\mathbf{2 4})$ : placebo regimen: daily low-dose sildenafil $25 \mathrm{mg}$ or placebo for 12 weeks

Treatment category in NMA: PDE5 inhibitor vs control

Outcomes Outcome data in analysis


Chen 2014 (Continued)

Cure or improvement: PORIS (Patient Overall Rating of Improvement in Symptoms) assessed and divided into worse, $0 \%, 25 \%, 50 \%, 75 \%$ and $100 \%$ improvement. The value of PORIS surpassing $50 \%$ was regarded as effective remedy: at 24 weeks

Pain: VAS score (range 0 to 5): at 24 weeks

Frequency per day: at 24 weeks

Nocturia: at 24 weeks

ICSI: at 24 weeks

ICPI: at 24 weeks

Adverse events: at 24 weeks

\begin{tabular}{ll}
\hline Funding & Zhejiang Provincial Top Key Discipline and Technology Foundation of Zhejiang Province \\
\hline Notes & Publication status: full text
\end{tabular}

\section{Risk of bias}

\begin{tabular}{|c|c|c|}
\hline Bias & Authors' judgement & Support for judgement \\
\hline $\begin{array}{l}\text { Random sequence genera- } \\
\text { tion (selection bias) }\end{array}$ & Low risk & Quote: "a computer-generated block scheme for randomization" \\
\hline $\begin{array}{l}\text { Allocation concealment } \\
\text { (selection bias) }\end{array}$ & Unclear risk & No information provided \\
\hline $\begin{array}{l}\text { Blinding of participants } \\
\text { and personnel (perfor- } \\
\text { mance bias) } \\
\text { All outcomes }\end{array}$ & Unclear risk & $\begin{array}{l}\text { "double blind, placebo-controlled trial", using oral tablet. Placebo not de- } \\
\text { scribed }\end{array}$ \\
\hline $\begin{array}{l}\text { Blinding of outcome as- } \\
\text { sessment (detection bias) } \\
\text { Subjective outcome }\end{array}$ & Unclear risk & $\begin{array}{l}\text { "double blind, placebo-controlled trial", using oral tablet. Placebo not de- } \\
\text { scribed }\end{array}$ \\
\hline $\begin{array}{l}\text { Incomplete outcome data } \\
\text { (attrition bias) } \\
\text { Cure or improvement }\end{array}$ & Low risk & All randomised participants were included in analysis \\
\hline $\begin{array}{l}\text { Incomplete outcome data } \\
\text { (attrition bias) } \\
\text { Pain }\end{array}$ & Low risk & All randomised participants were included in analysis \\
\hline $\begin{array}{l}\text { Incomplete outcome data } \\
\text { (attrition bias) } \\
\text { Frequency }\end{array}$ & Low risk & All randomised participants were included in analysis \\
\hline $\begin{array}{l}\text { Incomplete outcome data } \\
\text { (attrition bias) } \\
\text { Nocturia }\end{array}$ & Low risk & All randomised participants were included in analysis \\
\hline $\begin{array}{l}\text { Incomplete outcome data } \\
\text { (attrition bias) } \\
\text { Interstitial Cystitis Symp- } \\
\text { tom Index }\end{array}$ & Low risk & All randomised participants were included in analysis \\
\hline
\end{tabular}


Chen 2014 (Continued)
Incomplete outcome data
Low risk
All randomised participants were included in analysis
(attrition bias)

Interstitial Cystitis Prob-

lem Index

\begin{tabular}{lll}
\hline $\begin{array}{l}\text { Incomplete outcome data } \\
\text { (attrition bias) } \\
\text { Adverse events }\end{array}$ & Low risk & All randomised participants were included in analysis \\
\hline $\begin{array}{l}\text { Selective reporting (re- } \\
\text { porting bias) }\end{array}$ & Low risk & Results included all outcomes specified in the methods section \\
\hline Other bias & Low risk & None detected \\
\hline
\end{tabular}

Chuang 2017

\section{Study characteristics}

\begin{tabular}{ll}
\hline Methods & Study design: RCT \\
& Study duration (months): 1 \\
\hline
\end{tabular}

Participants

Number randomised: 90

Setting: 2 centres

Country: Taiwan

Sex: 80 females and 10 males

Age, years: mean 53.9 (SD 12.9) for lipotoxin group (Group A), mean 47.8 (SD 9.9) for 'onabotulinumtoxinA in normal saline' group (Group A), mean 55.9 (SD 8.6) for Group B

Diagnosis: IC/BPS (NIDDK criteria); Hunner's lesion not included

Inclusion criteria: patients 20 years of age or older with IC/BPS in whom at least 6 months of conventional treatments had failed

Exclusion criteria: not reported

Interventions

Group A ( $\mathbf{n}$ = 59): 2 arms combined for this review. Arm 1: lipotoxin (a liposomal formulated botulinum toxin A), containing onabotulinumtoxinA $200 \mathrm{U}$ with $80 \mathrm{mg}$ sphingomyelin. Arm 2: $200 \mathrm{U}$ g onabotulinumtoxinA in normal saline

Group B ( $\mathbf{n}$ 31): normal saline

Treatment category in NMA: neuromuscular blockade vs control

Outcomes Outcome data in analysis

Cure or improvement: 'moderately' or 'markedly' improved on GRA: at 4 weeks

Pain: 10-point VAS: at 4 weeks

Frequency: at 4 weeks

Nocturia: at 4 weeks

ICSI: at 4 weeks

ICPI: at 4 weeks 
Chuang 2017 (Continued)

Functional bladder capacity: at 4 weeks

Adverse events: at 4 weeks

Funding Chang Gang Medical Foundation-Kaohsiung Branch (CMRPG8D004), Buddhist Tzu Chi General Hospital
(TCRD-I-104-02) and Lipella Pharmaceuticals

Notes Publication status: full text

\section{Risk of bias}

\begin{tabular}{|c|c|c|}
\hline Bias & Authors' judgement & Support for judgement \\
\hline \multirow{2}{*}{$\begin{array}{l}\text { Random sequence genera- } \\
\text { tion (selection bias) }\end{array}$} & Low risk & Quote: "randomized by permutated block randomization" \\
\hline & & Comment: probably done \\
\hline $\begin{array}{l}\text { Allocation concealment } \\
\text { (selection bias) }\end{array}$ & Unclear risk & No information provided \\
\hline $\begin{array}{l}\text { Blinding of participants } \\
\text { and personnel (perfor- } \\
\text { mance bias) } \\
\text { All outcomes }\end{array}$ & Low risk & $\begin{array}{l}\text { "double-blind", "placebo-controlled" study. Study drugs and saline (placebo) } \\
\text { for bladder instillation "were obtained in blinded fashion without recognizable } \\
\text { labels from the hospital pharmacy" }\end{array}$ \\
\hline $\begin{array}{l}\text { Blinding of outcome as- } \\
\text { sessment (detection bias) } \\
\text { Subjective outcome }\end{array}$ & Low risk & $\begin{array}{l}\text { "double-blind", "placebo-controlled" study. Study drugs and saline (placebo) } \\
\text { for bladder instillation "were obtained in blinded fashion without recognizable } \\
\text { labels from the hospital pharmacy" }\end{array}$ \\
\hline $\begin{array}{l}\text { Blinding of outcome as- } \\
\text { sessment (detection bias) } \\
\text { Objective outcome }\end{array}$ & Low risk & Outcome measurement is not likely to be influenced by lack of blinding \\
\hline
\end{tabular}

\begin{tabular}{|c|c|c|}
\hline $\begin{array}{l}\text { Incomplete outcome data } \\
\text { (attrition bias) } \\
\text { Cure or improvement }\end{array}$ & Low risk & $\begin{array}{l}59 / 61(97 \%) \text { included in intervention group ( } 2 \text { discontinued due to lack of effi- } \\
\text { cacy); } 31 / 31 \text { included in control group }\end{array}$ \\
\hline
\end{tabular}

\begin{tabular}{|c|c|c|}
\hline $\begin{array}{l}\text { Incomplete outcome data } \\
\text { (attrition bias) } \\
\text { Pain }\end{array}$ & Low risk & $\begin{array}{l}59 / 61(97 \%) \text { included in intervention group ( } 2 \text { discontinued due to lack of effi- } \\
\text { cacy); } 31 / 31 \text { included in control group }\end{array}$ \\
\hline $\begin{array}{l}\text { Incomplete outcome data } \\
\text { (attrition bias) } \\
\text { Frequency }\end{array}$ & Low risk & $\begin{array}{l}59 / 61(97 \%) \text { included in intervention group ( } 2 \text { discontinued due to lack of effi- } \\
\text { cacy); } 31 / 31 \text { included in control group }\end{array}$ \\
\hline $\begin{array}{l}\text { Incomplete outcome data } \\
\text { (attrition bias) } \\
\text { Nocturia }\end{array}$ & Low risk & $\begin{array}{l}59 / 61(97 \%) \text { included in intervention group ( } 2 \text { discontinued due to lack of effi- } \\
\text { cacy); } 31 / 31 \text { included in control group }\end{array}$ \\
\hline $\begin{array}{l}\text { Incomplete outcome data } \\
\text { (attrition bias) } \\
\text { Interstitial Cystitis Symp- } \\
\text { tom Index }\end{array}$ & Low risk & $\begin{array}{l}59 / 61(97 \%) \text { included in intervention group ( } 2 \text { discontinued due to lack of effi- } \\
\text { cacy); } 31 / 31 \text { included in control group }\end{array}$ \\
\hline $\begin{array}{l}\text { Incomplete outcome data } \\
\text { (attrition bias) } \\
\text { Interstitial Cystitis Prob- } \\
\text { lem Index }\end{array}$ & Low risk & $\begin{array}{l}59 / 61(97 \%) \text { included in intervention group ( } 2 \text { discontinued due to lack of effi- } \\
\text { cacy); } 31 / 31 \text { included in control group }\end{array}$ \\
\hline
\end{tabular}




\section{Chuang 2017 (Continued)}

Incomplete outcome data (attrition bias)

Functional bladder capacity
Low risk $\quad 59 / 61(97 \%)$ included in intervention group (2 discontinued due to lack of efficacy); $31 / 31$ included in control group

\begin{tabular}{lll}
\hline $\begin{array}{l}\text { Incomplete outcome data } \\
\text { (attrition bias) } \\
\text { Adverse events }\end{array}$ & Low risk & $\begin{array}{l}59 / 61(97 \%) \text { included in intervention group (2 discontinued due to lack of effi- } \\
\text { cacy); 31/31 included in control group }\end{array}$ \\
\hline $\begin{array}{l}\text { Selective reporting (re- } \\
\text { porting bias) }\end{array}$ & Low risk & Results included all outcomes specified in the methods section \\
\hline Other bias & Low risk & None detected
\end{tabular}

Davis 2008

\section{Study characteristics}

$\begin{array}{ll}\text { Methods } & \begin{array}{l}\text { Study design: } \mathrm{RCT} \\ \text { Study duration (months): } 4.5\end{array}\end{array}$

Participants Number randomised: 40

Setting: single centre

Country: USA

Sex: female

Age, years: median 36.9 (IQR 31.9 to 45.1) for Group A, median 38.7 (IQR 26 to 42.7) for Group B

Diagnosis: IC

Inclusion criteria: females who were older than 18 years, diagnosed with IC within 1 year of the beginning of the study and previously untreated with either intravesical or oral PPS. To be included in the study, all subjects had to have the following examination requirements: cystoscopic examination under anaesthesia with hydrodistension and photo documentation showing petechial haemorrhage or ulcers; negative urine culture; score of at least 4 on a 9-point pain scale; 5 on the O'Leary-Sant IC Symptom Index; and 4 on IC Problem Index

Exclusion criteria: bladder capacity greater than $350 \mathrm{~mL}$ on an awake cystometrogram; absence of intense urge with bladder filled to $150 \mathrm{~mL}$ water on cystometrogram; biphasic involuntary bladder contractions; absence of nocturia; voiding frequency less than 8 times per day (voiding diaries); remission of symptoms by antimicrobials, urinary antiseptics, anticholinergics or antispasmodics; bacterial cystitis within 3 months; recurrent bladder; genital herpes within 3 months; cervical, vaginal or urethral cancer; chemical, tubercular or radiation cystitis; benign or malignant bladder tumour; vaginitis; vesicle ureteral reflux or urethral diverticula; neurogenic bladder dysfunction; prior urinary diversion; receiving any intravesical treatment at time of enrolment; pregnant or lactating mother. A total of 33 subjects had a cystometrogram (median bladder capacity $131 \mathrm{~mL}$ ). Subjects lacking this criterion (because it was painful) were entered into the study but must have met all other standard criteria for IC

Interventions

Group A (n = 20): intravesical $200 \mathrm{mg}$ in $30 \mathrm{~mL} \mathrm{NaCl}$ pentosan polysulfate sodium (PPS) + oral PPS

Group B ( $\mathbf{n}=\mathbf{2 0}): 30 \mathrm{~mL}$ of $\mathrm{NaCl}+$ oral PPS twice weekly for 6 weeks

Treatment category in NMA: PPS vs control

Outcomes Outcome data in analysis


Davis 2008 (Continued)

Cure or improvement: moderately, greatly or completely improved, on patient global assessment questionnaire: at 18 weeks

Adverse events: at 18 weeks

\begin{tabular}{ll}
\hline Funding & Ortho-McNeil Janssen Scientific Affairs, LLC, Raritan, New Jersey \\
\hline Notes & Publication status: full text
\end{tabular}

\title{
Risk of bias
}

\begin{tabular}{|c|c|c|}
\hline Bias & Authors' judgement & Support for judgement \\
\hline $\begin{array}{l}\text { Random sequence genera- } \\
\text { tion (selection bias) }\end{array}$ & Unclear risk & $\begin{array}{l}\text { Quote: "restricted randomization with a size of } 4 \text { per block" } \\
\text { Comment: probably done }\end{array}$ \\
\hline $\begin{array}{l}\text { Allocation concealment } \\
\text { (selection bias) }\end{array}$ & Unclear risk & No information provided \\
\hline $\begin{array}{l}\text { Blinding of participants } \\
\text { and personnel (perfor- } \\
\text { mance bias) } \\
\text { All outcomes }\end{array}$ & Low risk & $\begin{array}{l}\text { "double-blind", using intravesical saline solution as placebo. "The blinding } \\
\text { process was monitored... by an independent pharmacist, who was responsible } \\
\text { for preparing the trial intravesical treatment and placebo according to an FDA } \\
\text { approved method" }\end{array}$ \\
\hline $\begin{array}{l}\text { Blinding of outcome as- } \\
\text { sessment (detection bias) } \\
\text { Subjective outcome }\end{array}$ & Low risk & $\begin{array}{l}\text { "double-blind", using intravesical saline solution as placebo. "The blinding } \\
\text { process was monitored... by an independent pharmacist, who was responsible } \\
\text { for preparing the trial intravesical treatment and placebo according to an FDA } \\
\text { approved method" }\end{array}$ \\
\hline $\begin{array}{l}\text { Incomplete outcome data } \\
\text { (attrition bias) } \\
\text { Cure or improvement }\end{array}$ & Low risk & All randomised participants were included in analysis \\
\hline $\begin{array}{l}\text { Incomplete outcome data } \\
\text { (attrition bias) } \\
\text { Adverse events }\end{array}$ & Low risk & $21 / 21$ included in intervention group; $20 / 21$ included in control group \\
\hline $\begin{array}{l}\text { Selective reporting (re- } \\
\text { porting bias) }\end{array}$ & Low risk & Results included all outcomes specified in the methods section \\
\hline Other bias & Low risk & None detected \\
\hline
\end{tabular}

\section{De Ridder 2013}

\section{Study characteristics}

\begin{tabular}{ll}
\hline Methods & Study design: $\mathrm{RCT}$ \\
& Study duration (months): not reported \\
\hline
\end{tabular}

Participants

\author{
Number randomised: 36 \\ Setting: 4 centres \\ Country: Belgium \\ Sex: 31 females and 5 males
}


De Ridder 2013 (Continued)
Age, years: not reported
Diagnosis: PBS/IC
Inclusion criteria: men and women aged 18 to 75 years with history of symptoms of bladder pain/dis- comfort described as suprapubic pain related to bladder filling, accompanied by other symptoms such as daytime and/or nighttime frequency in the absence of infection or other pathology. All patients un- derwent urodynamic evaluation and cystoscopy with evidence of early bladder sensation and low max- imum bladder capacity. We also considered in this study patients with negative macroscopic and biop- tic findings of interstitial cystitis if significant symptoms were present. Patients should be willing and able to complete the necessary questionnaires

Exclusion criteria: transitional cell carcinoma of the bladder or other significant malignancy; pregnant or lactating; suffering from significant bacteriuria; diagnosis of haematuria; neurogenic bladder; indwelling catheter; chronic bacterial prostatitis; currently receiving or having received investigational drugs $\leq 30$ days before screening; currently receiving or having had prior therapy with intravesical treatment (e.g. Uracyst, Cystistat ${ }^{\oplus}$, heparin, bacillus Calmette-Guérin (BCG)); receiving therapy for $<3$ months with antidepressants, antihistaminics, hormonal agonists or antagonists; hence patient not stabilised on therapy (stable therapy defined as continuous treatment for $\geq 3$ months); IC symptoms relieved by antimicrobials, anticholinergics or antispasmodics; functional bladder capacity > $400 \mathrm{~mL}$; neurological disease affecting bladder function; any previous surgery or procedure having affected bladder function; current diagnosis of chemical, tuberculous or radiation cystitis; bladder or lower ureteral calculi; history of cancer within the last 5 years other than adequately treated non-melanoma skin cancer; active sexually transmitted disease; current vaginitis, endometriosis or any condition/disease that in the opinion of the investigator could interfere with patient compliance and/or interfere with interpretation of treatment results

$\begin{array}{ll}\text { Interventions } & \text { Group A }(\mathbf{n}=\mathbf{2 2}): 1 \mathrm{~g} / 50 \mathrm{~mL} \text { sodium chondroitin sulfate }(2 \%)\left(\text { Uracyst }^{\mathrm{TM}}\right) \\ & \text { Group B }(\mathbf{n}=\mathbf{1 4}) \text { : DMSO (dimethyl sulfoxide, } 5.4 \%) 27 \mathrm{~g} \text { in } 50 \mathrm{~mL}\left(\mathrm{RIMSO}-50^{\circledR}\right)\end{array}$

Weekly for 6 weeks

Treatment categoryin NMA: chondroitin sulfate vs DMSO

Outcomes
Cure or improvement: 'moderately' or 'markedly' improved on GRA: unclear time of measurement
Pain: O'Leary-Sant Questionniare (Interstitial Cystitis Symptom and Problem Index) pain subscale (as-
sumed 0 to 10 scale): unclear time of measurement

ICSI: unclear time of measurement

\begin{tabular}{lll}
\hline Funding & EUROCEPT, The Netherlands \\
\hline Notes & Publication status: full text \\
\hline Risk of bias & & \\
\hline Bias & Authors' judgement & Support for judgement \\
\hline $\begin{array}{l}\text { Random sequence genera- } \\
\text { tion (selection bias) }\end{array}$ & Unclear risk & Quote: "randomized" \\
\hline $\begin{array}{l}\text { Allocation concealment } \\
\text { (selection bias) }\end{array}$ & Unclear risk & No information provided \\
\hline $\begin{array}{l}\text { Blinding of participants } \\
\text { and personnel (perfor- } \\
\text { mance bias) }\end{array}$ & High risk & $\begin{array}{l}\text { Stated as "patients were single-blind randomized", but methods of blinding } \\
\text { were not described. Personnel probably not blinded. Intravesical instillation of } \\
\text { chondroitin sulfate "in 20 ml vials" or DMSO "in 50 ml physiologic serum" }\end{array}$
\end{tabular}


De Ridder 2013 (Continued)

All outcomes

\begin{tabular}{lll}
\hline Blinding of outcome as- & Unclear risk & Stated as "patients were single-blind randomized", but methods of blinding \\
sessment (detection bias) & were not described. Intravesical instillation of chondroitin sulfate "in $20 \mathrm{ml}$ \\
Subjective outcome & vials" or DMSO "in $50 \mathrm{ml}$ physiologic serum"
\end{tabular}

Subjective outcome

$16 / 22(73 \%)$ included in chondroitin sulfate group (withdrawal mainly due to

Incomplete outcome data High risk

(attrition bias)

lack of efficacy or side effects); 6/14 (43\%) included in DMSO group (withdraw-

Cure or improvement

al mainly due to adverse effects)

Incomplete outcome data Unclear risk Number analysed unclear

(attrition bias)

Pain

Selective reporting (re- High risk

porting bias)

Pain VAS (visual analogue scale), frequency and nocturia were specified in the methods section but were reported only as baseline characteristics in the results section. Functional bladder capacity was specified in the methods but was not reported in the results

\begin{tabular}{ll}
\hline Other bias $\quad$ Low risk & None detected \\
\hline
\end{tabular}

Dimitrakov 2001

\section{Study characteristics}

\begin{tabular}{ll}
\hline Methods & Study design: $\mathrm{RCT}$ \\
& Study duration (months): 3 \\
\hline
\end{tabular}

Participants

Number randomised: 30

Setting: not reported

Country: not reported

Sex: not reported

Age, years: not reported

Diagnosis: IC (NIDDK criteria)

Inclusion criteria: patients with symptoms and signs of IC

Exclusion criteria: not reported

Interventions Group $\mathbf{A}$ ( $\mathbf{n}=$ not reported): 1 of 2 doses ( 0.1 and $0.3 \mathrm{mg} / \mathrm{kg}$ of body weight) of recombinant human
nerve growth factor

Group B ( $\mathbf{n}=$ not reported): placebo

Treatment category in NMA: immune modulators vs control

\begin{tabular}{ll}
\hline Outcomes & Outcome data in analysis (no usable data) \\
\hline Funding & Prostatitis Foundation of America and the Bulgarian Ministry of Health \\
\hline Notes & Publication status: abstract \\
\hline
\end{tabular}

\section{Risk of bias}


Dimitrakov 2001 (Continued)

\begin{tabular}{|c|c|c|}
\hline Bias & Authors' judgement & Support for judgement \\
\hline $\begin{array}{l}\text { Random sequence genera- } \\
\text { tion (selection bias) }\end{array}$ & Unclear risk & "... patients ... randomly received" either intervention or placebo \\
\hline $\begin{array}{l}\text { Allocation concealment } \\
\text { (selection bias) }\end{array}$ & Unclear risk & No information provided \\
\hline $\begin{array}{l}\text { Blinding of participants } \\
\text { and personnel (perfor- } \\
\text { mance bias) } \\
\text { All outcomes }\end{array}$ & Unclear risk & No information provided. Placebo not described \\
\hline $\begin{array}{l}\text { Blinding of outcome as- } \\
\text { sessment (detection bias) } \\
\text { Subjective outcome }\end{array}$ & Unclear risk & No information provided. Placebo not described \\
\hline $\begin{array}{l}\text { Selective reporting (re- } \\
\text { porting bias) }\end{array}$ & Unclear risk & Outcomes not specified in the methods section (abstract only) \\
\hline Other bias & Low risk & None detected \\
\hline
\end{tabular}

El-Hefnawy 2015

\section{Study characteristics}

\begin{tabular}{ll}
\hline Methods & $\begin{array}{l}\text { Study design: RCT } \\
\text { Study duration (months): } 1\end{array}$ \\
\hline Participants & Number randomised: 26 \\
& Setting: single centre (assumed from reports) \\
& Country: Egypt \\
Sex: female & Age, years: mean 32 (SD 6) for Group A, mean 33 (SD 7) for Group B \\
& Diagnosis: IC/BPS. Diagnosis according to IC Database Study criteria (Hanno 1999) \\
& Inclusion criteria: Patients with complaint suggestive of IC/BPS. Patients who were not improved on \\
pain killers and analgesics after treatment for at least 3 months and were willing to participate in the \\
study. At least 4 weeks elapsed before receiving either line of treatment
\end{tabular}

Exclusion criteria: not reported

Interventions

Group A ( $\mathbf{n}=\mathbf{1 4})$ : superior hypogastric plexus neurolysis

Group B ( $=12$ ): hydrodistension

Treatment category in NMA: denervation vs hydrodistension

Outcome data in analysis
Pain: VAS (assumed range 0 to 10): at 4 weeks
Daytime frequency: at 4 weeks
Nocturia: at 4 weeks


El-Hefnawy 2015 (Continued)

\section{ICSI: at 4 weeks}

ICPI: at 4 weeks

Adverse events: at 4 weeks

\begin{tabular}{ll}
\hline Funding & Not reported \\
\hline Notes & Publication status: full text \\
\hline
\end{tabular}

\section{Risk of bias}

Bias Authors' judgement Support for judgement

Random sequence genera- Unclear risk
tion (selection bias)

Quote: "randomly allocated to receive either HD or SHN block according to results of closed envelope"

Comment: unclear how envelopes were used to ensure random allocation

\begin{tabular}{ll}
\hline $\begin{array}{l}\text { Allocation concealment } \\
\text { (selection bias) }\end{array}$ & $\begin{array}{l}\text { Unclear risk } \\
\text { Quote: "randomly allocated to receive either HD or SHN block according to re- } \\
\text { sults of closed envelope" }\end{array}$ \\
& Comment: unclear how envelopes were used to ensure random allocation
\end{tabular}

\begin{tabular}{|c|c|c|}
\hline $\begin{array}{l}\text { Blinding of participants } \\
\text { and personnel (perfor- } \\
\text { mance bias) } \\
\text { All outcomes }\end{array}$ & High risk & $\begin{array}{l}\text { Superior hypogastric plexus neurolysis (SHN) vs hydrodistension (HD). SHN } \\
\text { performed "In operating room, conscious sedation". Probably not done }\end{array}$ \\
\hline
\end{tabular}

\begin{tabular}{lll}
\hline Blinding of outcome as- & High risk & $\begin{array}{l}\text { Superior hypogastric plexus neurolysis (SHN) vs hydrodistension (HD). SHN } \\
\text { performent (detection bias) } \\
\text { Subjective outcome }\end{array}$
\end{tabular}

\begin{tabular}{|c|c|c|}
\hline $\begin{array}{l}\text { Incomplete outcome data } \\
\text { (attrition bias) } \\
\text { Pain }\end{array}$ & High risk & $\begin{array}{l}12 / 14(86 \%) \text { included in SHN group ( } 2 \text { excluded due to failed initial test); } 12 / 12 \\
\text { included in HD group }\end{array}$ \\
\hline $\begin{array}{l}\text { Incomplete outcome data } \\
\text { (attrition bias) } \\
\text { Frequency }\end{array}$ & High risk & $\begin{array}{l}12 / 14(86 \%) \text { included in SHN group ( } 2 \text { excluded due to failed initial test); } 12 / 12 \\
\text { included in HD group }\end{array}$ \\
\hline $\begin{array}{l}\text { Incomplete outcome data } \\
\text { (attrition bias) } \\
\text { Nocturia }\end{array}$ & High risk & $\begin{array}{l}12 / 14(86 \%) \text { included in SHN group ( } 2 \text { excluded due to failed initial test); } 12 / 12 \\
\text { included in HD group }\end{array}$ \\
\hline $\begin{array}{l}\text { Incomplete outcome data } \\
\text { (attrition bias) } \\
\text { Interstitial Cystitis Symp- } \\
\text { tom Index }\end{array}$ & High risk & $\begin{array}{l}12 / 14(86 \%) \text { included in SHN group ( } 2 \text { excluded due to failed initial test); } 12 / 12 \\
\text { included in HD group }\end{array}$ \\
\hline $\begin{array}{l}\text { Incomplete outcome data } \\
\text { (attrition bias) } \\
\text { Interstitial Cystitis Prob- } \\
\text { lem Index }\end{array}$ & High risk & $\begin{array}{l}12 / 14(86 \%) \text { included in SHN group ( } 2 \text { excluded due to failed initial test); } 12 / 12 \\
\text { included in HD group }\end{array}$ \\
\hline $\begin{array}{l}\text { Incomplete outcome data } \\
\text { (attrition bias) } \\
\text { Adverse events }\end{array}$ & High risk & $\begin{array}{l}12 / 14(86 \%) \text { included in SHN group ( } 2 \text { excluded due to failed initial test); } 12 / 12 \\
\text { included in HD group }\end{array}$ \\
\hline
\end{tabular}


El-Hefnawy 2015 (Continued)

Selective reporting (re- Low risk $\quad$ Results included all outcomes specified in the methods section
porting bias)

\begin{tabular}{lll}
\hline Other bias $\quad$ Low risk $\quad$ None detected \\
\hline
\end{tabular}

Evans 2011

\section{Study characteristics}

\begin{tabular}{|c|c|c|}
\hline Methods & \multicolumn{2}{|c|}{$\begin{array}{l}\text { Study design: } \mathrm{RCT} \\
\text { Study duration (months): } 4\end{array}$} \\
\hline \multirow[t]{7}{*}{ Participants } & \multirow{2}{*}{\multicolumn{2}{|c|}{$\begin{array}{l}\text { Number randomised: } 64 \\
\text { Setting: } 23 \text { centres }\end{array}$}} \\
\hline & & \\
\hline & \multirow{2}{*}{\multicolumn{2}{|c|}{$\begin{array}{l}\text { Country: USA } \\
\text { Sex: reported as 'mostly female (89\%)'. Unclear denominator } \\
\text { Age, years: range } 21 \text { to } 85\end{array}$}} \\
\hline & & \\
\hline & \multicolumn{2}{|c|}{ Diagnosis: IC, moderate to severe } \\
\hline & \multicolumn{2}{|c|}{$\begin{array}{l}\text { Inclusion criteria: moderate to severe IC defined as scores of } 13 \text { or greater on the Pelvic Pain and Ur- } \\
\text { gency/Frequency symptom questionnaire, and } 7 \text { or more on the O'Leary-Sant ICSI }\end{array}$} \\
\hline & \multicolumn{2}{|c|}{$\begin{array}{l}\text { Exclusion criteria: IC symptoms for less than } 6 \text { months, PVR volume greater than } 200 \mathrm{~mL} \text {, history of al- } \\
\text { lergic or anaphylactic reaction to mAbs or IgG fusion proteins }\end{array}$} \\
\hline \multirow[t]{4}{*}{ Interventions } & \multirow{2}{*}{\multicolumn{2}{|c|}{$\begin{array}{l}\text { Group A ( } \mathbf{n}=\mathbf{3 4 )} \text { : tanezumab (humanised anti-NGF (nerve growth factor) monoclonal antibody) intra- } \\
\text { venous dose of } 200 \mathrm{~g} / \mathrm{kg} \\
\text { Group B }(\mathbf{n}=\mathbf{3 0} \text { ): placebo }\end{array}$}} \\
\hline & & \\
\hline & \multirow{2}{*}{\multicolumn{2}{|c|}{$\begin{array}{l}\text { Patients remained on existing non-prohibited oral medications as background therapy for interstitial } \\
\text { cystitis } \\
\text { Treatment category in NMA: immune modulators vs control }\end{array}$}} \\
\hline & & \\
\hline \multirow[t]{5}{*}{ Outcomes } & \multicolumn{2}{|c|}{ Outcome data in analysis } \\
\hline & \multicolumn{2}{|c|}{ Cure or improvement: 'moderately' or 'markedly improved on GRA: at 16 weeks } \\
\hline & \multicolumn{2}{|c|}{ Pain: numerical rating scale (range 0 to 10 ): at 16 weeks } \\
\hline & \multicolumn{2}{|l|}{ Frequency: at 6 weeks } \\
\hline & \multicolumn{2}{|c|}{ Adverse events: at 16 weeks } \\
\hline Funding & \multicolumn{2}{|l|}{ Pfizer } \\
\hline Notes & \multicolumn{2}{|c|}{ Publication status: full text } \\
\hline \multicolumn{3}{|l|}{ Risk of bias } \\
\hline Bias & Authors' judgement & Support for judgement \\
\hline $\begin{array}{l}\text { Random sequence genera- } \\
\text { tion (selection bias) }\end{array}$ & Low risk & Quote: "randomized using an automated tele-randomization system" \\
\hline
\end{tabular}




\section{Evans 2011 (Continued)}

\begin{tabular}{|c|c|c|}
\hline $\begin{array}{l}\text { Allocation concealment } \\
\text { (selection bias) }\end{array}$ & Low risk & Quote: "randomized using an automated tele-randomization system" \\
\hline $\begin{array}{l}\text { Blinding of participants } \\
\text { and personnel (perfor- } \\
\text { mance bias) } \\
\text { All outcomes }\end{array}$ & Unclear risk & $\begin{array}{l}\text { "double-blind, placebo-controlled trial", using intravenous (IV) dose. Placebo } \\
\text { not described }\end{array}$ \\
\hline $\begin{array}{l}\text { Blinding of outcome as- } \\
\text { sessment (detection bias) } \\
\text { Subjective outcome }\end{array}$ & Unclear risk & $\begin{array}{l}\text { "double-blind, placebo-controlled trial", using intravenous (IV) dose. Placebo } \\
\text { not described }\end{array}$ \\
\hline $\begin{array}{l}\text { Incomplete outcome data } \\
\text { (attrition bias) } \\
\text { Cure or improvement }\end{array}$ & High risk & $\begin{array}{l}\text { 19/34 (56\%) included in intervention group; } 13 / 30(43 \%) \text { included in control } \\
\text { group }\end{array}$ \\
\hline $\begin{array}{l}\text { Incomplete outcome data } \\
\text { (attrition bias) } \\
\text { Pain }\end{array}$ & Low risk & $\begin{array}{l}27 / 34(79 \%) \text { included in intervention group; } 22 / 30(73 \%) \text { included in control } \\
\text { group }\end{array}$ \\
\hline $\begin{array}{l}\text { Incomplete outcome data } \\
\text { (attrition bias) } \\
\text { Frequency }\end{array}$ & Unclear risk & $\begin{array}{l}29 / 34(85 \%) \text { included in intervention group; } 23 / 30(77 \%) \text { included in control } \\
\text { group }\end{array}$ \\
\hline $\begin{array}{l}\text { Incomplete outcome data } \\
\text { (attrition bias) } \\
\text { Adverse events }\end{array}$ & Low risk & $\begin{array}{l}29 / 34(85 \%) \text { included in intervention group; } 23 / 30(77 \%) \text { included in control } \\
\text { group }\end{array}$ \\
\hline $\begin{array}{l}\text { Selective reporting (re- } \\
\text { porting bias) }\end{array}$ & Low risk & Results included all outcomes specified in the methods section \\
\hline Other bias & Low risk & None detected \\
\hline
\end{tabular}

\section{FitzGerald 2009}

\section{Study characteristics}

\begin{tabular}{ll}
\hline Methods & Study design: RCT \\
Study duration (months): 3
\end{tabular}

Participants

\section{Number randomised: 47}

Setting: 6 clinical centres

Country: USA

Sex: 24 females and 23 males

Age, years: mean 43, range 22 to 76

Diagnosis: IC/PBS or CP/CPPS. Clinical diagnosis

Inclusion criteria: patients with symptoms for less than 3 years. Patients must have previously undergone at least 1 course of another form of therapy for their symptoms

Exclusion criteria: patients who were intolerant to digital vaginal or rectal examination (i.e. unable to tolerate myofascial physical therapy treatments); participants who had previously undergone myofascial physical therapy for symptoms 
FitzGerald 2009 (Continued)

Interventions

Group A ( $\mathbf{n}=\mathbf{2 3})$ : myofascial physical therapy

Group B ( $\mathbf{n}=\mathbf{2 4})$ : global therapeutic massage

Treatment category in NMA: physical therapy vs control

\begin{tabular}{ll}
\hline Outcomes & Outcome data in analysis \\
Cure or improvement: 'moderately' or 'markedly' improved on GRA: at 12 weeks
\end{tabular}

The Urological Pelvic Pain Collaborative Research Network is a co-operative network of investigators
from 20 clinical centres and a Data Co-ordinating Center funded by NIDDK, NIH

Notes Publication status: full text

\section{Risk of bias}

\begin{tabular}{|c|c|c|}
\hline Bias & Authors' judgement & Support for judgement \\
\hline $\begin{array}{l}\text { Random sequence genera- } \\
\text { tion (selection bias) }\end{array}$ & Unclear risk & Quote: "randomly assigned ... via a prespecified sequence" \\
\hline $\begin{array}{l}\text { Allocation concealment } \\
\text { (selection bias) }\end{array}$ & Unclear risk & $\begin{array}{l}\text { Quote: "a prespecified sequence distributed in a series of sealed envelopes" } \\
\text { Comment: unclear if envelopes were opaque and sequentially numbered }\end{array}$ \\
\hline $\begin{array}{l}\text { Blinding of participants } \\
\text { and personnel (perfor- } \\
\text { mance bias) } \\
\text { All outcomes }\end{array}$ & High risk & $\begin{array}{l}\text { Quote: "single-blind". Participants were not informed of treatment assign- } \\
\text { ment but investigators stated that participants could not be blinded: "more } \\
\text { than } 90 \% \text { were aware of their treatment group when queried at the end of the } \\
\text { study". Study co-ordinator was blinded }\end{array}$ \\
\hline $\begin{array}{l}\text { Blinding of outcome as- } \\
\text { sessment (detection bias) } \\
\text { Subjective outcome }\end{array}$ & High risk & $\begin{array}{l}\text { Quote: "single-blind". Participants were not informed of treatment assign- } \\
\text { ment but investigators stated that participants could not be blinded: "more } \\
\text { than } 90 \% \text { were aware of their treatment group when queried at the end of the } \\
\text { study" }\end{array}$ \\
\hline $\begin{array}{l}\text { Incomplete outcome data } \\
\text { (attrition bias) } \\
\text { Cure or improvement }\end{array}$ & Low risk & $\begin{array}{l}\text { Data extracted from a subset of participants. All randomised participants were } \\
\text { included in analysis }\end{array}$ \\
\hline $\begin{array}{l}\text { Selective reporting (re- } \\
\text { porting bias) }\end{array}$ & Low risk & Results included all outcomes specified in the methods section \\
\hline Other bias & Low risk & None detected \\
\hline
\end{tabular}

FitzGerald 2012

\section{Study characteristics}

\begin{tabular}{ll}
\hline Methods & $\begin{array}{l}\text { Study design: RCT } \\
\text { Study duration (months): } 3\end{array}$ \\
\hline Participants & Number randomised: 81 \\
Setting: 11 clinical centres \\
Country: USA
\end{tabular}


FitzGerald 2012 (Continued)

Sex: female

Age, years: median 43, range 18 to 77

Diagnosis: IC/PBS

Inclusion criteria: women with a clinical diagnosis of IC/PBS and recorded ratings for bladder pain, frequency and urgency, each at a usual level of at least 3 on a 0 to 10 scale, present for at least 3 months but not for longer than 3 years. An additional eligibility requirement was the finding of pelvic floor tenderness during vaginal examination by the study physician and confirmed by the study physical therapist

Exclusion criteria: women were excluded from the study if they had not previously undergone at least 1 course of a standard therapy for IC/PBS, or if they had previously received treatment with pelvic floor myofascial physical therapy

Group A $(\mathbf{n}=\mathbf{3 9})$ : pelvic floor myofascial physical therapy
Group B $(\mathbf{n}=\mathbf{4 2})$ : global therapeutic massage

Treatment category in NMA: physical therapy vs control

Outcome data in analysis
Cure or improvement: 'moderately' or 'markedly' improved on GRA: at 12 weeks
Pain: numerical Likert scale (range 0 to 10): at 12 weeks
ICSI: at 12 weeks
ICPI: at 12 weeks

Adverse events: at 12 weeks

\begin{tabular}{ll}
\hline Funding & Not reported \\
\hline Notes & Publication status: full text \\
\hline
\end{tabular}

\section{Risk of bias}

\begin{tabular}{lll}
\hline Bias & Authors' judgement & Support for judgement \\
\hline $\begin{array}{l}\text { Random sequence genera- } \\
\text { tion (selection bias) }\end{array}$ & Unclear risk & Quote: "randomized" \\
& & $\begin{array}{l}\text { Comment: method of sequence generation judged to be unclear in FitzGerald } \\
\text { 2009, which uses identical methods to this trial }\end{array}$ \\
\hline $\begin{array}{l}\text { Allocation concealment } \\
\text { (selection bias) }\end{array}$ & Unclear risk & $\begin{array}{l}\text { No information. Method of allocation concealment judged to be unclear in } \\
\text { FitzGerald 2009, which uses identical methods to this trial }\end{array}$ \\
\hline $\begin{array}{l}\text { Blinding of participants } \\
\text { and personnel (perfor- } \\
\text { mance bias) }\end{array}$ & High risk & $\begin{array}{l}\text { Quote: "single-blind". Participants probably not blinded, as study authors state } \\
\text { All outcomes }\end{array}$ \\
\end{tabular}

\begin{tabular}{lll}
\hline $\begin{array}{l}\text { Blinding of outcome as- } \\
\text { sessment (detection bias) }\end{array}$ & High risk & $\begin{array}{l}\text { Quote: "single-blind". Participants probably not blinded. "Physician examin- } \\
\text { ers and research nurses collecting outcome data were masked to treatment } \\
\text { assignment" }\end{array}$
\end{tabular}

Subjective outcome All randomised participants were included in analysis

Incomplete outcome data Low risk (attrition bias)

Cure or improvement 
FitzGerald 2012 (Continued)

Incomplete outcome data Low risk (attrition bias)

Pain
38/39 (97\%) included in intervention group; 40/42 (95\%) included in control group. 3 withdrew from study, 1 due to dissatisfaction with treatment and 2 due to 'personal constraints'; group assignment unclear

\author{
Incomplete outcome data Low risk \\ (attrition bias) \\ Frequency
}

38/39 (97\%) included in intervention group; 40/42 (95\%) included in control group. 3 withdrew from study, 1 due to dissatisfaction with treatment and 2 due to 'personal constraints'; group assignment unclear Interstitial Cystitis Symptom Index

\begin{tabular}{lll}
\hline Incomplete outcome data & Low risk & $38 / 39(97 \%)$ included in intervention group; $40 / 42(95 \%)$ included in control \\
(attrition bias) & group. 3 withdrew from study, 1 due to dissatisfaction with treatment and 2 \\
Interstitial Cystitis Prob- & due to 'personal constraints'; group assignment unclear
\end{tabular}
lem Index

\begin{tabular}{lll}
\hline $\begin{array}{l}\text { Incomplete outcome data } \\
\text { (attrition bias) } \\
\text { Adverse events }\end{array}$ & Low risk & All randomised participants were included in analysis \\
\hline $\begin{array}{l}\text { Selective reporting (re- } \\
\text { porting bias) }\end{array}$ & Low risk & Results included all outcomes specified in the methods section \\
\hline Other bias & Low risk & None detected \\
\hline
\end{tabular}

\section{Foster 2010}

\section{Study characteristics}

\begin{tabular}{ll}
\hline Methods & $\begin{array}{l}\text { Study design: RCT } \\
\text { Study duration (months): } 3\end{array}$ \\
\hline Participants & Number randomised: 271 \\
& Setting: multi-centre \\
Country: USA & Sex: 226 females and 45 males \\
Age, years: mean 38.0 (SD 13.8) for Group A, mean 39.9 (SD 14.0) for Group B, median 38 for whole \\
group \\
Diagnosis: IC/PBS \\
Inclusion criteria: men and women at least 18 years old who reported bladder pain/discomfort and \\
urinary frequency of 3 or greater on separate 0 to 10 Likert scales during the previous 4 weeks at each \\
of 2 baseline screening visits. Current symptoms had to have been present for a minimum of 6 weeks, \\
and subjects were required to be treatment naïve, defined as having no prior significant treatment for \\
IC/PBS
\end{tabular}

Exclusion criteria: not reported

Interventions

Group A ( $\mathbf{n}=\mathbf{1 3 5})$ : amitriptyline + educational and behavioural modification programme (EBMP)

Group B ( $\mathbf{n}=\mathbf{1 3 6})$ : placebo + EBMP 
Dose regimen: dose of study drug was increased on a weekly basis from 10 to $25 \mathrm{mg}$, then to $50 \mathrm{mg}$ after a call from the research co-ordinator confirming tolerability. At the end of 3 weeks, participants were evaluated and their dose increased to $75 \mathrm{mg}$ daily

Treatment category in NMA: antidepressants vs control

Outcome data in analysis
Cure or improvement: 'moderately' or 'markedly' improved on GRA: at 12 weeks
Pain: Likert pain scale (range 0 to 10): at 3 months
Frequency: at 3 months
Nocturia: at 3 months
ICSI: at 3 months
ICPI: at 3 months
Adverse events: at 3 months

\begin{tabular}{ll}
\hline Funding & Not reported \\
\hline Notes & Publication status: full text
\end{tabular}

\section{Risk of bias}

\begin{tabular}{|c|c|c|}
\hline Bias & Authors' judgement & Support for judgement \\
\hline $\begin{array}{l}\text { Random sequence genera- } \\
\text { tion (selection bias) }\end{array}$ & Unclear risk & Quote: "randomized" \\
\hline $\begin{array}{l}\text { Allocation concealment } \\
\text { (selection bias) }\end{array}$ & Unclear risk & No information provided \\
\hline $\begin{array}{l}\text { Blinding of participants } \\
\text { and personnel (perfor- } \\
\text { mance bias) } \\
\text { All outcomes }\end{array}$ & Low risk & $\begin{array}{l}\text { "double-blind", "placebo-controlled" trial, using oral tablet. Participants were } \\
\text { randomised to study drug or "matching placebo". Probably done }\end{array}$ \\
\hline $\begin{array}{l}\text { Blinding of outcome as- } \\
\text { sessment (detection bias) } \\
\text { Subjective outcome }\end{array}$ & Low risk & "double-blind", using "matching" placebo. Probably done \\
\hline $\begin{array}{l}\text { Incomplete outcome data } \\
\text { (attrition bias) } \\
\text { Cure or improvement }\end{array}$ & Low risk & $\begin{array}{l}\text { Review authors chose to use number who completed the trial. } 112 / 135 \text { ( } 83 \%) \\
\text { included in intervention group ( } 7 \text { missing due to } \mathrm{AE} \text { ); } 119 / 136(88 \%) \text { included } \\
\text { in control group ( } 2 \text { missing due to } \mathrm{AE} \text { ) }\end{array}$ \\
\hline $\begin{array}{l}\text { Incomplete outcome data } \\
\text { (attrition bias) } \\
\text { Pain }\end{array}$ & Unclear risk & $\begin{array}{l}\text { Number analysed unclear. It is "not per intent to treat due to withdrawals and } \\
\text { missing data" }\end{array}$ \\
\hline $\begin{array}{l}\text { Incomplete outcome data } \\
\text { (attrition bias) } \\
\text { Frequency }\end{array}$ & Low risk & $\begin{array}{l}\text { 92/135 (68\%) included in intervention group; } 95 / 136(70 \%) \text { included in contro } \\
\text { group }\end{array}$ \\
\hline $\begin{array}{l}\text { Incomplete outcome data } \\
\text { (attrition bias) } \\
\text { Nocturia }\end{array}$ & Low risk & $\begin{array}{l}\text { 92/135 (68\%) included in intervention group; } 95 / 136(70 \%) \text { included in control } \\
\text { group }\end{array}$ \\
\hline
\end{tabular}


Foster 2010 (Continued)

Incomplete outcome data Unclear risk Number analysed unclear. It is "not per intent to treat due to withdrawals and (attrition bias) missing data"

Interstitial Cystitis Symp-

tom Index

Incomplete outcome data Unclear risk (attrition bias)

Interstitial Cystitis Prob-

lem Index
Number analysed unclear. It is "not per intent to treat due to withdrawals and missing data"

Incomplete outcome data Low risk All randomised participants were included in analysis
(attrition bias)

Adverse events

Selective reporting (re- Low risk Results included all outcomes specified in the methods section
porting bias)

\begin{tabular}{lll}
\hline Other bias $\quad$ Low risk $\quad$ None detected
\end{tabular}

Geirsson 1993

\section{Study characteristics}

\begin{tabular}{ll}
\hline Methods & $\begin{array}{l}\text { Study design: cross-over randomised trial } \\
\text { Study duration (months): } 1 \text { (assumed from reports) }\end{array}$ \\
\hline Pumber randomised: 12 \\
Setting: not reported \\
Country: Sweden \\
Sex: female \\
Age, years: median 41, range 22 to 80 \\
Diagnosis: IC \\
Inclusion criteria: female IC patients. No further details, but it is stated that "all patients had been \\
treated with various conservative measures with lack of response or recurrence of symptoms"
\end{tabular}

Exclusion criteria: not reported

Interventions

Group A ( $\mathbf{n}=$ not reported): acupuncture 2 to 3 times a week for 4 to 5 weeks

Group B ( $\mathbf{n}=$ not reported): transcutaneous tibial nerve stimulation (TENS) by patients at home, 30 minutes per day for 4 weeks

Treatment category in NMA: behavioural therapy vs physical therapy

\begin{tabular}{ll}
\hline Outcomes & Outcome data in analysis \\
& Adverse events: at 1 month (assumed from reports) \\
\hline Funding & Supported by Swedish Medical Research Council and Gothenburg Medical Society \\
\hline Notes & Publication status: full text \\
\hline
\end{tabular}

\section{Risk of bias}

Interventions for treating people with symptoms of bladder pain syndrome: a network meta-analysis (Review)

Copyright @ 2020 The Cochrane Collaboration. Published by John Wiley \& Sons, Ltd. 
Geirsson 1993 (Continued)

Bias Authors' judgement Support for judgement

Random sequence genera- Low risk tion (selection bias)
Quote: "randomized ... according to a cross-over design"; "allocation to initial treatment was done by the patient selecting an envelope containing a mark for either method"

\begin{tabular}{|c|c|c|}
\hline $\begin{array}{l}\text { Allocation concealment } \\
\text { (selection bias) }\end{array}$ & Unclear risk & $\begin{array}{l}\text { Quote: "allocation to initial treatment was done by the patient selecting an er } \\
\text { velope containing a mark for either method" }\end{array}$ \\
\hline & & $\begin{array}{l}\text { Comment: unclear if envelopes were sealed, opaque and sequentially num- } \\
\text { bered }\end{array}$ \\
\hline
\end{tabular}

Blinding of participants and personnel (performance bias)

All outcomes

\section{High risk}

\begin{tabular}{lll}
\hline $\begin{array}{l}\text { Blinding of outcome as- } \\
\text { sessment (detection bias) } \\
\text { Subjective outcome }\end{array}$ & High risk & $\begin{array}{l}\text { Probably not done. Accupuncture by a Chinese medical doctor vs TENS at } \\
\text { home. TENS is defined as trancutaneous nerve stimulation of the tibial nerve }\end{array}$ \\
\hline $\begin{array}{l}\text { Incomplete outcome data } \\
\text { (attrition bias) } \\
\text { Adverse events }\end{array}$ & Unclear risk & Number analysed unclear \\
\hline $\begin{array}{l}\text { Selective reporting (re- } \\
\text { porting bias) }\end{array}$ & Low risk & Results included all outcomes specified in the methods section \\
\hline Other bias & Low risk & None detected \\
\hline
\end{tabular}

Gottsch 2011

\section{Study characteristics}

\begin{tabular}{ll}
\hline Methods & $\begin{array}{l}\text { Study design: RCT } \\
\text { Study duration (months): } 3\end{array}$ \\
\hline Participants & Number randomised: 20 \\
& Setting: single centre \\
& Country: USA \\
Sex: female & Age, years: mean 43.9 (range 27 to 61 ) for Group A, mean 47.7 (range 22 to 61) for Group B \\
& Diagnosis: IC/PBS \\
& $\begin{array}{l}\text { Inclusion criteria: adult women with IC/PBS were identified from the Female Urology Clinic at our hos- } \\
\text { pital, which is a tertiary care referral centre. Women were eligible for enrolment if they had refractory } \\
\text { pelvic pain in the bladder, urethra, vagina or perineum; pain with bladder filling or voiding; and urinary } \\
\text { frequency greater than } 12 \text { voids per day }\end{array}$ \\
& $\begin{array}{l}\text { Exclusion criteria: women with isolated overactive bladder symptoms, active urinary tract infection, } \\
\text { pregnancy, genitourinary malignancy, suicidal or overtly psychotic behavior, postsurgical pain, pain } \\
\text { from another source in the genitourinary tract (e.g. renal calculi), history of radiation therapy or history } \\
\text { of genitourinary tuberculosis }\end{array}$ \\
\hline
\end{tabular}


Gottsch 2011 (Continued)

Group B ( $\mathbf{n}=\mathbf{1 1})$ : placebo injection of $2 \mathrm{~cm}^{3}$ normal saline

Treatment category in NMA: neuromuscular blockade vs control

\begin{tabular}{|c|c|c|}
\hline \multirow[t]{3}{*}{ Outcomes } & \multicolumn{2}{|c|}{ Outcome data in analysis } \\
\hline & \multicolumn{2}{|c|}{$\begin{array}{l}\text { Pain: CPSI-F (a female modification of Chronic Prostitis Symptom Index) pain subscale (range } 0 \text { to } 21 \text { ): } \\
\text { at } 3 \text { months }\end{array}$} \\
\hline & \multicolumn{2}{|c|}{ Adverse events: at 3 months } \\
\hline Funding & \multicolumn{2}{|l|}{ Not reported } \\
\hline Notes & \multicolumn{2}{|c|}{ Publication status: full text } \\
\hline \multicolumn{3}{|l|}{ Risk of bias } \\
\hline Bias & Authors' judgement & Support for judgement \\
\hline $\begin{array}{l}\text { Random sequence genera- } \\
\text { tion (selection bias) }\end{array}$ & Unclear risk & Quote: "randomized" \\
\hline $\begin{array}{l}\text { Allocation concealment } \\
\text { (selection bias) }\end{array}$ & Unclear risk & No information provided \\
\hline $\begin{array}{l}\text { Blinding of participants } \\
\text { and personnel (perfor- } \\
\text { mance bias) } \\
\text { All outcomes }\end{array}$ & Unclear risk & $\begin{array}{l}\text { "double-blind"; blinding methods not described. Periurethral injection botu- } \\
\text { linum toxin A vs saline (placebo). "The placebo injection ... delivered in a simi- } \\
\text { lar fashion" }\end{array}$ \\
\hline $\begin{array}{l}\text { Blinding of outcome as- } \\
\text { sessment (detection bias) } \\
\text { Subjective outcome }\end{array}$ & Unclear risk & $\begin{array}{l}\text { "double-blind"; blinding methods not described. Periurethral injection botu- } \\
\text { linum toxin A vs saline (placebo). "The placebo injection ... delivered in a simi- } \\
\text { lar fashion" }\end{array}$ \\
\hline $\begin{array}{l}\text { Incomplete outcome data } \\
\text { (attrition bias) } \\
\text { Pain }\end{array}$ & Low risk & All randomised participants were included in analysis \\
\hline $\begin{array}{l}\text { Incomplete outcome data } \\
\text { (attrition bias) } \\
\text { Adverse events }\end{array}$ & Low risk & All randomised participants were included in analysis \\
\hline $\begin{array}{l}\text { Selective reporting (re- } \\
\text { porting bias) }\end{array}$ & Low risk & Results included all outcomes specified in the methods section \\
\hline Other bias & Low risk & None detected \\
\hline
\end{tabular}

Gulpinar 2013

\section{Study characteristics}

\begin{tabular}{ll}
\hline Methods & Study design: $\mathrm{RCT}$ \\
& Study duration (months): 6 \\
\hline Participants
\end{tabular}


Gulpinar 2013 (Continued)

Setting: not reported

Country: Turkey

Sex: not reported

Age, years: mean 48.47

Diagnosis: PBS/IC

Inclusion criteria: patients with history of painful bladder syndrome/interstitial cystitis(PBS/IC) who had poor response or were refractory to previous treatment(s)

Exclusion criteria: not reported

Interventions
Group A ( $\mathbf{n}=\mathbf{3 0}): 800 \mathrm{mg} / 50 \mathrm{~mL}$ sodium hylauronic acid $(1.6 \%)+1 \mathrm{~g} / 50 \mathrm{~mL}$ sodium chondroitin sulfate $(2 \%)\left(\right.$ iAluRil $\left.^{\circledR}\right)$

Group B ( $\mathbf{n}=\mathbf{2 3}): 50 \mathrm{~mL}$ hyaluronic acid $\left(\right.$ Hyacyst $\left.^{\oplus}\right)$

Weekly in first month, once in 15 days in second month and monthly in third and fourth months, as total of 8 intravesical doses

Treatment category in NMA: chondroitin sulfate vs control

\begin{tabular}{|c|c|c|}
\hline \multirow[t]{6}{*}{ Outcomes } & \multicolumn{2}{|c|}{ Outcome data in analysis } \\
\hline & \multicolumn{2}{|c|}{ Pain: VAS (assumed 0 to 10 ): at 6 months } \\
\hline & \multicolumn{2}{|l|}{ Nocturia: at 6 months } \\
\hline & \multicolumn{2}{|l|}{ ICSI: at 6 months } \\
\hline & \multicolumn{2}{|l|}{ ICPI: at 6 months } \\
\hline & \multicolumn{2}{|c|}{ Adverse events: at 6 months } \\
\hline Funding & \multicolumn{2}{|l|}{ Not reported } \\
\hline Notes & \multicolumn{2}{|c|}{ Publication status: abstract } \\
\hline \multicolumn{3}{|l|}{ Risk of bias } \\
\hline Bias & Authors' judgement & Support for judgement \\
\hline $\begin{array}{l}\text { Random sequence genera- } \\
\text { tion (selection bias) }\end{array}$ & Unclear risk & Quote: "randomized" \\
\hline $\begin{array}{l}\text { Allocation concealment } \\
\text { (selection bias) }\end{array}$ & Unclear risk & No information provided \\
\hline $\begin{array}{l}\text { Blinding of participants } \\
\text { and personnel (perfor- } \\
\text { mance bias) } \\
\text { All outcomes }\end{array}$ & Unclear risk & $\begin{array}{l}\text { No information provided. Intravesical therapy of } 50 \mathrm{~mL} \text { chondroitin sulfate or } \\
\text { hyaluronic acid }\end{array}$ \\
\hline $\begin{array}{l}\text { Blinding of outcome as- } \\
\text { sessment (detection bias) } \\
\text { Subjective outcome }\end{array}$ & Unclear risk & No information provided \\
\hline $\begin{array}{l}\text { Incomplete outcome data } \\
\text { (attrition bias) } \\
\text { Pain }\end{array}$ & Unclear risk & Number analysed not stated \\
\hline
\end{tabular}

Interventions for treating people with symptoms of bladder pain syndrome: a network meta-analysis (Review) 
Gulpinar 2013 (Continued)

Incomplete outcome data Unclear risk Number analysed not stated
(attrition bias)

Nocturia

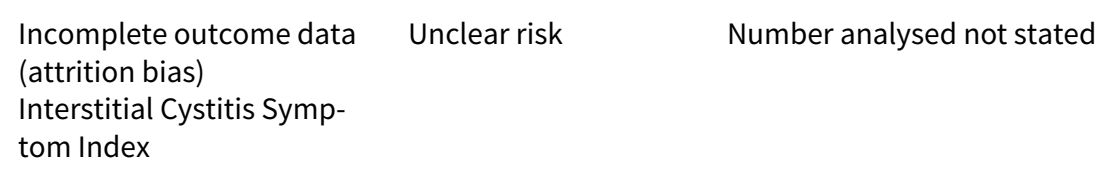

\begin{tabular}{lll}
\hline $\begin{array}{l}\text { Incomplete outcome data } \\
\text { (attrition bias) } \\
\text { Interstitial Cystitis Prob- }\end{array}$ & Unclear risk & \\
lem Index & \\
\hline $\begin{array}{l}\text { Incomplete outcome data } \\
\text { (attrition bias) } \\
\text { Adverse events }\end{array}$ & Unclear risk & Number analysed not stated \\
\hline $\begin{array}{l}\text { Selective reporting (re- } \\
\text { porting bias) }\end{array}$ & Low risk & Results included all outcomes specified in the methods section \\
\hline Other bias & Low risk & None detected \\
\hline
\end{tabular}

\section{Gulpinar 2015}

\section{Study characteristics}

\begin{tabular}{ll}
\hline Methods & Study design: RCT \\
& Study duration (months): 6
\end{tabular}

Participants Number randomised: 42

Setting: not reported

Country: Turkey

Sex: female

Age, years: mean 47.10 (SD 10.70) for Group A, mean 48.90 (SD 17.18) for Group B

Diagnosis: BPS/IC

Inclusion criteria: female patients with BPS/IC were included in the study. Patients with complaints of chronic pelvic pain related to bladder filling accompanied by voiding frequency $\geq 8$ times $/ 24 \mathrm{~h}$; nocturia $\geq 2$ times per night or persistent urge for at least 24 weeks; an average pain score of $\geq 4$ (VAS; 0 no pain, 10 unbearable pain); a negative pregnancy test; a sterile urine culture; and inadequate clinical response after 6 months of conservative and medical treatment were included in the study

Exclusion criteria: patients with positive pregnancy test, current urinary infection or sexually transmitted disease; chemical cystitis; tuberculous or radiation cystitis; urolithiasis; urological malignancy; or endometriosis or urethral diverticulum; breastfeeding women were excluded from the study

Interventions

Group A (n = 21): $800 \mathrm{mg} / 40 \mathrm{~mL}$ sodium chondroitin sulfate (Gepan Instill ${ }^{\circledR}$ )

Group B ( $\mathbf{n = 2 1 ) : 5 0 ~ m L / 1 2 0 ~ m g ~ h y a l u r o n i c ~ a c i d ~}\left(\right.$ Hyacyst $^{\circledR}$ )

Weekly in first month, once in 15 days in second month and monthly in third and fourth months, as total of 8 intravesical doses

Treatment category in NMA: chondroitin sulfate vs hyaluronic acid 
Gulpinar 2015 (Continued)
Outcomes
Outcome data in analysis
Cure or improvement: treatment response according to VAS pain score changes ('strong benefit' de-
fined as $>50 \%$ reduction in VAS score): at 6 months
Adverse events: at 6 months

\begin{tabular}{ll}
\hline Funding & Not reported \\
\hline Notes & Publication status: full text \\
\hline
\end{tabular}

Risk of bias

\begin{tabular}{|c|c|c|}
\hline Bias & Authors' judgement & Support for judgement \\
\hline $\begin{array}{l}\text { Random sequence genera- } \\
\text { tion (selection bias) }\end{array}$ & Unclear risk & Quote: "randomized" \\
\hline $\begin{array}{l}\text { Allocation concealment } \\
\text { (selection bias) }\end{array}$ & Unclear risk & No information provided \\
\hline $\begin{array}{l}\text { Blinding of participants } \\
\text { and personnel (perfor- } \\
\text { mance bias) } \\
\text { All outcomes }\end{array}$ & Unclear risk & $\begin{array}{l}\text { No information provided. Intravesical therapy of } 40 \mathrm{~mL} \text { chondroitin sulfate vs } \\
50 \mathrm{~mL} \text { hyaluronic acid }\end{array}$ \\
\hline $\begin{array}{l}\text { Blinding of outcome as- } \\
\text { sessment (detection bias) } \\
\text { Subjective outcome }\end{array}$ & Unclear risk & No information provided \\
\hline $\begin{array}{l}\text { Incomplete outcome data } \\
\text { (attrition bias) } \\
\text { Cure or improvement }\end{array}$ & Low risk & All randomised participants were included in analysis \\
\hline $\begin{array}{l}\text { Incomplete outcome data } \\
\text { (attrition bias) } \\
\text { Frequency }\end{array}$ & Low risk & \\
\hline $\begin{array}{l}\text { Incomplete outcome data } \\
\text { (attrition bias) } \\
\text { Adverse events }\end{array}$ & Low risk & All randomised participants were included in analysis \\
\hline $\begin{array}{l}\text { Selective reporting (re- } \\
\text { porting bias) }\end{array}$ & Low risk & Results included all outcomes specified in the methods section \\
\hline Other bias & Low risk & None detected \\
\hline
\end{tabular}

Ham 2012

\section{Study characteristics}

\begin{tabular}{ll}
\hline Methods & Study design: RCT \\
& Study duration (months): 3
\end{tabular}

Participants

Number randomised: 18 
Ham 2012 (Continued)

Setting: not reported

Country: Korea

Sex: female

Age, years: mean 54.5 (SD 9.1) for Group A, mean 56.9 (SD 7.8) for Group B, median 55.8 for whole group

Diagnosis: IC (NIDDK criteria)

Inclusion criteria: women with IC refractory to classic medical treatment

Exclusion criteria: not reported

Interventions

Group A ( $\mathbf{n}=\mathbf{8})$ : $50 \mathrm{~mL}$ resiniferatoxin (RTX) in 10\% ethanol + hydrodistension. (RTX = ultra potent analogue of chili pepper extract capsaicin)

Group B ( $=10)$ : hydrodistension

Treatment category in NMA: calcium channel agonists vs control

\begin{tabular}{ll}
\hline Outcomes & Outcome data in analysis \\
& Pain: VAS (range 0 to 5): at 3 months \\
& Frequency (mean voids/d): at 3 months \\
& Nocturia: at 3 months \\
& Functional bladder capacity: at 3 months \\
& Adverse events: at 3 months \\
\hline Funding & Not reported \\
\hline Notes & Publication status: full text \\
\hline
\end{tabular}

\section{Risk of bias}

\begin{tabular}{|c|c|c|}
\hline Bias & Authors' judgement & Support for judgement \\
\hline $\begin{array}{l}\text { Random sequence genera- } \\
\text { tion (selection bias) }\end{array}$ & Unclear risk & Quote: "randomized" \\
\hline $\begin{array}{l}\text { Allocation concealment } \\
\text { (selection bias) }\end{array}$ & Unclear risk & No information provided \\
\hline $\begin{array}{l}\text { Blinding of participants } \\
\text { and personnel (perfor- } \\
\text { mance bias) } \\
\text { All outcomes }\end{array}$ & Unclear risk & $\begin{array}{l}\text { Blinding not mentioned. Hydrodistension vs hydrodistension + intravexial RTX } \\
\text { "under general anesthesia" }\end{array}$ \\
\hline $\begin{array}{l}\text { Blinding of outcome as- } \\
\text { sessment (detection bias) } \\
\text { Subjective outcome }\end{array}$ & Unclear risk & $\begin{array}{l}\text { Blinding not mentioned. Hydrodistension vs hydrodistension + intravexial RTX } \\
\text { "under general anesthesia" }\end{array}$ \\
\hline
\end{tabular}

Blinding of outcome as- $\quad$ Low risk
$\begin{aligned} & \text { sessment (detection bias) } \\ & \text { Objective outcome }\end{aligned}$

Incomplete outcome data $\quad$ Unclear risk $\quad$ All randomised participants were included in analysis
(attrition bias)


Ham 2012 (Continued)

Pain

Incomplete outcome data Low risk All randomised participants were included in analysis
(attrition bias)

(attrition bias)

Frequency

\begin{tabular}{|c|c|c|}
\hline $\begin{array}{l}\text { Incomplete outcome data } \\
\text { (attrition bias) } \\
\text { Nocturia }\end{array}$ & Low risk & All randomised participants were included in analysis \\
\hline $\begin{array}{l}\text { Incomplete outcome data } \\
\text { (attrition bias) } \\
\text { Functional bladder capac- } \\
\text { ity }\end{array}$ & Low risk & All randomised participants were included in analysis \\
\hline $\begin{array}{l}\text { Incomplete outcome data } \\
\text { (attrition bias) } \\
\text { Adverse events }\end{array}$ & Low risk & All randomised participants were included in analysis \\
\hline $\begin{array}{l}\text { Selective reporting (re- } \\
\text { porting bias) }\end{array}$ & Low risk & Results included all outcomes specified in the methods section \\
\hline Other bias & Low risk & None detected \\
\hline
\end{tabular}

Hanno 2015

\section{Study characteristics}

\begin{tabular}{ll}
\hline Methods & Study design: RCT \\
& Study duration (months): 1
\end{tabular}

Participants Number randomised: 74

Setting: not reported

Country: USA

Sex: female

Age, years: not reported

Diagnosis: IC/PBS

Inclusion criteria: women 18 to 80 years of age who had clinical evidence of IC/BPS for at least 6 months with moderate to severe pain and urinary frequency

Exclusion criteria: not reported

\begin{tabular}{ll}
\hline Interventions & Group A $(\mathbf{n}=\mathbf{3 6}):$ AF-219 (P2X3 antagonist) \\
& Group B $(\mathbf{n}=\mathbf{3 8})$ : placebo \\
& Treatment category in NMA: P2X3 antagonist vs control \\
\hline Outcomes & Outcome data in analysis \\
& Pain: numerical pain rating scale (assumed range 0 to 10$):$ at 4 weeks \\
& Adverse events: at 4 weeks
\end{tabular}

Adverse events: at 4 weeks 
Hanno 2015 (Continued)

\begin{tabular}{ll} 
Funding & Not reported \\
\hline Notes & Publication status: abstract
\end{tabular}

\section{Risk of bias}

\begin{tabular}{|c|c|c|}
\hline Bias & Authors' judgement & Support for judgement \\
\hline $\begin{array}{l}\text { Random sequence genera- } \\
\text { tion (selection bias) }\end{array}$ & Unclear risk & Quote: "'randomized" \\
\hline $\begin{array}{l}\text { Allocation concealment } \\
\text { (selection bias) }\end{array}$ & Unclear risk & No information provided \\
\hline $\begin{array}{l}\text { Blinding of participants } \\
\text { and personnel (perfor- } \\
\text { mance bias) } \\
\text { All outcomes }\end{array}$ & Unclear risk & Participants randomised to an oral drug or placebo. Placebo not described \\
\hline $\begin{array}{l}\text { Blinding of outcome as- } \\
\text { sessment (detection bias) } \\
\text { Subjective outcome }\end{array}$ & Unclear risk & Participants randomised to an oral drug or placebo. Placebo not described \\
\hline $\begin{array}{l}\text { Incomplete outcome data } \\
\text { (attrition bias) } \\
\text { Pain }\end{array}$ & Unclear risk & Number analysed unclear \\
\hline $\begin{array}{l}\text { Incomplete outcome data } \\
\text { (attrition bias) } \\
\text { Adverse events }\end{array}$ & Unclear risk & Number analysed unclear \\
\hline $\begin{array}{l}\text { Selective reporting (re- } \\
\text { porting bias) }\end{array}$ & Unclear risk & Outcomes not specified in methods (abstract only) \\
\hline Other bias & Low risk & None detected \\
\hline
\end{tabular}

Herati 2011

\section{Study characteristics}

\begin{tabular}{ll}
\hline Methods & $\begin{array}{l}\text { Study design: RCT } \\
\text { Study duration (months): } 0.06 \text { (48 hours) }\end{array}$ \\
\hline Participants & Setting: not reported \\
Country: USA & Sex: not reported \\
& Age, years: not reported \\
& Diagnosis: IC/PBS \\
Inclusion criteria: consecutive IC/PBS patients \\
Exclusion criteria: not reported
\end{tabular}


Herati 2011 (Continued)

Number randomised: 30

\begin{tabular}{|c|c|c|}
\hline Interventions & \multicolumn{2}{|c|}{$\begin{array}{l}\text { Group A }(n=14) \text { : caffeine } 100 \mathrm{mg} \\
\text { Group B }(\mathbf{n = 1 6 )} \text { : placebo } \\
\text { Treatment category in NMA: caffeine vs control }\end{array}$} \\
\hline Outcomes & \multicolumn{2}{|c|}{ Outcome data in analysis - no usable data } \\
\hline Funding & \multicolumn{2}{|c|}{ The Fishbein Family IC Research Foundation Grant } \\
\hline Notes & \multicolumn{2}{|c|}{ Publication status: abstract } \\
\hline \multicolumn{3}{|l|}{ Risk of bias } \\
\hline Bias & Authors' judgement & Support for judgement \\
\hline $\begin{array}{l}\text { Random sequence genera- } \\
\text { tion (selection bias) }\end{array}$ & Low risk & $\begin{array}{l}\text { Quote: "randomized ... using a four block randomization scheme" } \\
\text { Comment: probably done }\end{array}$ \\
\hline $\begin{array}{l}\text { Allocation concealment } \\
\text { (selection bias) }\end{array}$ & Unclear risk & No information provided \\
\hline $\begin{array}{l}\text { Blinding of participants } \\
\text { and personnel (perfor- } \\
\text { mance bias) } \\
\text { All outcomes }\end{array}$ & Unclear risk & $\begin{array}{l}\text { "placebo-controlled, double-blind study", using a pill or placebo. Placebo not } \\
\text { described }\end{array}$ \\
\hline $\begin{array}{l}\text { Blinding of outcome as- } \\
\text { sessment (detection bias) } \\
\text { Subjective outcome }\end{array}$ & Unclear risk & "double-blind", using a pill or placebo. Placebo not described \\
\hline $\begin{array}{l}\text { Selective reporting (re- } \\
\text { porting bias) }\end{array}$ & High risk & ICPI listed in methods but not reported in results \\
\hline Other bias & Low risk & None detected \\
\hline
\end{tabular}

Hsieh 2012

\section{Study characteristics}

\begin{tabular}{ll}
\hline Methods & $\begin{array}{l}\text { Study design: } \mathrm{RCT} \\
\text { Study duration (months): } 6\end{array}$ \\
\hline Participants & Number randomised: 70 \\
& Setting: not reported \\
& Country: Taiwan \\
Sex: not reported \\
Age, years: mean 45.9 (SD 7.8) for Group A, mean 46.1 (SD 7.6) for Group B \\
Diagnosis: IC (NIDDK criteria) \\
Inclusion criteria: patients with IC
\end{tabular}


Hsieh 2012 (Continued)

Exclusion criteria: not reported

Interventions Group A $(\mathbf{n}=\mathbf{3 5})$ : hydrodistension plus bladder training (talk with physician, attempt to increase intervoid interval)

Group B ( $\mathbf{n}=\mathbf{3 5}$ ): hydrodistension (bladder filled with normal saline to maximal capacity at pressure of $80 \mathrm{cmh}^{2}$ )

Treatment category in NMA: behavioural therapy vs control

Outcomes data in analysis
Frequency: at 24 weeks
Nocturia: at 24 weeks

Funding Not reported

Notes Publication status: full text

\section{Risk of bias}

\begin{tabular}{lll}
\hline Bias & Authors' judgement & Support for judgement \\
\hline $\begin{array}{l}\text { Random sequence genera- } \\
\text { tion (selection bias) }\end{array}$ & Unclear risk & Quote: "randomly assigned" \\
\hline
\end{tabular}

tion (selection bias)

\begin{tabular}{ll}
\hline $\begin{array}{l}\text { Allocation concealment } \\
\text { (selection bias) }\end{array}$ & Unclear risk information provided
\end{tabular}

\begin{tabular}{lll}
\hline $\begin{array}{l}\text { Blinding of participants } \\
\text { and personnel (perfor- }\end{array}$ & High risk & Hydrodistension (HD) + bladder training (BT) vs HD. Probably not done
\end{tabular}
and personnel (performance bias)

All outcomes

\begin{tabular}{|c|c|c|}
\hline $\begin{array}{l}\text { Blinding of outcome as- } \\
\text { sessment (detection bias) } \\
\text { Subjective outcome }\end{array}$ & High risk & Hydrodistension (HD) + bladder training (BT) vs HD. Probably not done \\
\hline $\begin{array}{l}\text { Incomplete outcome data } \\
\text { (attrition bias) } \\
\text { Frequency }\end{array}$ & High risk & $\begin{array}{l}28 / 35(80 \%) \text { included in } \mathrm{HD}+\mathrm{BT} \text { group; } 23 / 35(66 \%) \text { included in HD group. } \\
\text { Missing data due to participants unable to return to follow-up or provide uri- } \\
\text { nary diaries }\end{array}$ \\
\hline $\begin{array}{l}\text { Incomplete outcome data } \\
\text { (attrition bias) } \\
\text { Nocturia }\end{array}$ & High risk & $\begin{array}{l}28 / 35(80 \%) \text { included in } \mathrm{HD}+\mathrm{BT} \text { group; } 23 / 35(66 \%) \text { included in HD group. } \\
\text { Missing data due to participants unable to return to follow-up or provide uri- } \\
\text { nary diaries }\end{array}$ \\
\hline
\end{tabular}

Selective reporting (re- Low risk Results included all outcomes specified in the methods section
porting bias)

\begin{tabular}{lll}
\hline Other bias $\quad$ Low risk $\quad$ None detected
\end{tabular}

Irani 2004

\section{Study characteristics}

Methods Study design: RCT


Irani 2004 (Continued)

\section{Study duration (months): 24}

Number randomised: 30
Setting: multi-centre (assumed from reports)
Country: Iran
Sex: female
Age, years: mean 40.8 (SD 13.96) for Group A, mean 36 (SD 12.84) for Group B
Diagnosis: IC (NIDDK criteria)

Inclusion criteria: met NIDDK diagnostic criteria, selected from among women with irritative symptoms and bladder pain, post cystoscopy under anaesthesia, bladder hydrodistension, other preliminary evaluations

Exclusion criteria: immunocompromising conditions; steroid, warfarin or immunosuppressant administration; pregnancy; vesicoureteral reflux; history of intravesical instillation in the last 3 months; positive HIV serology; positive cutaneous PPD; males (due to risk of catheterisation)

$\begin{array}{ll}\text { Interventions } & \text { Group A }(\mathbf{n}=\mathbf{1 5}): 120 \mathrm{mg} \text { bacillus Calmette-Guérin }(\mathrm{BCG}) \\ & \text { Group B }(\mathbf{n}=\mathbf{1 5}): 50 \mathrm{cc} \mathrm{NaCl} \\ & \text { Treatment category in NMA: immune modulators vs control }\end{array}$

\begin{tabular}{ll}
\hline Outcomes & Outcome data in analysis \\
Cure or improvement: 'responded to treatment' defined as over $40 \%$ improvement in valid scores of \\
Wisconsin University for interstitial cystitis at 24 months
\end{tabular}

Pain: pelvic pain VAS (10 cm rulers) at 24 months

Frequency: at 24 months

Functional bladder capacity: at 24 months

Adverse effects: at 24 months

\begin{tabular}{ll}
\hline Funding & Not reported \\
\hline Notes & Publication status: full text \\
\hline
\end{tabular}

\section{Risk of bias}

\begin{tabular}{|c|c|c|}
\hline Bias & Authors' judgement & Support for judgement \\
\hline $\begin{array}{l}\text { Random sequence genera- } \\
\text { tion (selection bias) }\end{array}$ & Unclear risk & Quote: "randomized" \\
\hline $\begin{array}{l}\text { Allocation concealment } \\
\text { (selection bias) }\end{array}$ & Low risk & $\begin{array}{l}\text { Quote: "... nominating the drugs and listing the patients were done by a third } \\
\text { person not enrolled in the study" }\end{array}$ \\
\hline $\begin{array}{l}\text { Blinding of participants } \\
\text { and personnel (perfor- } \\
\text { mance bias) } \\
\text { All outcomes }\end{array}$ & Low risk & $\begin{array}{l}\text { "double-blind", "placebo-controlled" study, using "vials of placebo with sim- } \\
\text { ilar appearance", "vials nominated blindly as drugs A and B"; "the staff who } \\
\text { were involved with the therapy were blind to the drug type" }\end{array}$ \\
\hline $\begin{array}{l}\text { Blinding of outcome as- } \\
\text { sessment (detection bias) } \\
\text { Subjective outcome }\end{array}$ & Low risk & $\begin{array}{l}\text { "double-blind", "placebo-controlled" study, using "vials of placebo with sim- } \\
\text { ilar appearance", "vials nominated blindly as drugs A and B"; "the staff who } \\
\text { were involved with the therapy were blind to the drug type" }\end{array}$ \\
\hline
\end{tabular}


Irani 2004 (Continued)

Blinding of outcome as- Low risk Outcome measurement is not likely to be influenced by lack of blinding sessment (detection bias)

Objective outcome

\begin{tabular}{lll}
\hline $\begin{array}{l}\text { Incomplete outcome data } \\
\text { (attrition bias) } \\
\text { Cure or improvement }\end{array}$ & Low risk & \\
\hline $\begin{array}{l}\text { Incomplete outcome data } \\
\text { (attrition bias) }\end{array}$ & Low risk & All randomised participants were included in analysis \\
Pain & \\
\hline $\begin{array}{l}\text { Incomplete outcome data } \\
\text { (attrition bias) }\end{array}$ & Low risk & All randomised participants were included in analysis \\
$\begin{array}{l}\text { Frequency } \\
\text { Incomplete outcome data }\end{array}$ & Low risk & \\
$\begin{array}{l}\text { (attrition bias) } \\
\text { Functional bladder capac- }\end{array}$ & & All randomised participants were included in analysis \\
\hline $\begin{array}{l}\text { Incomplete outcome data } \\
\text { (attrition bias) } \\
\text { Adverse events }\end{array}$ & Low risk & \\
\hline $\begin{array}{l}\text { Selective reporting (re- } \\
\text { porting bias) }\end{array}$ & Low risk & All randomised participants were included in analysis \\
\hline \begin{tabular}{l} 
Other bias \\
\hline
\end{tabular} & Low risk & Results included all outcomes specified in the methods section \\
\hline
\end{tabular}

Ismail 2016

\section{Study characteristics}

\begin{tabular}{ll}
\hline Methods & $\begin{array}{l}\text { Study design: RCT } \\
\text { Study duration (months): } 2\end{array}$ \\
\hline Participants & Number randomised: 30 \\
& Setting: not reported \\
& Country: not reported \\
& Sex: 26 females and 4 males \\
Age, years: range 17 to 45 \\
Diagnosis: IC/BPS \\
Inclusion criteria: patients diagnosed to have IC/BPS \\
Exclusion criteria: not reported \\
Group A ( $\mathbf{n}=\mathbf{1 5}$ ): intravesical 100 U botulinum toxin A injected into trigone under general anaesthesia \\
Group B ( $\mathbf{n}=\mathbf{1 5}$ ): equivalent amount of normal saline \\
Treatment category in NMA: neuromuscular blockade vs control \\
\hline Onterventions & Outcome data in analysis \\
\hline Outcomes &
\end{tabular}


Ismail 2016 (Continued)

Adverse events: at 0.5 months

\begin{tabular}{ll}
\hline Funding & Not reported \\
\hline Notes & Publication status: abstract \\
\hline
\end{tabular}

\section{Risk of bias}

\begin{tabular}{|c|c|c|}
\hline Bias & Authors' judgement & Support for judgement \\
\hline $\begin{array}{l}\text { Random sequence genera- } \\
\text { tion (selection bias) }\end{array}$ & Unclear risk & Quote: "randomized" \\
\hline $\begin{array}{l}\text { Allocation concealment } \\
\text { (selection bias) }\end{array}$ & Unclear risk & No information provided \\
\hline $\begin{array}{l}\text { Blinding of participants } \\
\text { and personnel (perfor- } \\
\text { mance bias) } \\
\text { All outcomes }\end{array}$ & Unclear risk & $\begin{array}{l}\text { Quote: "single-blinded". Unclear who is blinded and how. Intravesical instil- } \\
\text { lation of BoNT-A or "the equivalent amount of normal saline" under general } \\
\text { anaesthesia }\end{array}$ \\
\hline $\begin{array}{l}\text { Blinding of outcome as- } \\
\text { sessment (detection bias) } \\
\text { Subjective outcome }\end{array}$ & Unclear risk & $\begin{array}{l}\text { Quote: "single-blinded". Unclear who is blinded and how. Intravesical instil- } \\
\text { lation of BoNT-A or "the equivalent amount of normal saline" under general } \\
\text { anaesthesia }\end{array}$ \\
\hline $\begin{array}{l}\text { Incomplete outcome data } \\
\text { (attrition bias) } \\
\text { Adverse events }\end{array}$ & Unclear risk & Number analysed not stated \\
\hline $\begin{array}{l}\text { Selective reporting (re- } \\
\text { porting bias) }\end{array}$ & Low risk & Results included all outcomes specified in the methods section \\
\hline Other bias & Low risk & None detected \\
\hline
\end{tabular}

Kanter 2016

\section{Study characteristics}

\begin{tabular}{ll}
\hline Methods & Study design: RCT \\
& Study duration (months): 2 \\
\hline Participants & Number randomised: 20 \\
& Setting: not reported \\
Country: USA & Sex: female \\
Age, years: mean 46.3 (SD 15.2) for Group A, mean 44.4 (SD 13.9) for Group B \\
Diagnosis: IC/BPS (American Urological Association criteria) \\
Inclusion criteria: patients with IC/BPS. Negative urinalysis or urine culture within 2 months of enrol- \\
ment and ability to speak and understand English. We recruited only patients who were currently un- \\
dergoing first- or second-line treatments, as defined by the AUA (American Urological Association), and \\
who had not made changes in their IC/BPS treatment regimen within 4 weeks of beginning their as- \\
signed intervention. First-line treatments include relaxation/stress management, pain management
\end{tabular}


Kanter 2016 (Continued)

and self-care/behavioural modification. Second-line therapy involves physical therapy, in addition to oral or intravesical medications

Exclusion criteria: patients who were treatment-naïve or undergoing third-line or higher treatments at the time of enrolment; patients with unevaluated haematuria, urinary retention, history of cystectomy, augmentation cystoplasty or urinary diversion; history of radiation- or chemotherapy-induced cystitis or pregnant or lactating

Interventions

Group A ( $\mathbf{n}=\mathbf{9}$ ): 8-week group mindfulness-based stress reduction meditation programme (seven 2 hour courses, every week, with all-day retreat in 5th week) plus current care regimen. Also given 4-CD guide and a book

Group B ( $\mathbf{n}=\mathbf{1 1})$ : usual care

Treatment category in NMA: behavioural therapy vs control

Outcome data in analysis
Cure or improvement: Global Response Assessment as 'being improved'. Not clear whether this is de-
fined as 'moderate' and 'marked' improvement or 'moderate', 'marked' and 'slight' improvement: at 8
weeks
Pain: VAS (assumed range 0 to 10): at 8 weeks
ICSI: at 8 weeks
ICPI: at 8 weeks

\begin{tabular}{ll}
\hline Funding & National Center for Research Resources and National Center for Advancing Translational Sciences of \\
the NIH (grant \# ULI TR001449)
\end{tabular}
the NIH (grant \# ULI TR001449)

Notes Publication status: full text

\section{Risk of bias}

\begin{tabular}{|c|c|c|}
\hline Bias & Authors' judgement & Support for judgement \\
\hline $\begin{array}{l}\text { Random sequence genera- } \\
\text { tion (selection bias) }\end{array}$ & Low risk & Quote: "randomized ... by a computer-generated sequence" \\
\hline $\begin{array}{l}\text { Allocation concealment } \\
\text { (selection bias) }\end{array}$ & Low risk & $\begin{array}{l}\text { Quote: "allocation was concealed in serially numbered, opaque, sealed en- } \\
\text { velopes" }\end{array}$ \\
\hline $\begin{array}{l}\text { Blinding of participants } \\
\text { and personnel (perfor- } \\
\text { mance bias) } \\
\text { All outcomes }\end{array}$ & High risk & Probably not done. Stress reduction class + usual care vs usual care \\
\hline $\begin{array}{l}\text { Blinding of outcome as- } \\
\text { sessment (detection bias) } \\
\text { Subjective outcome }\end{array}$ & High risk & Probably not done. Stress reduction class + usual care vs usual care \\
\hline $\begin{array}{l}\text { Incomplete outcome data } \\
\text { (attrition bias) } \\
\text { Cure or improvement }\end{array}$ & High risk & $\begin{array}{l}8 / 9(89 \%) \text { included in intervention group ( } 1 \text { lost to follow-up before interven- } \\
\text { tion); } 11 / 11 \text { in control group }\end{array}$ \\
\hline $\begin{array}{l}\text { Incomplete outcome data } \\
\text { (attrition bias) } \\
\text { Pain }\end{array}$ & High risk & $\begin{array}{l}8 / 9(89 \%) \text { included in intervention group ( } 1 \text { lost to follow-up before interven- } \\
\text { tion); } 11 / 11 \text { in control group }\end{array}$ \\
\hline
\end{tabular}


Kanter 2016 (Continued)

\begin{tabular}{|c|c|c|}
\hline $\begin{array}{l}\text { Incomplete outcome data } \\
\text { (attrition bias) }\end{array}$ & High risk & $\begin{array}{l}8 / 9(89 \%) \text { included in intervention group (1 lost to follow-up before interven- } \\
\text { tion); } 11 / 11 \text { in control group }\end{array}$ \\
\hline
\end{tabular}

Interstitial Cystitis Symp-

tom Index

\begin{tabular}{|c|c|c|}
\hline $\begin{array}{l}\text { Incomplete outcome data } \\
\text { (attrition bias) }\end{array}$ & High risk & $\begin{array}{l}8 / 9(89 \%) \text { included in intervention group ( } 1 \text { lost to follow-up before interven- } \\
\text { tion); } 11 / 11 \text { in control group }\end{array}$ \\
\hline
\end{tabular}

Interstitial Cystitis Prob-

lem Index

\begin{tabular}{lll}
\hline $\begin{array}{l}\text { Selective reporting (re- } \\
\text { porting bias) }\end{array}$ & Low risk & Results included all outcomes specified in the methods section \\
\hline Other bias & Low risk & None detected \\
\hline
\end{tabular}

Kasyan 2012

\section{Study characteristics}

\begin{tabular}{|c|c|}
\hline Methods & $\begin{array}{l}\text { Study design: } \mathrm{RCT} \\
\text { Study duration (months): } 3\end{array}$ \\
\hline \multirow[t]{8}{*}{ Participants } & Number randomised: 32 \\
\hline & Setting: not reported \\
\hline & Country: Russia \\
\hline & Sex: female \\
\hline & Age, years: not reported \\
\hline & Diagnosis: BPS/IC \\
\hline & Inclusion criteria: female patients with BPS/IC \\
\hline & Exclusion criteria: not reported \\
\hline \multirow[t]{3}{*}{ Interventions } & Group A ( $\mathbf{n}=\mathbf{1 5})$ : $100 \mathrm{IU}$ of botulinum toxin $\mathrm{A}$ in $10 \mathrm{~mL}$ of $\mathrm{NaCl}$ into the trigone \\
\hline & Group B $(\mathbf{n}=\mathbf{1 7})$ : hydrodistension \\
\hline & Treatment category in NMA: neuromuscular blockade vs hydrodistension \\
\hline \multirow[t]{5}{*}{ Outcomes } & Outcome data in analysis \\
\hline & Pain: 10-point VAS (unclear minimum/maximum score): at 3 months \\
\hline & ICSI: at 3 months \\
\hline & ICPI: at 3 months \\
\hline & Adverse events: at 3 months \\
\hline Funding & None \\
\hline Notes & Publication status: abstract \\
\hline Risk of bias & \\
\hline
\end{tabular}


Kasyan 2012 (Continued)

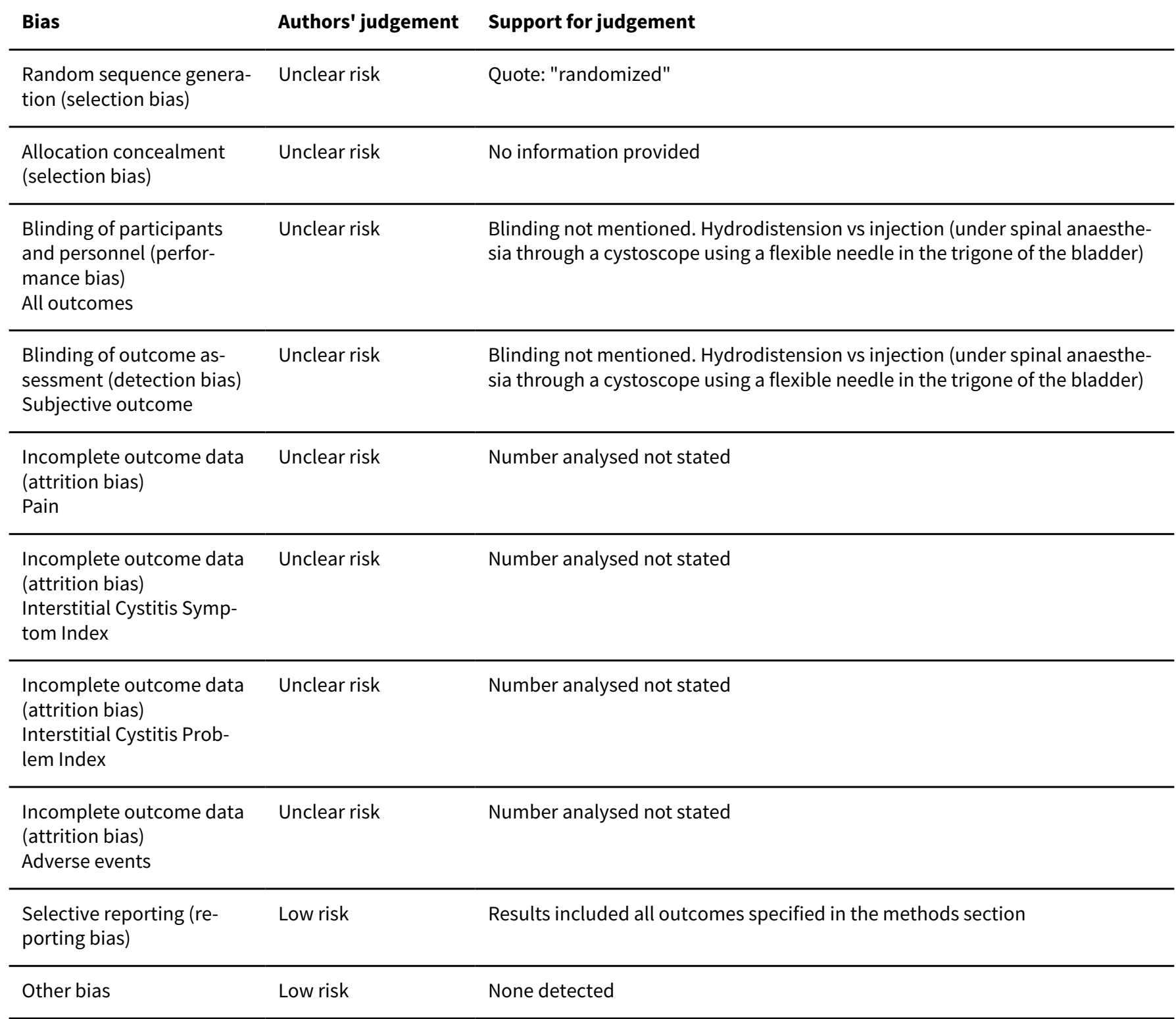

Kim 2012

\section{Study characteristics}

\begin{tabular}{ll}
\hline Methods & $\begin{array}{l}\text { Study design: } \mathrm{RCT} \\
\text { Study duration (months): } 3\end{array}$ \\
\hline Participants & Number randomised: 18 \\
& Setting: not reported \\
& Country: Korea \\
Sex: not reported \\
Age, years: median $55.8 \pm 6.9$ (unknown whether IQR) \\
Diagnosis: PBS/IC
\end{tabular}


Kim 2012 (Continued)

Inclusion criteria: consecutive patients with proven PBS/IC refractory to traditional medical treatment

Exclusion criteria: not reported

Interventions Group $\mathbf{A}(\mathbf{n}=$ not reported): resiniferatoxin $(\mathrm{RTX})+$ hydrodistension $(\mathrm{RTX}=\mathrm{ultra}$ potent analogue of
chili pepper extract capsaicin)

Group B ( $\mathbf{n}=$ not reported): hydrodistension

Treatment category in NMA: calcium channel agonists vs control

\begin{tabular}{ll}
\hline Outcomes & Outcome data in analysis - no usable data \\
\hline Funding & $\begin{array}{l}\text { Industrial Source Technology Development Programme of the Ministry of Knowledge Economy (MKE) } \\
\text { of Korea and the National Research Foundation of Korea (NRF) grant funded by the Korean government }\end{array}$
\end{tabular}

Notes $\quad$ Publication status: abstract

\section{Risk of bias}

\begin{tabular}{|c|c|c|}
\hline Bias & Authors' judgement & Support for judgement \\
\hline $\begin{array}{l}\text { Random sequence genera- } \\
\text { tion (selection bias) }\end{array}$ & Unclear risk & Quote: "randomized" \\
\hline $\begin{array}{l}\text { Allocation concealment } \\
\text { (selection bias) }\end{array}$ & Unclear risk & No information provided. \\
\hline $\begin{array}{l}\text { Blinding of participants } \\
\text { and personnel (perfor- } \\
\text { mance bias) } \\
\text { All outcomes }\end{array}$ & Unclear risk & $\begin{array}{l}\text { Blinding not mentioned. Hydrodistension + intravesical RTX vs hydrodisten- } \\
\text { sion }\end{array}$ \\
\hline $\begin{array}{l}\text { Blinding of outcome as- } \\
\text { sessment (detection bias) } \\
\text { Subjective outcome }\end{array}$ & Unclear risk & $\begin{array}{l}\text { Blinding not mentioned. Hydrodistension + intravesical RTX vs hydrodisten- } \\
\text { sion }\end{array}$ \\
\hline $\begin{array}{l}\text { Selective reporting (re- } \\
\text { porting bias) }\end{array}$ & Low risk & Results included all outcomes specified in the methods section \\
\hline Other bias & Low risk & None detected \\
\hline
\end{tabular}

Kim 2015

\begin{tabular}{ll}
\hline Study characteristics & $\begin{array}{l}\text { Study design: RCT } \\
\text { Study duration (months): } 1\end{array}$ \\
\hline Methods & Number randomised: 38 \\
\hline Participants & Setting: multi-centre \\
& Country: Korea \\
& Age, years: mean 63.76 (SD 7.70) for Group A, mean 63.62 (SD 9.34) for Group B \\
& Diagnosis: IC/PBS \\
\hline
\end{tabular}


Kim 2015 (Continued)

Inclusion criteria: patients who have had symptoms of IC/BPS for at least 6 months and had Hunner's lesion

Exclusion criteria: not reported

Interventions

Group A ( $\mathbf{n}=\mathbf{2 1})$ : transurethral fulguration

Group B ( $\mathbf{n} \mathbf{1 7})$ : hydrodistension

Treatment category in NMA: fulguration vs hydrodistension

\begin{tabular}{ll}
\hline Outcomes & Outcome data in analysis \\
& Pain: VAS (assumed range 0 to 10$):$ at 1 month
\end{tabular}

\begin{tabular}{ll}
\hline Funding & Not reported \\
\hline Notes & $\begin{array}{l}\text { Publication status: abstract } \\
\text { Trial stopped early: "... the authors felt a clear superiority of one procedure over the other and enroll- } \\
\text { ment after the 38th patient was stopped for ethical reasons" }\end{array}$ \\
\hline
\end{tabular}

\section{Risk of bias}

\begin{tabular}{|c|c|c|}
\hline Bias & Authors' judgement & Support for judgement \\
\hline $\begin{array}{l}\text { Random sequence genera- } \\
\text { tion (selection bias) }\end{array}$ & Unclear risk & Quote: "randomly divided". \\
\hline $\begin{array}{l}\text { Allocation concealment } \\
\text { (selection bias) }\end{array}$ & Unclear risk & No information provided \\
\hline $\begin{array}{l}\text { Blinding of participants } \\
\text { and personnel (perfor- } \\
\text { mance bias) } \\
\text { All outcomes }\end{array}$ & High risk & Probably not done. Fulguration vs hydrodistension (HD) \\
\hline $\begin{array}{l}\text { Blinding of outcome as- } \\
\text { sessment (detection bias) } \\
\text { Subjective outcome }\end{array}$ & High risk & Probably not done. Fulguration vs hydrodistension (HD) \\
\hline $\begin{array}{l}\text { Incomplete outcome data } \\
\text { (attrition bias) } \\
\text { Pain }\end{array}$ & Unclear risk & $\begin{array}{l}\text { Number analysed not stated. } 7 / 21 \text { (33\%) dropped out from fulguration group; } \\
11 / 17(64 \%) \text { dropped out from HD group. Unclear how missing data were han- } \\
\text { dled }\end{array}$ \\
\hline $\begin{array}{l}\text { Selective reporting (re- } \\
\text { porting bias) }\end{array}$ & Low risk & Results included all outcomes specified in the methods section \\
\hline Other bias & Low risk & None detected \\
\hline
\end{tabular}

Korting 1999

\section{Study characteristics}

\begin{tabular}{ll}
\hline Methods & Study design: RCT \\
Study duration (months): 3
\end{tabular}


Korting 1999 (Continued)

Setting: not reported

Country: USA

Sex: not reported

Age, years: mean 46.6 (SD 14.3) for Group A ( $n=21)$, mean 52.7 (SD 13.6) for Group B ( $n=26)$, mean 56.3 (SD 10.2) for Group A withdrawals $(n=6)$

Diagnosis: IC (NIH criteria)

Inclusion criteria: female patients with IC

Exclusion criteria: male sex, pregnancy or unreliable plans for avoiding pregnancy, unstable medical condition, prior use of L-arginine

$\begin{array}{ll}\text { Interventions } & \text { Group A }(\mathbf{n}=\mathbf{2 7}) \text { : L-arginine } 500 \mathrm{mg} \text { TDS for } 3 \text { months } \\ \text { Group B }(\mathbf{n}=\mathbf{2 6}) \text { : placebo }\end{array}$

Treatment category in NMA: amino acid vs control

\begin{tabular}{ll}
\hline Outcomes & Outcome data in analysis \\
Cure or improvement: change for the better in overall symptoms on 2 questionnaires: at 3 months \\
Frequency per day: at 3 months \\
Nocturia: at 3 months \\
Adverse events: at 3 months \\
\hline Funding & Not reported \\
\hline Notes & Publication status: full text
\end{tabular}

\section{Risk of bias}

\begin{tabular}{lll}
\hline Bias & Authors' judgement & Support for judgement \\
\hline $\begin{array}{l}\text { Random sequence genera- } \\
\text { tion (selection bias) }\end{array}$ & Low risk & Quote: "'simple block randomization ... using a random numbers table" \\
\hline $\begin{array}{l}\text { Allocation concealment } \\
\text { (selection bias) }\end{array}$ & Low risk & $\begin{array}{l}\text { Randomisation "was performed by the Investigational Drug Service of the Yale } \\
\text { New Haven Hospital Pharmacy"; "the researchers and patients were blinded } \\
\text { to patient assignment until after completion of the trial and all followup inter- } \\
\text { views". Probably done }\end{array}$
\end{tabular}

\begin{tabular}{ll}
\hline $\begin{array}{l}\text { Blinding of participants } \\
\text { and personnel (perfor- }\end{array}$ & "double-blind"; participants received study drug or "identical appearing \\
mance bias) & placebo ... capsules" \\
All outcomes &
\end{tabular}

\begin{tabular}{|c|c|c|}
\hline $\begin{array}{l}\text { Blinding of outcome as- } \\
\text { sessment (detection bias) } \\
\text { Subjective outcome }\end{array}$ & Low risk & $\begin{array}{l}\text { "double-blind"; participants received study drug or "identical appearing } \\
\text { placebo ... capsules" }\end{array}$ \\
\hline
\end{tabular}

\begin{tabular}{ll}
\hline $\begin{array}{l}\text { Incomplete outcome data } \\
\text { (attrition bias) } \\
\text { Cure or improvement }\end{array}$ & $\begin{array}{l}\text { Reviewers extracted per-protocol analysis data. 21/27 (78\%) included in inter- } \\
\text { vention group; 26/26 included in control group }\end{array}$ \\
\hline
\end{tabular}

Incomplete outcome data Low risk (attrition bias)

Number analysed not stated, but "an intention to treat analysis ... was performed ... using the methods suggested by Lewis and Machin" 
Korting 1999 (Continued)

Frequency

$\begin{array}{ll}\begin{array}{l}\text { Incomplete outcome data } \\ \text { (attrition bias) }\end{array} & \text { Low risk } \\ \text { formed ... using the methods suggested by Lewis and Machin" }\end{array}$

Nocturia

\begin{tabular}{lll}
\hline $\begin{array}{l}\text { Incomplete outcome data } \\
\text { (attrition bias) } \\
\text { Adverse events }\end{array}$ & High risk & $\begin{array}{l}\text { 21/27 (78\%) included in intervention group (6 withdrew); 25/26 included in } \\
\text { control group (1 withdrew) }\end{array}$ \\
\hline $\begin{array}{l}\text { Selective reporting (re- } \\
\text { porting bias) }\end{array}$ & Low risk & Results included all outcomes specified in the methods section \\
\hline Other bias & Low risk & None detected \\
\hline
\end{tabular}

Kuo 2009

\title{
Study characteristics
}

\begin{tabular}{ll}
\hline Methods & $\begin{array}{l}\text { Study design: RCT } \\
\text { Study duration (months): } 24\end{array}$
\end{tabular}

Participants

Number randomised: 70

Setting: not reported

Country: Taiwan

Sex: 56 females and 11 males

Age, years: not reported

Diagnosis: IC/PBS

Inclusion criteria: patients with IC/PBS who had failed conventional treatments

Exclusion criteria: not reported

Interventions

Group A ( $\mathbf{n}=\mathbf{4 6}$ ): botulinum toxin A (100 or 200 units) + hydrodistension 2 weeks later. In Group A, 15 patients: 200 IU botox, 29 patients: 100 IU botox

Group B ( $\mathbf{n} \mathbf{2 4})$ : hydrodistension

All patients continued with oral pentosan polysulfate during the trial

Treatment category in NMA: neuromuscular blockade vs control

\section{Outcomes}

\author{
Outcome data in analysis \\ Cure or improvement: 'moderately' or 'markedly' improved on GRA: at 12 months \\ Pain: 10-point VAS (unclear minimum/maximum score): at 3 months \\ Daytime frequency: at 3 months \\ Nocturia: at 3 months \\ ICSI: at 3 months \\ ICPI: at 3 months \\ Functional bladder capacity: at 3 months
}


Kuo 2009 (Continued)

Adverse events: at > 6 months

\begin{tabular}{ll}
\hline Funding & Not reported. One of the study authors is a consultant and investigator for Allergan \\
\hline Notes & Publication status: full text
\end{tabular}

\section{Risk of bias}

\begin{tabular}{|c|c|c|}
\hline Bias & Authors' judgement & Support for judgement \\
\hline $\begin{array}{l}\text { Random sequence genera- } \\
\text { tion (selection bias) }\end{array}$ & Unclear risk & Quote: "randomly assigned" \\
\hline $\begin{array}{l}\text { Allocation concealment } \\
\text { (selection bias) }\end{array}$ & Unclear risk & No information provided \\
\hline $\begin{array}{l}\text { Blinding of participants } \\
\text { and personnel (perfor- } \\
\text { mance bias) } \\
\text { All outcomes }\end{array}$ & High risk & $\begin{array}{l}\text { Sub-urothelial injection of BoNT-A followed by cystoscopic hydrodistension } \\
\text { (HD) } 2 \text { weeks later vs cystoscopic HD using "similar methods as in BoNT-A } \\
\text { groups" } \\
\text { Unclear if HD was repeated } 2 \text { weeks later in HD group. Blinding probably not } \\
\text { done }\end{array}$ \\
\hline $\begin{array}{l}\text { Blinding of outcome as- } \\
\text { sessment (detection bias) } \\
\text { Subjective outcome }\end{array}$ & High risk & $\begin{array}{l}\text { Sub-urothelial injection of BoNT-A followed by cystoscopic hydrodistension } \\
\text { (HD) } 2 \text { weeks later vs cystoscopic HD using "similar methods as in BoNT-A } \\
\text { groups" } \\
\text { Unclear if HD was repeated } 2 \text { weeks later in HD group. Blinding probably not } \\
\text { done }\end{array}$ \\
\hline
\end{tabular}

Blinding of outcome as-
sessment (detection bias) $\quad$ Low risk Outcome measurement is not likely to be influenced by lack of blinding

sessment (detection bias)

Objective outcome

\begin{tabular}{|c|c|c|}
\hline $\begin{array}{l}\text { Incomplete outcome data } \\
\text { (attrition bias) } \\
\text { Cure or improvement }\end{array}$ & Low risk & $\begin{array}{l}44 / 46(96 \%) \text { included in intervention group ( } 2 \text { refused treatment on the day it } \\
\text { was scheduled); } 23 / 24(96 \%) \text { included in control group ( } 1 \text { refused treatment on } \\
\text { the day it was scheduled) }\end{array}$ \\
\hline $\begin{array}{l}\text { Incomplete outcome data } \\
\text { (attrition bias) } \\
\text { Pain }\end{array}$ & Low risk & $\begin{array}{l}44 / 46(96 \%) \text { included in intervention group ( } 2 \text { refused treatment on the day it } \\
\text { was scheduled); } 23 / 24(96 \%) \text { included in control group ( } 1 \text { refused treatment on } \\
\text { the day it was scheduled) }\end{array}$ \\
\hline $\begin{array}{l}\text { Incomplete outcome data } \\
\text { (attrition bias) } \\
\text { Frequency }\end{array}$ & Low risk & $\begin{array}{l}44 / 46(96 \%) \text { included in intervention group ( } 2 \text { refused treatment on the day it } \\
\text { was scheduled); } 23 / 24(96 \%) \text { included in control group ( } 1 \text { refused treatment on } \\
\text { the day it was scheduled) }\end{array}$ \\
\hline $\begin{array}{l}\text { Incomplete outcome data } \\
\text { (attrition bias) } \\
\text { Nocturia }\end{array}$ & Low risk & $\begin{array}{l}44 / 46(96 \%) \text { included in intervention group ( } 2 \text { refused treatment on the day it } \\
\text { was scheduled); } 23 / 24(96 \%) \text { included in control group ( } 1 \text { refused treatment on } \\
\text { the day it was scheduled) }\end{array}$ \\
\hline $\begin{array}{l}\text { Incomplete outcome data } \\
\text { (attrition bias) } \\
\text { Interstitial Cystitis Symp- } \\
\text { tom Index }\end{array}$ & Low risk & $\begin{array}{l}44 / 46(96 \%) \text { included in intervention group ( } 2 \text { refused treatment on the day it } \\
\text { was scheduled); } 23 / 24(96 \%) \text { included in control group ( } 1 \text { refused treatment on } \\
\text { the day it was scheduled) }\end{array}$ \\
\hline $\begin{array}{l}\text { Incomplete outcome data } \\
\text { (attrition bias) } \\
\text { Interstitial Cystitis Prob- } \\
\text { lem Index }\end{array}$ & Low risk & $\begin{array}{l}44 / 46(96 \%) \text { included in intervention group ( } 2 \text { refused treatment on the day it } \\
\text { was scheduled); } 23 / 24(96 \%) \text { included in control group ( } 1 \text { refused treatment on } \\
\text { the day it was scheduled) }\end{array}$ \\
\hline
\end{tabular}


Kuo 2009 (Continued)

$\begin{array}{ll}\text { Incomplete outcome data } \quad \text { Low risk } & 44 / 46(96 \%) \text { included in intervention group (2 refused treatment on the day it } \\ \text { (attrition bias) } & \text { was scheduled); } 23 / 24(96 \%) \text { included in control group (1 refused treatment on } \\ \text { Functional bladder capac- } & \text { the day it was scheduled) }\end{array}$
ity was scheduled); $23 / 24$ (96\%) included in control group (1 refused treatment on

$\begin{array}{ll}\text { Incomplete outcome data } \quad \text { Low risk } & 44 / 46(96 \%) \text { included in intervention group (2 refused treatment on the day it } \\ \text { (attrition bias) } & \text { was scheduled); } 23 / 24(96 \%) \text { included in control group ( } 1 \text { refused treatment on } \\ \text { Adverse events } & \text { the day it was scheduled) }\end{array}$

Selective reporting (re- Low risk Results included all outcomes specified in the methods section
porting bias)

\begin{tabular}{ll}
\hline Other bias $\quad$ Low risk $\quad$ None detected \\
\hline
\end{tabular}

Kuo 2016

\section{Study characteristics}

\begin{tabular}{ll}
\hline Methods & Study design: $\mathrm{RCT}$ \\
Study duration (months): 2
\end{tabular}

Participants Number randomised: 60

Setting: 2 teaching hospitals

Country: Taiwan

Sex: 52 females and 8 males

Age, years: mean 52.9 (SD 14.3, range 20 to 82) for Group A, mean 50.2 (SD 13.2, range 22 to 71 ) for Group B

Diagnosis IC/BPS (NIDDK criteria); Hunner's lesion not included

Inclusion criteria: IC/BPS patients who had failed at least 6 months of conventional treatments. Patients who had been treated with at least 2 types of treatment modalities including non-steroid anti-inflammatory drugs, oral pentosan polysulfate sodium, intravesical instillation of heparin, hyaluronic acid or tricyclic antidepressant for at least 6 months but symptoms remained unchanged or relapsed

Exclusion criteria: (1) exclusion criteria by NIDDK; (2) use of anticholinergic drugs for treatment of lower urinary tract symptoms that have an effect; (3) severe cardiopulmonary disease such as congestive heart failure, arrhythmia, poorly controlled hypertension; not able to receive regular follow-up; (4) bladder outlet obstruction on enrolment; (5) urinary retention, PVR (postvoid residual) $150 \mathrm{~mL}$; (6) uncontrolled, confirmed diagnosis of acute urinary tract infection; (7) laboratory abnormalities at screening including alanine aminotransferase $(A L T)>3$ times upper limit of the normal range, aspartate aminotransferase (AST) $>3$ times upper limit of the normal range, abnormal serum creatinine level > 2 times upper limit of the normal range; (8) use of transurethral catheter; (9) pregnant and lactating woman or woman who intends to become pregnant during the study or who has myasthenia gravis or Eaton-Lambert syndrome; (10) any other serious disease or condition considered by the investigator not suitable for entry into the trial; (11) participation in an investigational drug trial within 1 month before entering this study; (12) unable or unwilling to provide written informed consent for the study; (13) incomplete 3-day micturition diary, according to the study protocol; (14) intestinal bladder augmentation with angioplasty for treatment of overactive bladder

Interventions

Group A ( $\mathbf{n}=\mathbf{4 0})$ : botulinum toxin A (100 units) + hydrodistension

Group B ( $\mathbf{n}=\mathbf{2 0})$ : $\mathrm{NaCl}$ injection + hydrodistension

Treatment category in NMA: neuromuscular blockade vs control 
Kuo 2016 (Continued)

\section{Outcomes}

Outcome data in analysis

Cure or improvement: patients considered 'successful' when they reported improvement on GRA of 1 or more points): at 3 months

Pain: 10-point VAS (unclear minimum/maximum score): at 8 weeks

Frequency (voids/day): at 8 weeks

Nocturia: at 8 weeks

ICSI: at 8 weeks

ICPI: at 8 weeks

Functional bladder capacity: at 8 weeks

Adverse events: at 2 months.

Funding Buddhist Tzu Chi General Hospital

Notes Publication status: full text

\section{Risk of bias}

\section{Bias}

Authors' judgement Support for judgement

Random sequence genera- Low risk tion (selection bias)

Quote: "'permuted block randomization code in a 2:1 ratio, which was centrally controlled by the clinical pharmacists"

Comment: probably done

\begin{tabular}{|c|c|c|}
\hline $\begin{array}{l}\text { Allocation concealment } \\
\text { (selection bias) }\end{array}$ & Low risk & $\begin{array}{l}\text { Quote: "'permuted block randomization code in a 2:1 ratio, which was cent } \\
\text { ly controlled by the clinical pharmacists" }\end{array}$ \\
\hline $\begin{array}{l}\text { Blinding of participants } \\
\text { and personnel (perfor- } \\
\text { mance bias) }\end{array}$ & Low risk & $\begin{array}{l}\text { "double-blind, placebo-controlled trial". Sub-urothelial injection of either } \\
\text { BoNT-A or "the equivalent amount of normal saline"; doctors, patients and } \\
\text { nurses "did not know which solution was injected into their bladders" }\end{array}$ \\
\hline
\end{tabular}

\begin{tabular}{|c|c|c|}
\hline $\begin{array}{l}\text { Blinding of outcome as- } \\
\text { sessment (detection bias) } \\
\text { Subjective outcome }\end{array}$ & Low risk & $\begin{array}{l}\text { "double-blind, placebo-controlled trial". Sub-urothelial injection of either } \\
\text { BoNT-A or "the equivalent amount of normal saline"; doctors, patients and } \\
\text { nurses "did not know which solution was injected into their bladders" }\end{array}$ \\
\hline
\end{tabular}

Blinding of outcome as-
$\begin{aligned} & \text { sessment (detection bias) } \\ & \text { Objective outcome }\end{aligned}$

\begin{tabular}{lll}
\hline $\begin{array}{l}\text { Incomplete outcome data } \\
\text { (attrition bias) }\end{array}$ & Low risk & All randomised participants were included in analysis \\
Cure or improvement & \\
\hline $\begin{array}{l}\text { Incomplete outcome data } \\
\text { (attrition bias) }\end{array}$ & Low risk & All randomised participants were included in analysis \\
$\begin{array}{l}\text { Pain } \\
\text { Incomplete outcome data }\end{array}$ & Low risk & \\
$\begin{array}{l}\text { (attrition bias) } \\
\text { Frequency }\end{array}$ & All randomised participants were included in analysis \\
\hline
\end{tabular}


Kuo 2016 (Continued)
Incomplete outcome data
Low risk
All randomised participants were included in analysis
(attrition bias)

Nocturia

\begin{tabular}{lll}
\hline $\begin{array}{l}\text { Incomplete outcome data } \\
\text { (attrition bias) }\end{array}$ & Low risk & All randomised participants were included in analysis \\
Interstitial Cystitis Symp- & \\
tom Index & All randomised participants were included in analysis \\
\hline $\begin{array}{l}\text { Incomplete outcome data } \\
\text { (attrition bias) }\end{array}$ & Low risk \\
$\begin{array}{l}\text { Interstitial Cystitis Prob- } \\
\text { lem Index }\end{array}$ & \\
\hline $\begin{array}{l}\text { Incomplete outcome data } \\
\text { (attrition bias) }\end{array}$ & Low risk & All randomised participants were included in analysis \\
$\begin{array}{l}\text { Functional bladder capac- } \\
\text { ity }\end{array}$ & \\
\hline $\begin{array}{l}\text { Incomplete outcome data } \\
\text { (attrition bias) } \\
\text { Adverse events }\end{array}$ & Low risk & All randomised participants were included in analysis \\
\hline $\begin{array}{l}\text { Selective reporting (re- } \\
\text { porting bias) }\end{array}$ & Low risk & \\
\hline \begin{tabular}{l} 
Other bias \\
\hline
\end{tabular} & Low risk & Results included all outcomes specified in the methods section \\
\hline
\end{tabular}

Lazzeri 1996

\section{Study characteristics}

\begin{tabular}{ll}
\hline Methods & $\begin{array}{l}\text { Study design: RCT } \\
\text { Study duration (months): } 6\end{array}$ \\
\hline Purticipants & Setting: not reported \\
Country: Italy \\
Sex: 23 females and 13 males \\
Age, years: mean 50.9 (SD 13.1) for Group A, mean 53.2 (SD 11.4) for Group B \\
Diagnosis: "severe bladder pain" \\
Inclusion criteria: women and men with severe bladder pain. Pelvic pain for at least 6 months and no \\
urinary tract infection (tuberculosis included) within the last 3 months, functional disorders of the low- \\
er urinary tract such as detrusor instability, calculi or proliferative vesical pathology \\
Exclusion criteria: patients with urethral syndrome were excluded based on abnormalities noted dur- \\
ing urodynamic evaluation (dysfunctional external urethral sphincter); patients with Hunner's ulcer at \\
cystoscopy were also excluded, but those with moderate pathological abnormality of the bladder mu- \\
cosa (edema, rare mast cells and plasma cellular inflammation) were included in the study. Before the \\
study was begun, all patients were assessed for current or previous psychiatric illness, and those with \\
significant psychiatric disease were excluded. However, psychological or related symptoms were noted
\end{tabular}

Interventions

Group A (n= 18): $10 \mu \mathrm{m}$ capsaicin $30 \mathrm{cc} \mathrm{NaCl}$ 
Group B (n= 18): $\mathrm{NaCl}$ at $42^{\circ} \mathrm{C}$

Twice weekly for 1 month

Treatment category in NMA: calcium channel agonists vs control

\begin{tabular}{|c|c|}
\hline \multirow[t]{3}{*}{ Outcomes } & $\begin{array}{l}\text { Outcome data in analysis } \\
\text { Cure or improvement: improvement in pain and symptoms (e.g. frequency), to the point that no med- } \\
\text { ication was required: at } 6 \text { months }\end{array}$ \\
\hline & Pain: numerical rating scale (range 0 to 9) on pain frequency and intensity: at 6 months \\
\hline & Adverse events: at 6 months \\
\hline Funding & Not reported \\
\hline \multirow[t]{2}{*}{ Notes } & Publication status: full text \\
\hline & $\begin{array}{l}\text { Notes from previous versions of the review: previous review authors excluded this trial from the origi- } \\
\text { nal review because patients with Hunner's lesions were excluded. We have included this trial as inclu- } \\
\text { sion criteria meet the diagnosis of bladder pain syndrome }\end{array}$ \\
\hline
\end{tabular}

\section{Risk of bias}

\begin{tabular}{|c|c|c|}
\hline Bias & Authors' judgement & Support for judgement \\
\hline $\begin{array}{l}\text { Random sequence genera- } \\
\text { tion (selection bias) }\end{array}$ & Unclear risk & Quote: "randomized" \\
\hline $\begin{array}{l}\text { Allocation concealment } \\
\text { (selection bias) }\end{array}$ & Unclear risk & No information provided \\
\hline $\begin{array}{l}\text { Blinding of participants } \\
\text { and personnel (perfor- } \\
\text { mance bias) } \\
\text { All outcomes }\end{array}$ & Low risk & $\begin{array}{l}\text { Blinding not mentioned, but in the control group, "the same procedure [as in- } \\
\text { travesical capsaicin intervention] was used but with saline } 42^{\circ} \mathrm{C} \text {, which mimics } \\
\text { the burning or warm sensation of capsaicin as described previously [ref pro- } \\
\text { vided]" }\end{array}$ \\
\hline $\begin{array}{l}\text { Blinding of outcome as- } \\
\text { sessment (detection bias) } \\
\text { Subjective outcome }\end{array}$ & Low risk & $\begin{array}{l}\text { Blinding not mentioned, but in the control group, "the same procedure [as in- } \\
\text { travesical capsaicin intervention] was used but with saline } 42^{\circ} \mathrm{C} \text {, which mimics } \\
\text { the burning or warm sensation of capsaicin as described previously [ref pro- } \\
\text { vided]" }\end{array}$ \\
\hline $\begin{array}{l}\text { Incomplete outcome data } \\
\text { (attrition bias) } \\
\text { Cure or improvement }\end{array}$ & Low risk & $\begin{array}{l}\text { 17/18 included in intervention group ( } 1 \text { refused treatment at } 4 \text { weeks and with- } \\
\text { drew); } 18 / 18 \text { included in control group }\end{array}$ \\
\hline $\begin{array}{l}\text { Incomplete outcome data } \\
\text { (attrition bias) } \\
\text { Pain }\end{array}$ & Low risk & $\begin{array}{l}\text { 17/18 included in intervention group ( } 1 \text { refused treatment at } 4 \text { weeks and with- } \\
\text { drew); } 18 / 18 \text { included in control group }\end{array}$ \\
\hline $\begin{array}{l}\text { Incomplete outcome data } \\
\text { (attrition bias) } \\
\text { Adverse events }\end{array}$ & Low risk & $\begin{array}{l}\text { 17/18 included in intervention group ( } 1 \text { refused treatment at } 4 \text { weeks and with- } \\
\text { drew); } 18 / 18 \text { included in control group }\end{array}$ \\
\hline $\begin{array}{l}\text { Selective reporting (re- } \\
\text { porting bias) }\end{array}$ & Low risk & Results included all outcomes specified in the methods section \\
\hline Other bias & Low risk & None detected \\
\hline
\end{tabular}


Lazzeri 2000

\section{Study characteristics}

\begin{tabular}{ll}
\hline Methods & $\begin{array}{l}\text { Study design: RCT } \\
\text { Study duration (months): } 3\end{array}$ \\
\hline Pumber randomised: 18 \\
Setting: not reported \\
Country: Italy \\
Sex: 15 females and 3 males \\
Age, years: mean 43.4 \\
Diagnosis: "hypertensive disorder and severe pain" \\
Inclusion criteria: men and women with hypersensitive disorder and severe bladder pain. Frequen- \\
cy greater than 8 voids, nocturia greater than 2 voids, daily urgency and bladder pain for at least 6 \\
months. Furthermore, we considered absent urinary tract infection, including tuberculosis, within the \\
last 3 months; absent functional disorders of the lower urinary tract as detrusor overactivity; and no \\
calculi or proliferative vesical pathology \\
Exclusion criteria: patients diagnosed with urethral syndrome were excluded from the study based on \\
abnormalities identified at urodynamic evaluation such as dysfunctional behaviour of the external ure- \\
thral sphincter. Those for whom cystoscopy revealed Hunner's ulcer were also excluded, but we includ- \\
ed in our analysis patients with moderate pathological abnormalities such as edema, rare mast cells \\
and plasmacellular inflammation. Before study initiation, all patients were assessed for current or pre- \\
vious psychiatric illness; those with significant psychiatric disease were also excluded from analysis. \\
However, psychological or associated symptoms were recorded
\end{tabular}

Interventions Group A $(\mathbf{n}=\mathbf{9})$ : resiniferatoxin $(\mathrm{RTX}) 10 \mu \mathrm{m}$ in $0.1 \%$ ethanol (RTX = ultra potent analogue of chili pepper extract capsaicin)

Group B (n= 9): $\mathrm{NaCl}$

Treatment category in NMA: calcium channel agonists vs control

\begin{tabular}{ll}
\hline Outcomes & Outcome data in analysis \\
& Pain: numerical rating scale (range 0 to 9) on pain frequency and intensity: at 3 months \\
& Frequency: at 3 months \\
& Nocturia: at 3 months \\
& Adverse events: at 3 months \\
\hline Funding & Not reported \\
\hline Notes & Publication status: full text \\
\hline Risk of bias & Authors' judgement Support for judgement \\
\hline Bias & Unclear risk $\quad$ Quote: "randomized" \\
\hline $\begin{array}{l}\text { Random sequence genera- } \\
\text { tion (selection bias) }\end{array}$ & \\
\hline $\begin{array}{l}\text { Allocation concealment } \\
\text { (selection bias) }\end{array}$ & Unclear risk No information provided. \\
\hline \hline
\end{tabular}




\section{Lazzeri 2000 (Continued)}

Blinding of participants and personnel (performance bias)

All outcomes
High risk

"The same procedure" used to instill resiniferatoxin or saline (placebo). During infusion 4 in intervention group "noticed a light warm or burning sensation at the suprapubic and/or urethral level but those who received placebo noticed no sensation".

\section{Blinding of outcome as- High risk sessment (detection bias)}

Subjective outcome
"The same procedure" used to instill resiniferatoxin or saline (placebo). During infusion 4 in intervention group "noticed a light warm or burning sensation at the suprapubic and/or urethral level but those who received placebo noticed no sensation".

Incomplete outcome data Unclear risk Number analysed not stated.

(attrition bias)

Pain

Incomplete outcome data Unclear risk Number analysed not stated.
(attrition bias)

Frequency

Incomplete outcome data Unclear risk Number analysed not stated.
(attrition bias)

Nocturia

Incomplete outcome data $\quad$ Unclear risk $\quad$ Number analysed not stated.
(attrition bias)

Adverse events

Selective reporting (re- Low risk Results included all outcomes specified in the methods section.
porting bias)

Other bias Low risk Not detected.

Leadership 201 Trial 2016

\section{Study characteristics}

\begin{tabular}{|c|c|}
\hline Methods & $\begin{array}{l}\text { Study design: } \mathrm{RCT} \\
\text { Study duration (months): } 1.5\end{array}$ \\
\hline Participants & $\begin{array}{l}\text { Number randomised: } 69 \\
\text { Setting: } 31 \text { sites ( } 19 \text { in Canada and } 12 \text { in USA) } \\
\text { Country: Canada, USA } \\
\text { Sex: female } \\
\text { Age, years: mean } 52.1 \text { (SD 14.9) for Group A, mean } 53.1 \text { (SD 12.9) for Group B } \\
\text { Diagnosis: IC/BPS } \\
\text { Inclusion criteria: women } 18 \text { to } 75 \text { years old with a diagnosis of IC/BPS for greater than } 6 \text { months but } \\
\text { 15 years or less, and bladder pain for } 12 \text { months or longer, were eligible for enrolment in a screening } \\
\text { period of } 9 \text { to } 21 \text { days if they met inclusion criteria including baseline mean pain } 5 \text { or greater on an } \\
\text { 11-point scale, BPIC-SS score } 19 \text { or greater, } 20 \text { baseline combined O'Leary-Sant ICSI/PI } 21 \text { score } 8 \text { or } \\
\text { greater, at least } 8 \text { urinary voids per } 24 \text { hours and history of cystoscopy within } 36 \text { months, revealing } \\
\text { signs consistent with IC/BPS diagnosis including but not restricted to Hunner's lesion }\end{array}$ \\
\hline
\end{tabular}


Leadership 201 Trial 2016 (Continued)

Exclusion criteria: women were excluded from analysis if they had pelvic floor pain greater than 5 of 10 as assessed by the investigator, BMI less than 18 or greater than $39 \mathrm{~kg} / \mathrm{m}^{2}$, recent cystoscopy with therapeutic hydrodistension within 3 months or bladder surgery within 3 years

Group A $(\mathbf{n}=\mathbf{3 7})$ : daily $200 \mathrm{mg} \mathrm{AQX}-1125$ capsule (oral)
Group B $(\mathbf{n}=\mathbf{3 2})$ : placebo
Participants in this trial were allowed to remain on stable doses of most IC/BPS medications. The 2
most common medications were pentosan polysulfate sodium and amitriptyline

Treatment category in NMA: AQX-1125 vs control

Outcomes data in analysis
Pain: numerical rating scale (range 0 to 10): at 4 weeks
ICSI: at 4 weeks
ICPI: at 4 weeks

\begin{tabular}{ll}
\hline Funding & Aquinox Pharmaceuticals \\
\hline Notes & Publication status: full text \\
\hline
\end{tabular}

\section{Risk of bias}

\begin{tabular}{|c|c|c|}
\hline Bias & Authors' judgement & Support for judgement \\
\hline $\begin{array}{l}\text { Random sequence genera- } \\
\text { tion (selection bias) }\end{array}$ & Unclear risk & Quote: "centrally ramdomized" \\
\hline $\begin{array}{l}\text { Allocation concealment } \\
\text { (selection bias) }\end{array}$ & Low risk & Quote: "centrally ramdomized" \\
\hline $\begin{array}{l}\text { Blinding of participants } \\
\text { and personnel (perfor- } \\
\text { mance bias) } \\
\text { All outcomes }\end{array}$ & Low risk & $\begin{array}{l}\text { "double-blind, placebo controlled" study, using a single daily capsule of study } \\
\text { drug or "matched placebo" }\end{array}$ \\
\hline
\end{tabular}

\begin{tabular}{ll}
\hline $\begin{array}{l}\text { Blinding of outcome as- } \\
\text { sessment (detection bias) } \\
\text { Subjective outcome }\end{array}$ & Low risk
\end{tabular}$\quad \begin{aligned} & \text { "double-blind, placebo controlled" study, using a single daily capsule of study } \\
& \text { drug or "matched placebo" }\end{aligned}$

\begin{tabular}{ll}
\hline $\begin{array}{l}\text { Incomplete outcome data } \\
\text { (attrition bias) }\end{array}$ & Low risk \\
$\begin{array}{l}\text { Pain } \\
\text { using the last observation carried forward approach") }\end{array}$
\end{tabular}

\begin{tabular}{|c|c|c|}
\hline $\begin{array}{l}\text { Incomplete outcome data } \\
\text { (attrition bias) } \\
\text { Frequency }\end{array}$ & Low risk & \\
\hline $\begin{array}{l}\text { Incomplete outcome data } \\
\text { (attrition bias) } \\
\text { Interstitial Cystitis Symp- } \\
\text { tom Index }\end{array}$ & Low risk & $\begin{array}{l}\text { All randomised participants were included in analysis ("missing data imputed } \\
\text { using the last observation carried forward approach") }\end{array}$ \\
\hline $\begin{array}{l}\text { Incomplete outcome data } \\
\text { (attrition bias) }\end{array}$ & Low risk & $\begin{array}{l}\text { All randomised participants were included in analysis ("missing data imputed } \\
\text { using the last observation carried forward approach") }\end{array}$ \\
\hline
\end{tabular}


Leadership 201 Trial 2016 (Continued) Interstitial Cystitis Prob-

lem Index

\begin{tabular}{lll}
\hline $\begin{array}{l}\text { Incomplete outcome data } \\
\text { (attrition bias) } \\
\text { Adverse events }\end{array}$ & Low risk & All randomised participants were included in analysis \\
\hline $\begin{array}{l}\text { Selective reporting (re- } \\
\text { porting bias) }\end{array}$ & Low risk & Results included all outcomes specified in the methods section \\
\hline Other bias & Low risk & None detected \\
\hline
\end{tabular}

Lee 2014

\section{Study characteristics}

\begin{tabular}{|c|c|c|}
\hline Methods & \multicolumn{2}{|c|}{$\begin{array}{l}\text { Study design: RCT } \\
\text { Study duration (months): } 2\end{array}$} \\
\hline \multirow[t]{8}{*}{ Participants } & \multicolumn{2}{|c|}{ Number randomised: 80} \\
\hline & \multicolumn{2}{|c|}{ Setting: not reported } \\
\hline & \multirow{3}{*}{\multicolumn{2}{|c|}{$\begin{array}{l}\text { Country: Taiwan } \\
\text { Sex: not reported } \\
\text { Age, years: mean } 46.5 \text { (SD 10.2) for Group A, mean } 49.5 \text { (SD 11.8) for Group B }\end{array}$}} \\
\hline & & \\
\hline & & \\
\hline & \multicolumn{2}{|l|}{ Diagnosis: IC/BPS } \\
\hline & \multicolumn{2}{|c|}{ Inclusion criteria: BPS/IC patients } \\
\hline & \multicolumn{2}{|c|}{ Exclusion criteria: not reported } \\
\hline \multirow[t]{3}{*}{ Interventions } & \multicolumn{2}{|c|}{$\begin{array}{l}\text { Group A ( } \mathbf{n}=\mathbf{4 0}) \text { : e-health system (Internet intervention to change habitual behaviour; no treatment, } \\
\text { with questionnaires, SMS question/answer service for symptom relief) }\end{array}$} \\
\hline & \multicolumn{2}{|c|}{ Group B ( $\mathbf{n}=\mathbf{4 0 )}$ : control (unclear what this entails - includes treatment) } \\
\hline & \multicolumn{2}{|c|}{ Treatment category in NMA: behavioural therapy vs control } \\
\hline \multirow[t]{4}{*}{ Outcomes } & \multicolumn{2}{|c|}{ Outcome data in analysis } \\
\hline & \multicolumn{2}{|c|}{ Pain: VAS (assumed range 0 to 10 ): at 8 weeks } \\
\hline & \multicolumn{2}{|l|}{ ICSI: at 8 weeks } \\
\hline & \multicolumn{2}{|l|}{ ICPI: at 8 weeks } \\
\hline Funding & \multicolumn{2}{|c|}{ Supported in part by Taichung Hospital and National Science Council of Taiwan } \\
\hline Notes & \multicolumn{2}{|c|}{ Publication status: full text } \\
\hline \multicolumn{3}{|l|}{ Risk of bias } \\
\hline Bias & Authors' judgement & Support for judgement \\
\hline $\begin{array}{l}\text { Random sequence genera- } \\
\text { tion (selection bias) }\end{array}$ & Unclear risk & Quote: "randomly assigned" \\
\hline
\end{tabular}


Lee 2014 (Continued)

\begin{tabular}{|c|c|c|}
\hline $\begin{array}{l}\text { Allocation concealment } \\
\text { (selection bias) }\end{array}$ & Unclear risk & No information provided \\
\hline $\begin{array}{l}\text { Blinding of participants } \\
\text { and personnel (perfor- } \\
\text { mance bias) } \\
\text { All outcomes }\end{array}$ & High risk & $\begin{array}{l}\text { Probably not done. E-health system vs control treatment } \\
\text { Quote: "treatment was only given to the patients in the control group" }\end{array}$ \\
\hline $\begin{array}{l}\text { Blinding of outcome as- } \\
\text { sessment (detection bias) } \\
\text { Subjective outcome }\end{array}$ & High risk & $\begin{array}{l}\text { Probably not done. E-health system vs control treatment } \\
\text { Quote: "treatment was only given to the patients in the control group" }\end{array}$ \\
\hline $\begin{array}{l}\text { Incomplete outcome data } \\
\text { (attrition bias) } \\
\text { Pain }\end{array}$ & Low risk & $\begin{array}{l}33 / 40(83 \%) \text { included in intervention group; } 32 / 40(80 \%) \text { included in control } \\
\text { group. } 7 \text { and } 8 \text { from each group excluded for not filling out the questionnaire } \\
\text { before or after testing }\end{array}$ \\
\hline $\begin{array}{l}\text { Incomplete outcome data } \\
\text { (attrition bias) } \\
\text { Interstitial Cystitis Symp- } \\
\text { tom Index }\end{array}$ & Low risk & $\begin{array}{l}33 / 40(83 \%) \text { included in intervention group; } 32 / 40(80 \%) \text { included in control } \\
\text { group. } 7 \text { and } 8 \text { from each group excluded for not filling out the questionnaire } \\
\text { before or after testing }\end{array}$ \\
\hline $\begin{array}{l}\text { Incomplete outcome data } \\
\text { (attrition bias) } \\
\text { Interstitial Cystitis Prob- } \\
\text { lem Index }\end{array}$ & Low risk & $\begin{array}{l}33 / 40(83 \%) \text { included in intervention group; } 32 / 40(80 \%) \text { included in control } \\
\text { group. } 7 \text { and } 8 \text { from each group excluded for not filling out the questionnaire } \\
\text { before or after testing }\end{array}$ \\
\hline $\begin{array}{l}\text { Selective reporting (re- } \\
\text { porting bias) }\end{array}$ & Low risk & Results included all outcomes specified in the methods section \\
\hline Other bias & Low risk & None detected \\
\hline
\end{tabular}

Lee 2016

\section{Study characteristics}

\begin{tabular}{|c|c|}
\hline Methods & $\begin{array}{l}\text { Study design: } \mathrm{RCT} \\
\text { Study duration (months): } 2\end{array}$ \\
\hline Participants & $\begin{array}{l}\text { Number randomised: } 56 \\
\text { Setting: not reported } \\
\text { Country: Taiwan } \\
\text { Sex: not reported } \\
\text { Age, years: not reported } \\
\text { Diagnosis: IC/BPS } \\
\text { Inclusion criteria: IC/BPS patients } \\
\text { Exclusion criteria: not reported }\end{array}$ \\
\hline
\end{tabular}

Interventions Group A $(\mathbf{n}=\mathbf{2 9})$ : self-management telecare system (patient video education, mobile phone app, lifestyles)

Group B ( $\mathbf{n}=\mathbf{2 7})$ : control (no detail) 
Treatment category in NMA: behavioural therapy vs control

\begin{tabular}{|c|c|c|}
\hline \multirow[t]{4}{*}{ Outcomes } & \multicolumn{2}{|c|}{ Outcome data in analysis } \\
\hline & \multicolumn{2}{|c|}{ Pain: VAS (assumed 0 to 10 ): at 8 weeks } \\
\hline & \multicolumn{2}{|l|}{ ICSI: at 8 weeks } \\
\hline & \multicolumn{2}{|l|}{ ICPI: at 8 weeks } \\
\hline Funding & \multicolumn{2}{|l|}{ None } \\
\hline Notes & \multicolumn{2}{|c|}{ Publication status: abstract } \\
\hline \multicolumn{3}{|l|}{ Risk of bias } \\
\hline Bias & Authors' judgement & Support for judgement \\
\hline $\begin{array}{l}\text { Random sequence genera- } \\
\text { tion (selection bias) }\end{array}$ & Unclear risk & Quote: "randomized" \\
\hline $\begin{array}{l}\text { Allocation concealment } \\
\text { (selection bias) }\end{array}$ & Unclear risk & No information provided \\
\hline $\begin{array}{l}\text { Blinding of participants } \\
\text { and personnel (perfor- } \\
\text { mance bias) } \\
\text { All outcomes }\end{array}$ & Unclear risk & Blinding not mentioned. Video education system vs control \\
\hline $\begin{array}{l}\text { Blinding of outcome as- } \\
\text { sessment (detection bias) } \\
\text { Subjective outcome }\end{array}$ & Unclear risk & Blinding not mentioned. Video education system vs control \\
\hline $\begin{array}{l}\text { Incomplete outcome data } \\
\text { (attrition bias) } \\
\text { Pain }\end{array}$ & Unclear risk & Number analysed not stated \\
\hline $\begin{array}{l}\text { Incomplete outcome data } \\
\text { (attrition bias) } \\
\text { Interstitial Cystitis Symp- } \\
\text { tom Index }\end{array}$ & Unclear risk & Number analysed not stated \\
\hline $\begin{array}{l}\text { Incomplete outcome data } \\
\text { (attrition bias) } \\
\text { Interstitial Cystitis Prob- } \\
\text { lem Index }\end{array}$ & Unclear risk & Number analysed not stated \\
\hline $\begin{array}{l}\text { Selective reporting (re- } \\
\text { porting bias) }\end{array}$ & Low risk & Results included all outcomes specified in the methods section \\
\hline Other bias & Low risk & None detected \\
\hline
\end{tabular}

Lu 2015

\section{Study characteristics}

Methods Study design: RCT


Lu 2015 (Continued)

Study duration (months): 12

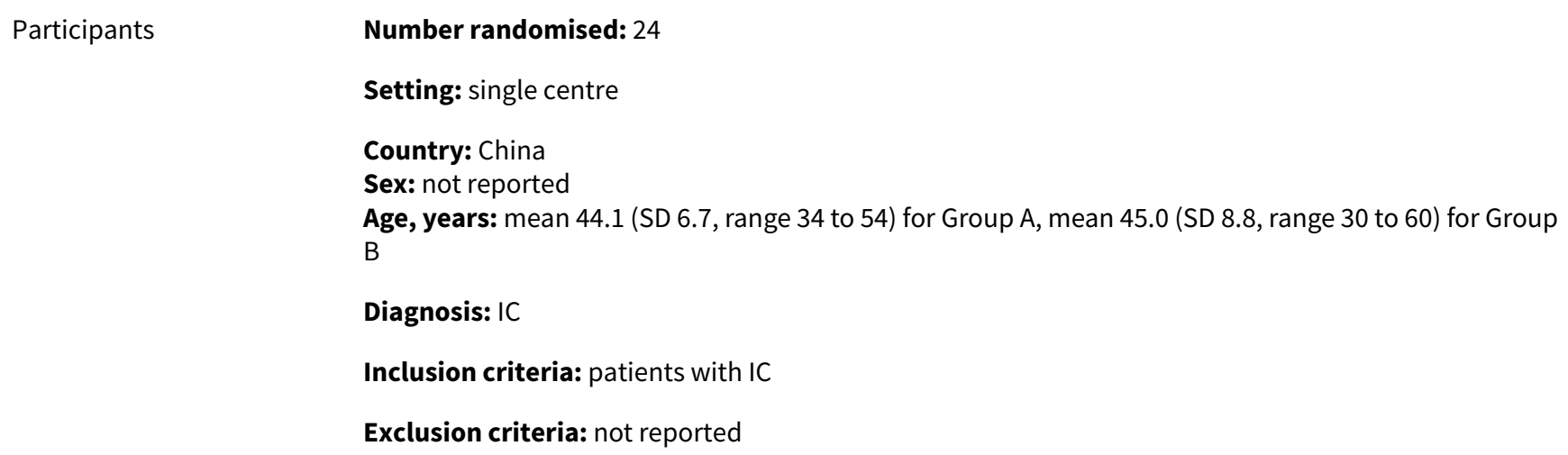

Treatment category in NMA: anticoagulants + local anaesthetics vs hyaluronic acid

\begin{tabular}{ll}
\hline Outcomes & Outcome data in analysis \\
Cure: complete remission: at 12 months \\
Pain: VAS (range 0 to 6 ): at 12 months \\
Frequency, daily: at 12 months \\
Adverse events: at 12 months (assumed from reports) \\
\hline Funding & Not reported \\
\hline Notes & Publication status: full text \\
& $\begin{array}{l}\text { Publication in Chinese language with English abstract. Information was extracted mainly from the ab- } \\
\text { stract }\end{array}$
\end{tabular}

\section{Risk of bias}

\begin{tabular}{lll}
\hline Bias & Authors' judgement & Support for judgement \\
\hline $\begin{array}{l}\text { Random sequence genera- } \\
\text { tion (selection bias) }\end{array}$ & Unclear risk & $\begin{array}{l}\text { Quote: "randomly divided" } \\
\text { Comment: no further information available (paper in Chinese) }\end{array}$ \\
\hline $\begin{array}{l}\text { Allocation concealment } \\
\text { (selection bias) }\end{array}$ & Unclear risk & No information available (paper in Chinese) \\
\hline $\begin{array}{l}\text { Blinding of participants } \\
\text { and personnel (perfor- } \\
\text { mance bias) } \\
\text { All outcomes }\end{array}$ & Unclear risk & $\begin{array}{l}\text { No information available (paper in Chinese). Intravesical instillation of he- } \\
\text { parin-lidocaine vs hyaluronic acid }\end{array}$ \\
\hline
\end{tabular}

\begin{tabular}{lll}
\hline $\begin{array}{l}\text { Blinding of outcome as- } \\
\text { sessment (detection bias) } \\
\text { Subjective outcome }\end{array}$ & Unclear risk & $\begin{array}{l}\text { No information available (paper in Chinese). Intravesical instillation of he- } \\
\text { parin-lidocaine vs hyaluronic acid }\end{array}$ \\
\hline $\begin{array}{l}\text { Incomplete outcome data } \\
\text { (attrition bias) }\end{array}$ & Low risk & All randomised participants were included in analysis \\
\hline
\end{tabular}


Lu 2015 (Continued)

Cure or improvement

\begin{tabular}{|c|c|c|}
\hline $\begin{array}{l}\text { Incomplete outcome data } \\
\text { (attrition bias) } \\
\text { Pain }\end{array}$ & Low risk & All randomised participants were included in analysis \\
\hline $\begin{array}{l}\text { Incomplete outcome data } \\
\text { (attrition bias) } \\
\text { Frequency }\end{array}$ & Low risk & All randomised participants were included in analysis \\
\hline $\begin{array}{l}\text { Incomplete outcome data } \\
\text { (attrition bias) } \\
\text { Adverse events }\end{array}$ & Low risk & All randomised participants were included in analysis \\
\hline $\begin{array}{l}\text { Selective reporting (re- } \\
\text { porting bias) }\end{array}$ & Unclear risk & No information available (paper in Chinese) \\
\hline Other bias & Low risk & None detected \\
\hline
\end{tabular}

Manning 2014

\section{Study characteristics}

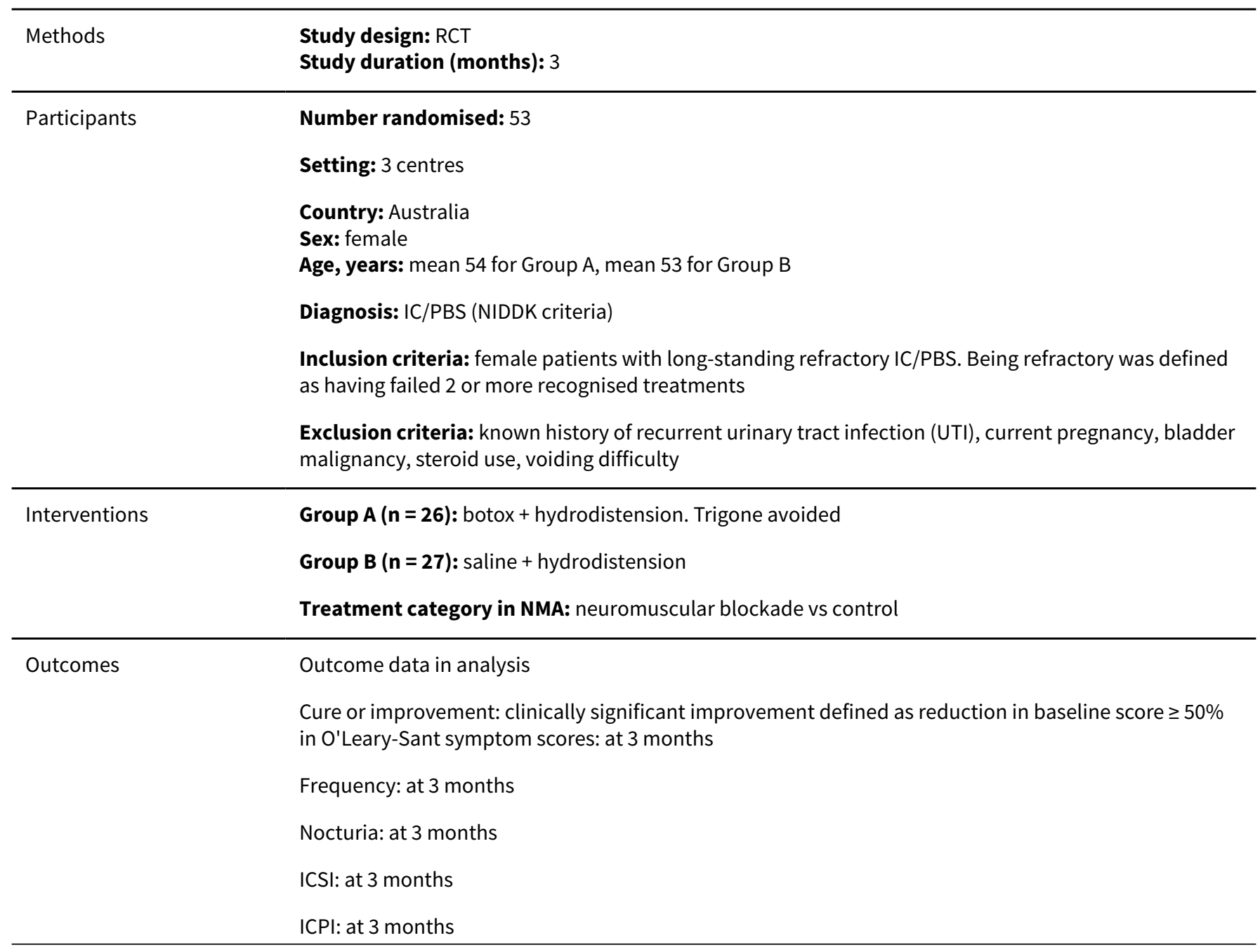


Manning 2014 (Continued)

Functional bladder capacity: at 3 months

Adverse events: at 3 months

\begin{tabular}{ll}
\hline Funding & Not reported. One of the study authors is on Advisory Board for Allergan \\
\hline Notes & Publication status: full text
\end{tabular}

\section{Risk of bias}

\begin{tabular}{|c|c|c|}
\hline Bias & Authors' judgement & Support for judgement \\
\hline $\begin{array}{l}\text { Random sequence genera- } \\
\text { tion (selection bias) }\end{array}$ & Low risk & $\begin{array}{l}\text { Quote: "a series of three separate computer-generated randomisation num- } \\
\text { bers for each centre" }\end{array}$ \\
\hline $\begin{array}{l}\text { Allocation concealment } \\
\text { (selection bias) }\end{array}$ & Low risk & $\begin{array}{l}\text { Randomisation numbers were "provided by the mathematics department and } \\
\text { were held confidentially by pharmacy. De-identified syringes were delivered to } \\
\text { theatre" }\end{array}$ \\
\hline $\begin{array}{l}\text { Blinding of participants } \\
\text { and personnel (perfor- } \\
\text { mance bias) } \\
\text { All outcomes }\end{array}$ & Low risk & $\begin{array}{l}\text { "double-blind". Sub-urothelial injection of saline or AboBTXA in de-identified } \\
\text { syringe with hydrodistension under general anaesthesia. "Patients and treat- } \\
\text { ing doctors were blinded to initial treatment allocation" }\end{array}$ \\
\hline $\begin{array}{l}\text { Blinding of outcome as- } \\
\text { sessment (detection bias) } \\
\text { Subjective outcome }\end{array}$ & Low risk & $\begin{array}{l}\text { "double-blind". Sub-urothelial injection of saline or AboBTXA in de-identified } \\
\text { syringe with hydrodistension under general anaesthesia. "Patients and treat- } \\
\text { ing doctors were blinded to initial treatment allocation" }\end{array}$ \\
\hline
\end{tabular}

\begin{tabular}{lll}
\hline Blinding of outcome as- & Low risk & Outcome measurement is not likely to be influenced by lack of blinding \\
sessment (detection bias)
\end{tabular}

sessment (detection bias)

Objective outcome

Incomplete outcome data Low risk All randomised participants were included in analysis
(attrition bias)
Cure or improvement

\begin{tabular}{|c|c|c|}
\hline $\begin{array}{l}\text { Incomplete outcome data } \\
\text { (attrition bias) } \\
\text { Frequency }\end{array}$ & Low risk & $\begin{array}{l}25 / 26 \text { included in intervention group; } 26 / 27 \text { included in control group. } 1 \text { in } \\
\text { each group missing due to incomplete bladder diary }\end{array}$ \\
\hline $\begin{array}{l}\text { Incomplete outcome data } \\
\text { (attrition bias) } \\
\text { Nocturia }\end{array}$ & Low risk & $\begin{array}{l}25 / 26 \text { included in intervention group; } 26 / 27 \text { included in control group. } 1 \text { in } \\
\text { each group missing due to incomplete bladder diary }\end{array}$ \\
\hline $\begin{array}{l}\text { Incomplete outcome data } \\
\text { (attrition bias) } \\
\text { Interstitial Cystitis Symp- } \\
\text { tom Index }\end{array}$ & Low risk & All randomised participants were included in analysis \\
\hline $\begin{array}{l}\text { Incomplete outcome data } \\
\text { (attrition bias) } \\
\text { Interstitial Cystitis Prob- } \\
\text { lem Index }\end{array}$ & Low risk & All randomised participants were included in analysis \\
\hline $\begin{array}{l}\text { Incomplete outcome data } \\
\text { (attrition bias) } \\
\text { Functional bladder capac- } \\
\text { ity }\end{array}$ & Low risk & $\begin{array}{l}25 / 26 \text { included in intervention group; } 26 / 27 \text { included in control group. } 1 \text { in } \\
\text { each group missing due to incomplete bladder diary }\end{array}$ \\
\hline
\end{tabular}


Manning 2014 (Continued)
Incomplete outcome data
Low risk
All randomised participants were included in analysis

(attrition bias)

Adverse events

Selective reporting (re- Low risk Results included all outcomes specified in the methods section
porting bias)

Other bias Low risk None detected

Matsumoto 2013

\section{Study characteristics}

\begin{tabular}{ll}
\hline Methods & Study design: $\mathrm{RCT}$ \\
& Study duration (months): 2
\end{tabular}

\section{Participants}

\section{Number randomised: 30}

Setting: not reported

Country: Japan

Sex: 27 females and 1 male (participants in analysis only)

Age, years: mean 65.2 (SD 7.9) for Group A, mean 64.5 (SD 4.5) for Group B (participants in analysis only)

Diagnosis: IC/PBS (clinical diagnosis)

Inclusion criteria: patients aged $>50$ years with IC/PBS, who fulfilled the diagnostic criteria for IC proposed by the clinical guideline for IC. Stable history of IC/PBS symptoms $\geq 12$ weeks after bladder hydrodistension, total ICSI score $\geq 7$ and bladder pain (question 4 on ICSI) $\geq 4$

Exclusion criteria $>200 \mathrm{~mL}$ of average voided volume; urinary tract infection and vaginitis; urolithiasis; significant hepatic, renal, cardiac or cerebrospinal disease; neurological bladder (e.g. spinal cord injury, Parkinson's disease); surgery and/or radiotherapy to the pelvis; use of any dietary and/or antioxidant supplement; initiation of bladder training in the 12 weeks before the start of the study; initiation or discontinuation or change of the dose of the following drugs within 4 weeks after registration: antidepressant, anticholinergic drug, antihistaminergic drug, any drugs for lower urinary tract symptoms and steroids

Group B ( $\mathbf{n}=$ not reported): placebo water 3 packs/d (1 pack, $200 \mathrm{~mL}$ )

Regimen: 8 weeks

18 analysed in Group A, 10 analysed in Group B

Treatment category in NMA: hydrogen-rich water vs control

Outcome data in analysis
Pain: VAS (range 0 to 10): at 8 weeks
ICSI: at 8 weeks
ICPI: at 8 weeks
Adverse events: at 8 weeks


Matsumoto 2013 (Continued)
Funding
Public Health Research Foundation Comprehensive Support Project for Clinical Research Office on lifestyle-related disease

Notes

Publication status: full text

\section{Risk of bias}

Bias Authors' judgement Support for judgement

Random sequence genera- Low risk tion (selection bias)

Quote: "the randomization was performed by an independent statistician and was stratified by the Public Health Research Centre"

Comment: probably done

\begin{tabular}{ll}
\hline $\begin{array}{l}\text { Allocation concealment } \\
\text { (selection bias) }\end{array}$ & Low risk \\
& $\begin{array}{l}\text { Quote: "the randomization was performed by an independent statistician and } \\
\text { was stratified by the Public Health Research Centre" }\end{array}$
\end{tabular}

Comment: probably done

\begin{tabular}{|c|c|c|}
\hline $\begin{array}{l}\text { Blinding of participants } \\
\text { and personnel (perfor- }\end{array}$ & Unclear risk & $\begin{array}{l}\text { "double-blind, placebo-controlled" trial, using hydrogen-rich water and } \\
\text { "placebo water". Placebo not described }\end{array}$ \\
\hline
\end{tabular}

mance bias)

All outcomes

\begin{tabular}{lll}
\hline $\begin{array}{l}\text { Blinding of outcome as- } \\
\text { sessment (detection bias) } \\
\text { Subjective outcome }\end{array}$ & Unclear risk & "double-blind, placebo-controlled" trial. Placebo not described \\
\hline $\begin{array}{l}\text { Incomplete outcome data } \\
\text { (attrition bias) }\end{array}$ & Unclear risk & $\begin{array}{l}\text { Number randomised per group not stated. } 30 \text { randomised; } 28 \text { analysed (18 in } \\
\text { intervention group, } 10 \text { in placebo group) }\end{array}$ \\
\hline Pain & &
\end{tabular}

\begin{tabular}{lll}
\hline $\begin{array}{l}\text { Incomplete outcome data } \\
\text { (attrition bias) } \\
\text { Interstitial Cystitis Symp- } \\
\text { tom Index }\end{array}$ & Unclear risk & $\begin{array}{l}\text { Number randomised per group not stated. } 30 \text { randomised; } 28 \text { analysed (18 in } \\
\text { intervention group, 10 in placebo group) }\end{array}$ \\
\hline $\begin{array}{l}\text { Incomplete outcome data } \\
\text { (attrition bias) } \\
\text { Interstitial Cystitis Prob- } \\
\text { lem Index }\end{array}$ & Unclear risk & $\begin{array}{l}\text { Number randomised per group not stated. } 30 \text { randomised; } 28 \text { analysed (18 in } \\
\text { intervention group, } 10 \text { in placebo group) }\end{array}$ \\
\hline $\begin{array}{l}\text { Incomplete outcome data } \\
\text { (attrition bias) } \\
\text { Adverse events }\end{array}$ & Unclear risk & Number analysed or number randomised per group not stated \\
\hline $\begin{array}{l}\text { Selective reporting (re- } \\
\text { porting bias) }\end{array}$ & Low risk & Results included all outcomes specified in the methods section \\
\hline \begin{tabular}{l} 
Other bias \\
\hline
\end{tabular} & Low risk & None detected \\
\hline
\end{tabular}

Mayer 2005

\section{Study characteristics}

Methods Study design: RCT




\section{Participants}

\section{Number randomised: 265}

Setting: multi-centre

Country: USA

Sex: 217 females and 48 males

Age, years: mean 46.1 for 217 women

Diagnosis: IC (NIDDK criteria)

Inclusion criteria: eligible participants were at least 18 years old and received a diagnosis of IC, confirmed by cystoscopy and hydrodistension, according to National Institutes of Health-NIDDK criteria. All patients were required to have urinary frequency (self-reported 11 or more daily) and pain/discomfort ( 4 or more on a 0 to 9 Likert scale) for at least 24 weeks before study entry. Minimum of 12 weeks of treatment with any standard form of therapy or combination of therapies for IC must have failed; patients could not have been previously treated with BCG

Exclusion criteria 1 (medical history, comorbid conditions and tests): any history of bladder calculus, tuberculous cystitis; neurological disease affecting bladder function; bladder cancer, urethral cancer, prostate cancer (men only); other neoplasms requiring systemic therapy. Prior 12 weeks: genital herpes. Prior 6 weeks: positive urine culture (100,000 colony count). Concurrent: active tuberculosis requiring ongoing therapy; immunocompromised or known positive for HIV; vesicoureteral reflux; unable to void spontaneously; active urethral calculus, ureteral calculus, urethral diverticulum; documented chronic bacterial prostatitis (men only); active vaginitis, pregnancy, breastfeeding (women only); severe debilitating medical conditions; at least 1 voided volume $75 \mathrm{cc}$ in a 24-hour period; residual urine volume $150 \mathrm{cc}$ by ultrasound or catheter (men only)

Exclusion criteria 2 (prior and concurrent treatment): any history of: intravesical BCG, known allergy to or intolerance of BCG; cyclophosphamide; pelvic radiation; augmentation cystoplasty, cystectomy or cystolysis; neurectomy, implanted peripheral nerve stimulator. Prior 24 weeks: botulinum toxin injections for voiding dysfunction; urinary incontinence surgery; other bladder or urethral surgery that could interfere with bladder function; TURP, TUIP, TUIBN, TUMT, TUNA, balloon dilation of the prostate, open prostatectomy or any other prostate treatment such as cryotherapy or thermal therapy (men only); transvaginal surgery, hysterectomy, prolapse surgery, vaginal delivery or C-section (women only). Prior 12 weeks: hydrodistension, any intravesical treatment. Prior 6 weeks: urethral dilation, urodynamics, cystoscopy, bladder biopsy. Prior 4 weeks: initiation of any new medications for IC; any use of pentosan polysulfate; participation in another intervention study. Concurrent: isoniazid, rifampin, other antituberculosis therapies; anticoagulant therapy with the exception of low-dose aspirin

Interventions

Group B ( $\mathbf{n}=\mathbf{1 3 4}): 50 \mathrm{~mL}$ of normal saline

Up to six $50 \mathrm{~mL}$ instillations, each lasting up to 2 hours. Interval of 6 days to 3 weeks between instillations, and all completed within 10 weeks

Treatment category in NMA: immune modulators vs control

Outcomes Outcome data in analysis

Cure or improvement: response to instillation at week 34 (from start of treatment). This is defined as report of moderate or marked improvement on GRA, as well as recording no new IC treatments, no additional narcotic analgesia and no increase in IC medication dosage during weeks 31 to 34

Pain: VAS (range 0 to 9): at 34 weeks

ICSI: at 34 weeks

ICPI: at 34 weeks 
Mayer 2005 (Continued)

Functional bladder capacity: at 34 weeks

Adverse events: at 34 weeks
Co-operative agreements from NIDDK, University of Maryland General Clinical Research Centre Grant, General Clinical Research Centres Program, National Centre for Research Resources, NIH (National Institutes of Health)

\begin{tabular}{|c|c|c|}
\hline Notes & Publication status: $\mathrm{fl}$ & text \\
\hline \multicolumn{3}{|l|}{ Risk of bias } \\
\hline Bias & Authors' judgement & Support for judgement \\
\hline $\begin{array}{l}\text { Random sequence genera- } \\
\text { tion (selection bias) }\end{array}$ & Unclear risk & Quote: "randomized" \\
\hline $\begin{array}{l}\text { Allocation concealment } \\
\text { (selection bias) }\end{array}$ & Unclear risk & No information provided \\
\hline $\begin{array}{l}\text { Blinding of participants } \\
\text { and personnel (perfor- } \\
\text { mance bias) } \\
\text { All outcomes }\end{array}$ & Unclear risk & $\begin{array}{l}\text { "double-blind, placebo-controlled". Placebo not described. Intravesical BCG } \\
\text { vs intravesical placebo }\end{array}$ \\
\hline $\begin{array}{l}\text { Blinding of outcome as- } \\
\text { sessment (detection bias) } \\
\text { Subjective outcome }\end{array}$ & Unclear risk & $\begin{array}{l}\text { "double-blind, placebo-controlled". Placebo not described. For improvement } \\
\text { outcome, "a blinded, centralised review of the GRA [global response assess- } \\
\text { ment) and medication diaries was performed". Unclear for other outcomes }\end{array}$ \\
\hline $\begin{array}{l}\text { Blinding of outcome as- } \\
\text { sessment (detection bias) } \\
\text { Objective outcome }\end{array}$ & Low risk & Outcome measurement is not likely to be influenced by lack of blinding \\
\hline $\begin{array}{l}\text { Incomplete outcome data } \\
\text { (attrition bias) } \\
\text { Cure or improvement }\end{array}$ & Low risk & All randomised participants were included in analysis \\
\hline $\begin{array}{l}\text { Incomplete outcome data } \\
\text { (attrition bias) } \\
\text { Pain }\end{array}$ & Low risk & $\begin{array}{l}\text { 120/131 (92\%) included in intervention group; } 126 / 134 \text { (94\%) included in } \\
\text { placebo group }\end{array}$ \\
\hline
\end{tabular}

\section{Incomplete outcome data Low risk}

(attrition bias)

Frequency

\begin{tabular}{lll}
\hline $\begin{array}{l}\text { Incomplete outcome data } \\
\text { (attrition bias) }\end{array}$ & Low risk \\
$\begin{array}{l}\text { Interstitial Cystitis Symp- } \\
\text { tom Index }\end{array}$ & $\begin{array}{l}\text { 120/131 (92\%) included in intervention group; 126/134 (94\%) included in } \\
\text { placebo group }\end{array}$ \\
\hline $\begin{array}{l}\text { Incomplete outcome data } \\
\text { (attrition bias) }\end{array}$ & Low risk \\
$\begin{array}{l}\text { Interstitial Cystitis Prob- } \\
\text { lem Index }\end{array}$ & $\begin{array}{l}120 / 131(92 \%) \text { included in intervention group; 126/134 (94\%) included in } \\
\text { placebo group }\end{array}$ \\
\hline $\begin{array}{l}\text { Incomplete outcome data } \\
\text { (attrition bias) }\end{array}$ & Low risk & $\begin{array}{l}109 / 131(83 \%) \text { included in intervention group; 113/134 (84\%) included in } \\
\text { placebo group }\end{array}$
\end{tabular}


Mayer 2005 (Continued)

Functional bladder capac-

ity

\begin{tabular}{lll}
\hline $\begin{array}{l}\text { Incomplete outcome data } \\
\text { (attrition bias) } \\
\text { Adverse events }\end{array}$ & Low risk & $\begin{array}{l}\text { 129/131 (98\%) included in intervention group; 132/134 (99\%) included in } \\
\text { placebo group }\end{array}$ \\
\hline $\begin{array}{l}\text { Selective reporting (re- } \\
\text { porting bias) }\end{array}$ & Low risk & Results included all outcomes specified in the methods section \\
\hline Other bias & Low risk & None detected \\
\hline
\end{tabular}

Mirkin 2012

\section{Study characteristics}

\begin{tabular}{|c|c|c|}
\hline Methods & \multicolumn{2}{|c|}{ Study design: RCTStudy duration (month): 0.2} \\
\hline \multirow[t]{5}{*}{ Participants } & \multicolumn{2}{|c|}{$\begin{array}{l}\text { Number randomised: } 23 \\
\text { Setting: not reported }\end{array}$} \\
\hline & \multicolumn{2}{|c|}{$\begin{array}{l}\text { Country: Russia } \\
\text { Sex: female } \\
\text { Age, years: mean 38, SD } 11\end{array}$} \\
\hline & \multicolumn{2}{|l|}{ Diagnosis: PBS } \\
\hline & \multicolumn{2}{|c|}{ Inclusion criteria: women with PBS } \\
\hline & \multicolumn{2}{|c|}{ Exclusion criteria: not reported } \\
\hline \multirow[t]{3}{*}{ Interventions } & \multicolumn{2}{|c|}{$\begin{array}{l}\text { Group A ( } \mathbf{n}=\mathbf{1 5}) \text { : incobotulinumtoxin A } 200 \mathrm{IU} \text { with } 20 \mathrm{ml} \text { distilled water with } 200 \mathrm{mcl} 0.1 \mathrm{~N} \mathrm{HCl} \text { and } 2 \\
\text { ml DMSO (dimethyl sulfoxide) }\end{array}$} \\
\hline & \multicolumn{2}{|c|}{ Group B (n= 8): $\mathrm{NaCl} 25 \mathrm{ml}$} \\
\hline & \multicolumn{2}{|c|}{ Treatment category in NMA: neuromuscular blockade + DMSO versus control } \\
\hline \multirow[t]{4}{*}{ Outcomes } & \multicolumn{2}{|c|}{ Outcome data in analysis } \\
\hline & \multicolumn{2}{|c|}{ Pain: VAS (assumed range 0 to 10 ) at 5 days } \\
\hline & \multicolumn{2}{|l|}{ Frequency: at 5 days } \\
\hline & \multicolumn{2}{|c|}{ Adverse events: at 5 days } \\
\hline Funding & \multicolumn{2}{|l|}{ NMTC International } \\
\hline Notes & \multicolumn{2}{|c|}{ Publication status: abstract } \\
\hline \multicolumn{3}{|l|}{ Risk of bias } \\
\hline Bias & Authors' judgement & Support for judgement \\
\hline $\begin{array}{l}\text { Random sequence genera- } \\
\text { tion (selection bias) }\end{array}$ & Unclear risk & Quote: "randomized" \\
\hline
\end{tabular}


Mirkin 2012 (Continued)

Allocation concealment $\quad$ Unclear risk $\quad$ No information provided.
(selection bias)

Blinding of participants

Unclear risk

Blinding not mentioned. Intravesical electromotive incobotulinumtoxinA and and personnel (perforDMSO $(20 \mathrm{ml})$ versus saline $(25 \mathrm{ml})$.

mance bias)

All outcomes

\begin{tabular}{|c|c|c|}
\hline $\begin{array}{l}\text { Blinding of outcome as- } \\
\text { sessment (detection bias) }\end{array}$ & Unclear risk & $\begin{array}{l}\text { Blinding not mentioned. Intravesical electromotive incobotulinumtoxinA and } \\
\text { DMSO }(20 \mathrm{ml}) \text { vs. Saline }(25 \mathrm{ml}) \text {. }\end{array}$ \\
\hline
\end{tabular}

Subjective outcome

Incomplete outcome data Unclear risk Number analysed not stated.
(attrition bias)

Pain

Incomplete outcome data Unclear risk Number analysed not stated.
(attrition bias)

(attrition bias)

Frequency

Incomplete outcome data $\quad$ Unclear risk $\quad$ Number analysed not stated.
(attrition bias)

Adverse events

Selective reporting (re- Low risk $\quad$ Results included all outcomes specified in the methods section.
porting bias)

\begin{tabular}{ll}
\hline Other bias $\quad$ Low risk $\quad$ Not detected. \\
\hline
\end{tabular}

Mirkin 2015

\section{Study characteristics}

\begin{tabular}{ll}
\hline Methods & $\begin{array}{l}\text { Study design: RCT } \\
\text { Study duration (months): } 1\end{array}$
\end{tabular}

Participants

\section{Number randomised: 68}

Setting: not reported

Country: Russia

Sex: female

Age, years: not reported

\section{Diagnosis: BPS}

Inclusion criteria: women with BPS

Exclusion criteria: not reported

Interventions

Group A ( $\mathbf{n}=\mathbf{3 8}$ ): hyaluronic acid (HA) $40 \mathrm{mg} / 50 \mathrm{~mL}$ plus $15 \mathrm{mg}$ of tacrolimus (anticytokine substance). Tacrolimus was preliminarily dissolved in dimethyl sulfoxide (DMSO) $15 \mathrm{mg} / 5 \mathrm{~mL}$ and was mixed with HA before instillation

Group B ( $\mathbf{n}=\mathbf{3 0}$ ): HA $40 \mathrm{mg} / 50 \mathrm{~mL}$ (BioCyst) twice a week for 3 months

Treatment category in NMA: anticytokines vs control 
Mirkin 2015 (Continued)
Outcomes
Outcome data in analysis
Pain: VAS (assumed range 0 to 10): at 1 month
Frequency: at 1 month

\begin{tabular}{|c|c|c|}
\hline Funding & \multicolumn{2}{|l|}{ Not reported } \\
\hline Notes & \multicolumn{2}{|c|}{ Publication status: abstract } \\
\hline \multicolumn{3}{|l|}{ Risk of bias } \\
\hline Bias & Authors' judgement & Support for judgement \\
\hline $\begin{array}{l}\text { Random sequence genera- } \\
\text { tion (selection bias) }\end{array}$ & Unclear risk & Quote: "randomized" \\
\hline $\begin{array}{l}\text { Allocation concealment } \\
\text { (selection bias) }\end{array}$ & Unclear risk & No information provided \\
\hline $\begin{array}{l}\text { Blinding of participants } \\
\text { and personnel (perfor- } \\
\text { mance bias) } \\
\text { All outcomes }\end{array}$ & Unclear risk & $\begin{array}{l}\text { Blinding not mentioned. Intravesical instillation of hyaluronic acid (HA) vs HA + } \\
\text { anticytokine substances (tacrolimus) }\end{array}$ \\
\hline $\begin{array}{l}\text { Blinding of outcome as- } \\
\text { sessment (detection bias) } \\
\text { Subjective outcome }\end{array}$ & Unclear risk & $\begin{array}{l}\text { Blinding not mentioned. Intravesical instillation of hyaluronic acid (HA) vs HA + } \\
\text { anticytokine substances (tacrolimus) }\end{array}$ \\
\hline $\begin{array}{l}\text { Incomplete outcome data } \\
\text { (attrition bias) } \\
\text { Pain }\end{array}$ & Unclear risk & $\begin{array}{l}\text { Number analysed not stated. } 2 / 19(11 \%) \text { dropped out from HA group; } 3 / 19 \\
(16 \%) \text { dropped out from HA + tacrolimus group, all due to pain after instilla- } \\
\text { tion. Unclear how missing data were handled }\end{array}$ \\
\hline $\begin{array}{l}\text { Incomplete outcome data } \\
\text { (attrition bias) } \\
\text { Frequency }\end{array}$ & Unclear risk & $\begin{array}{l}\text { Number analysed not stated. } 2 / 19(11 \%) \text { dropped out from HA group; } 3 / 19 \\
(16 \%) \text { dropped out from HA + tacrolimus group, all due to pain after instilla- } \\
\text { tion. Unclear how missing data were handled }\end{array}$ \\
\hline $\begin{array}{l}\text { Selective reporting (re- } \\
\text { porting bias) }\end{array}$ & Low risk & Results included all outcomes specified in the methods section \\
\hline Other bias & Low risk & None detected \\
\hline
\end{tabular}

Moldwin 2015

\section{Study characteristics}

\begin{tabular}{ll}
\hline Methods & $\begin{array}{l}\text { Study design: RCT } \\
\text { Study duration (months): } 1\end{array}$
\end{tabular}

Participants Number randomised: 74

Setting: not reported

Country: USA

Sex: female

Age, years: not reported 
Diagnosis: IC/BPS with moderate to severe pain

Inclusion criteria: women with IC/BPS with moderate to severe pain

Exclusion criteria: not reported

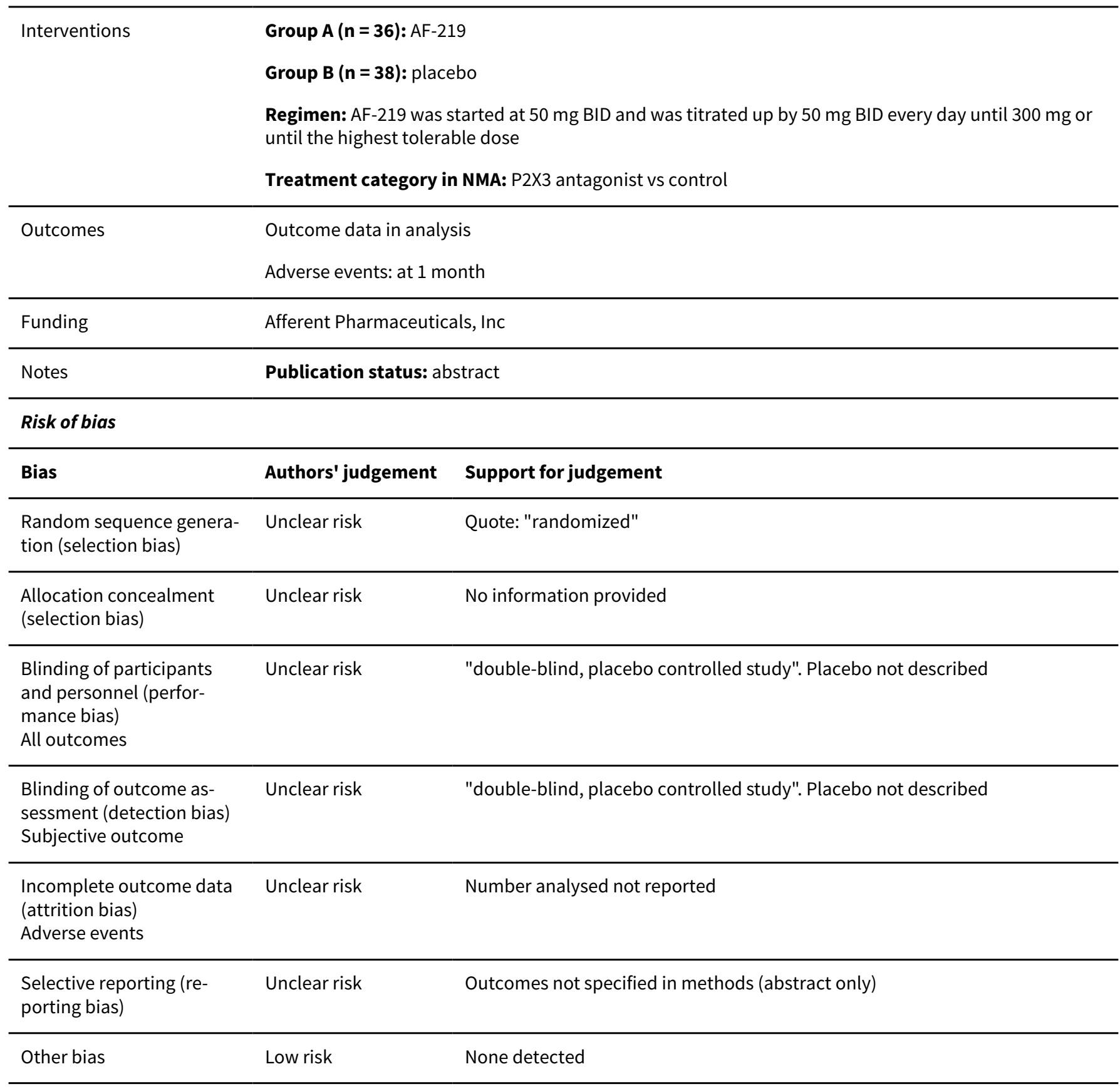

Mulholland 1990

\section{Study characteristics}

\begin{tabular}{ll}
\hline Methods & Study design: RCTStudy duration (months): 3 \\
\hline Participants & Number randomised: 110 \\
\hline
\end{tabular}


Mulholland 1990 (Continued)

\section{Setting: 5 centres}

Country: USA

Sex: 98 females and 12 males

Age, years: mean 43.3 for Group A, mean 45.3 for Group B

\section{Diagnosis: IC}

Inclusion criteria: patients with the following examination requirement and symptom complex: urgency expressed as moderate on a 5-point analog scale; frequency of at least 10 voids per day; nocturia of at least 2 voids per night; pain as recorded on a 5-point analog scale; continuous duration of symptom for at least 1 year; failed previous conventional therapy such as Clorpactin, hydrodilation or DMSO; average voided volume of $200 \mathrm{~mL}$ measured over 3-day period; negative urine culture and cytology; cystoscopic examination under anaesthesia showing petechial haemorrhages or ulcers with gross blood in the fluid return and bladder capacity of $800 \mathrm{~mL}$ or less

Exclusion criteria: patients with any of the following conditions: younger than 18 years; pregnancy; premenopausal and not practicing effective means of birth control; evidence of active bleeding peptic ulcer disease; bleeding diathesis; anticoagulant therapy; long-term use of narcotics; known allergy to pentosan polysulfate sodium; lack of availability for the duration of the study or inability to follow instructions; use of artificial sweeteners; lactating mothers; signs of recurrent bacteriuria; obvious neurological impairment; previous treatment with known bladder irritants; bladder carcinoma; urinary tuberculosis; schistosomiasis; treatment with Elmiron within 6 weeks of study

$\begin{array}{ll}\text { Interventions } & \text { Group A }(\mathbf{n}=\mathbf{5 4 )} \text { : pentosan polysulfate (PPS, oral) } \\ \text { Group B }(\mathbf{n}=\mathbf{5 6}) \text { : placebo } \\ \text { Treatment category in NMA: PPS vs control }\end{array}$

Outcome data in analysis
Cure or improvement: patient self-evaluation: overall improved: at 3 months
Pain: VAS (range 0 to 5): at 12 weeks
Adverse events: at 12 weeks

Funding PPS and placebo supplied by Medical Market Specialities, Inc., Boonton, New Jersey, USA

Notes Publication status: full text

\section{Risk of bias}

\begin{tabular}{|c|c|c|}
\hline Bias & Authors' judgement & Support for judgement \\
\hline $\begin{array}{l}\text { Random sequence genera- } \\
\text { tion (selection bias) }\end{array}$ & Low risk & Quote: "randomly assigned ... with a computer-generated random code" \\
\hline $\begin{array}{l}\text { Allocation concealment } \\
\text { (selection bias) }\end{array}$ & Low risk & $\begin{array}{l}\text { Quote: "all investigators were blinded during the study with the code estab- } \\
\text { lished and maintained by a separate centre" }\end{array}$ \\
\hline $\begin{array}{l}\text { Blinding of participants } \\
\text { and personnel (perfor- } \\
\text { mance bias) } \\
\text { All outcomes }\end{array}$ & Low risk & $\begin{array}{l}\text { "double blind"; "identically-appearing placebo capsules were given in the } \\
\text { same manner" as study drug }\end{array}$ \\
\hline $\begin{array}{l}\text { Blinding of outcome as- } \\
\text { sessment (detection bias) } \\
\text { Subjective outcome }\end{array}$ & Low risk & $\begin{array}{l}\text { "double blind"; "identically-appearing placebo capsules were given in the } \\
\text { same manner" as study drug }\end{array}$ \\
\hline
\end{tabular}


Mulholland 1990 (Continued)

Incomplete outcome data Low risk 51/54 (94\%) included in intervention group; 47/56 (84\%) included in control (attrition bias) group. "It is likely that lack of efficacy was responsible for patients dropping

Cure or improvement out"; "only 1 PPS and 2 placebo patients discontinued treatment due to adverse reactions"

\begin{tabular}{lll}
\hline $\begin{array}{l}\text { Incomplete outcome data } \\
\text { (attrition bias) }\end{array}$ & Unclear risk & Number analysed not reported \\
Pain & & \\
\hline $\begin{array}{l}\text { Incomplete outcome data } \\
\text { (attrition bias) } \\
\text { Adverse events }\end{array}$ & Unclear risk & Number analysed not reported \\
\hline $\begin{array}{l}\text { Selective reporting (re- } \\
\text { porting bias) }\end{array}$ & Low risk & Results included all outcomes specified in the methods section \\
\hline Other bias & Low risk & None detected \\
\hline
\end{tabular}

Nguan 2005

\section{Study characteristics}

\begin{tabular}{ll}
\hline Methods & $\begin{array}{l}\text { Study design: cross-over randomised trial } \\
\text { Study duration (months): } 5\end{array}$ \\
\hline Participants & Number randomised: 26 \\
& Setting: multi-centre \\
& Country: Canada \\
Sex: female & Age, years: not reported \\
& Diagnosis: IC (NIDDK criteria) \\
& Inclusion criteria: patients with IC \\
& Exclusion criteria: not reported \\
\hline
\end{tabular}

Interventions

Group A ( $\mathbf{n}=\mathbf{1 3})$ : acidic-buffered solution with $\mathrm{pH}$ of 5.0

Group B ( $\mathbf{n}=\mathbf{1 3})$ : neutral buffered solution ( $\mathrm{H} 2 \mathrm{PO} 4)$ with $\mathrm{pH}$ of 7.5

Single instillation via catheter of $100 \mathrm{~mL}$ solution, lasting for 30 minutes. Bladder then drained and washed twice with sterile de-ionised water; a second $100 \mathrm{~mL}$ solution then instilled

Treatment category in NMA: buffer solutions vs control

Outcome data in analysis
Pain: 10 -point numerical rating scale (assumed range 0 to 9): at 5 minutes after instillation

\begin{tabular}{ll}
\hline Funding Interstitial Association, USA \\
\hline
\end{tabular}

Notes Publication status: full text

Cross-over trial. Data for the first phase only were sought for this review 
Nguan 2005 (Continued)

Risk of bias

\begin{tabular}{|c|c|c|}
\hline Bias & Authors' judgement & Support for judgement \\
\hline \multirow[t]{2}{*}{$\begin{array}{l}\text { Random sequence genera- } \\
\text { tion (selection bias) }\end{array}$} & Low risk & $\begin{array}{l}\text { Quote: "randomly assigned"; "in blocks of four"; "generated using appropriate } \\
\text { software" }\end{array}$ \\
\hline & & Comment: probably done \\
\hline $\begin{array}{l}\text { Allocation concealment } \\
\text { (selection bias) }\end{array}$ & Unclear risk & No information provided \\
\hline $\begin{array}{l}\text { Blinding of participants } \\
\text { and personnel (perfor- } \\
\text { mance bias) } \\
\text { All outcomes }\end{array}$ & Unclear risk & $\begin{array}{l}\text { Blinding not mentioned. Bladder instillation with acidic vs neutral buffered so- } \\
\text { lution }\end{array}$ \\
\hline $\begin{array}{l}\text { Blinding of outcome as- } \\
\text { sessment (detection bias) } \\
\text { Subjective outcome }\end{array}$ & Unclear risk & $\begin{array}{l}\text { Blinding not mentioned. Bladder instillation with acidic vs neutral buffered so- } \\
\text { lution }\end{array}$ \\
\hline $\begin{array}{l}\text { Incomplete outcome data } \\
\text { (attrition bias) } \\
\text { Pain }\end{array}$ & Low risk & All randomised participants were included in analysis \\
\hline $\begin{array}{l}\text { Selective reporting (re- } \\
\text { porting bias) }\end{array}$ & Low risk & Results included all outcomes specified in the methods section \\
\hline Other bias & Low risk & None detected \\
\hline
\end{tabular}

\section{Nickel 2009}

\section{Study characteristics}

Methods Study design: RCTStudy duration (months): 0.5

Participants

Number randomised: 102

Setting: 19 centres

Country: USA and Canada

Sex: 99 female and 3 male

Age, years: median 42.5 (range 20 to 70 ) for Group A, median 49.0 (range 21 to 74 ) for Group B

Diagnosis: IC/PBS (clinical diagnosis)

Inclusion criteria: men and women aged 18 to 75 years with a history of symptoms of bladder pain/ discomfort $\geq 4$ on a 10-point Likert scale, described as suprapubic pain related to bladder filling, accompanied by other symptoms including increased daytime and nighttime frequency ( $\geq 8$ and $\geq 2$, respectively) in the absence of infection or other pathology, with or without the typical cystoscopic appearance of IC. Symptoms of abnormal urinary frequency and bladder pain/discomfort must have been present for $\geq 3$ months before study entry, as well as anterior vaginal wall/bladder wall pain on bimanual examination

Exclusion criteria: patients were excluded from the study if any of the following criteria were present: (1) currently receiving local anaesthetic analogue therapy or had received treatment for IC/PBS within 4 weeks before baseline visit; (2) unable to void spontaneously; (3) history of cardiac arrhythmias, other cardiac conduction disturbances and/or significant cardiovascular disease; (4) liver disease; (5) pelvic 
Nickel 2009 (Continued)

radiotherapy; (6) tuberculous cystitis; (7) neurological disease affecting bladder function; (8) bladder cancer, or carcinoma in situ, or urethral cancer; (9) bladder, urethral or ureteric calculi or clinical evidence of urethritis; (10) severely debilitating or urgent concurrent medical condition; (11) men with history of prostate cancer or an unevaluated suspicious prostate examination, or who were receiving treatment for chronic bacterial prostatitis, as documented by a positive urine culture; or previous history of recurrent bacterial UTI; (12) women who were pregnant or breastfeeding or had symptoms of bladder pain/discomfort and urinary frequency present only during menstruation; (13) women of childbearing potential, or men with partners of child-bearing potential, who were not prepared to commit to use of a reliable form of contraception during the course of the study

Interventions Group A $(\mathbf{n}=\mathbf{5 0})$ : PSD597 (200 mg lidocaine $+8.4 \%$ sodium bicarbonate solution to a final volume of 10 $\mathrm{mL})$ (PSD597 = intravesical alkalinised lidocaine)

Group B ( $\mathbf{~ = ~ 5 2 ) : ~ s a l i n e ~}$

Treatment category in NMA: local anaesthetics vs control

\begin{tabular}{ll}
\hline Outcomes & Outcome data in analysis \\
Cure or improvement: 'moderately' or 'markedly' improved on GRA: at 15 days \\
Pain: 10 -point Likert scale (assumed range 0 to 9 as reported in Nickel 2010 but could be 1 to 10 ): at 15 \\
days \\
ICSI: at 15 days \\
ICPI: at 15 days \\
Adverse events: at 15 days \\
\hline Funding & Plethora Solutions Plc \\
\hline Notes & Publication status: full text
\end{tabular}

\section{Risk of bias}

\begin{tabular}{|c|c|c|}
\hline Bias & Authors' judgement & Support for judgement \\
\hline $\begin{array}{l}\text { Random sequence genera- } \\
\text { tion (selection bias) }\end{array}$ & Unclear risk & Quote: "randomly allocated" \\
\hline $\begin{array}{l}\text { Allocation concealment } \\
\text { (selection bias) }\end{array}$ & Unclear risk & No information provided \\
\hline $\begin{array}{l}\text { Blinding of participants } \\
\text { and personnel (perfor- } \\
\text { mance bias) } \\
\text { All outcomes }\end{array}$ & Unclear risk & $\begin{array}{l}\text { "double-blind, placebo-controlled" trial. Blinding methods not described. } \\
\text { Bladder instillation of } 10 \mathrm{~mL} \text { of local anaesthestic or } 10 \mathrm{~mL} \text { of saline (placebo) }\end{array}$ \\
\hline $\begin{array}{l}\text { Blinding of outcome as- } \\
\text { sessment (detection bias) } \\
\text { Subjective outcome }\end{array}$ & Unclear risk & $\begin{array}{l}\text { "double-blind, placebo-controlled" trial. Blinding methods not described. } \\
\text { Bladder instillation of } 10 \mathrm{~mL} \text { of local anaesthestic or } 10 \mathrm{~mL} \text { of saline (placebo) }\end{array}$ \\
\hline $\begin{array}{l}\text { Incomplete outcome data } \\
\text { (attrition bias) } \\
\text { Cure or improvement }\end{array}$ & Low risk & $\begin{array}{l}45 / 50(90 \%) \text { included in intervention group; 50/52 (96\%) included in control } \\
\text { group }\end{array}$ \\
\hline $\begin{array}{l}\text { Incomplete outcome data } \\
\text { (attrition bias) } \\
\text { Pain }\end{array}$ & Low risk & $\begin{array}{l}45 / 50(90 \%) \text { included in intervention group; 50/52 (96\%) included in control } \\
\text { group }\end{array}$ \\
\hline
\end{tabular}


Nickel 2009 (Continued)

Incomplete outcome data (attrition bias)

Frequency

\begin{tabular}{|c|c|c|}
\hline $\begin{array}{l}\text { Incomplete outcome data } \\
\text { (attrition bias) } \\
\text { Interstitial Cystitis Symp- } \\
\text { tom Index }\end{array}$ & Low risk & $\begin{array}{l}45 / 50(90 \%) \text { included in intervention group; } 48 / 52(92 \%) \text { included in control } \\
\text { group }\end{array}$ \\
\hline $\begin{array}{l}\text { Incomplete outcome data } \\
\text { (attrition bias) } \\
\text { Interstitial Cystitis Prob- } \\
\text { lem Index }\end{array}$ & Low risk & $\begin{array}{l}45 / 50(90 \%) \text { included in intervention group; } 48 / 52(92 \%) \text { included in control } \\
\text { group }\end{array}$ \\
\hline $\begin{array}{l}\text { Incomplete outcome data } \\
\text { (attrition bias) } \\
\text { Adverse events }\end{array}$ & Low risk & All randomised participants were included in analysis \\
\hline $\begin{array}{l}\text { Selective reporting (re- } \\
\text { porting bias) }\end{array}$ & Low risk & Results included all outcomes specified in the methods section \\
\hline Other bias & Low risk & None detected \\
\hline
\end{tabular}

\section{Nickel 2010}

\section{Study characteristics}

$\begin{array}{ll}\text { Methods } & \text { Study design: RCT } \\ & \text { Study duration (months): } 3\end{array}$

Participants Number randomised: 65

Setting: multi-centre

Country: Canada, USA

Sex: 64 females and 1 male

Age, years: mean 45.5 (SD 16.07) for Group A, mean 44.4 (SD 14.87) for Group B

Diagnosis: IC/PBS. Clinical diagnosis consistent with the IC Database Study (Hanno 1999), and definition of IC/PBS described at the NIH Urologic Chronic Pelvic Pain Consensus Symposium (Baltimore, December 2007)

Inclusion criteria: females and males at least 18 years of age with clinical diagnosis of IC/PBS and no medical condition or therapy that would exclude safe concomitant use of chondroitin sulfate were evaluated in this clinical trial. Patients met all of the following inclusion criteria for this study: female or male patient 18 years or older; negative bacterial urine culture from urine collected aseptically during the screening period; patient-reported average urinary frequency at least 11 times per 24-hour period during the screening period, as captured by a 2-day diary; average pain/discomfort score of at least 4 on a 0 to 9 Likert pain scale during the screening period. In addition, all female patients of child-bearing age had a negative urine pregnancy test at baseline, or assurance of previous surgery, condition or state rendering conception impossible

Exclusion criteria: patients who met any of the following criteria: lactating females; currently receiving or having previously received investigational drugs within 30 days of screening; received any intravesical therapy for IC/PBS within 4 months of first study instillation; received any oral therapy for IC/PBS within 2 months of first study instillation (an exception is permitted for oral tricyclic antidepressants). Patients were excluded if they were prescribed antihistamines, hormonal agonists or antagonist therapies within the last 2 months (they could be included if doses of these therapies had been stable during 
Nickel 2010 (Continued)

the last 2 months and did not change during the duration of the study); had neurological disease that is known to or may affect bladder function; had previous surgeries or procedures that affected bladder function; had a current diagnosis of chemical tuberculosis or radiation cystitis; had a history of bladder or lower ureteral calculi; had a history of cancer within the last 5 years other than adequately treated non-melanoma skin cancer; were known to have an active sexually transmitted disease; were known to have current vaginitis; or had current endometriosis confirmed by laparoscopy or biopsy. Patients receiving allowable pre-study therapies for IC/PBS were asked not to change these regimens throughout the course of treatment and follow-up periods. Instead, to manage any episodes of increased pain associated with IC/PBS, the following analgesic therapies were allowed: narcotic analgesics, urinary analgesics, non-steroidal anti-inflammatory drugs, salicylate and other non-narcotic analgesics

Interventions

Group A ( $\mathbf{n}=\mathbf{3 3}): 20 \mathrm{~mL}$ of $2 \%$ sodium chondroitin sulfate

Group B (n = 32): $20 \mathrm{~mL} \mathrm{NaCl}$

Treatment category in NMA: chondroitin sulfate vs control

\begin{tabular}{|c|c|c|}
\hline \multirow[t]{7}{*}{ Outcomes } & \multicolumn{2}{|c|}{ Outcome data in analysis } \\
\hline & \multicolumn{2}{|c|}{ Cure or improvement: 'moderately' or 'markedly' improved on GRA: at 12 weeks } \\
\hline & \multicolumn{2}{|c|}{ Pain: 10-point Likert scale (range 0 to 9): at 7 weeks } \\
\hline & \multicolumn{2}{|l|}{ Frequency: at 7 weeks } \\
\hline & \multicolumn{2}{|l|}{ ICSI: at 12 weeks } \\
\hline & \multicolumn{2}{|l|}{ ICPI: at 12 weeks } \\
\hline & \multicolumn{2}{|c|}{ Adverse events: at 12 weeks } \\
\hline Funding & \multicolumn{2}{|c|}{ Watson Pharmaceuticals, Inc. } \\
\hline Notes & \multicolumn{2}{|c|}{ Publication status: full text } \\
\hline \multicolumn{3}{|l|}{ Risk of bias } \\
\hline Bias & Authors' judgement & Support for judgement \\
\hline $\begin{array}{l}\text { Random sequence genera- } \\
\text { tion (selection bias) }\end{array}$ & Low risk & Quote: "randomized ... after a predetermined randomization schedule" \\
\hline $\begin{array}{l}\text { Allocation concealment } \\
\text { (selection bias) }\end{array}$ & Unclear risk & No information provided \\
\hline $\begin{array}{l}\text { Blinding of participants } \\
\text { and personnel (perfor- } \\
\text { mance bias) } \\
\text { All outcomes }\end{array}$ & Low risk & $\begin{array}{l}\text { Quote: "double-blind". Intravesical instillation of study drug or vehicle control. } \\
\text { "Blinding ... was maintained throughout the study by use of identical patient } \\
\text { kits containing identically appearing active or vehicle control vials and pack- } \\
\text { aging" }\end{array}$ \\
\hline $\begin{array}{l}\text { Blinding of outcome as- } \\
\text { sessment (detection bias) } \\
\text { Subjective outcome }\end{array}$ & Low risk & $\begin{array}{l}\text { Quote: "double-blind". Intravesical instillation of study drug or vehicle control. } \\
\text { "Blinding ... was maintained throughout the study by use of identical patient } \\
\text { kits containing identically appearing active or vehicle control vials and pack- } \\
\text { aging" }\end{array}$ \\
\hline $\begin{array}{l}\text { Incomplete outcome data } \\
\text { (attrition bias) } \\
\text { Cure or improvement }\end{array}$ & Low risk & $\begin{array}{l}29 / 33(88 \%) \text { included in intervention group ( } 2 \text { discontinued due to consent } \\
\text { withdrawal, } 1 \text { due to lack of efficacy, } 1 \text { lost to follow-up); } 29 / 33(88 \%) \text { included } \\
\text { in control group ( } 1 \text { discontinued due to adverse event, } 1 \text { due to consent with- } \\
\text { drawal); LOCF also used }\end{array}$ \\
\hline
\end{tabular}


Nickel 2010 (Continued)

Incomplete outcome data Low risk (attrition bias)

Pain
$29 / 33(88 \%)$ included in intervention group ( 2 discontinued due to consent withdrawal, 1 due to lack of efficacy, 1 lost to follow-up); 29/33 (88\%) included in control group (1 discontinued due to adverse event, 1 due to consent withdrawal); LOCF also used

Incomplete outcome data Low risk
(attrition bias)
(attrition bias)

Frequency
$29 / 33(88 \%)$ included in intervention group (2 discontinued due to consent withdrawal, 1 due to lack of efficacy, 1 lost to follow-up); 29/33 (88\%) included in control group (1 discontinued due to adverse event, 1 due to consent withdrawal); LOCF also used

$29 / 33(88 \%$ ) included in intervention group ( 2 discontinued due to consent withdrawal, 1 due to lack of efficacy, 1 lost to follow-up); 29/33 (88\%) included in control group (1 discontinued due to adverse event, 1 due to consent withdrawal); LOCF also used
Incomplete outcome data Low risk (attrition bias) Interstitial Cystitis Symptom Index
$29 / 33(88 \%)$ included in intervention group ( 2 discontinued due to consent withdrawal, 1 due to lack of efficacy, 1 lost to follow-up); 29/33 (88\%) included in control group (1 discontinued due to adverse event, 1 due to consent withdrawal); LOCF also used
Incomplete outcome data Low risk (attrition bias)

Interstitial Cystitis Problem Index
All randomised participants were included in analysis

Incomplete outcome data Low risk (attrition bias)

Adverse events

\begin{tabular}{lll}
\hline $\begin{array}{l}\text { Selective reporting (re- } \\
\text { porting bias) }\end{array}$ & Low risk & Results included all outcomes specified in the methods section \\
\hline Other bias & Low risk & None detected \\
\hline
\end{tabular}

Nickel 2012a

\title{
Study characteristics
}

\begin{tabular}{ll}
\hline Methods & $\begin{array}{l}\text { Study design: } \mathrm{RCT} \\
\text { Study duration (months): } 2.8\end{array}$
\end{tabular}

Participants

\author{
Number randomised: 98 \\ Setting: multi-centre \\ Country: USA \\ Sex: female \\ Age, years: mean 44.4 (SD 14.59) for Group A, mean 46.8 (SD 14.06) for Group B. 8 women (8.2\%) were \\ aged 65 and above
}

\section{Diagnosis: IC/BPS}

Inclusion criteria: women were considered for inclusion in the present study if they had been diagnosed or re-diagnosed with IC/BPS within the previous 2 years; had a subject-reported average urinary frequency of 8 times/24 hours during the screening period, as captured by a 3-day diary; had a pain/ pressure/discomfort score of 40 to $80 \mathrm{~mm}$ on a pain visual analog scale (VAS) during the screening period; and had an inadequate clinical response after 6 months of conservative treatment. Conservative treatment could have included $\geq 1$ of the following: patient education, timed voiding and behavioural modification therapy, dietary restrictions, stress reduction and/or oral therapy with tricyclic antidepressants, antihistamines, antimuscaranic (anticholinergic) agents, $\boldsymbol{\alpha}$-adrenergic blockers or analgesics. Subjects were also required to have had a negative urine pregnancy test at screening and had to 
Nickel 2012a (Continued)

agree to use an acceptable form of birth control, as agreed to by the investigator, during the study period, if of child-bearing potential

Exclusion criteria: subjects were excluded from participation if they were lactating; had previously received investigational products or devices within 30 days of screening; had previously received Uracyst; had had symptoms of IC/BPS for > 8 years; or had received any intravesical therapy (including hydrodistension), oral pentosan polysulfate or oral chondroitin within 12 weeks of screening. They were also excluded if they had received any of the following medications within 4 weeks of screening, unless such medications had been administered at a stable dose during that month and no changes had been made to these medications during the study: tricyclic antidepressants, antihistamines (use of antihistamines as needed for allergies were allowed), anticonvulsants, adrenergic blockers, hormonal agonists or antagonists or anticholinergic agents. Also, women were excluded if they had used $\geq 70 \mathrm{mg}$ of morphine equivalents of opioids weekly within 4 weeks of screening; were currently receiving therapy with invasive neuromodulation; had any current condition that could be confused with IC/BPS or could confuse the presentation of IC/BPS; had a screening period postvoid residual urine volume $>100 \mathrm{~mL}$; or had a history of bladder or lower ureteral calculi or previous surgery or procedures that could have affected bladder function or any cancer within 5 years before screening, other than adequately treated non-melanoma skin cancer

Interventions

Group A ( $\mathbf{n}=\mathbf{4 9}): 20 \mathrm{~mL}$ of $2 \%$ sodium chondroitin sulfate

Group B ( $\mathbf{n}=49): 20 \mathrm{~mL}$ of $\mathrm{NaCl}$

Weekly for 8 weeks

Treatment category in NMA: chondroitin sulfate vs control

Outcome data in analysis
Cure or improvement: 'moderately' or 'markedly' improved at 15 days: at 11 weeks
Pain: VAS (assumed range 0 to 100): at 11 weeks
Frequency: at 11 weeks
ICSI: at 11 weeks
ICPI: at 11 weeks

Adverse events: at 11 weeks

\begin{tabular}{lll}
\hline Funding & Watson Pharmaceuticals, Inc. \\
\hline Notes & Publication status: full text \\
\hline Risk of bias & & \\
\hline Bias & Authors' judgement & Support for judgement \\
\hline $\begin{array}{l}\text { Random sequence genera- } \\
\text { tion (selection bias) }\end{array}$ & Low risk & $\begin{array}{l}\text { Quote: "the treatment assignment was made according to a randomization } \\
\text { schedule generated using a permuted block by a randomisation statistician } \\
\text { (independent from the project statistician)" }\end{array}$ \\
\hline $\begin{array}{l}\text { Allocation concealment } \\
\text { (selection bias) }\end{array}$ & Low risk & $\begin{array}{l}\text { Quote: "the treatment assignment was made according to a randomization } \\
\text { schedule generated using a permuted block by a randomisation statistician } \\
\text { (independent from the project statistician)" }\end{array}$ \\
& & \begin{tabular}{l} 
Comment: probably done \\
\hline
\end{tabular}
\end{tabular}


Nickel 2012a (Continued)

Blinding of participants Low risk Quote: "double-blind". Bladder instillation of study drug or inactive control and personnel (perfor("the identical phosphate-buffered saline vehicle used") mance bias)

All outcomes

\begin{tabular}{lll}
\hline $\begin{array}{l}\text { Blinding of outcome as- } \\
\text { sessment (detection bias) } \\
\text { Subjective outcome }\end{array}$ & Low risk & $\begin{array}{l}\text { Quote: "double-blind". Bladder instillation of study drug or inactive control } \\
\text { ("the identical phosphate-buffered saline vehicle used") }\end{array}$ \\
\hline $\begin{array}{l}\text { Incomplete outcome data } \\
\text { (attrition bias) } \\
\text { Cure or improvement }\end{array}$ & Low risk & $\begin{array}{l}41 / 49 \text { included in intervention group (discontinued due to } 1 \text { adverse event, } 1 \\
\text { consent withdrawal, } 5 \text { lack of efficacy, } 1 \text { lost to follow-up); } 40 / 49 \text { included in } \\
\text { control group (discontinued due to } 1 \text { consent withdrawal, } 5 \text { lack of efficacy, } 2 \\
\text { lost to FU, } 1 \text { other); LOCF }\end{array}$ \\
\hline
\end{tabular}

\begin{tabular}{lll}
\hline Incomplete outcome data & Low risk & $\begin{array}{l}\text { All randomised participants were included in analysis (assumption made - in- } \\
\text { (attrition bias) }\end{array}$
\end{tabular}

(attrition bias)

consistent reporting of denominators)

\section{All randomised participants were included in analysis (assumption made - in- consistent reporting of denominators)}

\section{Incomplete outcome data Low risk (attrition bias) \\ Frequency}

\begin{tabular}{|c|c|c|}
\hline $\begin{array}{l}\text { Incomplete outcome data } \\
\text { (attrition bias) } \\
\text { Interstitial Cystitis Symp- } \\
\text { tom Index }\end{array}$ & Low risk & $\begin{array}{l}\text { All randomised participants were included in analysis (assumption made - in- } \\
\text { consistent reporting of denominators) }\end{array}$ \\
\hline $\begin{array}{l}\text { Incomplete outcome data } \\
\text { (attrition bias) } \\
\text { Interstitial Cystitis Prob- } \\
\text { lem Index }\end{array}$ & Low risk & $\begin{array}{l}\text { All randomised participants were included in analysis (assumption made - in- } \\
\text { consistent reporting of denominators) }\end{array}$ \\
\hline $\begin{array}{l}\text { Incomplete outcome data } \\
\text { (attrition bias) } \\
\text { Adverse events }\end{array}$ & Low risk & $\begin{array}{l}\text { All randomised participants were included in analysis (assumption made - in- } \\
\text { consistent reporting of denominators) }\end{array}$ \\
\hline $\begin{array}{l}\text { Selective reporting (re- } \\
\text { porting bias) }\end{array}$ & Low risk & Results included all outcomes specified in the methods section \\
\hline Other bias & Low risk & None detected \\
\hline
\end{tabular}

Nickel 2012b

\section{Study characteristics}

\begin{tabular}{|c|c|}
\hline Methods & Study design: RCTStudy duration (months): 3 \\
\hline \multirow[t]{6}{*}{ Participants } & Number randomised: 161 \\
\hline & Setting: 35 centres \\
\hline & Country: USA, Canada, Denmark, Finland, France, Germany \\
\hline & Sex: 147 females and 14 males \\
\hline & $\begin{array}{l}\text { Age, years: mean } 49.9 \text { (SD 13.6, range } 19 \text { to } 76) \text { for Group A ( } 30 \mathrm{mg} / \mathrm{d}, \mathrm{n}=54) \text {, mean } 49.6 \text { (SD 14.6, range } \\
21 \text { to } 80 \text { ) for Group A ( } 60 \mathrm{mg} / \mathrm{d}, \mathrm{n}=55) \text {, mean } 52.1 \text { (SD } 14.0 \text {, range } 22 \text { to } 79) \text { for Group } B(n=52)\end{array}$ \\
\hline & Diagnosis: IC, moderate to severe \\
\hline
\end{tabular}


Nickel 2012b (Continued)

Inclusion criteria: participants had moderate to severe IC based on scores of 13 or more on the Pelvic Pain and Urgency/Frequency Questionnaire and 7 or greater on the O'Leary-Sant ICSI. Study inclusion also required evidence of cystoscopy within 2 years of screening to confirm the absence of other significant lower urinary tract pathology and the presence or absence of cystoscopic features of IC. Study continuation required completion of 4 or more daily worst pain severity scores during the 7 days before randomisation, with a mean daily worst pain severity score of 4 or more on an 11-point numerical rating scale (range 0 (no IC pain) to 10 (IC pain as bad as you can imagine)). Mean severity score was the average of 24-hour worst pain severity scores recorded for the 7 days before randomisation. Mean micturition frequency per 24 hours of 8 or more (derived from the symptom diary before randomisation) was also required

Exclusion criteria: IC symptoms less than 6 months; PVR urine volume greater than $200 \mathrm{~mL}$ at screening; history, diagnosis, signs or symptoms of any clinically significant psychiatric disorder; MVV less than $50 \mathrm{~mL}$ or greater than $350 \mathrm{~mL}$ during 3 consecutive days; total volume voided greater than 3000 $\mathrm{mL}$ on average per 24 hours; greater than 1 haematuria on dipstick test at screening, unless fully investigated to rule out significant urological disease; and/or microbiologically proven urinary tract infection at screening or randomisation

Group A ( $\mathbf{n}=\mathbf{1 0 9})$ : PD-0299685 (Ca2 Channel 2 Ligand)
Group B ( $\mathbf{n}=\mathbf{5 2}$ ): placebo
Regimen: after the run-in, patients received placebo, $30 \mathrm{mg}$ PD-0299685 daily (administered as $15 \mathrm{mg}$
BID) or $60 \mathrm{mg}$ PD-0299685 daily (administered as $30 \mathrm{mg}$ BID) for 12 weeks

Treatment category in NMA: calcium channel agonists vs control

Outcome data in analysis
Cure or improvement: based on GRA (assumed from reports): at 12 weeks
Pain: 11 -point numerical rating scale (range 0 to 10): at 12 weeks
Frequency per 24 hours: at 12 weeks
ICSI: at 12 weeks

Adverse events: at 12 weeks

\begin{tabular}{ll}
\hline Funding & Pfizer \\
\hline Notes & Publication status: full text \\
\hline
\end{tabular}

\section{Risk of bias}

\begin{tabular}{lll}
\hline Bias & Authors' judgement & Support for judgement \\
\hline $\begin{array}{l}\text { Random sequence genera- } \\
\text { tion (selection bias) }\end{array}$ & Low risk & $\begin{array}{l}\text { Quote: "the randomization list was created with computer-generated pseu- } \\
\text { do-random code using the method of random permuted blocks" }\end{array}$ \\
\hline $\begin{array}{l}\text { Allocation concealment } \\
\text { (selection bias) }\end{array}$ & Unclear risk & No information provided \\
\hline $\begin{array}{l}\text { Blinding of participants } \\
\begin{array}{l}\text { and personnel (perfor- } \\
\text { mance bias) }\end{array}\end{array}$ & Unclear risk & "double-blind, placebo-controlled" trial. Placebo not described \\
$\begin{array}{l}\text { All outcomes } \\
\text { Blinding of outcome as- } \\
\text { sessment (detection bias) } \\
\begin{array}{l}\text { Subjective outcome } \\
\hline\end{array}\end{array}$ & Unclear risk & "double-blind, placebo-controlled" trial. Placebo not described \\
\hline
\end{tabular}


Nickel 2012b (Continued)

Incomplete outcome data High risk 71/109 (65\%) included in intervention group; 40/52 (76\%) included in control (attrition bias) group

Cure or improvement

$\begin{array}{lll}\text { Incomplete outcome data } & \text { High risk } & \begin{array}{l}64 / 109(59 \%) \text { included in intervention group; 37/52 (71\%) included in control } \\ \text { (attrition bias) }\end{array} \\ \text { group }\end{array}$

Pain

\begin{tabular}{ll}
\hline $\begin{array}{l}\text { Incomplete outcome data } \\
\text { (attrition bias) }\end{array}$ & High risk \\
Frequency & $\begin{array}{l}76 / 109(70 \%) \text { included in intervention group; 43/52 (83\%) included in control } \\
\text { group }\end{array}$
\end{tabular}

Frequency

Incomplete outcome data High risk

(attrition bias)

$70 / 109$ (64\%) included in intervention group; 40/52 (77\%) included in control

Interstitial Cystitis Sympgroup

tom Index

\begin{tabular}{lll}
\hline $\begin{array}{l}\text { Incomplete outcome data } \\
\text { (attrition bias) } \\
\text { Adverse events }\end{array}$ & Low risk & All randomised participants were included in analysis \\
\hline $\begin{array}{l}\text { Selective reporting (re- } \\
\text { porting bias) }\end{array}$ & Low risk & Results included all outcomes specified in the methods section \\
\hline Other bias & Low risk & None detected \\
\hline
\end{tabular}

Nickel 2015

\section{Study characteristics}

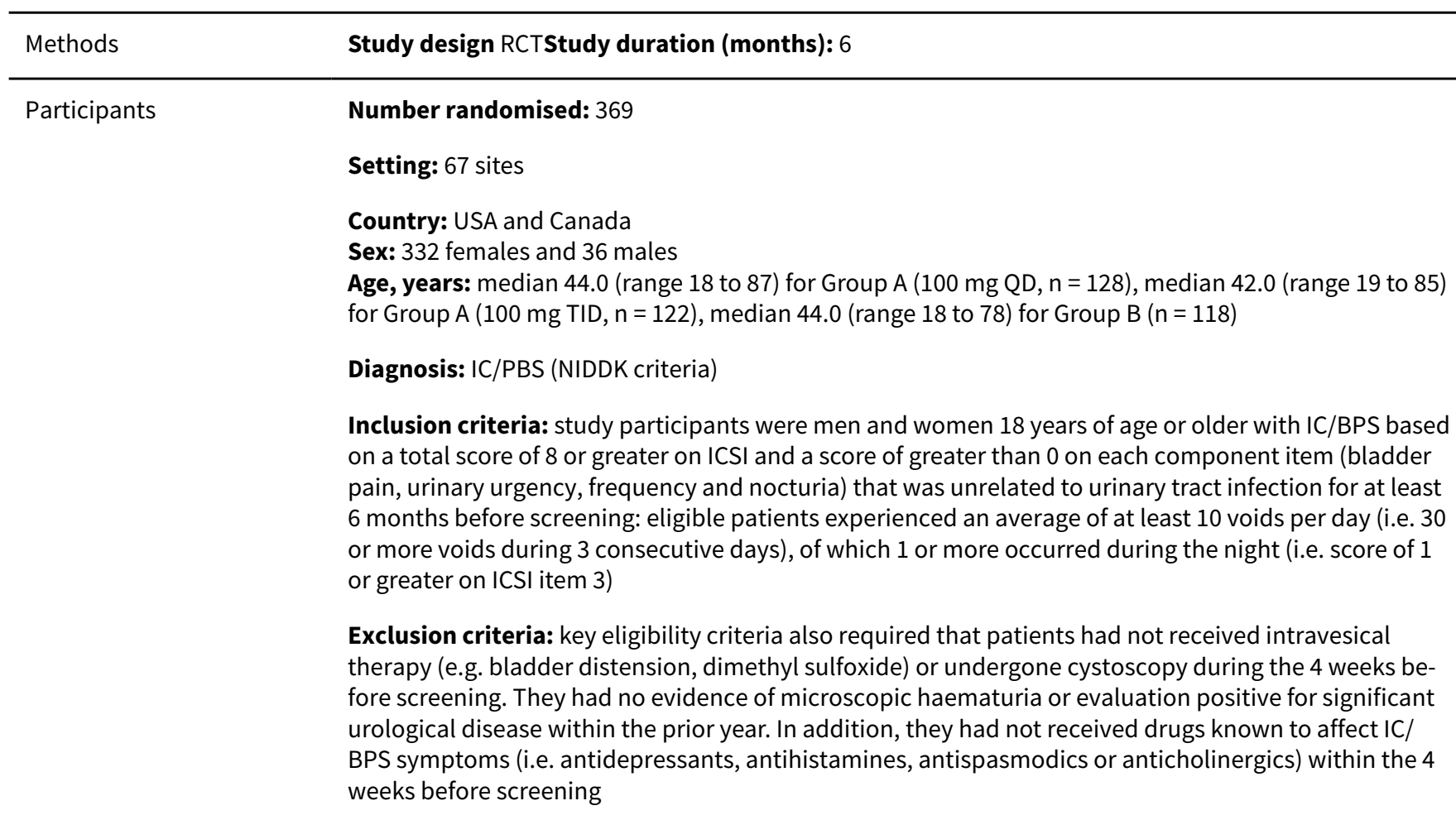


Nickel 2015 (Continued)

Group B ( $\mathbf{n}=118)$ : placebo

Regimen: PPS $100 \mathrm{mg}$ QD (i.e. once a day) or PPS $100 \mathrm{mg}$ TID (i.e. 3 times a day) for 24 weeks

Treatment category in NMA: PPS vs control

\begin{tabular}{ll}
\hline Outcomes & Outcome data in analysis \\
& Cure or improvement: 'moderately' or 'markedly' improved on GRA: at 24 weeks \\
& Pain: 11-point numerical rating scale (range 0 to 10): at 24 weeks \\
& Frequency: at 24 weeks \\
& Adverse events: at 24 weeks \\
\hline Funding & Janssen Research \& Development \\
\hline Notes & Publication status: full text
\end{tabular}

\section{Risk of bias}

\begin{tabular}{|c|c|c|}
\hline Bias & Authors' judgement & Support for judgement \\
\hline $\begin{array}{l}\text { Random sequence genera- } \\
\text { tion (selection bias) }\end{array}$ & Low risk & $\begin{array}{l}\text { Quote: "randomized ... based on a computer generated randomization sched- } \\
\text { ule" }\end{array}$ \\
\hline $\begin{array}{l}\text { Allocation concealment } \\
\text { (selection bias) }\end{array}$ & Unclear risk & No information provided \\
\hline $\begin{array}{l}\text { Blinding of participants } \\
\text { and personnel (perfor- } \\
\text { mance bias) } \\
\text { All outcomes }\end{array}$ & Low risk & "double-blind, placebo-controlled" trial, using "matching placebo" \\
\hline $\begin{array}{l}\text { Blinding of outcome as- } \\
\text { sessment (detection bias) } \\
\text { Subjective outcome }\end{array}$ & Low risk & "double-blind, placebo-controlled" trial, using "matching placebo" \\
\hline $\begin{array}{l}\text { Incomplete outcome data } \\
\text { (attrition bias) } \\
\text { Cure or improvement }\end{array}$ & Low risk & $\begin{array}{l}\text { For missing data, "the last observed data were carried forward to the end } \\
\text { point for analysis" (despite large number discontinuing trial: 106/251 from in- } \\
\text { tervention group and 55/118 from control group discontinued) }\end{array}$ \\
\hline $\begin{array}{l}\text { Incomplete outcome data } \\
\text { (attrition bias) } \\
\text { Pain }\end{array}$ & Low risk & $\begin{array}{l}232 / 251(92 \%) \text { included in intervention group; } 111 / 118(94 \%) \text { included in con- } \\
\text { trol group }\end{array}$ \\
\hline $\begin{array}{l}\text { Incomplete outcome data } \\
\text { (attrition bias) } \\
\text { Frequency }\end{array}$ & Low risk & $\begin{array}{l}232 / 251(92 \%) \text { included in intervention group; } 111 / 118(94 \%) \text { included in con- } \\
\text { trol group }\end{array}$ \\
\hline $\begin{array}{l}\text { Incomplete outcome data } \\
\text { (attrition bias) } \\
\text { Adverse events }\end{array}$ & Low risk & All randomised participants were included in analysis \\
\hline $\begin{array}{l}\text { Selective reporting (re- } \\
\text { porting bias) }\end{array}$ & Low risk & Results included all outcomes specified in the methods section \\
\hline Other bias & Low risk & None detected \\
\hline
\end{tabular}


Nickel 2016

\section{Study characteristics}

\begin{tabular}{ll}
\hline Methods & Study design: RCT \\
Study duration (months): 2 \\
Number randomised: 82 \\
Setting: not reported \\
Country: not reported \\
Sex: 70 females and 12 males \\
Age, years: mean 45.3 (range 22 to 74 ) for Group A, mean 51.4 (range 24 to 77 ) for Group B \\
Diagnosis: IC/BPS \\
Inclusion criteria: male and female patients aged $\geq 18$ years. Female patients had to meet 1 of the fol- \\
lowing criteria: non-child-bearing potential: postmenopausal, defined as women who aged $\geq 45$ years \\
with amenorrhoea for 24 consecutive months; child-bearing potential: were not pregnant or lactating \\
and abstinent, or using adequate contraception. Inclusion criteria also required evidence of cystoscopy \\
within 2 years of screening confirming the absence of significant lower urinary tract pathology and the \\
presence or absence of cystoscopic features of interstitial cystitis/bladder pain syndrome (IC/BPS). Pa- \\
tients were randomised if at visit 2 (randomisation), they met the continuation criteria of completed 4 \\
or more average bladder pain scores within any of the 7 days before randomisation with a mean aver- \\
age bladder pain intensity score of 4 or greater (on an 11 -point NRS) and a mean micturition frequency \\
of 8 or greater per 24 hours during any 3 consecutive days in the previous 7 days
\end{tabular}

Exclusion criteria key exclusion criteria were patients with body mass index $>39 \mathrm{~kg} / \mathrm{m}^{2}$; pregnant women, lactating women, women suspected of being pregnant and women wishing to become pregnant during the course of the study; patients with symptoms of IC/BPS for $<6$ months before screening; patients with postvoid residual volume $>200 \mathrm{~mL}$ at screening; patients with mean voided volume $<40$ and $>400 \mathrm{~mL}$ per micturition as measured over 1 day of the 7-day e-diary period completed before randomisation (visit 2); patients with total daily volume voided $>3500 \mathrm{~mL}$, as confirmed by the e-diary completed before randomisation

Group B ( $=42)$ : placebo

Treatment category in NMA: immune modulators vs control

\begin{tabular}{ll}
\hline Outcomes & Outcome data in analysis \\
& Pain: 11-point numerical rating scale (range 0 to 10): at 8 weeks \\
& Adverse events: at 8 weeks \\
\hline Funding & Pfizer \\
\hline Notes & Publication status: full text \\
& This paper reports multiple trials. Data for this review were extracted only from "Study A4091035" \\
\hline Risk of bias & Authors' judgement Support for judgement \\
\hline Bias & Unclear risk Q Q \\
\hline $\begin{array}{l}\text { Random sequence genera- "randomized" } \\
\text { tion (selection bias) }\end{array}$ & \\
\hline
\end{tabular}


Nickel 2016 (Continued)

\begin{tabular}{|c|c|c|}
\hline $\begin{array}{l}\text { Allocation concealment } \\
\text { (selection bias) }\end{array}$ & Unclear risk & No information provided \\
\hline $\begin{array}{l}\text { Blinding of participants } \\
\text { and personnel (perfor- } \\
\text { mance bias) } \\
\text { All outcomes }\end{array}$ & Unclear risk & $\begin{array}{l}\text { "double-blind, placebo-controlled" trial using subcutaneous dosing. Placebo } \\
\text { not described }\end{array}$ \\
\hline $\begin{array}{l}\text { Blinding of outcome as- } \\
\text { sessment (detection bias) } \\
\text { Subjective outcome }\end{array}$ & Unclear risk & $\begin{array}{l}\text { "double-blind, placebo-controlled" trial using subcutaneous dosing. Placebo } \\
\text { not described }\end{array}$ \\
\hline $\begin{array}{l}\text { Incomplete outcome data } \\
\text { (attrition bias) } \\
\text { Pain }\end{array}$ & Low risk & All randomised participants were included in analysis \\
\hline $\begin{array}{l}\text { Incomplete outcome data } \\
\text { (attrition bias) } \\
\text { Adverse events }\end{array}$ & Low risk & All randomised participants were included in analysis \\
\hline $\begin{array}{l}\text { Selective reporting (re- } \\
\text { porting bias) }\end{array}$ & Low risk & Results included all outcomes specified in the methods section \\
\hline Other bias & Low risk & None detected \\
\hline
\end{tabular}

Nomiya 2017

\section{Study characteristics}

\begin{tabular}{|c|c|}
\hline Methods & $\begin{array}{l}\text { Study design: } \mathrm{RCT} \\
\text { Study duration (months): } 1\end{array}$ \\
\hline Participants & $\begin{array}{l}\text { Number randomised: } 20 \\
\text { Setting: not reported } \\
\text { Country: Japan } \\
\text { Sex: } 19 \text { females and } 1 \text { male } \\
\text { Age, years: mean } 66.9 \text { (SD 17.0) for Group A, mean } 72.5 \text { (SD 8.8) for Group B } \\
\text { Diagnosis: IC } \\
\text { Inclusion criteria: patients with refractory IC, defined as persisting symptom of O'Leary and Sant In- } \\
\text { terstitial Cystitis Symptom Index/Problem Index (OSSI/OSPI) score greater than } 6 \text { points, respectively, } \\
\text { and numerical rating scale for pain (NRS) more than } 3 \text { out of } 10 \text { points, despite multiple conventional } \\
\text { therapies such as lifestyle modification, hydrodistension and oral medication } \\
\text { Exclusion criteria: not reported }\end{array}$ \\
\hline Interventions & $\begin{array}{l}\text { Group A ( } \mathbf{n}=\mathbf{1 0}) \text { : } 6 \text {-week weekly } 20,000 \mathrm{U} \text { heparin and } 5 \mathrm{~mL} 4 \% \text { lidocaine in phosphate-buffered saline } \\
\text { at pH } 7.5 \text { (intravesical instillation) } \\
\text { Group B }(\mathbf{n}=\mathbf{1 0}): 6 \text {-week weekly } 20,000 \mathrm{U} \text { heparin in } 30 \mathrm{~mL} \text { physiological saline } \\
\text { Treatment category in NMA: local anaesthetics vs control }\end{array}$ \\
\hline Outcomes & Outcome data in analysis \\
\hline
\end{tabular}


Pain: 10-point numerical rating scale (unclear minimum/maximum score): at 4 weeks

Frequency: at 4 weeks

Nocturia: at 4 weeks

ICSI: at 4 weeks

ICPI: at 4 weeks

Adverse events: at 4 weeks

\begin{tabular}{|c|c|c|}
\hline Funding & \multicolumn{2}{|c|}{ lida Grant of Mitsui Memorial Hospital } \\
\hline Notes & \multicolumn{2}{|c|}{ Publication status: abstract } \\
\hline \multicolumn{3}{|l|}{ Risk of bias } \\
\hline Bias & Authors' judgement & Support for judgement \\
\hline $\begin{array}{l}\text { Random sequence genera- } \\
\text { tion (selection bias) }\end{array}$ & Unclear risk & Quote: "randomized" \\
\hline $\begin{array}{l}\text { Allocation concealment } \\
\text { (selection bias) }\end{array}$ & Unclear risk & No information provided \\
\hline $\begin{array}{l}\text { Blinding of participants } \\
\text { and personnel (perfor- } \\
\text { mance bias) } \\
\text { All outcomes }\end{array}$ & Unclear risk & $\begin{array}{l}\text { Quote: "double-blind" } \\
\text { Comment: blinding methods not described. Intravesical instillation of heparin } \\
\text { + lidocaine vs heparin }\end{array}$ \\
\hline $\begin{array}{l}\text { Blinding of outcome as- } \\
\text { sessment (detection bias) } \\
\text { Subjective outcome }\end{array}$ & Unclear risk & $\begin{array}{l}\text { Quote: "double-blind" } \\
\text { Comment: blinding methods not described. Intravesical instillation of heparin } \\
\text { + lidocaine vs heparin }\end{array}$ \\
\hline $\begin{array}{l}\text { Incomplete outcome data } \\
\text { (attrition bias) } \\
\text { Cure or improvement }\end{array}$ & Low risk & All randomised participants were included in analysis \\
\hline
\end{tabular}

\begin{tabular}{|c|c|c|}
\hline $\begin{array}{l}\text { Incomplete outcome data } \\
\text { (attrition bias) } \\
\text { Pain }\end{array}$ & High risk & $\begin{array}{l}7 / 10 \text { included in intervention group ( } 3 \text { withdrew because of symptom worsen- } \\
\text { ing); } 10 / 10 \text { included in control group }\end{array}$ \\
\hline $\begin{array}{l}\text { Incomplete outcome data } \\
\text { (attrition bias) } \\
\text { Frequency }\end{array}$ & High risk & $\begin{array}{l}7 / 10 \text { included in intervention group ( } 3 \text { withdrew because of symptom worsen- } \\
\text { ing); } 10 / 10 \text { included in control group }\end{array}$ \\
\hline $\begin{array}{l}\text { Incomplete outcome data } \\
\text { (attrition bias) } \\
\text { Nocturia }\end{array}$ & High risk & $\begin{array}{l}7 / 10 \text { included in intervention group ( } 3 \text { withdrew because of symptom worsen- } \\
\text { ing); } 10 / 10 \text { included in control group }\end{array}$ \\
\hline $\begin{array}{l}\text { Incomplete outcome data } \\
\text { (attrition bias) } \\
\text { Interstitial Cystitis Symp- } \\
\text { tom Index }\end{array}$ & High risk & $\begin{array}{l}7 / 10 \text { included in intervention group ( } 3 \text { withdrew because of symptom worsen- } \\
\text { ing); } 10 / 10 \text { included in control group }\end{array}$ \\
\hline
\end{tabular}


Nomiya 2017 (Continued)

Incomplete outcome data High risk 7/10 included in intervention group (3 withdrew because of symptom worsen(attrition bias) ing); $10 / 10$ included in control group

Interstitial Cystitis Prob-

lem Index

Incomplete outcome data Low risk $\quad$ All randomised participants were included in analysis
(attrition bias)

Adverse events

Selective reporting (re- Low risk Results included all outcomes specified in the methods section porting bias)

\begin{tabular}{ll}
\hline Other bias $\quad$ Low risk $\quad$ None detected \\
\hline
\end{tabular}

\section{O'Reilly 2004}

\section{Study characteristics}

\begin{tabular}{ll}
\hline Methods & Study design RCT \\
& Study duration (months): 2.8 \\
\hline
\end{tabular}

Participants

Number randomised: 56

Setting: not reported

Country: Australia

Sex: not reported

Age, years: not reported

Diagnosis: IC (NIDDK criteria)

Inclusion criteria: patients with interstitial cystitis who fulfilled the National Institutes of Health National Institute for Diabetes and Digestive and Kidney Diseases criteria were prospectively recruited from our urogynaecology clinics. They were well-motivated patients in whom interstitial cystitis had failed to respond to various oral and intravesical therapies. Inclusion criteria consisted of ability to give informed consent, ability to perform treatment during 84 days and attend for follow-up, pain on bladder filling relieved by emptying; suprapubic, urethral, vaginal or perineal pain; glomerulations at cystoscopy and decreased bladder capacity or compliance at urodynamics

Exclusion criteria: younger than 18 years of age, duration of symptoms less than 12 months, daytime frequency less than 7 times in 12 hours and nocturia less than 2 times, detrusor overactivity on urodynamics, bladder tumour or calculus, urinary tract infection, radiation-induced cystitis and any cause of peripheral neuropathy or degenerative conditions of the spinal cord

Interventions

Group A ( $\mathbf{n}=\mathbf{2 9}$ ): transdermal posterior tibial nerve stimulation using active device (laser on for 30 seconds over SP6/Sanyinjiao acupuncture point, once daily for 12 weeks): at home

Group B ( $\mathbf{n} \mathbf{2 7})$ : placebo device

Treatment category in NMA: behavioural therapy vs control

Outcome data in analysis
Pain: SF-36 bodily pain score (range 100 to 0 , with higher scores indicating less pain): at 12 weeks
ICSI: at 12 weeks


O'Reilly 2004 (Continued)

ICPI: at 12 weeks

\begin{tabular}{ll}
\hline Funding & Not reported \\
\hline Notes & Publication status: full text \\
\hline
\end{tabular}

\title{
Risk of bias
}

\begin{tabular}{|c|c|c|}
\hline Bias & Authors' judgement & Support for judgement \\
\hline $\begin{array}{l}\text { Random sequence genera- } \\
\text { tion (selection bias) }\end{array}$ & Unclear risk & Quote: "randomly allocated" \\
\hline $\begin{array}{l}\text { Allocation concealment } \\
\text { (selection bias) }\end{array}$ & Unclear risk & No information provided \\
\hline $\begin{array}{l}\text { Blinding of participants } \\
\text { and personnel (perfor- } \\
\text { mance bias) } \\
\text { All outcomes }\end{array}$ & Low risk & $\begin{array}{l}\text { Trandermal laser therapy using an active or placebo device } \\
\text { "The sham devices were identical but inactivated so that neither patient nor } \\
\text { recruiter were aware of device type" }\end{array}$ \\
\hline $\begin{array}{l}\text { Blinding of outcome as- } \\
\text { sessment (detection bias) } \\
\text { Subjective outcome }\end{array}$ & Low risk & $\begin{array}{l}\text { Trandermal laser therapy using an active or placebo device } \\
\text { "The sham devices were identical but inactivated so that neither patient nor } \\
\text { recruiter were aware of device type" }\end{array}$ \\
\hline $\begin{array}{l}\text { Incomplete outcome data } \\
\text { (attrition bias) } \\
\text { Pain }\end{array}$ & Low risk & $\begin{array}{l}\text { 29/29 included in intervention group; } 27 / 27 \text { included in control group. "Inter- } \\
\text { mittent missing data" imputed with "horizontal mean imputation" }\end{array}$ \\
\hline $\begin{array}{l}\text { Incomplete outcome data } \\
\text { (attrition bias) } \\
\text { Frequency }\end{array}$ & Low risk & \\
\hline $\begin{array}{l}\text { Incomplete outcome data } \\
\text { (attrition bias) } \\
\text { Interstitial Cystitis Symp- } \\
\text { tom Index }\end{array}$ & Low risk & $\begin{array}{l}27 / 29 \text { included in intervention group; } 26 / 27 \text { included in control group. "Inter- } \\
\text { mittent missing data" were imputed with "horizontal mean imputation" }\end{array}$ \\
\hline $\begin{array}{l}\text { Incomplete outcome data } \\
\text { (attrition bias) } \\
\text { Interstitial Cystitis Prob- } \\
\text { lem Index }\end{array}$ & Low risk & $\begin{array}{l}27 / 29 \text { included in intervention group; } 26 / 27 \text { included in control group. "Inter- } \\
\text { mittent missing data" were imputed with "horizontal mean imputation" }\end{array}$ \\
\hline $\begin{array}{l}\text { Selective reporting (re- } \\
\text { porting bias) }\end{array}$ & Low risk & Results included all outcomes specified in the methods section \\
\hline Other bias & Low risk & None detected \\
\hline
\end{tabular}

Oliver 2013

\section{Study characteristics}

Methods

\author{
Study design: RCT
}

Study duration (months): 3 
Oliver 2013 (Continued)
Participants
Number randomised: 10
Setting: not reported
Country: USA
Sex: 8 females and 2 males
Age, years: average 68
Diagnosis: IC (Hunner's ulcer-type)
Inclusion criteria: patients presenting with Hunner's ulcer-type IC were recruited for the study begin- ning in January 2012. The study included patients with urgency, frequency and chronic pelvic pain con- sistent with IC as well as cystoscopy and biopsy confirming the presence of Hunner's ulcers
Exclusion criteria: patients were excluded if they had an active urinary tract infection, history of blad- der malignancy, recent bladder surgery, allergy to triamcinolone or were pregnant or unable to under- go anaesthesia

Interventions

Group A ( $\mathbf{n}=\mathbf{5})$ : triamcinolone injection ( $10 \mathrm{~mL}$ of triamcinolone acetonide, $40 \mathrm{mg} / \mathrm{mL}$ ) of Hunner's ulcers

Group B ( $\mathbf{n}=\mathbf{5}$ ): fulguration (using Bugbee electrocautery)

Once-only treatment

Treatment category in NMA: immune modulator vs fulguration

\begin{tabular}{|c|c|c|}
\hline Outcomes & \multicolumn{2}{|c|}{ Outcome data in analysis - no usable data } \\
\hline Funding & \multicolumn{2}{|l|}{ None } \\
\hline Notes & \multicolumn{2}{|c|}{ Publication status: abstract } \\
\hline \multicolumn{3}{|l|}{ Risk of bias } \\
\hline Bias & Authors' judgement & Support for judgement \\
\hline $\begin{array}{l}\text { Random sequence genera- } \\
\text { tion (selection bias) }\end{array}$ & Unclear risk & Quote: "randomized" \\
\hline $\begin{array}{l}\text { Allocation concealment } \\
\text { (selection bias) }\end{array}$ & Unclear risk & $\begin{array}{l}\text { Concealment methods not described. Stated only as "Patients were blinded to } \\
\text { the type of procedure they received. The surgeon was blinded ... until just pri- } \\
\text { or to the start of surgery in the operating room" }\end{array}$ \\
\hline $\begin{array}{l}\text { Blinding of participants } \\
\text { and personnel (perfor- } \\
\text { mance bias) } \\
\text { All outcomes }\end{array}$ & High risk & $\begin{array}{l}\text { Probably not done (fulguration vs triamcinolone injection). Surgeons could } \\
\text { not be blinded }\end{array}$ \\
\hline $\begin{array}{l}\text { Blinding of outcome as- } \\
\text { sessment (detection bias) } \\
\text { Subjective outcome }\end{array}$ & Unclear risk & $\begin{array}{l}\text { Stated as "patients were blinded to the type of procedure they received", even } \\
\text { though how this was achieved was not explicit, given the different modes of } \\
\text { treatment }\end{array}$ \\
\hline $\begin{array}{l}\text { Selective reporting (re- } \\
\text { porting bias) }\end{array}$ & Low risk & Results included all outcomes specified in the methods section \\
\hline Other bias & Low risk & None detected \\
\hline
\end{tabular}


Parsons 2012

\section{Study characteristics}

\begin{tabular}{|c|c|}
\hline Methods & $\begin{array}{l}\text { Study design: cross-over randomised trial } \\
\text { Study duration (months): } 0.001 \text { ( } 1 \text { hour) }\end{array}$ \\
\hline Participants & $\begin{array}{l}\text { Number randomised: } 28 \\
\text { Setting: } 4 \text { sites } \\
\text { Country: USA } \\
\text { Sex: not reported } \\
\text { Age, years: not reported } \\
\text { Diagnosis: IC (NIDDK criteria) } \\
\text { Inclusion criteria: IC patients meeting all of the clinical criteria of the NIDDK, with the exception that } \\
\text { cystoscopy under anaesthesia was not required. In addition, they had to have a score of at least } 15 \text { on } \\
\text { the Pelvic Pain and Urgency/Frequency Patient Symptom Scale } \\
\text { Exclusion criteria: patients taking tricyclic antidepressants, neurontin or narcotics were excluded. Pa- } \\
\text { tients taking any other medications had to have been on them for a minimum of } 3 \text { months }\end{array}$ \\
\hline
\end{tabular}

Interventions

Group A ( $\mathbf{n}=$ not reported): 50,000 units heparin + $200 \mathrm{mg}$ lidocaine HCL (hydrochloride) + $420 \mathrm{mg}$ sodium bicarbonate in $15 \mathrm{~mL}$ water

Group B ( $\mathbf{n}=$ not reported): $420 \mathrm{mg}$ sodium bicarbonate in $15 \mathrm{~mL}$ water

Treatment category in NMA: anticoagulants + local anaesthetics vs control

\begin{tabular}{|c|c|c|}
\hline Outcomes & \multicolumn{2}{|c|}{ Outcome data in analysis - no usable data } \\
\hline Funding & \multicolumn{2}{|l|}{ Urigen Pharmaceuticals } \\
\hline Notes & \multicolumn{2}{|c|}{ Publication status: full text } \\
\hline \multicolumn{3}{|l|}{ Risk of bias } \\
\hline Bias & Authors' judgement & Support for judgement \\
\hline $\begin{array}{l}\text { Random sequence genera- } \\
\text { tion (selection bias) }\end{array}$ & Unclear risk & $\begin{array}{l}\text { Quote: "randomized". "All subjects received both drug and control... in a blind- } \\
\text { ed and random order" }\end{array}$ \\
\hline $\begin{array}{l}\text { Allocation concealment } \\
\text { (selection bias) }\end{array}$ & Low risk & $\begin{array}{l}\text { Quote: "The blind was provided by the statistician for all treatments such that } \\
\text { no site knew what treatment was given" }\end{array}$ \\
\hline $\begin{array}{l}\text { Blinding of participants } \\
\text { and personnel (perfor- } \\
\text { mance bias) } \\
\text { All outcomes }\end{array}$ & Low risk & $\begin{array}{l}\text { Quote: "double-blind, placebo-controlled, crossover trial ... control was an ex- } \\
\text { cipient, sodium bicarbonate"; "the blinded kits containing the medications or } \\
\text { control were supplied to each site's pharmacy" }\end{array}$ \\
\hline $\begin{array}{l}\text { Blinding of outcome as- } \\
\text { sessment (detection bias) } \\
\text { Subjective outcome }\end{array}$ & Low risk & $\begin{array}{l}\text { Quote: "double-blind, placebo-controlled, crossover trial ... control was an ex- } \\
\text { cipient, sodium bicarbonate"; "the blinded kits containing the medications or } \\
\text { control were supplied to each site's pharmacy" }\end{array}$ \\
\hline $\begin{array}{l}\text { Selective reporting (re- } \\
\text { porting bias) }\end{array}$ & Low risk & Results included all outcomes specified in the methods section \\
\hline
\end{tabular}


Parsons 2012 (Continued)
Other bias
Low risk
None detected

Payne 2005

\section{Study characteristics}

\begin{tabular}{ll}
\hline Methods & Study design: RCT \\
& Study duration (months): 3 \\
\hline
\end{tabular}

Participants

Number randomised: 163

Setting: 30 centres

Country: USA

Sex: 140 females and 23 males

Age, years: mean 47, range 20 to 77

Diagnosis: IC (diagnosis made on clinical and cystoscopic grounds)

Inclusion criteria: patients at least 18 years of age with a diagnosis of IC confirmed by visualisation of glomerulations at cystoscopy/hydrodistension, symptoms of bladder pain and urinary urgency for at least 6 months; urinary frequency while awake at least 8 times a day; nocturia at least twice a night; a pain score of at least 4 (on a 0 to 9 Likert scale) on average over the 30 days before study drug treatment; and at least 1 voided volume of $75 \mathrm{cc}$ or greater in 24 hours during the screening period

Exclusion criteria: patients with Hunner's ulcers. Other exclusion criteria were as follows: (1) currently pregnant or breastfeeding; (2) presence of ulcers on pre-treatment cystoscopy; (3) intravesical therapy or bladder hydrodistension within the previous 60 days; (4) initiation of pentosan polysulfate sodium (Elmiron) within previous 16 weeks; (5) use of fentanyl patches, morphine sulfate, methadone or B\&O Supprettes within the previous 30 days; (6) prior augmentation cystoplasty, cystectomy or cystolysis, neurectomy (i.e. hypogastric nerve plexus ablation) or implanted peripheral nerve stimulator that has affected bladder function; (7) history of ureteral reflux; patients with a history of childhood urinary tract infections, recurrent urinary tract infections as an adult (defined as more than 3 culture-documented episodes within the previous 12 months) or pyelonephritis at any time must have a cystourethogram to rule out ureteral reflux; (8) evidence of renal impairment, hepatic impairment or clinically significant cardiovascular, respiratory or psychiatric disease; (9) urinary tract infection or prostatic infection within 3 months before study entry; (10) active genital herpes or vaginitis; (11) urethral diverticulum; (12) uterine, cervical, vaginal or urethral cancer within 5 years before study entry (13) history of cyclophosphamide or chemical cystitis, urinary tuberculosis or radiation cystitis; (14) history of bladder tumours (benign or malignant)

Interventions

Group A ( $\mathbf{n}=\mathbf{1 1 9}$ ): 3 arms combined for this review: A: resiniferatoxin (RTX) $0.01 \mathrm{microMol} / \mathrm{L}$ solution in $10 \%$ ethanol in saline. Arm B: RTX 0.05 microMol/L solution in $10 \%$ ethanol in saline. Arm C: RTX 0.10 microMol/L solution in $10 \%$ ethanol in saline

Group B ( $\mathbf{n}=\mathbf{4 4 )}$ : $10 \%$ ethanol in saline (placebo)

Group A \& B: bladder then drained and rinsed with normal saline. Pre-treatment instillation with lidocaine solution (initially $50 \mathrm{~mL}$ of $2 \%$ lidocaine for 10 minutes, increased later in study to $100 \mathrm{~mL}$ of $4 \%$ lidocaine for 30 minutes). Single instillation treatment of $50 \mathrm{~mL}$ of RTX solution or placebo retained for 30 minutes

Treatment category in NMA: calcium channel agonists ( 3 arms) vs control

\section{Outcomes}

Outcome data in analysis

Cure or improvement: 'moderately' or 'markedly' improved on GRA: at 4 weeks 
Payne 2005 (Continued)

Pain: numerical rating scale (pain score from diary) (range 0 to 9): at 12 weeks

Adverse events: at 4 weeks

\begin{tabular}{ll}
\hline Funding & ICOS Corporation (American biotechnology company) \\
\hline Notes & Publication status: full text \\
& $\begin{array}{l}\text { Notes from previous versions of the review: attempted study author contact regarding data for pain, } \\
\text { void volume and frequency. No response }\end{array}$
\end{tabular}

\section{Risk of bias}

\begin{tabular}{|c|c|c|}
\hline Bias & Authors' judgement & Support for judgement \\
\hline $\begin{array}{l}\text { Random sequence genera- } \\
\text { tion (selection bias) }\end{array}$ & Low risk & $\begin{array}{l}\text { Quote: "randomization was centrally performed and stratified by center in } \\
\text { blocks according to a computer-generated random number table" }\end{array}$ \\
\hline $\begin{array}{l}\text { Allocation concealment } \\
\text { (selection bias) }\end{array}$ & Low risk & $\begin{array}{l}\text { Quote: "randomization was centrally performed and stratified by center in } \\
\text { blocks according to a computer-generated random number table" }\end{array}$ \\
\hline $\begin{array}{l}\text { Blinding of participants } \\
\text { and personnel (perfor- } \\
\text { mance bias) } \\
\text { All outcomes }\end{array}$ & Low risk & $\begin{array}{l}\text { Quote: "'double-blind, placebo-controlled" trial. "All patients and site person- } \\
\text { nel were blinded to treatment assignment except for study pharmacists re- } \\
\text { sponsible for preparing study drug" }\end{array}$ \\
\hline $\begin{array}{l}\text { Blinding of outcome as- } \\
\text { sessment (detection bias) } \\
\text { Subjective outcome }\end{array}$ & Low risk & $\begin{array}{l}\text { Quote: "'double-blind, placebo-controlled" trial. "All patients and site person- } \\
\text { nel were blinded to treatment assignment except for study pharmacists re- } \\
\text { sponsible for preparing study drug" }\end{array}$ \\
\hline $\begin{array}{l}\text { Incomplete outcome data } \\
\text { (attrition bias) } \\
\text { Cure or improvement }\end{array}$ & Low risk & $\begin{array}{l}\text { Review authors chose to use available case analysis. } 116 / 119(97 \%) \text { included in } \\
\text { intervention group; } 43 / 44(98 \%) \text { included in control group }\end{array}$ \\
\hline $\begin{array}{l}\text { Incomplete outcome data } \\
\text { (attrition bias) } \\
\text { Pain }\end{array}$ & Low risk & $\begin{array}{l}119 / 119 \text { included in intervention group; } 43 / 44 \text { included in control group ( } 1 \\
\text { missing post-baseline efficacy assessment). "Missing data were imputed with } \\
\text { last-observation-carried forward" }\end{array}$ \\
\hline $\begin{array}{l}\text { Incomplete outcome data } \\
\text { (attrition bias) } \\
\text { Adverse events }\end{array}$ & Low risk & All randomised participants were included in analysis \\
\hline $\begin{array}{l}\text { Selective reporting (re- } \\
\text { porting bias) }\end{array}$ & Low risk & Results included all outcomes specified in the methods section \\
\hline Other bias & Low risk & None detected \\
\hline
\end{tabular}

Payne 2014

\section{Study characteristics}

\begin{tabular}{ll}
\hline Methods & Study design: RCT \\
& Study duration (months): 6 \\
\hline
\end{tabular}

Participants

Number randomised: 16 
Payne 2014 (Continued)

Setting: single institution

Country: USA

Sex: 14 females and 2 males

Age, years: mean 53.7, range 24 to 88

Diagnosis: IC (NIDDK criteria)

Inclusion criteria: adults diagnosed by investigators with IC/BPS as the primary cause of their lower urinary tract symptoms. Symptoms were present for $>6$ months and were refractory to standard therapies; current pain and urgency scores were $\geq 4 / 10$ on a visual analogue scale. Cystoscopy with bladder distension under anaesthesia was required at some point in the diagnostic evaluation

Exclusion criteria: NIDDK exclusion criteria were employed and residual urine $>100 \mathrm{cc}$ was exclusionary. Prior botox injection and neurostimulators were not allowed

Interventions

Group A ( $\mathbf{n}=\mathbf{1 4})$ : varying dose of botox injection into trigone and detrusor

Group B ( $\mathbf{n}$ 2): saline injection

Once-only treatment

Treatment category in NMA: neuromuscular blockade vs control

\begin{tabular}{|c|c|c|}
\hline \multirow[t]{3}{*}{ Outcomes } & \multicolumn{2}{|c|}{ Outcome data in analysis } \\
\hline & \multicolumn{2}{|c|}{$\begin{array}{l}\text { Cure or improvement: 'moderately' or 'markedly' improved on GRA: at } 6 \text { months (assumed from re- } \\
\text { ports) }\end{array}$} \\
\hline & \multicolumn{2}{|c|}{ Adverse events: at 6 months (assumed from reports) } \\
\hline Funding & \multicolumn{2}{|c|}{ Investigator-initiated grant from Allergan } \\
\hline Notes & \multicolumn{2}{|c|}{$\begin{array}{l}\text { Publication status: abstract } \\
\text { "... the study was stopped due to futility without reaching the target recruitment goal after eight } \\
\text { months with no enrollment" }\end{array}$} \\
\hline \multicolumn{3}{|l|}{ Risk of bias } \\
\hline Bias & Authors' judgement & Support for judgement \\
\hline $\begin{array}{l}\text { Random sequence genera- } \\
\text { tion (selection bias) }\end{array}$ & Low risk & Quote: "randomized ... by drawing presealed envelopes" \\
\hline Allocation concealment & Unclear risk & Quote: "randomized ... by drawing presealed envelopes" \\
\hline & & Comment: unclear if envelopes were opaque and sequentially numbered \\
\hline $\begin{array}{l}\text { Blinding of participants } \\
\text { and personnel (perfor- } \\
\text { mance bias) } \\
\text { All outcomes }\end{array}$ & Unclear risk & $\begin{array}{l}\text { "double-blind" trial. Injections in the trigone (sub-epithelial level) of botu- } \\
\text { linum toxin or "placebo" (not described). Participants "were pretreated with } \\
\text {... lidocaine in the bladder ... prior to injection along with an oral narcotic and } \\
\text { anxiolytic" }\end{array}$ \\
\hline $\begin{array}{l}\text { Blinding of outcome as- } \\
\text { sessment (detection bias) } \\
\text { Subjective outcome }\end{array}$ & Unclear risk & $\begin{array}{l}\text { "double-blind" trial. Injections in the trigone (sub-epithelial level) of botu- } \\
\text { linum toxin or "placebo" (not described). Participants "were pretreated with } \\
\text {... lidocaine in the bladder ... prior to injection along with an oral narcotic and } \\
\text { anxiolytic" }\end{array}$ \\
\hline $\begin{array}{l}\text { Incomplete outcome data } \\
\text { (attrition bias) } \\
\text { Cure or improvement }\end{array}$ & Low risk & $\begin{array}{l}\text { All randomised participants were included in analysis ("only two subjects were } \\
\text { randomized to placebo") }\end{array}$ \\
\hline
\end{tabular}


Payne 2014 (Continued)

Incomplete outcome data Low risk All randomised participants were included in analysis ("only two subjects were (attrition bias) randomized to placebo")

Adverse events

\begin{tabular}{|c|c|c|}
\hline $\begin{array}{l}\text { Selective reporting (re- } \\
\text { porting bias) }\end{array}$ & High risk & $\begin{array}{l}\text { Pain, ICSI, ICPI and "24 hour bladder dairy variables" were mentioned in the } \\
\text { methods but were not reported in the results }\end{array}$ \\
\hline
\end{tabular}

Other bias Low risk None detected

Peeker 2000

\section{Study characteristics}

\begin{tabular}{ll}
\hline Methods & Study design: cross-over randomised trial \\
& Study duration (months): 3 \\
\hline Participants & Setting: not reported \\
& Country: USA \\
Sex: 20 females and 1 male & Age, years: mean 59 (range 36 to 79 ) for 11 women with ulcerative (classic) disease; mean 43 (range 24 \\
& to 61 ) for 9 women and 1 man with non-ulcerative disease \\
& Diagnosis: IC (NIDDK criteria) \\
& Inclusion criteria: patients with IC who had non-ulcer disease \\
& Exclusion criteria: not reported
\end{tabular}

Interventions Group A ( $\mathbf{n}=$ not reported): $6 \times$ weekly instillations via catheter with bacillus Calmette-Guérin (BCG). Dose of $5 \times 108$ colony-forming units, reconstituted with $1 \mathrm{~mL}$ of saline and diluted with $50 \mathrm{~mL}$ of saline. Each instillation for duration of up to 2 hours

Group B ( $\mathbf{n}=$ not reported): $6 \times$ weekly instillations of dimethyl sulfoxide (DMSO). $50 \mathrm{~mL}$ of solution at concentration of $500 \mathrm{mg} / \mathrm{mL}$

Treatment category in NMA: immune modulators vs DMSO

\begin{tabular}{ll}
\hline Outcomes & Outcome data in analysis - no usable data \\
\hline Funding & BCG ampules were provided by OncoTICE, Organon Teknika, Askim, Sweden \\
\hline Notes & $\begin{array}{l}\text { Publication status: full text } \\
\text { Notes from previous versions of the review: very poor data available. Numbers in each treatment group } \\
\text { are missing. Study author contacted, no response }\end{array}$ \\
\hline Risk of bias & Authors' judgement Support for judgement \\
\hline Bias & Unclear risk
\end{tabular}


Peeker 2000 (Continued)

\begin{tabular}{l}
$\begin{array}{l}\text { Allocation concealment } \\
\text { (selection bias) }\end{array} \quad \begin{array}{l}\text { Quote: "the randomizaton procedure was performed by } 1 \text { of us ... who subse- } \\
\text { quently did not participate in the care or final evaluation of patients" }\end{array}$ \\
\hline
\end{tabular}

\begin{tabular}{|c|c|c|}
\hline $\begin{array}{l}\text { Blinding of participants } \\
\text { and personnel (perfor- } \\
\text { mance bias) } \\
\text { All outcomes }\end{array}$ & High risk & $\begin{array}{l}\text { Stated as "double-blind", cross-over study; "evaluation was performed blind- } \\
\text { ly"; "data concerning given substance were concealed until evaluation". How- } \\
\text { ever, "the given substance could not be blinded due to the distinctive breath } \\
\text { odor of dimethyl sufoxide" }\end{array}$ \\
\hline $\begin{array}{l}\text { Blinding of outcome as- } \\
\text { sessment (detection bias) } \\
\text { Subjective outcome }\end{array}$ & High risk & $\begin{array}{l}\text { Stated as "double-blind", cross-over study; "evaluation was performed blind- } \\
\text { ly"; "data concerning given substance were concealed until evaluation". How- } \\
\text { ever, "the given substance could not be blinded due to the distinctive breath } \\
\text { odor of dimethyl sufoxide" }\end{array}$ \\
\hline $\begin{array}{l}\text { Selective reporting (re- } \\
\text { porting bias) }\end{array}$ & High risk & $\begin{array}{l}\text { Outcomes reported in the results were not specified in the methods, except } \\
\text { the primary outcome ("subjective improvement") }\end{array}$ \\
\hline Other bias & High risk & $\begin{array}{l}\text { Some patients may have received both treatments. "Patients randomly under- } \\
\text { went [treatment] and, if not improved, were treated with the other substance } \\
\text { after a washout period, the end of which constituted the point of final analy- } \\
\text { sis" }\end{array}$ \\
\hline
\end{tabular}

Perez-Marrero 1988

\section{Study characteristics}

\section{Methods}

Study design: cross-over randomised trial

Study duration (months): 1.5

\section{Participants}

Number randomised: 33

Setting: single centre

Country: Canada

Sex: 30 females and 3 males

Age, years: mean 48

Diagnosis: IC (diagnosis made clinically and with cystoscopy/biopsy)

Inclusion criteria: patients with IC

Exclusion criteria: not reported

Interventions

Group A ( $\mathbf{n}=\mathbf{1 5}): 50 \mathrm{~mL}$ of $50 \%$ dimethyl sulfoxide (DMSO)

Group B (n= 18): $50 \mathrm{~mL}$ of normal saline

Four treatments, each 2 weeks apart, involving outpatient bladder instillations given via catheter and lasting at least 15 minutes. After a 4-week 'rest' period, the 2 groups crossed over, to complete instillations with the 'other' treatment (i.e. placebo for Group A and DMSO for Group B). Timing of assessment is unclear, but it looks to have occurred soon after each phase of treatment was given

Treatment category in NMA: DMSO vs control

\begin{tabular}{ll}
\hline Outcomes & Outcome data in analysis \\
& $\begin{array}{l}\text { Cure or improvement: response to treatment rated as moderate or marked improvement: at } 6 \text { weeks } \\
\text { (assumed from reports) (at end of first period, which was "4 treatments ... at 2-week intervals") }\end{array}$
\end{tabular}


Perez-Marrero 1988 (Continued)

\begin{tabular}{ll} 
Funding & Not reported \\
\hline Notes & Publication status: full text \\
& Cross-over trial. Data for the first phase only were sought for this review
\end{tabular}

\section{Risk of bias}

\begin{tabular}{|c|c|c|}
\hline Bias & Authors' judgement & Support for judgement \\
\hline $\begin{array}{l}\text { Random sequence genera- } \\
\text { tion (selection bias) }\end{array}$ & Unclear risk & Quote: "randomized" \\
\hline $\begin{array}{l}\text { Allocation concealment } \\
\text { (selection bias) }\end{array}$ & Unclear risk & No information provided \\
\hline $\begin{array}{l}\text { Blinding of participants } \\
\text { and personnel (perfor- } \\
\text { mance bias) } \\
\text { All outcomes }\end{array}$ & High risk & $\begin{array}{l}\text { "an evaluator blinded, complete crossover study". Review authors assumed } \\
\text { that patients and carers were not blinded, given breath odor caused by DMSO } \\
\text { bladder instillation mentioned in another trial (Peeker 2000), along with NICE } \\
\text { guidance. "All instillations were performed by a nurse ... who had no other in- } \\
\text { volvement" }\end{array}$ \\
\hline $\begin{array}{l}\text { Blinding of outcome as- } \\
\text { sessment (detection bias) } \\
\text { Subjective outcome }\end{array}$ & High risk & $\begin{array}{l}\text { "an evaluator blinded, complete crossover study". Review authors assumed } \\
\text { that patients were not blinded }\end{array}$ \\
\hline $\begin{array}{l}\text { Incomplete outcome data } \\
\text { (attrition bias) } \\
\text { Cure or improvement }\end{array}$ & Low risk & $\begin{array}{l}15 / 15 \text { included in intervention group; } 17 / 18(94 \%) \text { included in control group (1 } \\
\text { excluded as she was "found to be pregnant after the first instillation") }\end{array}$ \\
\hline $\begin{array}{l}\text { Selective reporting (re- } \\
\text { porting bias) }\end{array}$ & Low risk & Results included all outcomes specified in the methods section \\
\hline Other bias & Low risk & None detected \\
\hline
\end{tabular}

Peters 1997

\section{Study characteristics}

Methods

\section{Study design: RCT}

Study duration (months): 27 (for the purpose of this review, data for 8 months were used in the analysis)

\section{Participants}

\section{Number randomised: 33}

Setting: single centre

Country: USA

Sex: female

Age, years: median 44 (range 30 to 71 ) for Group A, median 40 (range 23 to 56) for Group B

Diagnosis: IC (NIDDK criteria)

Inclusion criteria: women with IC

Exclusion criteria: immunocompromised patients, concomitant steroid medications, chemotherapy for other carcinomas, warfarin sodium anticoagulation therapy, pregnancy or unwillingness to practice 
Peters 1997 (Continued)

protected intercourse, intravesical therapy for IC within 3 months before the study, grade III or greater vesicoureteral reflux

Interventions

Group A ( $\mathbf{n}=$ not reported): $50 \mathrm{mg}$ Tice strain bacillus Calmette-Guérin (BCG)

Group B ( $\mathbf{n}=$ not reported): $50 \mathrm{~mL}$ of sterile saline

Weekly instillations $\times 6$, each comprising $50 \mathrm{~mL}$ volume instilled via Foley catheter. Fluid retained for 2 hours, although temporary drainage and re-instillation permitted if discomfort during 2 hours

Numbers analysed: Group A: 17; Group B: 15

Treatment category in NMA: immune modulators vs control

Outcome data in analysis
Cure or improvement: 'responders' to treatment, defined as moderate improvement, greatly improved
or cured in subjective rating of overall symptoms at 6 months
Pain: RAND-36 question pain score (assumed range 100 to 0 , with higher scores indicating less pain) at 6
months

Adverse events: at 6 months

Funding
and by Perlmmune, Inc., Rockville, Maryland

Notes Publication status: full text

Notes from previous versions of the review: attempted to contact study author regarding outcome data in terms of treatment group, rather than just responder/non-responder. Replied 11/06 "looking for data"

\section{Risk of bias}

\begin{tabular}{|c|c|c|}
\hline Bias & Authors' judgement & Support for judgement \\
\hline $\begin{array}{l}\text { Random sequence genera- } \\
\text { tion (selection bias) }\end{array}$ & Unclear risk & Quote: "randomized" \\
\hline \multirow{2}{*}{$\begin{array}{l}\text { Allocation concealment } \\
\text { (selection bias) }\end{array}$} & Unclear risk & Quote: "randomized in a double-blind fashion" \\
\hline & & Comment: unclear whether this refers to blinding or allocation concealment \\
\hline $\begin{array}{l}\text { Blinding of participants } \\
\text { and personnel (perfor- } \\
\text { mance bias) } \\
\text { All outcomes }\end{array}$ & Low risk & $\begin{array}{l}\text { "double-blind, placebo controlled". Intravesical treatments of study drug or } \\
\text { "placebo (sterile saline)". "The subjects and investigators remained blinded } \\
\text { to experimental group assignments until all subjects had completed at least } 6 \\
\text { months of followup" }\end{array}$ \\
\hline $\begin{array}{l}\text { Blinding of outcome as- } \\
\text { sessment (detection bias) } \\
\text { Subjective outcome }\end{array}$ & Low risk & $\begin{array}{l}\text { "double-blind, placebo controlled". Intravesical treatments of study drug or } \\
\text { "placebo (sterile saline)". "The subjects and investigators remained blinded } \\
\text { to experimental group assignments until all subjects had completed at least } 6 \\
\text { months of followup" }\end{array}$ \\
\hline $\begin{array}{l}\text { Incomplete outcome data } \\
\text { (attrition bias) } \\
\text { Cure or improvement }\end{array}$ & Unclear risk & $\begin{array}{l}33 \text { randomised, } 15 \text { included in intervention group; } 15 \text { included in control } \\
\text { group. Group assignment of "the } 3 \text { unevaluable subjects" unclear }\end{array}$ \\
\hline
\end{tabular}

\begin{tabular}{|c|c|c|}
\hline $\begin{array}{l}\text { Incomplete outcome data } \\
\text { (attrition bias) }\end{array}$ & Unclear risk & $\begin{array}{l}33 \text { randomised, } 15 \text { included in intervention group; } 15 \text { included in control } \\
\text { group. Group assignment of "the } 3 \text { unevaluable subjects" unclear }\end{array}$ \\
\hline
\end{tabular}


Peters 1997 (Continued)

Pain

$\begin{array}{ll}\begin{array}{l}\text { Incomplete outcome data } \\ \text { (attrition bias) }\end{array} & \text { Unclear risk }\end{array} \begin{aligned} & 33 \text { randomised, } 17 \text { included in intervention group; } 15 \text { included in control } \\ & \text { group. Group assignment of } 1 \text { missing subject unclear }\end{aligned}$

Adverse events group. Group assignment of 1 missing subject unclear

Selective reporting (re- Low risk Results included all outcomes specified in the methods section
porting bias)

Other bias Low risk None detected

Pinto 2016

\section{Study characteristics}

\begin{tabular}{ll}
\hline Methods & Study design: RCT \\
& Study duration (months): 3 \\
\hline
\end{tabular}

Number randomised: 19
Setting: not reported
Country: Portugal
Sex: female
Age, years: mean 47 (SD 8, range 35 to 60 for Group A; mean 49 (SD 10, range 31 to 61 ) for Group B
Diagnosis: BPS/IC
Inclusion criteria: women with refractory BPS/IC and a minimum pain score of 4 on a 0 to 10 visual
analogue scale (VAS)

Exclusion criteria: not reported

Interventions

Group A ( $\mathbf{n}=\mathbf{1 0})$ : $100 \mathrm{U}$ of OnaBotA in $10 \mathrm{~mL}$ saline (intratrigonal injection)

Group B ( $\mathbf{n}=9): 10 \mathrm{~mL}$ saline

Treatment category in NMA: neuromuscular blockade vs control

\begin{tabular}{ll}
\hline Outcomes & Outcome data in analysis \\
& Pain: VAS (assumed range 0 to 10): at 3 months \\
& Frequency: at 3 months \\
& Adverse events: at 3 months \\
\hline Funding & Allergan \\
\hline Notes & Publication status: abstract \\
\hline Risk of bias & Authors' judgement Support for judgement \\
\hline Bias & Unclear risk Q Q \\
\hline $\begin{array}{l}\text { Random sequence genera- } \\
\text { tion (selection bias) }\end{array}$ & \\
\hline
\end{tabular}


Pinto 2016 (Continued)

\begin{tabular}{|c|c|c|}
\hline $\begin{array}{l}\text { Allocation concealment } \\
\text { (selection bias) }\end{array}$ & Unclear risk & No information provided \\
\hline $\begin{array}{l}\text { Blinding of participants } \\
\text { and personnel (perfor- } \\
\text { mance bias) } \\
\text { All outcomes }\end{array}$ & Unclear risk & $\begin{array}{l}\text { Quote: "double-blind, placebo-controlled trial" } \\
\text { Comment: intratrigonal injection of OnaBotA or saline. Placebo not described }\end{array}$ \\
\hline $\begin{array}{l}\text { Blinding of outcome as- } \\
\text { sessment (detection bias) } \\
\text { Subjective outcome }\end{array}$ & Unclear risk & $\begin{array}{l}\text { Quote: "double-blind, placebo-controlled trial" } \\
\text { Comment: intratrigonal injection of OnaBotA or saline. Placebo not described }\end{array}$ \\
\hline $\begin{array}{l}\text { Incomplete outcome data } \\
\text { (attrition bias) } \\
\text { Pain }\end{array}$ & Low risk & All randomised participants were included in analysis \\
\hline $\begin{array}{l}\text { Incomplete outcome data } \\
\text { (attrition bias) } \\
\text { Frequency }\end{array}$ & Low risk & All randomised participants were included in analysis \\
\hline $\begin{array}{l}\text { Incomplete outcome data } \\
\text { (attrition bias) } \\
\text { Adverse events }\end{array}$ & Low risk & All randomised participants were included in analysis \\
\hline
\end{tabular}

Selective reporting (re- Low risk Results included all outcomes specified in the methods section
porting bias)

Other bias Low risk None detected

\section{Study characteristics}

\begin{tabular}{ll}
\hline Methods & Study design: RCT \\
& Study duration (months): 6
\end{tabular}

\section{Participants}

\section{Number randomised: 64}

Setting: 7 urological units

Country: Finland

Sex: 53 females and 11 males

Age, years: mean 56.2 (SD 14.7) for Group A, mean 59.7 (SD 13.0) for Group B

Diagnosis: IC (NIDDK criteria)

Inclusion criteria: patients meeting NIDDK criteria for IC. Serum transaminase, bilirubin and serum cholesterol had to be within normal range

Exclusion criteria: history of cancer in the last 10 years; untreated hypertension or renal insufficiency

Regimen: $1.5 \mathrm{mg} / \mathrm{kg}$ CyA twice daily or $100 \mathrm{mg}$ PPS 3 times daily for a period of 6 months 
Sairanen 2005 (Continued)

Treatment category in NMA: immune modulators vs PPS

Outcome data in analysis
Cure or improvement: based on GRA (assumed from reports): at 6 months
Pain: VAS (0 to 10 centimetres): at 6 months
Frequency: at 6 months
Nocturia: at 6 months
ICSI: at 6 months
ICPI: at 6 months

Adverse events: at 6 months

\begin{tabular}{ll}
\hline Funding & Finnish Urological Association \\
\hline Notes & Publication status: full text
\end{tabular}

\section{Risk of bias}

\begin{tabular}{lll}
\hline Bias & Authors' judgement & Support for judgement \\
\hline $\begin{array}{l}\text { Random sequence genera- } \\
\text { tion (selection bias) }\end{array}$ & Unclear risk & Quote: "randomized" \\
\hline
\end{tabular}

\begin{tabular}{lll}
\hline $\begin{array}{l}\text { Allocation concealment } \\
\text { (selection bias) }\end{array}$ & Low risk & $\begin{array}{l}\text { Quote: "randomization was centralized. Closed envelopes were divided into 2 } \\
\text { identical blocks, and a nurse not otherwise involved in the study opened the } \\
\text { envelopes containing the name of the drug" }\end{array}$ \\
\hline $\begin{array}{l}\text { Blinding of participants } \\
\begin{array}{l}\text { and personnel (perfor- } \\
\text { mance bias) }\end{array}\end{array}$ & High risk & Quote: "open-label" \\
All outcomes & Comment: probably not done
\end{tabular}

\begin{tabular}{|c|c|c|}
\hline $\begin{array}{l}\text { Blinding of outcome as- } \\
\text { sessment (detection bias) } \\
\text { Subjective outcome }\end{array}$ & High risk & $\begin{array}{l}\text { Quote: "open-label" } \\
\text { Comment: probably not done }\end{array}$ \\
\hline $\begin{array}{l}\text { Incomplete outcome data } \\
\text { (attrition bias) } \\
\text { Cure or improvement }\end{array}$ & Low risk & $\begin{array}{l}\text { Review authors chose to use number who completed trial: } 29 / 32 \text { included in } \\
\text { PPS group ( } 1 \text { missing due to gross haematuria, } 2 \text { discontinued as not benefit- } \\
\text { ing from treatment); } 29 / 32 \text { ( } 3 \text { discontinued including } 1 \text { due to AE) included in } \\
\text { cyclosporin A group }\end{array}$ \\
\hline
\end{tabular}

\begin{tabular}{|c|c|c|}
\hline $\begin{array}{l}\text { Incomplete outcome data } \\
\text { (attrition bias) } \\
\text { Pain }\end{array}$ & Low risk & $\begin{array}{l}\text { Review authors chose to use number who completed trial: } 29 / 32 \text { included in } \\
\text { PPS group ( } 1 \text { missing due to gross haematuria, } 2 \text { discontinued as not benefit- } \\
\text { ing from treatment); } 29 / 32 \text { ( } 3 \text { discontinued including } 1 \text { due to AE) included in } \\
\text { cyclosporin A group }\end{array}$ \\
\hline
\end{tabular}

\begin{tabular}{|c|c|c|}
\hline $\begin{array}{l}\text { Incomplete outcome data } \\
\text { (attrition bias) } \\
\text { Frequency }\end{array}$ & Low risk & $\begin{array}{l}\text { Review authors chose to use number who completed trial: } 29 / 32 \text { included in } \\
\text { PPS group ( } 1 \text { missing due to gross haematuria, } 2 \text { discontinued as not benefit- } \\
\text { ing from treatment); } 29 / 32 \text { ( } 3 \text { discontinued including } 1 \text { due to } A E \text { ) included in } \\
\text { cyclosporin A group }\end{array}$ \\
\hline
\end{tabular}

\begin{tabular}{|c|c|c|}
\hline $\begin{array}{l}\text { Incomplete outcome data } \\
\text { (attrition bias) } \\
\text { Nocturia }\end{array}$ & Low risk & $\begin{array}{l}\text { Review authors chose to use number who completed trial: } 29 / 32 \text { included in } \\
\text { PPS group ( } 1 \text { missing due to gross haematuria, } 2 \text { discontinued as not benefit- }\end{array}$ \\
\hline
\end{tabular}


Sairanen 2005 (Continued)

ing from treatment); 29/32 (3 discontinued including 1 due to $A E$ ) included in cyclosporin A group

\begin{tabular}{|c|c|c|}
\hline $\begin{array}{l}\text { Incomplete outcome data } \\
\text { (attrition bias) } \\
\text { Interstitial Cystitis Symp- } \\
\text { tom Index }\end{array}$ & Low risk & $\begin{array}{l}\text { Review authors chose to use number who completed trial: } 29 / 32 \text { included in } \\
\text { PPS group ( } 1 \text { missing due to gross haematuria, } 2 \text { discontinued as not benefit- } \\
\text { ing from treatment); } 29 / 32 \text { ( } 3 \text { discontinued including } 1 \text { due to AE) included in } \\
\text { cyclosporin A group }\end{array}$ \\
\hline $\begin{array}{l}\text { Incomplete outcome data } \\
\text { (attrition bias) } \\
\text { Interstitial Cystitis Prob- } \\
\text { lem Index }\end{array}$ & Low risk & $\begin{array}{l}\text { Review authors chose to use number who completed trial: } 29 / 32 \text { included in } \\
\text { PPS group ( } 1 \text { missing due to gross haematuria, } 2 \text { discontinued as not benefit- } \\
\text { ing from treatment); } 29 / 32 \text { ( } 3 \text { discontinued including } 1 \text { due to AE) included in } \\
\text { cyclosporin A group }\end{array}$ \\
\hline $\begin{array}{l}\text { Incomplete outcome data } \\
\text { (attrition bias) } \\
\text { Adverse events }\end{array}$ & Low risk & All randomised participants were included in analysis \\
\hline $\begin{array}{l}\text { Selective reporting (re- } \\
\text { porting bias) }\end{array}$ & Low risk & Results included all outcomes specified in the methods section \\
\hline Other bias & Low risk & None detected \\
\hline
\end{tabular}

Sairanen 2009

\section{Study characteristics}

\begin{tabular}{|c|c|}
\hline Methods & $\begin{array}{l}\text { Study design: } R C T \\
\text { Study duration (months): } 3\end{array}$ \\
\hline Participants & $\begin{array}{l}\text { Number randomised: } 75 \\
\text { Setting: not reported } \\
\text { Country: not reported } \\
\text { Sex: } 71 \text { females and } 4 \text { males } \\
\text { Age, years: mean } 57.9 \text { (SD 14.7) for Group A, mean } 61.4 \text { (SD 11.3) for Group B } \\
\text { Diagnosis: PBS/IC } \\
\text { Inclusion criteria: patients with PBS/IC } \\
\text { Exclusion criteria: not specified }\end{array}$ \\
\hline
\end{tabular}

Interventions

Group A ( $\mathbf{n}=\mathbf{3 8}$ ): $50 \mathrm{~mL}$ Tice strain BCG (bacillus Calmette-Guérin)

Group B ( $\mathbf{n}=\mathbf{3 7}$ ): $50 \mathrm{~mL} 50 \%$ dimethyl sulfoxide (DMSO)

Treatment category in NMA: immune modulator vs DMSO

\begin{tabular}{ll}
\hline Outcomes & $\begin{array}{l}\text { Outcome data in analysis } \\
\text { Cure or improvement: GRA (global assessment to treatment response), much better or completely } \\
\text { cured }\end{array}$ \\
\hline Funding & Not reported \\
\hline
\end{tabular}

Notes

Publication status: full text 
Sairanen 2009 (Continued)

This paper reports multiple trials. Data for this review were extracted from only 1 study comparing DMSO and BCG

\section{Risk of bias}

\begin{tabular}{|c|c|c|}
\hline Bias & Authors' judgement & Support for judgement \\
\hline $\begin{array}{l}\text { Random sequence genera- } \\
\text { tion (selection bias) }\end{array}$ & Unclear risk & Quote: "randomized" \\
\hline $\begin{array}{l}\text { Allocation concealment } \\
\text { (selection bias) }\end{array}$ & Unclear risk & No information provided \\
\hline $\begin{array}{l}\text { Blinding of participants } \\
\text { and personnel (perfor- } \\
\text { mance bias) } \\
\text { All outcomes }\end{array}$ & Unclear risk & No information provided \\
\hline $\begin{array}{l}\text { Blinding of outcome as- } \\
\text { sessment (detection bias) } \\
\text { Subjective outcome }\end{array}$ & Unclear risk & No information provided \\
\hline $\begin{array}{l}\text { Incomplete outcome data } \\
\text { (attrition bias) } \\
\text { Cure or improvement }\end{array}$ & Unclear risk & $31 / 37(84 \%)$ included in DMSO group; $31 / 38(84 \%)$ included in BCG group \\
\hline $\begin{array}{l}\text { Selective reporting (re- } \\
\text { porting bias) }\end{array}$ & Unclear risk & Insufficient information (RCT is part of a paper reporting multiple trials) \\
\hline Other bias & Low risk & None detected \\
\hline
\end{tabular}

Sant 2003

\section{Study characteristics}

\begin{tabular}{ll}
\hline Methods & Study design: $\mathrm{RCT}$ \\
& Study duration (months): 6 \\
\hline Participants & Number randomised: 121 \\
& Setting: 7 institutions \\
& Country: USA \\
& Sex: 108 females and 13 males \\
& Age, years: mean 47.8 (SD 13.9) for Group A, mean 48.7 (SD 15.1) for Group B, mean 43.7 (SD 15.1) for \\
& Group C, mean 41.0 (SD 15.5) for Group D
\end{tabular}

Diagnosis: IC (NIDDK criteria)

Inclusion criteria: eligible participants had to be at least 18 years old, receive a diagnosis of IC confirmed by cystoscopy and hydrodistension, according to NIH NIDDK criteria. Moderate symptoms of urinary frequency (at least 11 times daily) and pain/discomfort (at least 4 on a 0 to 9 Likert scale) for at least 24 weeks before study entry

Exclusion criteria: not reported 
Sant 2003 (Continued)

Group B ( $\mathbf{n}=\mathbf{2 9}$ ): pentosan polysulfate (PPS) alone

Group C ( $\mathbf{n}=\mathbf{3 0}$ ): hydroxyzine and PPS combination therapy

Group D ( $\mathbf{n}=\mathbf{3 1})$ : placebo

Regimen: the dose of PPS was one $100 \mathrm{mg}$ capsule 3 times daily. The target dose of hydroxyzine was 50 $\mathrm{mg}$ daily taken at bedtime titrated from 10 to 25 to $50 \mathrm{mg}$ daily during 3 weeks

Treatment category in NMA: antihistamines vs PPS vs PPS + antihistamines vs control

Outcome data in analysis
Cure or improvement: 'moderately' or 'markedly' improved on GRA: at 24 weeks
Pain: pain score (score range 0 to 9): at 24 weeks
ICSI: at 24 weeks
ICPI: at 24 weeks

Adverse events: at 24 weeks

Funding NIDDK, NIH (individual study authors have relationships with pharmaceutical companies)

Notes Publication status: full text

\section{Risk of bias}

\begin{tabular}{|c|c|c|}
\hline Bias & Authors' judgement & Support for judgement \\
\hline \multirow[t]{2}{*}{$\begin{array}{l}\text { Random sequence genera- } \\
\text { tion (selection bias) }\end{array}$} & Low risk & $\begin{array}{l}\text { Quote: "randomized ... using a randomized block design stratified by clinical } \\
\text { site" }\end{array}$ \\
\hline & & Comment: probably done \\
\hline $\begin{array}{l}\text { Allocation concealment } \\
\text { (selection bias) }\end{array}$ & Unclear risk & No information provided \\
\hline $\begin{array}{l}\text { Blinding of participants } \\
\text { and personnel (perfor- } \\
\text { mance bias) } \\
\text { All outcomes }\end{array}$ & Unclear risk & "double masked". Placebo not described \\
\hline $\begin{array}{l}\text { Blinding of outcome as- } \\
\text { sessment (detection bias) } \\
\text { Subjective outcome }\end{array}$ & Unclear risk & "double masked". Placebo not described \\
\hline $\begin{array}{l}\text { Incomplete outcome data } \\
\text { (attrition bias) } \\
\text { Cure or improvement }\end{array}$ & High risk & $\begin{array}{l}\text { Review authors chose to use number who completed trial: } 24 / 31(63 \%) \text { in hy- } \\
\text { droxyzine group; } 26 / 29(90 \%) \text { in PPS group; } 23 / 30(77 \%) \text { in PPS + hydroxyzine } \\
\text { group; } 23 / 31(74 \%) \text { in placebo group }\end{array}$ \\
\hline $\begin{array}{l}\text { Incomplete outcome data } \\
\text { (attrition bias) } \\
\text { Pain }\end{array}$ & Unclear risk & Number analysed not stated \\
\hline $\begin{array}{l}\text { Incomplete outcome data } \\
\text { (attrition bias) } \\
\text { Interstitial Cystitis Symp- } \\
\text { tom Index }\end{array}$ & Unclear risk & Number analysed not stated \\
\hline
\end{tabular}


Sant 2003 (Continued)

\begin{tabular}{|c|c|c|}
\hline $\begin{array}{l}\text { Incomplete outcome data } \\
\text { (attrition bias) } \\
\text { Interstitial Cystitis Prob- } \\
\text { lem Index }\end{array}$ & Unclear risk & Number analysed not stated \\
\hline $\begin{array}{l}\text { Incomplete outcome data } \\
\text { (attrition bias) } \\
\text { Adverse events }\end{array}$ & Low risk & All randomised participants were included in analysis \\
\hline $\begin{array}{l}\text { Selective reporting (re- } \\
\text { porting bias) }\end{array}$ & Low risk & Results included all outcomes specified in the methods section \\
\hline Other bias & Low risk & None detected \\
\hline
\end{tabular}

\section{Shirvan 2015}

\section{Study characteristics}

\begin{tabular}{|c|c|c|}
\hline Methods & \multicolumn{2}{|c|}{$\begin{array}{l}\text { Study design: } \mathrm{RCT} \\
\text { Study duration (months): } 1\end{array}$} \\
\hline Participants & $\begin{array}{l}\text { Number randomised } \\
\text { Setting: not reported } \\
\text { Country: Iran } \\
\text { Sex: female } \\
\text { Age, years: not report } \\
\text { Diagnosis: PBS } \\
\text { Inclusion criteria: kn } \\
\text { mendations by Americ } \\
\text { Exclusion criteria: no }\end{array}$ & $\begin{array}{l}10 \\
\text { Nn female patients with PBS, who were treated according to therapeutic recom } \\
\text { n Urological Association Guideline with no success } \\
\text { reported }\end{array}$ \\
\hline Interventions & \multicolumn{2}{|c|}{$\begin{array}{l}\text { Group A }(\mathbf{n}=\mathbf{2 0}) \text { : hydrodistension with } 400 \mathrm{mg} \text { SinaCurcumin in } 500 \mathrm{cc} \text { normal saline } \\
\text { Group B }(\mathbf{n}=\mathbf{2 0}) \text { : hydrodistension with } 500 \mathrm{cc} \text { normal saline only } \\
\text { Treatment category in NMA: immune modulators vs control }\end{array}$} \\
\hline Outcomes & \multicolumn{2}{|c|}{ Outcome data in analysis; no usable data } \\
\hline Funding & \multicolumn{2}{|l|}{ Not reported } \\
\hline Notes & \multicolumn{2}{|c|}{ Publication status: abstract } \\
\hline \multicolumn{3}{|l|}{ Risk of bias } \\
\hline Bias & Authors' judgement & Support for judgement \\
\hline $\begin{array}{l}\text { Random sequence genera- } \\
\text { tion (selection bias) }\end{array}$ & Unclear risk & Quote: "randomized" \\
\hline
\end{tabular}


Shirvan 2015 (Continued)

\begin{tabular}{lll}
$\begin{array}{l}\text { Allocation concealment } \\
\text { (selection bias) }\end{array}$ & Unclear risk & No information provided \\
\hline $\begin{array}{l}\text { Blinding of participants } \\
\text { and personnel (perfor- } \\
\text { mance bias) } \\
\text { All outcomes }\end{array}$ & Unclear risk & $\begin{array}{l}\text { Blinding not mentioned. Hydrodistension (HD) with } 500 \text { cc saline vs HD with } \\
\text { curcumin in } 500 \text { cc saline }\end{array}$ \\
\hline $\begin{array}{l}\text { Blinding of outcome as- } \\
\text { sessment (detection bias) } \\
\text { Subjective outcome }\end{array}$ & Unclear risk & $\begin{array}{l}\text { Blinding not mentioned. Hydrodistention (HD) with 500 cc saline vs HD with } \\
\text { curcumin in } 500 \text { cc saline }\end{array}$ \\
\hline $\begin{array}{l}\text { Selective reporting (re- } \\
\text { porting bias) }\end{array}$ & Low risk & Results included all outcomes specified in the methods section \\
\hline Other bias & Low risk & None detected \\
\hline
\end{tabular}

Singh 2003

\section{Study characteristics}

\begin{tabular}{ll} 
Study design: RCT \\
Study duration (months): 6 \\
\hline
\end{tabular}

\section{Participants}

\section{Number randomised: 30}

Setting: not reported

Country: UK

Sex: not reported

Age, years: not reported

Diagnosis: IC (NIH criteria)

Inclusion criteria: patients who met NIH modified diagnostic and exclusion criteria for IC. All patients also had to undergo cystoscopy to confirm the presence of Hunner's ulcers or glomerulations

Exclusion criteria: not reported

Group A (n = 15): $40 \mathrm{mg} / 50 \mathrm{~mL}$ sodium hyaluronate (Cystostat)

Group B (n = 15): DMSO (dimethyl sulfoxide, 5.4\%) $27 \mathrm{~g}$ in $50 \mathrm{~mL}$ (RIMSO-50)

Regimen: Group A: weekly for 4 weeks, then monthly for 2 months; Group B: 2 weekly for 3 months

Treatment category in NMA: hyaluronic acid vs DMSO

\begin{tabular}{ll}
\hline Outcomes & Outcome data in analysis; no usable data \\
\hline Funding & Not reported \\
\hline Notes & Publication status: abstract \\
& $\begin{array}{l}\text { Notes from previous versions of the review: previously excluded from the last review as no reported da- } \\
\text { ta }\end{array}$
\end{tabular}

\section{Risk of bias}

Interventions for treating people with symptoms of bladder pain syndrome: a network meta-analysis (Review) 
Singh 2003 (Continued)

\begin{tabular}{lll} 
Bias & Authors' judgement & Support for judgement \\
\hline $\begin{array}{l}\text { Random sequence genera- } \\
\text { tion (selection bias) }\end{array}$ & Unclear risk & Quote: "randomized" \\
\hline
\end{tabular}

\begin{tabular}{|c|c|c|}
\hline $\begin{array}{l}\text { Allocation concealment } \\
\text { (selection bias) }\end{array}$ & Unclear risk & No information provided \\
\hline $\begin{array}{l}\text { Blinding of participants } \\
\text { and personnel (perfor- } \\
\text { mance bias) } \\
\text { All outcomes }\end{array}$ & Unclear risk & No information provided \\
\hline $\begin{array}{l}\text { Selective reporting (re- } \\
\text { porting bias) }\end{array}$ & Unclear risk & $\begin{array}{l}\text { This abstract presented no outcome data. "We present the rest of the data } \\
\text { when all patients should have had a six months' follow-up" }\end{array}$ \\
\hline Other bias & Low risk & None detected \\
\hline
\end{tabular}

\section{Souza 2012}

\section{Study characteristics}

\begin{tabular}{ll}
\hline Methods & Study design: $\mathrm{RCT}$ \\
& Study duration (months): 0.7 \\
\hline Participants & Number randomised: 22 \\
& Setting: single centre \\
& Country: Brazil \\
& Sex: 18 females and 4 males \\
& Age, years: mean 54.9 (SD 5.1) for Group A, mean 55.3 (SD 5.8) for Group B
\end{tabular}

Diagnosis: IC/PBS (diagnostic criteria according to the 'IC Data Base Study'; referenced as Hanno 1999)

Inclusion criteria: females and males with clinical diagnosis of IC/PBS and no medical condition or therapy that would exclude safe concomitant use of Cystex; negative bacterial urine culture; patient-reported average urinary frequency of at least 11 times per 24 hour period during the screening period

Exclusion criteria: to be included, urine must have been sterile at time of diagnosis and assessment and urinary cytology negative; all other diseases that could cause pelvic symptoms were excluded

Group B (n= 11): placebo for 3 weeks

Treatment category in NMA: parasympathomimetic (+ urinary antiseptics) vs control

\begin{tabular}{ll}
\hline Outcomes & Outcome data in analysis \\
Pain: VAS (assumed 0 to 100$):$ at 21 days \\
Functional bladder capacity: at 21 days \\
Adverse events: at 21 days
\end{tabular}


Souza 2012 (Continued)

\begin{tabular}{|c|c|c|}
\hline Funding & \multicolumn{2}{|l|}{ Not reported } \\
\hline Notes & \multicolumn{2}{|c|}{ Publication status: full text } \\
\hline \multicolumn{3}{|l|}{ Risk of bias } \\
\hline Bias & Authors' judgement & Support for judgement \\
\hline $\begin{array}{l}\text { Random sequence genera- } \\
\text { tion (selection bias) }\end{array}$ & Low risk & $\begin{array}{l}\text { Quote: "'Randomization is being performed by computer-generated random } \\
\text { allocation sequence" }\end{array}$ \\
\hline $\begin{array}{l}\text { Allocation concealment } \\
\text { (selection bias) }\end{array}$ & Unclear risk & No information provided \\
\hline $\begin{array}{l}\text { Blinding of participants } \\
\text { and personnel (perfor- } \\
\text { mance bias) } \\
\text { All outcomes }\end{array}$ & Low risk & $\begin{array}{l}\text { "placebo-controlled and double blind design". Study drug "capsule" vs "place- } \\
\text { bo capsules, identical in form, colour and taste to the ones of the active formu- } \\
\text { lation" }\end{array}$ \\
\hline
\end{tabular}

\begin{tabular}{|c|c|c|}
\hline $\begin{array}{l}\text { Blinding of outcome as- } \\
\text { sessment (detection bias) } \\
\text { Subjective outcome }\end{array}$ & Low risk & $\begin{array}{l}\text { "placebo-controlled and double blind design". Study drug "capsule" vs "place- } \\
\text { bo capsules, identical in form, colour and taste to the ones of the active formu- } \\
\text { lation" }\end{array}$ \\
\hline
\end{tabular}

Blinding of outcome as-
$\begin{aligned} & \text { sessment (detection bias) } \\ & \text { Objective outcome }\end{aligned}$

\begin{tabular}{|c|c|c|}
\hline $\begin{array}{l}\text { Incomplete outcome data } \\
\text { (attrition bias) } \\
\text { Pain }\end{array}$ & Low risk & All randomised participants were included in analysis \\
\hline $\begin{array}{l}\text { Incomplete outcome data } \\
\text { (attrition bias) } \\
\text { Frequency }\end{array}$ & Low risk & \\
\hline $\begin{array}{l}\text { Incomplete outcome data } \\
\text { (attrition bias) } \\
\text { Functional bladder capac- } \\
\text { ity }\end{array}$ & Low risk & All randomised participants were included in analysis \\
\hline $\begin{array}{l}\text { Incomplete outcome data } \\
\text { (attrition bias) } \\
\text { Adverse events }\end{array}$ & Low risk & All randomised participants were included in analysis \\
\hline $\begin{array}{l}\text { Selective reporting (re- } \\
\text { porting bias) }\end{array}$ & Low risk & Results included all outcomes specified in the methods section \\
\hline Other bias & Low risk & None detected \\
\hline
\end{tabular}

Taha 2007

\section{Study characteristics}

Methods Study design: RCT


Taha 2007 (Continued)

Study duration (months): 24

Number randomised: 36
Setting: not reported
Country: Egypt
Sex: not reported
Age, years: not reported
Diagnosis: IC (NIDDK criteria)
Inclusion criteria: patients who met NIH NIDDK criteria for IC and reported at least moderate pain and
frequency for a minimum of 6 months

Exclusion criteria: not reported

Interventions

Group A ( $\mathbf{n} \mathbf{3 6}$ ): bacillus Calmette-Guerin (BCG) instillation

Group B ( $\mathbf{n}=\mathbf{3 6}$ ): 300 IU botulinum toxin A injection

Regimen: Group A: once-only treatment; Group B: 6 weekly instillations

Treatment category in NMA: immune modulators vs neuromuscular blockade

\begin{tabular}{|c|c|c|}
\hline Outcomes & \multicolumn{2}{|c|}{ Outcome data in analysis } \\
\hline & \multicolumn{2}{|c|}{$\begin{array}{l}\text { Cure or improvement: positive clinical response with no additional treatment for intractable interstitial } \\
\text { cystitis (no further definition provided) }\end{array}$} \\
\hline Funding & \multicolumn{2}{|c|}{ Faculty of Medicine, Tanta University } \\
\hline Notes & \multicolumn{2}{|c|}{ Publication status: abstract } \\
\hline \multicolumn{3}{|l|}{ Risk of bias } \\
\hline Bias & Authors' judgement & Support for judgement \\
\hline $\begin{array}{l}\text { Random sequence genera- } \\
\text { tion (selection bias) }\end{array}$ & High risk & $\begin{array}{l}\text { Quote: "'randomly divided into two groups (cases 1, 3, } 5 \text { \& 2, 4, 6)" } \\
\text { Comment: this is likely to be alternate allocation }\end{array}$ \\
\hline $\begin{array}{l}\text { Allocation concealment } \\
\text { (selection bias) }\end{array}$ & High risk & $\begin{array}{l}\text { Quote: "'randomly divided into two groups (cases } 1,3,5 \& 2,4,6 \text { )" } \\
\text { Comment: this is likely to be alternate allocation }\end{array}$ \\
\hline $\begin{array}{l}\text { Blinding of participants } \\
\text { and personnel (perfor- } \\
\text { mance bias) } \\
\text { All outcomes }\end{array}$ & High risk & $\begin{array}{l}\text { Probably not done. Intravesical instillation of BCG vs intravesical injection of } \\
\text { botulinum toxin A (BTX-A) }\end{array}$ \\
\hline $\begin{array}{l}\text { Blinding of outcome as- } \\
\text { sessment (detection bias) } \\
\text { Subjective outcome }\end{array}$ & High risk & $\begin{array}{l}\text { Probably not done. Intravesical instillation of BCG vs intravesical injection of } \\
\text { botulinum toxin A (BTX-A) }\end{array}$ \\
\hline $\begin{array}{l}\text { Incomplete outcome data } \\
\text { (attrition bias) } \\
\text { Cure or improvement }\end{array}$ & Low risk & 16/18 (89\%) included in BCG group; 16/18 (89\%) included in BTX-A group \\
\hline $\begin{array}{l}\text { Selective reporting (re- } \\
\text { porting bias) }\end{array}$ & Unclear risk & Outcomes not specified in methods (abstract only) \\
\hline
\end{tabular}


Taha 2007 (Continued)
Other bias
Low risk
None detected

Thilagarajah 2001

\section{Study characteristics}

\begin{tabular}{|c|c|}
\hline Methods & $\begin{array}{l}\text { Study design: RCT } \\
\text { Study duration (months): } 3\end{array}$ \\
\hline Participants & $\begin{array}{l}\text { Number randomised: } 36 \\
\text { Setting: not reported } \\
\text { Country: UK } \\
\text { Sex: } 33 \text { females and } 1 \text { male (participants who completed study) } \\
\text { Age, years: median 42, range } 23 \text { to } 73 \\
\text { Diagnosis: PBD (painful bladder disease) } \\
\text { Inclusion criteria: patients with a diagnosis of PBD, based on the following criteria: (1) clinical history } \\
\text { of suprapubic pain, frequency and occasionally urgency, nocturia and dysuria, lasting for < } 3 \text { months } \\
\text { despite repeatedly negative urine culture; (2) petechial haemorrhages apparent on cystoscopy af- } \\
\text { ter distension; (3) histological examination of bladder biopsies taken from patients, which showed a } \\
\text { chronic inflammatory infiltrate with submucosal angiogenesis and increased collagen deposition in the } \\
\text { muscle. The basement membrane also appeared discontinuous; (4) urodynamic studies were deemed } \\
\text { unnecessary for a diagnosis of PBD as, in keeping with previous studies, results obtained in this group } \\
\text { of patients are too variable to be valid } \\
\text { Exclusion criteria: patients were excluded from the study if they had taken antibiotics or NSAIDs or } \\
\text { had undergone intravesical therapy in the preceding month; in women, if there was any possibility of } \\
\text { pregnancy, as there is a theoretical risk of teratogenic effects in the fetus under H2-antagonist treat- } \\
\text { ment; if there was a history of renal/hepatic impairment or blood dyscrasias, as these may worsen or } \\
\text { become apparent during treatment with cimetidine; if there was concomitant treatment with drugs } \\
\text { metabolised within the liver using the P450 cytochrome family of enzymes (warfarin, phenytoin, quini- } \\
\text { dine, theophylline and tricyclic antidepressants), as cimetidine can inhibit these enzymes }\end{array}$ \\
\hline
\end{tabular}

Interventions

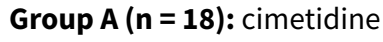

Group B ( $\mathbf{n}=\mathbf{1 8})$ : placebo

Regimen: oral cimetidine $400 \mathrm{mg}$ or placebo (both twice daily)

Treatment category in NMA: antihistamines vs control

\begin{tabular}{|c|c|c|}
\hline Outcomes & \multicolumn{2}{|c|}{ Outcome data in analysis; no usable data } \\
\hline Funding & \multicolumn{2}{|l|}{ Not reported } \\
\hline Notes & \multicolumn{2}{|c|}{ Publication status: full text } \\
\hline \multicolumn{3}{|l|}{ Risk of bias } \\
\hline Bias & Authors' judgement & Support for judgement \\
\hline $\begin{array}{l}\text { Random sequence genera- } \\
\text { tion (selection bias) }\end{array}$ & Unclear risk & Quote: "randomized" \\
\hline
\end{tabular}


Thilagarajah 2001 (Continued)

\begin{tabular}{|c|c|c|}
\hline $\begin{array}{l}\text { Allocation concealment } \\
\text { (selection bias) }\end{array}$ & Unclear risk & $\begin{array}{l}\text { Quote: "blindly allocated" } \\
\text { Comment: unclear whether this refers to blinding or allocation concealment }\end{array}$ \\
\hline $\begin{array}{l}\text { Blinding of participants } \\
\text { and personnel (perfor- } \\
\text { mance bias) } \\
\text { All outcomes }\end{array}$ & Low risk & "double blind"; "at the end of the study, the allocation of groups was revealed" \\
\hline
\end{tabular}

Blinding of outcome as- $\quad$ Low risk "double blind"; "at the end of the study, the allocation of groups was revealed"
sessment (detection bias)
Subjective outcome

Selective reporting (re- Low risk Results included all outcomes specified in the methods section
porting bias)

Other bias Low risk None detected

\section{Study characteristics}

\begin{tabular}{ll}
\hline Methods & Study design: RCT \\
& Setting: single centre \\
& Study duration (months): 4 \\
\hline Participants & Number randomised: 50 \\
& Setting: single centre \\
Country: Germany & Sex: 44 females and 6 males \\
Age, years: mean 50.5 (SD 14.4) for Group A, mean 60.2 (SD 17.5) for Group B \\
Diagnosis: IC (NIDDK criteria) \\
Inclusion criteria: women and men who met symptom criteria of the NIDDK for IC. All patients had re- \\
ceived previous conservative medical treatment, including hydrostatic distension, intravesical instilla- \\
tions (e.g. dimethyl sulfoxide, hyaluronic acid) or oral medication (e.g. antiallergics, sodium pentosan \\
polysulfate), which at best achieved short symptomatic relief
\end{tabular}

Exclusion criteria: previous or current intake of amitriptyline

Group A $(\mathbf{n}=\mathbf{2 5})$ : amitriptyline
Group B $(\mathbf{n}=\mathbf{2 5})$ : placebo
Regimen: 4 months with a self-titration protocol that allowed them to escalate drug dosage in $25 \mathrm{mg}$
increments at 1 week intervals (maximum dosage $100 \mathrm{mg})$

Treatment category in NMA: antidepressants vs control

Outcome data in analysis
Cure or improvement: subjective cure at 4 months
Pain: VAS $(0$ to $100 \mathrm{~mm})$ on pain intensity: at 4 months


van Ophoven 2004 (Continued)

Functional bladder capacity: at 4 months

Adverse events: at 4 months

\begin{tabular}{ll}
\hline Funding & Study drug supplied by Bayer Pharmaceutical, Germany \\
\hline Notes & Publication status: full text
\end{tabular}

\section{Risk of bias}

\begin{tabular}{|c|c|c|}
\hline Bias & Authors' judgement & Support for judgement \\
\hline $\begin{array}{l}\text { Random sequence genera- } \\
\text { tion (selection bias) }\end{array}$ & Low risk & Randomisation "using a block randomization design". Probably done \\
\hline $\begin{array}{l}\text { Allocation concealment } \\
\text { (selection bias) }\end{array}$ & Unclear risk & No information provided \\
\hline $\begin{array}{l}\text { Blinding of participants } \\
\text { and personnel (perfor- } \\
\text { mance bias) } \\
\text { All outcomes }\end{array}$ & Low risk & $\begin{array}{l}\text { "double blind"; "placebo-controlled". The drug was supplied by manufacturer; } \\
\text { placebo was supplied by the university hospital pharmacy, "which packed and } \\
\text { blinded placebo and drug tablets" }\end{array}$ \\
\hline $\begin{array}{l}\text { Blinding of outcome as- } \\
\text { sessment (detection bias) } \\
\text { Subjective outcome }\end{array}$ & Low risk & $\begin{array}{l}\text { "double blind"; "placebo-controlled". The drug was supplied by manufacturer; } \\
\text { placebo was supplied by the university hospital pharmacy, "which packed and } \\
\text { blinded placebo and drug tablets" }\end{array}$ \\
\hline
\end{tabular}

$\begin{array}{lll}\text { Blinding of outcome as- } & \text { Low risk } \quad \text { Outcome measurement is not likely to be influenced by lack of blinding } \\ \text { sessment (detection bias) } & \end{array}$

sessment (detection bias)

Objective outcome

\begin{tabular}{|c|c|c|}
\hline $\begin{array}{l}\text { Incomplete outcome data } \\
\text { (attrition bias) } \\
\text { Cure or improvement }\end{array}$ & Low risk & $\begin{array}{l}24 / 25 \text { ( } 1 \text { dropped out due to } A E \text { ) included in intervention group; } 24 / 25 \text { ( } 1 \\
\text { dropped out due to } A E \text { ) included in control group }\end{array}$ \\
\hline $\begin{array}{l}\text { Incomplete outcome data } \\
\text { (attrition bias) } \\
\text { Pain }\end{array}$ & Low risk & $\begin{array}{l}24 / 25 \text { ( } 1 \text { dropped out due to } A E \text { ) included in intervention group; } 24 / 25 \text { (1 } \\
\text { dropped out due to } A E \text { ) included in control group }\end{array}$ \\
\hline $\begin{array}{l}\text { Incomplete outcome data } \\
\text { (attrition bias) } \\
\text { Frequency }\end{array}$ & Low risk & \\
\hline $\begin{array}{l}\text { Incomplete outcome data } \\
\text { (attrition bias) } \\
\text { Functional bladder capac- } \\
\text { ity }\end{array}$ & Low risk & $\begin{array}{l}24 / 25 \text { ( } 1 \text { dropped out due to } A E \text { ) included in intervention group; } 24 / 25 \text { (1 } \\
\text { dropped out due to } A E \text { ) included in control group }\end{array}$ \\
\hline $\begin{array}{l}\text { Incomplete outcome data } \\
\text { (attrition bias) } \\
\text { Adverse events }\end{array}$ & Low risk & $\begin{array}{l}24 / 25 \text { ( } 1 \text { dropped out due to } A E) \text { included in intervention group; } 24 / 25 \text { (1 } \\
\text { dropped out due to } A E \text { ) included in control group }\end{array}$ \\
\hline $\begin{array}{l}\text { Selective reporting (re- } \\
\text { porting bias) }\end{array}$ & Low risk & Results included all outcomes specified in the methods section \\
\hline Other bias & Low risk & None detected \\
\hline
\end{tabular}


van Ophoven 2006

\section{Study characteristics}

\begin{tabular}{|c|c|}
\hline Methods & $\begin{array}{l}\text { Study design: } \mathrm{RCT} \\
\text { Study duration (months): } 3\end{array}$ \\
\hline Participants & $\begin{array}{l}\text { Number randomised: } 21 \\
\text { Setting: not reported } \\
\text { Country: Germany } \\
\text { Sex: female } \\
\text { Age, years: mean } 65.5, \text { SD } 8.8 \text {, range } 42.2 \text { to } 78.0 \\
\text { Diagnosis: IC (NIDDK criteria) } \\
\text { Inclusion criteria: patients } 18 \text { years of age or older who met diagnostic criteria of the NIDDK for IC } \\
\text { Exclusion criteria: not stated }\end{array}$ \\
\hline Interventions & $\begin{array}{l}\text { Group A }(\mathbf{n}=\mathbf{1 4}) \text { : hyperbaric oxygen (HBO) } \\
\text { Group B }(\mathbf{n}=\mathbf{7}) \text { : placebo } \\
\text { Regimen: } 90 \text { minutes treatment in a hyperbaric chamber pressurised with } 100 \% \mathrm{O} 2 \text { to } 2.4 \text { atmosphere } \\
\text { absolute for } 30 \text { treatment sessions or } 1.3 \text { atmosphere absolute, breathing normal air in the control } \\
\text { group. Treatment was given in daily sessions, } 6 \text { times a week during treatment }\end{array}$ \\
\hline
\end{tabular}

Treatment category in NMA: hyperbaric oxygen vs control

\begin{tabular}{|c|c|c|}
\hline \multirow[t]{5}{*}{ Outcomes } & \multicolumn{2}{|c|}{ Outcome data in analysis } \\
\hline & \multicolumn{2}{|c|}{ Cure or improvement: 'moderately' or 'markedly' improved on GRA: at 3 months } \\
\hline & \multicolumn{2}{|c|}{ Pain: pain VAS (mm): at 3 months } \\
\hline & \multicolumn{2}{|c|}{ Functional bladder capacity: at 3 months } \\
\hline & \multicolumn{2}{|c|}{ Adverse events: at 3 months } \\
\hline Funding & \multicolumn{2}{|c|}{ Fishbein Family Foundation } \\
\hline Notes & \multicolumn{2}{|c|}{ Publication status: full text } \\
\hline \multicolumn{3}{|l|}{ Risk of bias } \\
\hline Bias & Authors' judgement & Support for judgement \\
\hline $\begin{array}{l}\text { Random sequence genera- } \\
\text { tion (selection bias) }\end{array}$ & Low risk & $\begin{array}{l}\text { "randomly assigned" using "code"; "the code was broken after evaluation at } 3 \\
\text { months" }\end{array}$ \\
\hline $\begin{array}{l}\text { Allocation concealment } \\
\text { (selection bias) }\end{array}$ & Unclear risk & $\begin{array}{l}\text { "randomly assigned" using "code"; "the code was broken after evaluation at } 3 \\
\text { months". Unclear whether this refers to blinding or allocation concealment }\end{array}$ \\
\hline $\begin{array}{l}\text { Blinding of participants } \\
\text { and personnel (perfor- } \\
\text { mance bias) } \\
\text { All outcomes }\end{array}$ & Low risk & $\begin{array}{l}\text { "double-blind", "sham-controlled". Treatment given via facial mask at cham- } \\
\text { ber pressure of } 2.4 \text { ata. Sham treatment "was conducted identically" except } \\
\text { for a facial mask used at a faintly increased pressure of } 1.3 \text { to } 1.4 \text { ata }\end{array}$ \\
\hline
\end{tabular}


van Ophoven 2006 (Continued)

\begin{tabular}{|c|c|c|}
\hline $\begin{array}{l}\text { Blinding of outcome as- } \\
\text { sessment (detection bias) } \\
\text { Subjective outcome }\end{array}$ & Low risk & $\begin{array}{l}\text { "double-blind", "sham-controlled". Treatment given via facial mask at cham- } \\
\text { ber pressure of } 2.4 \text { ata. Sham treatment "was conducted identically" except } \\
\text { for a facial mask used at a faintly increased pressure of } 1.3 \text { to } 1.4 \text { ata }\end{array}$ \\
\hline
\end{tabular}

\begin{tabular}{|c|c|c|}
\hline $\begin{array}{l}\text { Blinding of outcome as- } \\
\text { sessment (detection bias) } \\
\text { Objective outcome }\end{array}$ & Low risk & Outcome measurement is not likely to be influenced by lack of blinding \\
\hline $\begin{array}{l}\text { Incomplete outcome data } \\
\text { (attrition bias) } \\
\text { Cure or improvement }\end{array}$ & High risk & $\begin{array}{l}12 / 14 \text { ( } 85 \% ; 1 \text { dropped out due to a mild oxygen intoxication, } 1 \text { due to poor } \\
\text { adherence to protocol) included in treatment group; } 7 / 7 \text { included in control } \\
\text { group }\end{array}$ \\
\hline $\begin{array}{l}\text { Incomplete outcome data } \\
\text { (attrition bias) } \\
\text { Pain }\end{array}$ & Low risk & $\begin{array}{l}\text { Quote: "For the } 2 \text { dropouts, the latest evaluable post-baseline observation was } \\
\text { analyzed" }\end{array}$ \\
\hline $\begin{array}{l}\text { Incomplete outcome data } \\
\text { (attrition bias) } \\
\text { Frequency }\end{array}$ & Low risk & \\
\hline $\begin{array}{l}\text { Incomplete outcome data } \\
\text { (attrition bias) } \\
\text { Functional bladder capac- } \\
\text { ity }\end{array}$ & Low risk & $\begin{array}{l}\text { Quote: "for the } 2 \text { dropouts, the latest evaluable post-baseline observation was } \\
\text { analyzed" }\end{array}$ \\
\hline $\begin{array}{l}\text { Incomplete outcome data } \\
\text { (attrition bias) } \\
\text { Adverse events }\end{array}$ & Unclear risk & Number analysed not reported \\
\hline $\begin{array}{l}\text { Selective reporting (re- } \\
\text { porting bias) }\end{array}$ & Low risk & Results included all outcomes specified in the methods section \\
\hline Other bias & Low risk & None detected \\
\hline
\end{tabular}

Wang 2017a

\section{Study characteristics}

Methods

Study design: RCT

Study duration (months): 6.5

Participants

Number randomised: 31

Setting: 12 sites

Country: USA and Canada

Sex: 26 females and 5 males

Age, years: mean 50.6 (SD 10.68, range 38 to 78 ) for Group A, mean 46.2 (SD 13.56, range 25 to 69 ) for Group B

\section{Diagnosis: IC/PBS}

Inclusion criteria: adult ( $\geq 18$ to 80 years, inclusive) men and women with IC/BPS based on a total score $\geq 8$ on the validated O'Leary-Sant Interstitial Cystitis Symptom Index (ICSI) and chronic bladder pain for at least 6 months before screening, accompanied by urinary urgency, urinary frequency ( $\geq 8$ voids daily) and/ or nocturia. On the basis of patient self-assessment of pain using a 11-point numeri- 
Wang 2017a (Continued)

cal rating scale (NRS) ( 0 = "no pain", $10=$ "worst pain imaginable"), the mean of average pain intensity scores for the last 7 days of screening had to be $\geq 5$ based on at least 6 of 7 days. Other key eligibility criteria required that patients had no evidence of a urinary tract infection or significant urological disease, including neurogenic bladder and diabetic cystopathy, and had not received intravesical therapy or undergone cystoscopy during the 6 weeks before screening

Exclusion criteria: patients were excluded if they had received opioid analgesic at a dosage of oral morphine equivalent $\geq 40 \mathrm{mg} / \mathrm{d}$ or had changed drugs known to affect IC/BPS-associated pain (i.e. antidepressants, antihistamines, antispasmodics, anticholinergics, anticonvulsants) within the 4 weeks before screening

\section{Interventions}

Group A ( $\mathbf{n}=\mathbf{1 4})$ : subcutaneous fulranumab $9 \mathrm{mg}$ every 4 weeks

Group B ( $\mathbf{n}=\mathbf{1 7})$ : matching placebo

Treatment category in NMA: immune modulators vs control

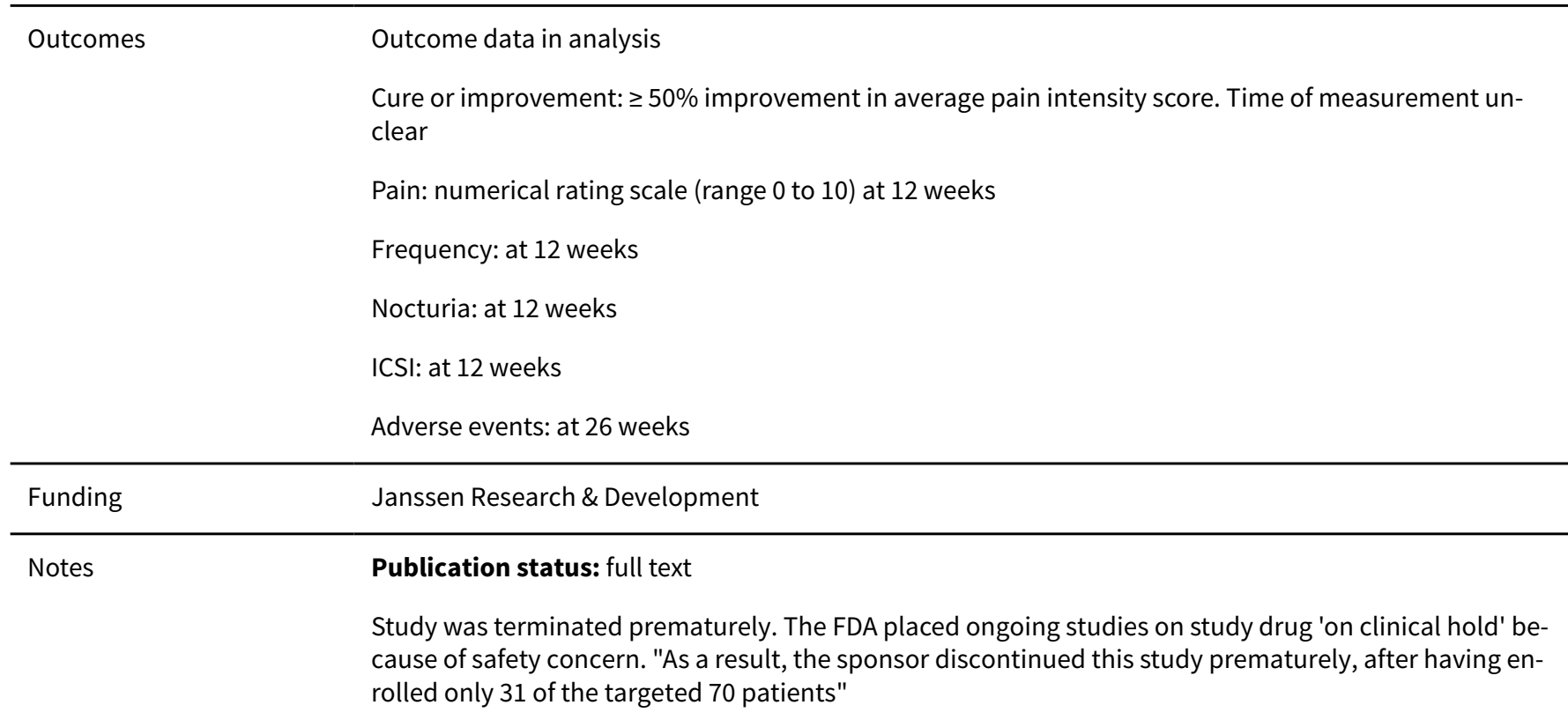

\section{Risk of bias}

\begin{tabular}{lll}
\hline Bias & Authors' judgement & Support for judgement \\
\hline $\begin{array}{l}\text { Random sequence genera- } \\
\text { tion (selection bias) }\end{array}$ & Low risk & $\begin{array}{l}\text { Quote: "randomized ... based on a computer-generated randomization sched- } \\
\text { ule" }\end{array}$ \\
\hline $\begin{array}{l}\text { Allocation concealment } \\
\text { (selection bias) }\end{array}$ & Unclear risk & No information provided \\
\hline
\end{tabular}

\begin{tabular}{|c|c|c|}
\hline $\begin{array}{l}\text { Blinding of participants } \\
\text { and personnel (perfor- }\end{array}$ & Low risk & $\begin{array}{l}\text { "double-blind, placebo-controlled" study using subcutaneous injection of } \\
\text { study drug or "matching placebo" }\end{array}$ \\
\hline
\end{tabular}

mance bias)

All outcomes

\begin{tabular}{lll}
\hline $\begin{array}{l}\text { Blinding of outcome as- } \\
\text { sessment (detection bias) } \\
\text { Subjective outcome }\end{array}$ & Low risk & $\begin{array}{l}\text { "double-blind, placebo-controlled" study using subcutaneous injection of } \\
\text { study drug or "matching placebo" }\end{array}$ \\
\hline $\begin{array}{l}\text { Incomplete outcome data } \\
\text { (attrition bias) }\end{array}$ & Low risk & $\begin{array}{l}\text { All randomised participants were included in analysis (4/14 and 3/17 withdrew } \\
\text { from study; "the last observed data were carried forward") }\end{array}$
\end{tabular}


Wang 2017a (Continued)

Cure or improvement

\begin{tabular}{|c|c|c|}
\hline $\begin{array}{l}\text { Incomplete outcome data } \\
\text { (attrition bias) } \\
\text { Pain }\end{array}$ & Low risk & $\begin{array}{l}\text { All randomised participants were included in analysis ( } 4 / 14 \text { and 3/17 withdrew } \\
\text { from study; "the last observed data were carried forward") }\end{array}$ \\
\hline $\begin{array}{l}\text { Incomplete outcome data } \\
\text { (attrition bias) } \\
\text { Frequency }\end{array}$ & Low risk & $\begin{array}{l}\text { All randomised participants were included in analysis (4/14 and 3/17 withdrew } \\
\text { from study; "the last observed data were carried forward") }\end{array}$ \\
\hline $\begin{array}{l}\text { Incomplete outcome data } \\
\text { (attrition bias) } \\
\text { Nocturia }\end{array}$ & Low risk & $\begin{array}{l}\text { All randomised participants were included in analysis ( } 4 / 14 \text { and 3/17 withdrew } \\
\text { from study; "the last observed data were carried forward") }\end{array}$ \\
\hline $\begin{array}{l}\text { Incomplete outcome data } \\
\text { (attrition bias) } \\
\text { Interstitial Cystitis Symp- } \\
\text { tom Index }\end{array}$ & Low risk & $\begin{array}{l}\text { All randomised participants were included in analysis ( } 4 / 14 \text { and 3/17 withdrew } \\
\text { from study; "the last observed data were carried forward") }\end{array}$ \\
\hline $\begin{array}{l}\text { Incomplete outcome data } \\
\text { (attrition bias) } \\
\text { Adverse events }\end{array}$ & Low risk & $\begin{array}{l}\text { All randomised participants were included in analysis ( } 4 / 14 \text { and 3/17 withdrew } \\
\text { from study; "the last observed data were carried forward") }\end{array}$ \\
\hline $\begin{array}{l}\text { Selective reporting (re- } \\
\text { porting bias) }\end{array}$ & Low risk & Results included all outcomes specified in the methods section \\
\hline Other bias & Low risk & None detected \\
\hline
\end{tabular}

\section{Warren 2000}

\section{Study characteristics}

Methods

Study design: RCT

Study duration (months): 4.5

Participants

Number randomised: 50
Setting: 6 centres

Country: USA

Sex: 45 females and 5 males

Age, years: mean 49.7 (SD 16.0) for Group A, mean 54.8 (SD 8.9) for Group B

Diagnosis: IC (NIDDK criteria)

Inclusion criteria: those who met published NIDDK criteria. When cystoscopy was performed by others, we obtained reports of past procedures and confirmed Hunner's ulcers or glomerulations. Semi-quantitative assessment of bladder pain on a scale of mild, discomforting, distressing, horrible and excruciating, and urgency on a scale of never, rarely, sometimes, frequently and always was obtained from each patient. For study inclusion, at least 2 of 3 criteria were required, including interstitial cystitis pain that was distressing or worse, urinary urgency sometimes or more often and/or urinary frequency for 8 or more waking hours. Patients on pentosan polysulfate were required to withdraw from the medication during the study because of anecdotal reports of improvement months after initiation. Other interstitial cystitis therapy was continued if it had been administered for 2 months or longer

Exclusion criteria: patients were excluded from the study when they were pregnant or breastfeeding, could not swallow or absorb oral medications, could not follow instructions or participate for 18 weeks 
Warren 2000 (Continued)

or had known renal or liver disease. Those with a clean midstream voided urine sample that yielded 13 $105 / \mathrm{mL}$ or greater bacteria of any species were also excluded from the study. In addition, patients with allergy or intolerance to a study antibiotic participated but did not receive that antibiotic, and those who could not receive 2 or more study antibiotics were excluded from the study

Group A ( $\mathbf{n}=\mathbf{2 5})$ : antibiotic regimen
Group B $(\mathbf{n}=\mathbf{2 5})$ : placebo
Regimen: 18 weeks of placebo or antibiotics, including rifampin $300 \mathrm{mg}$ OD plus a sequence of doxy-
cycline $100 \mathrm{mg}$ BD, erythromycin $250 \mathrm{mg}$ QDS, metronidazole $500 \mathrm{mg}$ QDS, clindamycin $300 \mathrm{mg}$ QDS,
amoxicillin $500 \mathrm{mg}$ TDS and ciprofloxacin $250 \mathrm{mg}$ BD for 3 weeks each

Treatment category in NMA: antibiotics vs control

\begin{tabular}{|c|c|c|}
\hline Outcomes & \multicolumn{2}{|c|}{ Outcome data in analysis } \\
\hline & \multicolumn{2}{|c|}{ Cure or improvement: subjective cure: at 18 weeks (assumed from reports) } \\
\hline & \multicolumn{2}{|c|}{ Adverse events: at 18 weeks. } \\
\hline Funding & \multicolumn{2}{|c|}{ Interstititial Association; Bayer, Hoechst Marion Roussel, Pharmacia and Upjohn and Roerig Pfizer } \\
\hline Notes & \multicolumn{2}{|c|}{ Publication status: full text } \\
\hline \multicolumn{3}{|l|}{ Risk of bias } \\
\hline Bias & Authors' judgement & Support for judgement \\
\hline $\begin{array}{l}\text { Random sequence genera- } \\
\text { tion (selection bias) }\end{array}$ & Unclear risk & Quote: "randomized" \\
\hline $\begin{array}{l}\text { Allocation concealment } \\
\text { (selection bias) }\end{array}$ & Unclear risk & No information provided \\
\hline $\begin{array}{l}\text { Blinding of participants } \\
\text { and personnel (perfor- } \\
\text { mance bias) } \\
\text { All outcomes }\end{array}$ & Unclear risk & Quote: "double-blind, placebo controlled". Placebo not described \\
\hline $\begin{array}{l}\text { Blinding of outcome as- } \\
\text { sessment (detection bias) } \\
\text { Subjective outcome }\end{array}$ & Unclear risk & Quote: "double-blind, placebo controlled". Placebo not described \\
\hline $\begin{array}{l}\text { Incomplete outcome data } \\
\text { (attrition bias) } \\
\text { Cure or improvement }\end{array}$ & Low risk & $\begin{array}{l}\text { 18/25 ( } 72 \% ; 7 \text { withdrew due to perceived AE or unrelieved IC symptom or both) } \\
\text { included in intervention group; } 19 / 25 \text { ( } 2 \text { withdrew before treatment, } 4 \text { with- } \\
\text { drew due to diarrhoea, unrelieved symptoms, stress or constitutional symp- } \\
\text { toms) included in control group }\end{array}$ \\
\hline $\begin{array}{l}\text { Incomplete outcome data } \\
\text { (attrition bias) } \\
\text { Adverse events }\end{array}$ & Low risk & All randomised participants were included in analysis \\
\hline $\begin{array}{l}\text { Selective reporting (re- } \\
\text { porting bias) }\end{array}$ & Low risk & Results included all outcomes specified in the methods section \\
\hline Other bias & Low risk & None detected \\
\hline
\end{tabular}


Yang 2011

\section{Study characteristics}

\begin{tabular}{ll}
\hline Methods & Study design: RCT \\
& Study duration (months): 4 \\
\hline Pumber randomised: 58 & \\
Setting: 11 clinics & Country: USA and Canada \\
Sex: 48 females and 10 males \\
Age, years: mean 51.3 (SD 10.3) for Group A, mean 51.8 (SD 11.6) for Group B \\
Diagnosis: IC/PBS (clinical criteria) \\
Inclusion criteria: men and women older than 18 years. Eligibility required fulfilment of all of certain \\
criteria, including (1) persistent symptoms of urinary frequency and pain rated at least 4 on a scale of 0 \\
to $10,(2)$ failure of at least 24 weeks of active treatment with a minimum of 3 standard forms of therapy \\
or combination of therapies for IC/PBS, (3) cystoscopic diagnosis of IC/PBS in the past with findings of \\
glomerulations and/or ulcerations and (4) screening cystoscopy within the 24 weeks before study entry \\
to evaluate for an unevaluated pathological condition \\
Exclusion criteria: "there were additional exclusion criteria" [exclusion criteria not reported]. Except \\
for medications listed in the exclusion criteria, subjects were allowed to continue on the current med- \\
ication regimen
\end{tabular}

Interventions $\quad$ Group A ( $\mathbf{n}=\mathbf{3 9}$ ): an immunosuppressant 1 gram daily, mycophenolate mofetil (MMF) for 14 days, then 1 gram BID for 10 weeks

Group B ( $\mathbf{n}=\mathbf{1 9})$ : placebo

Treatment category in NMA: immune modulators vs control

Outcomes
Cure or improvement: 'moderately' or 'markedly' improved on GRA: at 16 weeks
Pain: defined as ratings on a '10-point scale' with score range 0 to 10 (but 0 to 10 is actually an 11 -point
scale) at 16 weeks
ICSI: at 16 weeks
ICPI: at 16 weeks
Adverse events: at 16 weeks
NIDDK Cooperative Agreements
Funding
Publication status full text
The trial was "prematurely halted". "A black box warning for MMF [mycophenolate mofetil] was issued"
by manufacturer. Early termination recommended by monitoring committee due to lack of efficacy,
increased safety concerns and slow recruitment. 19/39 in intervention group were not receiving study
drug at the primary end point (14 due to study suspension and 5 due to drug tolerability)

\section{Risk of bias}

Bias Authors' judgement Support for judgement


Yang 2011 (Continued)

\begin{tabular}{lll}
$\begin{array}{l}\text { Random sequence genera- } \\
\text { tion (selection bias) }\end{array}$ & Unclear risk & Quote: "randomized ... in a 2:1 ratio" \\
\hline $\begin{array}{l}\text { Allocation concealment } \\
\text { (selection bias) }\end{array}$ & Unclear risk & No information provided \\
\hline $\begin{array}{l}\text { Blinding of participants } \\
\begin{array}{l}\text { and personnel (perfor- } \\
\text { mance bias) }\end{array}\end{array}$ & Low risk & "Placebo-controlled" trial, using "matching placebo" \\
\begin{tabular}{l} 
All outcomes \\
\hline
\end{tabular}
\end{tabular}

Blinding of outcome as- Low risk $\quad$ "Placebo-controlled" trial, using "matching placebo"
sessment (detection bias)
Subjective outcome

Subjective outcome

Incomplete outcome data Low risk $\quad 39 / 39$ included in intervention group; 18/19 included in control group
(attrition bias)

Cure or improvement

\begin{tabular}{|c|c|c|}
\hline $\begin{array}{l}\text { Incomplete outcome data } \\
\text { (attrition bias) } \\
\text { Pain }\end{array}$ & Low risk & $39 / 39$ included in intervention group; $18 / 19$ included in control group \\
\hline $\begin{array}{l}\text { Incomplete outcome data } \\
\text { (attrition bias) } \\
\text { Interstitial Cystitis Symp- } \\
\text { tom Index }\end{array}$ & Low risk & $39 / 39$ included in intervention group; $18 / 19$ included in control group \\
\hline $\begin{array}{l}\text { Incomplete outcome data } \\
\text { (attrition bias) } \\
\text { Interstitial Cystitis Prob- } \\
\text { lem Index }\end{array}$ & Low risk & $39 / 39$ included in intervention group; $18 / 19$ included in control group \\
\hline $\begin{array}{l}\text { Incomplete outcome data } \\
\text { (attrition bias) } \\
\text { Adverse events }\end{array}$ & Low risk & All randomised participants were included in analysis \\
\hline $\begin{array}{l}\text { Selective reporting (re- } \\
\text { porting bias) }\end{array}$ & Low risk & Results included all outcomes specified in the methods section \\
\hline Other bias & Low risk & None detected \\
\hline
\end{tabular}

Yassin 2011

\section{Study characteristics}

\begin{tabular}{ll}
\hline Methods & Study design: $\mathrm{RCT}$ \\
& Study duration (months): 6 \\
\hline Participants & Number randomised: 28 \\
& Setting: not reported \\
& Country: Egypt \\
Sex: 23 females and 5 males \\
Age, years: not reported
\end{tabular}


Diagnosis: PBS/IC

Inclusion criteria: patients with PBS/IC who did not respond to any of the conventional treatment modalities

Exclusion criteria: not reported

Interventions

Group A ( $\mathbf{n}=\mathbf{1 8})$ : $200 \mathrm{IU}$ of botulinum toxin A into $20 \mathrm{~mL}$ of normal saline + hydrodistension

Group B ( $\mathbf{n}=\mathbf{1 0}): \mathrm{NaCl}+$ hydrodistension

Treatment category in NMA: neuromuscular blockade vs control

\begin{tabular}{|c|c|c|}
\hline Outcomes & \multicolumn{2}{|c|}{ Outcome data in analysis } \\
\hline & \multicolumn{2}{|c|}{ Cure or improvement: subjective Improvement (no definition) at 6 months (assumed from reports) } \\
\hline & \multicolumn{2}{|c|}{ Adverse events: at 6 months } \\
\hline Funding & \multicolumn{2}{|l|}{ None } \\
\hline Notes & \multicolumn{2}{|c|}{ Publication status: abstract } \\
\hline \multicolumn{3}{|l|}{ Risk of bias } \\
\hline Bias & Authors' judgement & Support for judgement \\
\hline $\begin{array}{l}\text { Random sequence genera- } \\
\text { tion (selection bias) }\end{array}$ & Unclear risk & Quote: "randomly divided" \\
\hline $\begin{array}{l}\text { Allocation concealment } \\
\text { (selection bias) }\end{array}$ & Unclear risk & No information provided \\
\hline $\begin{array}{l}\text { Blinding of participants } \\
\text { and personnel (perfor- } \\
\text { mance bias) } \\
\text { All outcomes }\end{array}$ & Unclear risk & $\begin{array}{l}\text { Blinding not mentioned. Submucosal injection of botuinum toxin A or normal } \\
\text { saline "under general anaesthetics ... with video recording of the injection } \\
\text { sites in a similar mapping in both groups" }\end{array}$ \\
\hline $\begin{array}{l}\text { Blinding of outcome as- } \\
\text { sessment (detection bias) } \\
\text { Subjective outcome }\end{array}$ & Unclear risk & $\begin{array}{l}\text { Blinding not mentioned. Submucosal injection of botuinum toxin A or normal } \\
\text { saline "under general anaesthetics ... with video recording of the injection } \\
\text { sites in a similar mapping in both groups" }\end{array}$ \\
\hline $\begin{array}{l}\text { Incomplete outcome data } \\
\text { (attrition bias) } \\
\text { Cure or improvement }\end{array}$ & Unclear risk & $\begin{array}{l}\text { Appeared that all randomised participants were included in analysis, but no } \\
\text { description of missing data was provided }\end{array}$ \\
\hline $\begin{array}{l}\text { Incomplete outcome data } \\
\text { (attrition bias) } \\
\text { Adverse events }\end{array}$ & Unclear risk & $\begin{array}{l}\text { Appeared that all randomised participants were included in analysis, but no } \\
\text { description of missing data was provided }\end{array}$ \\
\hline $\begin{array}{l}\text { Selective reporting (re- } \\
\text { porting bias) }\end{array}$ & Low risk & Results included all outcomes specified in the methods section \\
\hline Other bias & Low risk & None detected \\
\hline
\end{tabular}


Zakaria 2016

\section{Study characteristics}

\begin{tabular}{ll}
\hline Methods & Study design: $\mathrm{RCT}$ \\
& Study duration (months): 4 \\
\hline Participants & Number randomised: 30 \\
& Setting: not reported \\
& Country: Egypt \\
& Sex: male \\
Age, years: range 30 to 50 \\
Diagnosis: IC/PBS \\
Inclusion criteria: male patients who had interstitial cystitis/painful bladder syndrome \\
Exclusion criteria: not reported
\end{tabular}

Interventions

Group A ( $\mathbf{n}=\mathbf{1 5}$ ): transcutaneous electrical nerve stimulation (TENS) for 15 minutes, once daily, $3 \times /$ week for 4 months. 2 suprapubic electrodes and 2 under the lower back (T10-L1). Square wave form, 80 to $100 \mathrm{~Hz}$ frequency, 10 to $30 \mathrm{~mA}$ amplitude, pulse width 50 to 60 us. Traditional physical therapy (PFMT) and medical care (clomipramine, a tricyclic antidepressant) also received

Group B ( $\mathbf{n}=\mathbf{1 5}$ ): sham TENS, traditional physical therapy (PFMT) and medical care (clomipramine, a tricyclic antidepressant)

Treatment category in NMA: physical therapy vs control

\begin{tabular}{ll}
\hline Outcomes & $\begin{array}{l}\text { Outcome data in analysis } \\
\text { Pain: VAS (range } 0 \text { to } 10) \text { at } 4 \text { months }\end{array}$ \\
\hline Funding & Not reported \\
\hline Notes & Publication status: full text
\end{tabular}

\section{Risk of bias}

\begin{tabular}{|c|c|c|}
\hline Bias & Authors' judgement & Support for judgement \\
\hline $\begin{array}{l}\text { Random sequence genera- } \\
\text { tion (selection bias) }\end{array}$ & Unclear risk & Quote: "randomly divided" \\
\hline $\begin{array}{l}\text { Allocation concealment } \\
\text { (selection bias) }\end{array}$ & Unclear risk & No information provided \\
\hline $\begin{array}{l}\text { Blinding of participants } \\
\text { and personnel (perfor- } \\
\text { mance bias) } \\
\text { All outcomes }\end{array}$ & Low risk & TENS vs sham TENS (with physical therapy) \\
\hline $\begin{array}{l}\text { Blinding of outcome as- } \\
\text { sessment (detection bias) } \\
\text { Subjective outcome }\end{array}$ & Low risk & TENS vs sham TENS (with physical therapy) \\
\hline $\begin{array}{l}\text { Incomplete outcome data } \\
\text { (attrition bias) } \\
\text { Pain }\end{array}$ & Low risk & All randomised participants were included in analysis \\
\hline
\end{tabular}


Zakaria 2016 (Continued)

Selective reporting (re- Low risk $\quad$ Results included all outcomes specified in the methods section
porting bias)

Other bias Low risk None detected

AE: adverse event.

ALT: alanine aminotransferase.

AST: aspartate aminotransferase.

BCG: bacille Camille-Guerin.

BMI: body mass index.

BoNT-A: botulinum toxin type A.

BPS: bladder pain syndrome.

BT: bladder training.

CP: chronic prostatitis.

CPPS: chronic pelvic pain syndrome.

CPSI-F: female modification of Chronic Prostitis Symptom Index.

CS: chondroitin sulfate.

DMSO: dimethyl sulfoxide.

EBMP: educational and behavioural modification programme.

GRA: Global Response Assessment.

$\mathrm{HA}$ : hyaluronic acid.

HD: hydrodistension.

IC: interstitial cystitis.

ICPI: Interstitial Cystitis Problem Index.

ICSI: Interstitial Cystitis Symptom Index.

IgG: immunoglobulin G.

IQR: interquartile ratio.

LOCF: last observation carried forward.

mAbs: monoclonal antibodies.

NGF: nerve growth factor.

NIDDK: National Institute of Diabetes and Digestive and Kidney Disease.

$\mathrm{NIH}$ : National Institutes of Health.

NMA: network meta-analysis.

NSAID: non-steroidal anti-inflammatory drug.

OSPI: O'Leary and Sant Interstitial Cystitis Problem Index.

OSSI: O'Leary and Sant Interstitial Cystitis Symptom Index.

PBD: painful bladder disease.

PBS: painful bladder syndrome.

PDE5: phosphodiesterase-5 inhibitor.

PORIS: Patient Overall Rating of Improvement in Symptoms.

PPS: pentosan polysulfate.

PUF: Pelvic Pain and Urgency/Frequency Questionnaire.

PVR: postvoid residual.

$\mathrm{RCT}$ : randomised controlled trial.

RTX: resiniferatoxin.

SD: standard deviation.

SHN: superior hypogastric plexus neurolysis.

TENS: transcutaneous electrical nerve stimulation.

TUIBN: transurethral incision of the bladder neck.

TUIP: transurethral incision of the prostate.

TUMT: transurethral microwave therapy.

TUNA: transurethral needle ablation.

TURP: transurethral resection of the prostate.

UTI: urinary tract infection.

VAS: visual analogue scale.

Characteristics of excluded studies [ordered by study ID] 


\begin{tabular}{ll}
\hline Study & Reason for exclusion \\
\hline Akiyama 2014 & Not a relevant study design. Treatments are not the same for all participants \\
\hline Baert 1975 & $\begin{array}{l}\text { Not a relevant population (includes mixed diagnoses, e.g. cystitis, prostatitis, urethritis, as well as } \\
\text { "spasm following diagnostic or therapeutic procedures of the genitourinary tract (cystoscopies, } \\
\text { urethral dilatation, pyelography, catheterisation)") }\end{array}$ \\
\hline
\end{tabular}

\section{Choa 1983}

Not a relevant population. Includes "urethral syndrome", which is an old term for symptoms similar to BPS, but it is not BPS in its current definition

\section{Costantini 2003}

Not a relevant population. Includes "urethral syndrome", which is an old term for symptoms similar to BPS, but it is not BPS in its current definition sponders) that are not consistent with other participants in the network meta-analysis

\begin{tabular}{ll}
\hline Keay 2007 & Not a relevant intervention. RCT of biomarker \\
\hline Ko 2016 & Not a relevant study design. High suspicion that randomisation was not done by participants. Re- \\
ports data by number of procedure rather than by number of participants. Data are reported by \\
number of procedures, not by number of participants. Compares transurethral resection (TUR) vs \\
transurethral coagulation (TUC). Possibly linked to the Lee 2015 study. Available as meeting ab- \\
stract only with no contact details for study authors
\end{tabular}

\begin{tabular}{ll}
\hline Lai 2013 & Not a relevant comparison. Compares different regimens of interstitial hyaluronic acid instillation \\
\hline Lee 2015 & $\begin{array}{l}\text { Not a relevant study design. High suspicion that randomisation was not done by participant, as } \\
\text { participants received more than } 1 \text { procedure. Reports data by number of procedures, not by num- } \\
\text { ber of participants. Compares transurethral resection (TUR) vs transurethral coagulation (TUC). } \\
\text { Possibly linked to the Ko } 2016 \text { study. Available as meeting abstract only with no contact details for } \\
\text { study authors }\end{array}$ \\
\hline Li 2016 & Not a relevant population. Includes cystitis induced by ketamine misuse \\
\hline Lubeck 2001 & $\begin{array}{l}\text { Not a relevant comparison. Compares } 3 \text { doses of pentosan polysulfate (PPS) and no other interven- } \\
\text { tion }\end{array}$ \\
\hline Netto 1980 & $\begin{array}{l}\text { Not a relevant population. Active infection among participants is mentioned } \\
\text { Nickel } 2005\end{array}$ \\
\hline $\begin{array}{l}\text { Not a relevant comparison. Compares } 3 \text { doses of pentosan polysulfate (PPS) and no other interven- } \\
\text { tion }\end{array}$ \\
$\begin{array}{l}\text { Not a relevant comparison. Compares } 2 \text { types of neuromodulation (sacral nerve stimulation vs pu- } \\
\text { dendal nerve stimulation) }\end{array}$
\end{tabular}

BPS: bladder pain syndrome.

DMSO: dimethyl sulfoxide.

PPS: pentosan polysulfate.

RCT: randomised controlled trial.

TUC: transurethral coagulation.

TUR: transurethral resection.

\section{Characteristics of studies awaiting classification [ordered by study ID]}

\section{Aboyan 2018}

Methods Study design: RCT


Aboyan 2018 (Continued)

Participants
Sex: not specified

Age (mean): Group A: 57.1 years; Group B: 58.63 years

Condition: BPS/IC

Target sample size: 37 reported, original target not stated
Group A ( $\mathbf{n}=19)$ : intravesical hyaluronic acid alone

Group B ( $\mathbf{n}=\mathbf{1 8})$ : intravesical hyaluronic acid in combination with oral chondroitin

Time point/follow-up unclear: "visual analogue pain scale (VAS), interstitial cystitis symptom index (ICSI), interstitial cystitis problem index (ICPI), voiding diary for frequency/nocturia"

\begin{tabular}{ll}
\hline Notes & Funding: not stated \\
Trial registration number: none reported \\
Publication type: conference abstract \\
Status in relation to this review: new study
\end{tabular}

Asumpinwong 2018

\begin{tabular}{|c|c|}
\hline Methods & Study design: RCT \\
\hline \multirow[t]{4}{*}{ Participants } & Sex: female \\
\hline & Age: 18 years or over \\
\hline & Condition: BPS (VAS score of 4) \\
\hline & Target sample size: 62 \\
\hline \multirow[t]{2}{*}{ Interventions } & Group A: intravesical heparin instillation with conservative treatment \\
\hline & Group B: conservative treatment alone (no description of 'conservative treatment') \\
\hline Outcomes & $\begin{array}{l}\text { Follow-up: } 12 \text { weeks after treatment, when these outcomes will be measured: pain (VAS); daytime } \\
\text { frequency; QoL; adverse effects }\end{array}$ \\
\hline \multirow[t]{6}{*}{ Notes } & Funding: not reported \\
\hline & Trial registration number: TCTR20180912004 \\
\hline & Publication type: trial registration \\
\hline & Status in relation to this review: new ongoing study \\
\hline & Recruitment started: 1 October 2018 (anticipated) \\
\hline & Recruitment due to end: 29 January 2021 \\
\hline
\end{tabular}

Methods Study design: RCT


Bosch 2018 (Continued)

Participants
Sex: female

Age: 18 to 65 years

Condition: IC/BPS - participants with "moderate to severe IC/BPS as defined with scores of 7 on the O'Leary-Sant Interstitial Cystitis Symptom Index (ICSI)"

Target sample size: 42
Group A (n= 28): subcutaneous certolizumab pegol $400 \mathrm{mg}$

Group B ( $\mathbf{n}=\mathbf{1 4})$ : placebo (sterile saline)

Certolizumab pegol is an anti-tumour necrosis factor-alpha agent (i.e. an anti-TNF-alpha agent)

Follow-up: 18 weeks: GRA; ICSI; ICPI; pain (pain intensity numerical rating scale (MCID used as 30\% reduction from baseline))

\section{Notes}

Funding: UCB (Union Chimique Belge), Brussels, Belgium (biopharmaceutical company)

Trial registration number: NCT02497976

Publication type: full journal article

Status in relation to this review: new study

\section{Carty 2019}

\begin{tabular}{|c|c|}
\hline Methods & Study design: RCT \\
\hline \multirow[t]{4}{*}{ Participants } & Sex: female \\
\hline & Age: 18 to 80 years \\
\hline & Condition: "chronic urogenital pain" \\
\hline & Number randomised: 70 \\
\hline \multirow[t]{2}{*}{ Interventions } & Group A: 90-minute life stress interview (stress and emotion interview) \\
\hline & Group B: wait-list control (no interview) \\
\hline \multirow[t]{2}{*}{ Outcomes } & Follow-up: 6 weeks \\
\hline & $\begin{array}{l}\text { Outcomes: pain severity and pain Interference (using Brief Pain Inventory); pelvic floor symptoms } \\
\text { (using Pelvic Floor Distress Inventory - Short Form-20; depression and anxiety (using Brief Symp- } \\
\text { tom Inventory - 18) }\end{array}$ \\
\hline \multirow[t]{5}{*}{ Notes } & $\begin{array}{l}\text { Funding: "Student Award from the Blue Cross Blue Shield of Michigan Foundation and grants from } \\
\text { the National Institute of Arthritis and Musculoskeletal and Skin Diseases (AR057808 and AR057047" }\end{array}$ \\
\hline & Trial registration number: NCT02286115 \\
\hline & Publication type: full journal article \\
\hline & $\begin{array}{l}\text { Status in relation to this review: additional report of the already included Carty } 2017 \text { (already } \\
\text { with a PhD thesis, a conference abstract and a trial registration) }\end{array}$ \\
\hline & Treatment category in NMA: behavioural therapy vs control \\
\hline
\end{tabular}




\begin{tabular}{ll}
\hline Methods & Study design: cross-over RCT \\
\hline Participants & Sex: female (no males recruited) \\
& Age: mean 52.6 years (SD \pm 12.6$)$ \\
& Condition: BPS/IC (ESSIC criteria) \\
& Target sample size: 15 (of which 2 dropouts) \\
\hline Interventions & Group A: transcranial magnetic stimulation \\
& Group B: sham stimulation
\end{tabular}

Outcomes Two weeks' treatment followed by 6 weeks' washout period followed by 2 weeks on alternative treatment. 6 weeks' follow-up at the end of the final treatment session

Outcomes include pain (VAS); Overactive Bladder Questionnaire (OABq); O'Leary-Saint Questionnaire; QoL (36-Item Short Form Health Survey - SF-36)

\begin{tabular}{ll}
\hline Notes & Funding: Associazione Italiana Cistite Interstiziale $(\mathrm{AICI})$ \\
& Trial registration number: not reported \\
& Publication type: full journal article \\
& Status in relation to this review: new study \\
\hline
\end{tabular}

El Refaye 2019

\begin{tabular}{ll}
\hline Methods & Study design: $\mathrm{RCT}$ \\
\hline Participants & Sex: female \\
& Age: 25 to 40 years \\
& Condition: interstitial cystitis \\
& Target sample size: 40 \\
\hline Interventions & Group A ( $\mathbf{n}=\mathbf{2 0})$ : interferential current (lower abdomen) + anticholinergic (propiverine hydrochlo- \\
& ride) \\
& Group $\mathbf{B}(\mathbf{n}=\mathbf{2 0}):$ anticholinergic (propiverine hydrochloride) \\
\hline
\end{tabular}

Outcomes Treatment period: 8 weeks

Outcomes measured at the end of the treatment period: pain (VAS); ICSI

Notes

Funding: unclear

Trial registration number: NCT03844581

Publication type: trial registration

Status in relation to this review: new ongoing study

Recruitment started: 1 January 2019 


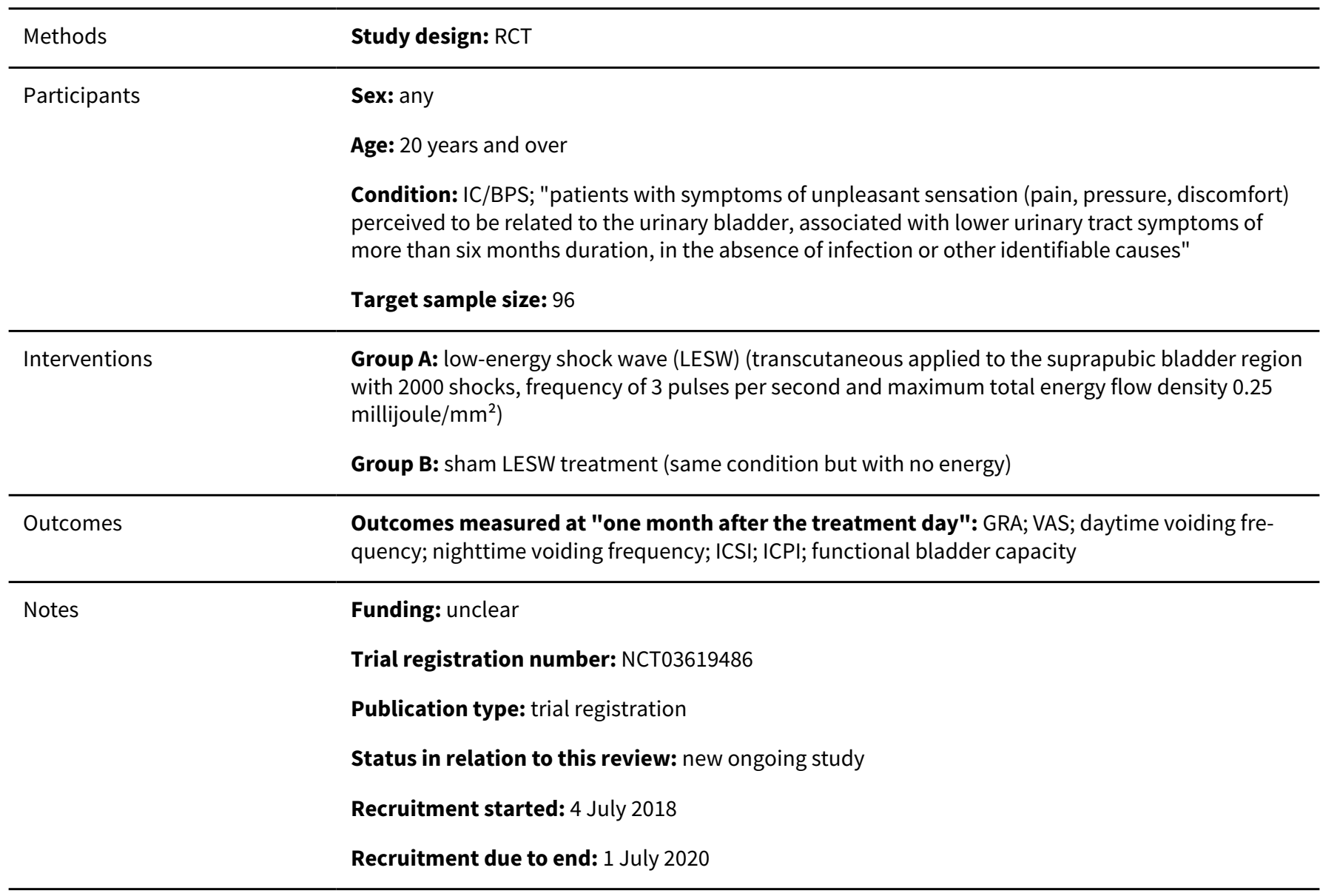

Kenny 2016

\begin{tabular}{|c|c|}
\hline Methods & Study design: RCT \\
\hline \multirow[t]{4}{*}{ Participants } & Sex: female \\
\hline & Age: 18 to 60 years \\
\hline & $\begin{array}{l}\text { Condition: chronic pelvic pain - study authors included BPS/IC due to the difficulties of excluding } \\
\text { from chronic pelvic pain }\end{array}$ \\
\hline & Target sample size: 79 \\
\hline \multirow[t]{2}{*}{ Interventions } & Group A: manual therapy \\
\hline & Group B: trigger point dry needling \\
\hline Outcomes & $\begin{array}{l}\text { Outcomes at each treatment session for up to } \mathbf{1 0} \text { weeks: } 1 \text { treatment session per week: pain (on } \\
0 \text { to } 10 \text { Pain Rating Scale); Pelvic Pain Questionnaire; Pain Treatment Satisfaction Scale }\end{array}$ \\
\hline
\end{tabular}


Kenny 2016 (Continued)

Notes
Funding: not reported

Trial registration number: NCT02795026

Publication type: trial registration

Status in relation to this review: new ongoing study

Recruitment started: April 2016

Recruitment due to end: June 2018

\begin{tabular}{|c|c|}
\hline Methods & Study design: CCT \\
\hline \multirow[t]{4}{*}{ Participants } & Sample size: 60 \\
\hline & Sex: female \\
\hline & Age: adult \\
\hline & Condition: IC/BPS \\
\hline \multirow[t]{2}{*}{ Interventions } & Group I: self-management telecare system (patient video education, mobile phone app, lifestyles) \\
\hline & Group II: control (no detail - "only regular treatments") \\
\hline Outcomes & $\begin{array}{l}\text { Outcomes measured at } 8 \text { weeks: O'Leary-Sant Interstitial Cystitis Symptom Index (ICSI); pain and } \\
\text { urgency (both using VAS); QoL (SF-36) }\end{array}$ \\
\hline \multirow[t]{5}{*}{ Notes } & $\begin{array}{l}\text { Funding: "partly funded by Feng Yuan Hospital, Ministry of Health and Welfare (Grant no. } \\
\text { FYH1030709-2) and Ministry of Science and Technology (Grant no. MOST106-2410-H-166-004) }\end{array}$ \\
\hline & Trial registration number: not reported \\
\hline & Publication type: full journal article \\
\hline & $\begin{array}{l}\text { Status in relation to this review: additional report of the already included Lee } 2016 \text { (currently on- } \\
\text { ly } 2 \text { conference abstracts are included in the full review) }\end{array}$ \\
\hline & Treatment category in NMA: behavioural therapy vs control \\
\hline
\end{tabular}

Moldwin 2018

\begin{tabular}{ll}
\hline Methods & Study design: $\mathrm{RCT}$ \\
\hline Participants & Target sample size: 433 \\
& Sex: any \\
& Age: 18 to 80 years \\
& Condition: IC/BPS \\
\hline Interventions & Group I: AQX-1125 $100 \mathrm{mg}$ \\
& Group II: AQX-1125 $200 \mathrm{mg}$ \\
\hline
\end{tabular}


Moldwin 2018 (Continued)

\section{Group III: placebo}

Oral administration
Outcomes to be measured at 12 weeks: "average bladder pain based on an 11-point numerical rating scale (NRS); voiding over a 24-hour period; and symptom scores based on the following questionnaires: Bladder Pain/Interstitial Cystitis Symptom Score (BPIC-SS), O'Leary-Sant Interstitial Cystitis Symptom Index (ICSI) and O'Leary-Sant Interstitial Cystitis Problem Index (ICPI)"

Notes

Trial registration number: NCT02858453; EUCTR2016-000906-12

Publication type: conference abstract

Status in relation to this review: additional report of the already included ongoing study Leadership 301 Trial 2016 - this abstract reports only baseline details of participants

\section{Moon 2019}

\begin{tabular}{|c|c|}
\hline Methods & Study design: RCT \\
\hline \multirow[t]{4}{*}{ Participants } & Sex: any \\
\hline & Age: 45 years or over \\
\hline & Condition: interstitial cystitis with an IPSS total score of 8 or higher \\
\hline & Target sample size: 80 \\
\hline \multirow[t]{2}{*}{ Interventions } & Group A (target $n=\mathbf{4 0}$ ): pentosan polysulphate + alpha blocker \\
\hline & Group B (target $n=40$ ): alpha blocker alone \\
\hline Outcomes & $\begin{array}{l}\text { At end of } 12 \text { week treatment period, these outcomes will be measured: ICSI; ICPI; Pelvic Pain and } \\
\text { Urgency/Frequency Patient Symptom Scale; functional bladder capacity }\end{array}$ \\
\hline \multirow[t]{6}{*}{ Notes } & Funding: Chong Kun Dang (a pharmaceutical company) \\
\hline & Trial registration number: $\mathrm{KCT0003772}$ \\
\hline & Publication type: trial registration \\
\hline & Status in relation to this review: new ongoing study \\
\hline & Recruitment started: 1 May 2019 \\
\hline & Recruitment due to end: 30 November 2019 \\
\hline
\end{tabular}

\section{Oh-Oka 2017}

\begin{tabular}{ll}
\hline Methods & Study design: RCT \\
\hline Participants & Sex: female \\
& Age: 20 years or over \\
& Condition: IC/BPS \\
\hline
\end{tabular}


Oh-Oka 2017 (Continued)

\section{Target sample size: 40}

\begin{tabular}{ll}
\hline Interventions & $\begin{array}{l}\text { Group A }(\mathbf{n}=\mathbf{3 0}) \text { : intensive systematic dietary manipulation } \\
\text { Group } \mathbf{B}(\mathbf{n}=\mathbf{1 0}) \text { : did not receive intensive dietary manipulation }\end{array}$ \\
\hline Outcomes & Outcomes measured at 3 months and 1 year from baseline: pain; urinary urgency; ICSI; ICPI; QoL \\
\hline Notes & Trial registration number: none given \\
& Publication type: 2 reports (1 full journal article and 1 conference abstract) \\
& Status in relation to this review: new study
\end{tabular}

Rahimi 2018

\begin{tabular}{|c|c|}
\hline Methods & Study design: RCT \\
\hline \multirow[t]{4}{*}{ Participants } & Sex: female \\
\hline & Age: over 18 years \\
\hline & Condition: interstitial cystitis \\
\hline & Target sample size: 24 \\
\hline \multirow[t]{2}{*}{ Interventions } & Group A $(\mathbf{n}=\mathbf{1 2})$ : hydrodistension + hyaluronic acid \\
\hline & Group B $(\mathbf{n}=\mathbf{1 2})$ : hydrodistension alone \\
\hline Outcomes & $\begin{array}{l}\text { At } 3 \text { months' follow-up, the following outcomes were measured using the O'Leary-Sant question- } \\
\text { naire: frequency; urgency; nocturia; dysuria }\end{array}$ \\
\hline \multirow[t]{6}{*}{ Notes } & Funding: Mashhad University of Medical Sciences (states: public funding) \\
\hline & Trial registration number: IRCT20130811014330N5 \\
\hline & Publication type: trial registration \\
\hline & Status in relation to this review: new ongoing study \\
\hline & Recruitment started: 22 April 2017 \\
\hline & Recruitment due to end: 26 July 2017 \\
\hline
\end{tabular}

Yusefi 2018

\begin{tabular}{ll}
\hline Methods & Study design: $\mathrm{RCT}$ \\
\hline Participants & Sex: any \\
& Age: over 18 years to 80 years \\
& Condition: interstitial cystitis
\end{tabular}


Yusefi 2018 (Continued)

\section{Target sample size: 50}

Interventions Group A: topical use of chamomile oil "in the bladder area"

Group B: topical use of placebo oil "in the bladder area"

\begin{tabular}{ll}
\hline Outcomes & Outcomes measured at the end of the treatment period (2 months): ICSI \\
\hline Notes & Funding: The Qom University of Medical Science (states: public funding) \\
Trial registration number: IRCT20170112031893N2 \\
Publication type: trial registration \\
Status in relation to this review: new ongoing study \\
Recruitment started: 6 December 2018 \\
Recruitment due to end: 6 December 2019 \\
\hline
\end{tabular}

BPIC-SS: Bladder Pain/Interstitial Cystitis Symptom Score.

BPS: bladder pain syndrome.

CCT: controlled clinical trial.

ESSIC: International Society for the Study of Bladder Pain Syndrome (BPS).

GRA: Global Response Assessment.

IC: interstitial cystitis.

ICPI: Interstitial Cystitis Problem Index.

ICSI: Interstitial Cystitis Symptom Index.

IPSS: International Prostate Symptom Score.

LESW: low-energy shock wave.

MCID: minimal clinically important difference.

NMA: network meta-analysis.

QoL: quality of life.

$\mathrm{RCT}$ : randomised controlled trial.

SD: standard deviation.

SF-36: 36-Item Short Form Health Survey.

TNF: tumour necrosis factor.

VAS: visual analogue scale.\&\&

Characteristics of ongoing studies [ordered by study ID]

\section{Bhat 2018}

\begin{tabular}{ll}
\hline Study name & Tadalafil for painful bladder \\
\hline Methods & Study design: parallel-group RCT \\
& Blinding: participant and investigator \\
\hline
\end{tabular}

Participants

Target sample size: 100

Country: India

Sex: any

Age: 15 to 85 years

Condition: "painful bladder syndrome"

Exclusion criteria: "those with co-morbidities such as Diabetes Mellitus, Hypertension, IHD, Asthma, immune compromised status and proved urinary bladder diseases shall be excluded." 
Bhat 2018 (Continued)

$\begin{array}{ll}\text { Interventions } & \text { Group A: tadalafil } 5 \mathrm{mg} \\ & \text { Group B: placebo }\end{array}$

Group B: placebo

Outcomes At 3 months

Primary outcomes: pain score (O'Leary-Sant and numerical rating scale); bladder capacity (USG)

Secondary outcomes: dropout rate "due to adverse events or worsening of symptoms"

\begin{tabular}{ll}
\hline Starting date & 1 April 2018 \\
\hline Contact information & Dr Gajanan Bhat \\
& Consultant Urologist and Andrologist \\
& TSS Shripad Hegde Kadave Institute of Medical Sciences, Sirsi \\
& Uttara Kannada \\
& KARNATAKA \\
& 581402 \\
& India \\
& Email: gajubhatru@gmail.com \\
\hline End date & "Not yet recruiting" \\
\hline Notes & Funding: "nil" \\
& Clinical Trials Registry - India (CTRI) number: CTRI/2018/03/012720 \\
\hline
\end{tabular}

Bond 2016

$\begin{array}{ll}\text { Study name } & \begin{array}{l}\text { A pilot study investigating the use of a therapeutic wand in addition to physiotherapy for bladder } \\ \text { pain syndrome }\end{array}\end{array}$

A pilot study investigating the use of a therapeutic wand in addition to physiotherapy for bladder Study design: parallel-group RCT

Methods

Blinding: none

Participants

Target sample size: 10

Country: United Kingdom

Sex: female

Age: 18 to 65 years

Condition: "diagnosis of Bladder Pain Syndrome or interstitial Cystitis as per the definition of the International Society for the Study of Bladder Pain Syndrome"

Group B: physiotherapy

\section{Outcomes}

At 6 weeks and 12 weeks 
Primary outcomes: O'Leary-Sant IC Symptom Index Score and Problem Index Score

\section{At 12 weeks}

Secondary outcomes: Genitourinary Pain Index; Pelvic Pain and Urinary Urgency Frequency Patient Symptom Scale; patient-reported urinary urgency; overall pain; ease of use of wand; adverse effects

\begin{tabular}{ll}
\hline Starting date & "April 2016" \\
\hline Contact information & Jilly Bond, Clinical Specialist Physiotherapist, University of Bradford \\
\hline End date & "October 2016" \\
\hline Notes & Funding: not reported \\
& ClinicalTrials.gov registration number: NCT02743962 \\
& $\begin{array}{l}\text { Results posted on ClinicalTrials.gov 'Study Results' tab: } 3 \text { May } 2018 \text { (not yet incorporated into } \\
\text { this review) }\end{array}$
\end{tabular}

Brucker 2016

\begin{tabular}{ll}
\hline Study name & Randomized controlled trial of PTNS versus sham efficacy in treatment of bladder pain syndrome \\
\hline Methods & Study design: parallel-group RCT \\
& Blinding: participant and investigator \\
\hline
\end{tabular}

\begin{tabular}{|c|c|}
\hline \multirow[t]{5}{*}{ Participants } & Target sample size: 100 \\
\hline & Country: USA \\
\hline & Sex: female \\
\hline & Age: 18 years or older \\
\hline & Condition: "Bladder Pain Syndrome/Interstitial Cystitis (BPS/IC)"... "with visual analog scale > 5" \\
\hline \multirow[t]{2}{*}{ Interventions } & Group A: percutaneous tibial nerve stimulation \\
\hline & Group B: sham \\
\hline \multirow[t]{3}{*}{ Outcomes } & At 12 weeks \\
\hline & Primary outcomes: Patient Global Impression of Improvement (PGI-I) \\
\hline & $\begin{array}{l}\text { Secondary outcomes: quality of life scores (VAS); O'Leary-Sant Pain Scores ("pain intensity, lo- } \\
\text { cation of pain and associated symptoms"); Overactive Bladder-Questionnaire; Short Form SF-12 } \\
\text { Health Scale }\end{array}$ \\
\hline Starting date & June 2016 \\
\hline \multirow[t]{3}{*}{ Contact information } & Dominique Malacarne \\
\hline & New York University School of Medicine \\
\hline & New York, New York, USA 10016 \\
\hline
\end{tabular}


Brucker 2016 (Continued)

Email: malacd01@nyumc.org

\begin{tabular}{ll}
\hline End date & March 2020 \\
\hline Notes & Funding: unclear \\
& ClinicalTrials.gov registration number: NCT02747420
\end{tabular}

Cardenas-Trowers 2018

$\begin{array}{ll}\text { Study name } & \begin{array}{l}\text { Randomized controlled trial comparing two different bladder instillation treatments for interstitial } \\ \text { cystitis/bladder pain syndrome }\end{array}\end{array}$

\begin{tabular}{ll}
\hline Methods & Study design: parallel-group RCT \\
& Blinding: participant and care provider \\
\hline Participants & Target sample size: 80 \\
Country: USA & Sex: female \\
Age: 18 years or older \\
Condition: "with IC/BPS who have a score of $\geq 6$ on either index (problem or symptom index) of the \\
O'Leary-Sant questionnaire who have selected bladder instillations as part of their IC/BPS treat- \\
ment"
\end{tabular}

Group A: intravesical instillation of "standard cocktail" plus triamcinolone acetonide $(40 \mathrm{mg} / 1 \mathrm{~mL})$
Group B: intravesical instillation of "standard cocktail" alone.
Standard cocktail = "heparin $(10,000$ units), $2 \%$ viscous lidocaine $(10 \mathrm{~mL}), 8.4 \%$ sodium bicarbon-
ate $(15 \mathrm{~mL}$ of $1 \mathrm{mEq} / \mathrm{mL})$ and $0.5 \%$ bupivacaine $(10 \mathrm{~mL}$ of $5 \mathrm{mg} / \mathrm{mL}) "$

\begin{tabular}{ll}
\hline Outcomes & $\begin{array}{l}\text { At } 3 \text { weeks and 6 weeks } \\
\text { Primary outcomes: O'Leary-Sant Questionnaire } \\
\text { Secondary outcomes: Pelvic Pain and Urgency/Frequency Questionnaire; Overactive Bladder } \\
\text { Questionnaire; Pelvic Floor Distress Inventory; Pelvic Organ Prolapse Incontinence Sexual Ques- } \\
\text { tionnaire; VAS for pain; adverse effects }\end{array}$ \\
\hline Starting date & 25 January 2019 \\
\hline Contact information & Alyce Goodman-Abraham \\
& University of Louisville Urogynecology at Springs Medical Center \\
& Louisville, Kentucky, United States, 40205 \\
& Email: contactus@ulp.org
\end{tabular}

\begin{tabular}{ll}
\hline End date & December 2020 \\
\hline Notes & Funding: not reported \\
& ClinicalTrials.gov registration number: NCT03463915 \\
\hline
\end{tabular}


Cvach 2011

Study name

Efficacy of Clorpactin(R) in bladder pain syndrome/interstitial cystitis: a randomised placebo-controlled trial

\begin{tabular}{|c|c|}
\hline Methods & $\begin{array}{l}\text { Study design: parallel-group RCT } \\
\text { Blinding: "blinded (masking used)". No further details }\end{array}$ \\
\hline Participants & $\begin{array}{l}\text { Target sample size: } 54 \\
\text { Final sample size: } 50 \\
\text { Country: Australia } \\
\text { Sex: female } \\
\text { Age: } 18 \text { to } 70 \text { years } \\
\text { Condition: "diagnosed with bladder pain syndrome/interstitial cystitis". No further details }\end{array}$ \\
\hline Interventions & $\begin{array}{l}\text { Group A: intravesical: Clorpactin (sodium oxychlorosene) } \\
\text { Group B: placebo (cystodistension) }\end{array}$ \\
\hline Outcomes & $\begin{array}{l}\text { At } 3 \text { months } \\
\text { Primary outcomes: "subject improvement as reflected in the Global Response Assessment" } \\
\text { Secondary outcomes: "nil" }\end{array}$ \\
\hline Starting date & Actual recruitment start date: 1 March 2012 \\
\hline Contact information & $\begin{array}{l}\text { Dr Kristina Cvach } \\
\text { Mercy Hospital for Women } \\
163 \text { Studley Rd Heidelberg VIC } 3084 \\
\text { Australia } \\
\text { Email: kcvach@mercy.com.au }\end{array}$ \\
\hline
\end{tabular}

\begin{tabular}{ll}
\hline End date & Actual recruitment end date: 31 December 2016 \\
\hline Notes & Funding: "self-funded/unfunded" \\
& Trial registration number: ACTRN12611000717954 \\
\hline
\end{tabular}

Drug Company 2005

Study name
A phase 2, randomized, double-blind, placebo-controlled study of YM672 in the treatment of
painful bladder syndrome/interstitial cystitis

\begin{tabular}{ll}
\hline Methods & Study design: parallel-group RCT \\
& Blinding: double blind - no other details \\
\hline Participants & Target sample size: 150
\end{tabular}




\section{Country: multi-national}

Sex: any

Age: 18 years or older

Condition: "diagnosis of PBS/IC defined as suprapubic pain related to bladder filling, accompanied by other symptoms, such as increased daytime and nighttime frequency, in the absence of proven urinary infection or other obvious pathology, with symptoms for at least 12 consecutive weeks prior to the screening visit." A score of a least 1 on the PBS/IC Problem Index Question \#4. PBS/IC Symptom Index Score of at least 7 (total score) at baseline

Interventions

Group A: oral: YM672 (IPD(R)) ("suplatast tosilate" on trial registration)

Group B: placebo

Outcomes At 12 weeks and/or at "end of treatment"

Primary outcome: "...success, defined as "moderately improved" or "markedly improved" PBS/IC on the subject-rated 7-point Global Response Assessment (GRA)"

Secondary outcomes: including GRA at weeks 4 and 8; IC Symptom Index; IC Problem Index; mean number of micturitions per day; mean number of micturitions per night; severity of urinary urgency on VAS; severity of bladder pain, pelvic pain and pain (including discomfort) accompanied by urinary urgency on VAS; adverse events, etc.

\begin{tabular}{ll}
\hline Starting date & Not reported (ethics committee opinion 05/01/2005) \\
\hline Contact information & Astellas Pharma Europe B.V. No further details \\
\hline End date & 23 April 2007 \\
\hline Notes & Funding: Astellas Pharma Europe B.V. \\
& Trials registration number: EUCTR2005-003367-23-DE \\
& Sponsor's Protocol Code Number: $672-C L-035$ \\
\hline
\end{tabular}

Drug Company 2017a

$\begin{array}{ll}\text { Study name } & \begin{array}{l}\text { Exploratory, randomized, double-blind, placebo-controlled evaluation of efficacy, tolerability, and } \\ \text { safety of intravesical instillation of GRT6010 compared to placebo in subjects with bladder pain } \\ \text { syndrome }\end{array}\end{array}$

Methods

Study design: parallel-group RCT

Blinding: double blind - no other details

Participants

Target sample size: 120 (of which 15 will be 65 years of age or older)

Country: multi-national

Sex: female

Age: 18 to 75 years

Condition: "pain perceived to be related to the urinary bladder and consistent presence of at least 1 other urinary symptom such as persistent urge to void or frequency for at least 12 months. Princi- 
Drug Company 2017a (Continued)

pal exclusion criteria: presence of Hunner's lesion as demonstrated by a cystoscopy with hydrodistention"

\begin{tabular}{|c|c|}
\hline Interventions & $\begin{array}{l}\text { Group A: intravesical: GRT6010 } \\
\text { Group B: placebo }\end{array}$ \\
\hline \multirow[t]{3}{*}{ Outcomes } & $\begin{array}{l}\text { Treatment period/time points/length of follow-up: unclear, total length of study in all countries } \\
\text { reported as } 1 \text { year }\end{array}$ \\
\hline & Primary outcome: average daily paln scores on a 0 to 100 VAS \\
\hline & $\begin{array}{l}\text { Secondary outcomes: including O'Leary/Sant Questionnaire (Symptom and Problem Index) score; } \\
\text { Bladder Pain/Interstitial Cystitis Symptom Score (BPIC-SS); mean number of micturitions per day; } \\
\text { adverse events, etc. }\end{array}$ \\
\hline Starting date & Not reported (ethics committee opinion 22/05/2017) \\
\hline \multirow[t]{2}{*}{ Contact information } & Grünenthal GmbH \\
\hline & Email: Clinical-Trials@grunenthal.com \\
\hline
\end{tabular}

End date Date of the global end of the trial: 2 May 2018

Notes $\quad$ Funding: Grünenthal GmbH

Trial registration number: EUCTR2016-003940-35

WHO Trial Reference Number (UTRN): U1111-1188-0214

Sponsor's Protocol Code Number: KF6010-02

\section{Drug Company 2017b}

\begin{tabular}{ll}
\hline Study name & $\begin{array}{l}\text { A Phase III, multicenter, randomized, double-blind, placebo controlled, parallel group study to as- } \\
\text { sess the efficacy and safety of KRP-116D in Japanese patients with interstitial cystitis }\end{array}$ \\
\hline Methods & Study design: parallel-group RCT \\
& Blinding: double blind - no other details \\
\hline
\end{tabular}

$$
\text { Participants }
$$

Target sample size: 90

Country: Japan

Sex: any

Age: 20 years or older

Condition: "diagnosed with IC"

Group A: intravesical: KRP-116D ("dimethyl sulfoxide" according to the trial registration)
Group B: placebo

Outcomes

Treatment period/time points/length of follow-up: not reported

Primary outcome: O'Leary and Sant's IC Symptom Index 
Drug Company 2017b (Continued)

Secondary outcomes: "O'Leary and Sant's IC Problem Index; Urinary Symptom, Bladder Pain Score, etc.; Safety Questionnaire; Symptom Diary; adverse event and adverse drug reaction"

\begin{tabular}{ll}
\hline Starting date & 25 May 2017 \\
\hline Contact information & Kyorin Pharmaceutical Co., Ltd \\
& Email: develop@mb.kyorin-pharm.co.jp \\
\hline End date & Not reported (expected end date: 30 June 2019) \\
\hline Notes & Funding: Kyorin Pharmaceutical Co., Ltd \\
& Trial registration number: JPRN-JapicCTI-173566 \\
\hline
\end{tabular}

\section{Drug Company 2017c}

\begin{tabular}{ll}
\hline Study name & $\begin{array}{l}\text { A study to investigate efficacy, safety, pharmacodynamics and pharmacokinetics of ASP6294 in the } \\
\text { treatment of female subjects with bladder pain syndrome/interstitial cystitis }\end{array}$ \\
\hline Methods & Study design: parallel-group RCT \\
& Blinding: participant and investigator \\
\hline
\end{tabular}

Target sample size: 117
Country: multi-national
Sex: female
Age: 18 years of age or older
Condition: used the ESSIC definition for BPS/IC with document proof of at least 2 months' dura-
tion. In addition: "a score of $\geq 4$ and $\leq 9$ for pain as assessed by scoring the average pain of the week
preceding Visit $1 /$ Screening, using an 11 -point NRS (0-10)"; "subject has an estimated voiding fre-
quency of $\geq 8$ and $\leq 30$ voids per 24 hours"; "subject has a score of $\geq 7$ on the Interstitial Cystitis
Symptom Index (ICSI) Questionnaire"

\begin{tabular}{ll}
\hline Interventions & Group A: ASP6294 (administration: subcutaneous injection) \\
& Group B: placebo \\
\hline
\end{tabular}

Outcomes At 12 weeks

Primary outcome: average mean daily pain (MDP)

Secondary outcomes: 13 listed, including Bladder Pain/Interstitial Cystitis Symptom Score (BPICSS); average worst daily pain; GRA; adverse effects, etc.

\begin{tabular}{ll}
\hline Starting date & 28 September 2017 \\
\hline Contact information & Astellas Pharma Europe B.V. No further details \\
\hline End date & 21 March 2019 \\
\hline Notes & Funding: Astellas Pharma Europe B.V. \\
& ClinicalTrials.gov registration number: NCT03282318
\end{tabular}


Other study ID/name: SERENITY

Protocol number: 6294-CL-0101

Leadership 301 Trial 2016

The LEADERSHIP 301 Trial: a 12-week, randomized, multi-center, double-blind, placebo-controlled,
3-arm, parallel-group, phase 3 trial to evaluate the efficacy and safety of 2 doses of AQX-1125 tar-
geting the Src homology 2-containing inositol-5'-phosphatase 1 (SHIP1) pathway in subjects with
interstitial cystitis/bladder pain syndrome followed by 14- or 40-week extension periods

Methods

Study design: parallel-group RCT

Blinding: "quadruple (participant, care provider, investigator, outcomes assessor)"

Target sample size: 433
Country: multi-national
Sex: any
Age: 18 to 80 years
Condition: "symptoms of bladder pain in addition to urinary urgency and/or urinary frequency for
more than 6 months"; "clinical diagnosis, or history consistent with the diagnosis, of interstitial
cystitis/bladder pain syndrome for $>3$ months but $\leq 20$ years". Must have undergone a cystoscopy
within the last 36 months before baseline

\begin{tabular}{ll}
\hline Interventions & Group A: AQX-1125 $100 \mathrm{mg}$ \\
& Group B: AQX-1125 $200 \mathrm{mg}$ \\
Group C: placebo \\
Oral administration \\
\hline
\end{tabular}

\section{Outcomes}

\section{At 12 weeks}

Primary outcome: maximum daily bladder pain score "based on a standardized 11-point numerical rating scale (NRS) recorded by electronic diary (e-diary)"

Secondary outcomes: IC Symptom Index Score; Bladder Pain/IC Symptom Score; GRA; voiding frequency over 24 hours; adverse effects

\begin{tabular}{ll}
\hline Starting date & July 2016 \\
\hline Contact information & Aquinox Pharmaceuticals (Canada), Inc. \\
\hline End date & February 2020 \\
\hline Notes & Funding: Aquinox Pharmaceuticals (Canada), Inc. \\
& ClinicalTrials.gov registration number: NCT02858453 \\
& Other trial registration number: EUCTR2016-000906-12 \\
& Other study ID numbers: AQX-1125-301 \\
\hline
\end{tabular}


Parsons 2015

Study name

A phase $2 a$, randomized, double-blind, placebo-controlled multi-center single dose study to evaluate the safety and effectiveness of URG101 compared with the individual components lidocaine and heparin in subjects with interstitial cystitis/bladder pain syndrome

Methods

Study design: parallel-group RCT

Blinding: triple (participant, care provider, investigator)

\section{Target sample size: 92}

Country: USA

Sex: any

Age: 18 years of age or older

Condition: diagnosed with BPS/IC and have "moderate-to-severe symptoms of bladder pain of bladder origin for at least 9 months prior to the study; may or may not have received a cystoscopy in association with their diagnosis of interstitial cystitis/bladder pain syndrome prior to or at time of screening; Have a score of $\geq 15$ and $<30$ on the PUF questionnaire, completed at screening; a minimum score of 5 is required on the VAS"
Group A: lidocaine

Group B: heparin

Group C: lidocaine plus heparin

Group D: placebo

Intravesical administration

Outcomes At 12 or 24 hours after administration

Primary outcome: change in bladder pain on VAS

Secondary outcomes: change in urgency on VAS; adverse effects

\begin{tabular}{ll}
\hline Starting date & September 2015 \\
\hline Contact information & Urigen \\
\hline End date & 18 June 2018 \\
\hline Notes & Funding: Urigen \\
& ClinicalTrials.gov registration number: NCT02591199 \\
& $\begin{array}{l}\text { On trial registration states: "terminated (prematurely terminated based on interim study analy- } \\
\text { sis)" } \\
\text { Other study ID numbers: URG101-105 }\end{array}$ \\
\hline
\end{tabular}

Peters 2016 
Peters 2016 (Continued)

Methods
Study design: parallel-group RCT

Blinding: single (outcome assessor)

\section{Participants}

\section{Target sample size: 128}

\section{Country: USA}

Sex: female

Age: 18 to 85 years of age

Condition: "history of patient self-reported IC/BPS symptoms for at least 6 months"

\begin{tabular}{ll}
\hline Interventions & Group A: physical therapy (pelvic floor) \\
& Group B: intravesical (heparin sulphate, lidocaine, sodium bicarbonate and Kenalog) \\
& Other names: Xylocaine, triamcinolone \\
\hline Outcomes & At week 9 (1 week after last treatment) \\
& $\begin{array}{l}\text { Primary outcome: GRA } \\
\text { Secondary outcomes: change in pelvic floor examination findings and symptoms as measured by } \\
\text { questionnaires }\end{array}$ \\
\hline Starting date & 21 April 2017 \\
\hline Contact information & KM Peters, William Beaumont Hospitals. Baylor College of Medicine \\
& Email: kmpeters@beaumont.edu \\
\hline End date & August 2020 \\
\hline Notes & Funding: unclear \\
ClinicalTrials.gov registration number: NCT02870738 \\
Other study ID numbers: 2016-253
\end{tabular}

\section{Shah 2016}

\begin{tabular}{ll}
\hline Study name & A pilot study of the effects of mirabegron on symptoms in patients with interstitial cystitis \\
\hline Methods & Study design: parallel-group RCT \\
& Blinding: single (participant) \\
\hline Participants & Target sample size: 60 \\
& Country: USA \\
& Sex: female \\
& Age: 18 to 95 years of age \\
Condition: "participants must be diagnosed with BPS/IC with a minimum O'Leary-Sant score of \\
8 on the ICSI, as well as 8 on the ICPI. Participants should be stable on their regimen (no increase \\
or change in medications, behavioral treatments or physical therapy in previous 4 weeks prior to
\end{tabular}


Shah 2016 (Continued)

starting the study) and be willing to remain on this regimen during the duration of the study. Participant must be stable on current IC/BPS regimen. Participant must have subjective complaints of i. urinary urgency, relieved with voiding; ii. urinary frequency, $\geq 8$ voids per day; or iii. pelvic pain, pressure, hypersensitivity or discomfort"

Interventions Group A: mirabegron (beta-3-adrenergic agonist; tablets; presumably oral administration)

Group B: placebo

Outcomes At 12 weeks

Primary outcome: IC symptom improvement on O'Leary Sant Questionnaire

Secondary outcomes: incontinence episodes via bladder diary and UDI-6 Questionnaire; QoL via PFIQ-7 Questionnaire; participant satisfaction via GRA; sexual function via FSFI Questionnaire; adverse effects

\begin{tabular}{ll}
\hline Starting date & August 2016 \\
\hline Contact information & Philadelphia Urosurgical Associates \\
& Email: drexelurogyn@gmail.com \\
\hline End date & December 2018 \\
\hline Notes & $\begin{array}{l}\text { Funding: unclear. Sponsors and collaborators: Philadelphia Urosurgical Associates; Astellas Phar- } \\
\text { ma Global Development, Inc. } \\
\text { ClinicalTrials.gov registration number: NCT02787083 } \\
\text { Other study ID numbers: MYRB-15G02 }\end{array}$ \\
\hline
\end{tabular}

BPS: bladder pain syndrome.

BPIC-SS: Bladder Pain/Interstitial Cystitis Symptom Score.

ESSIC: International Society for the Study of Bladder Pain Syndrome (BPS).

FSFI: Female Sexual Function Index.

GRA: Global Response Assessment.

IC: interstitial cystitis.

ICPI: Interstitial Cystitis Problem Index.

ICSI: Interstitial Cystitis Symptom Index.

IHD: ischaemic heart disease.

MDP: mean daily pain.

NRS: numerical rating scale.

PBS: painful bladder syndrome.

PFIQ-7: Pelvic Floor Impact Questionnaire-7.

PFMT: pelvic floor muscle training.

PGI-I: Patient Global Impression of Improvement.

PTNS: percutaneous tibial nerve stimulation.

PUF: Pelvic Pain and Urgency/Frequency Patient Symptom Scale.

QoL: quality of life.

$\mathrm{RCT}$ : randomised controlled trial.

UDI-6: Urinary Distress Inventory-6.

USG: ultrasonography.

VAS: visual analogue scale.

\section{ADDITIONAL TABLES}


Table 1. Interventions for the treatment of BPS

\section{Treatment category \\ Example of intervention}

\section{Conservative therapies}

\begin{tabular}{ll}
\hline $\begin{array}{l}\text { Behavioural, psychological and complemen- } \\
\text { tary therapies }\end{array}$ & $\cdot$ Bladder training \\
& $\cdot$ Stress management techniques \\
& $\cdot$ Complementary therapy (e.g. acupuncture) \\
\hline Physical therapy & $\cdot$ Pelvic floor muscle training (PFMT) \\
& $\cdot$ Non-invasive electrical stimulation (e.g. transcutaneous electrical nerve stimula- \\
tion (TENS))
\end{tabular}

Pharmacological treatments (by mode of action, irrespective of route of administration)

\begin{tabular}{ll}
\hline Amino acid & $\cdot$ L-Arginine \\
\hline Analgesics & \\
\hline Analgesics, local (local anaesthetics) & $\cdot$ Lidocaine \\
\hline Antibiotics & $\cdot$ Antibiotic regimen \\
\hline Anticholinergics & $\cdot$ Oxybutynin \\
\hline Anticoagulants & $\cdot$ Heparin \\
\hline Anticytokines & $\cdot$ Tacrolimus \\
\hline Antidepressants & $\cdot$ Amitriptyline \\
& $\cdot$ Doxepin \\
& $\cdot$ Desipramine \\
\hline Antihistamines & $\cdot$ Duloxetine \\
\hline AQX-1125 Cimetidine \\
Hydroxyzine
\end{tabular}

\section{AQX-1125}

Buffer solutions

\section{Caffeine}

\begin{tabular}{ll}
\hline Calcium channel agonists & $\cdot$ Capsaicin \\
$\cdot$ & $\cdot$ PD-0299685 \\
$\cdot$ & Resiniferatoxin (RTX)
\end{tabular}

(Sodium) chondroitin sulfate

Dimethyl sulfoxide (DMSO) 
Table 1. Interventions for the treatment of BPS

Hyaluronic acid

Hyperbaric oxygen

Hydrogen-rich water

Immune modulators

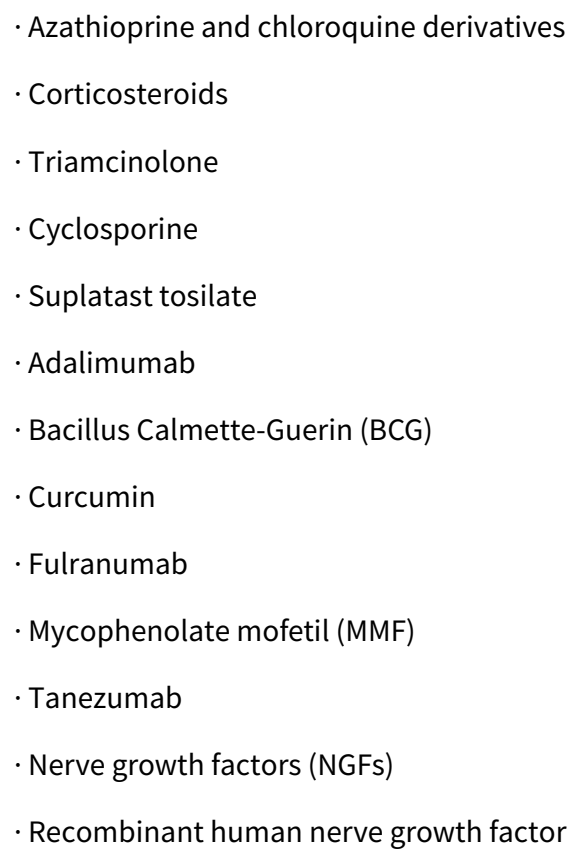

Methotrexate

Misoprostol

Nifedipine

P2X3 antagonist

- AF-219

Parasympathomimetic (+ urinary antiseptics) $\cdot$ Cystex

Phosphodiesterase-5 (PDE5) inhibitor · Sildenafil

(Sodium) pentosan polysulfate (PPS)

Quercetin

\section{Surgical interventions}

Hydrodistension

Neuromuscular blockade

- Botulinum toxin

- Lipotoxin (liposomal formulated onabotulinumtoxinA (onaBoNTA))

Fulguration

Transurethral resection 
Table 1. Interventions for the treatment of BPS

Neuromodulation (implanted)

\begin{tabular}{ll}
\hline Denervation & $\cdot$ Neurolysis \\
$\cdot$ & Superior hypogastric plexus neurolysis \\
$\cdot$ Surgical denervation \\
$\cdot$ Cystolysis - peripheral denervation \\
$\cdot$ Sympathetic denervation \\
$\cdot$ Parasympathetic denervation \\
\hline Bowel surgery $\quad$ Bladder augmentation - cystoplasty \\
$\cdot$ Cystoplasty with supratrigonal resection \\
$\cdot$ Cystoplasty with subtrigonal cystectomy - orthotopic continent bladder augmen- \\
tation \\
$\cdot$ Urinary diversion with or without total cystectomy and urethrectomy
\end{tabular}

Based on the intervention categories used by Hanno and colleagues for their work presented at the 6th International Consultation on Incontinence (Hanno 2017).

Table 2. Treatment category (by mode of action) for active interventions in the included studies

\begin{tabular}{lllll}
\hline $\begin{array}{l}\text { Treatment cate- } \\
\text { gory A }\end{array}$ & $\begin{array}{l}\text { Treat- } \\
\text { ment }\end{array}$ & Study name & Intervention A & Intervention B \\
& $\begin{array}{l}\text { cate- } \\
\text { gory B }\end{array}$ & \\
& & \\
\hline
\end{tabular}

\section{Conservative vs control}

\begin{tabular}{|c|c|c|c|c|}
\hline \multirow{7}{*}{$\begin{array}{l}\text { Behavioural ther- } \\
\text { apy }\end{array}$} & \multirow[t]{7}{*}{ Control } & Carrico 2008 & Guided imagery & Control (rest) \\
\hline & & Carty 2017 & Life-stress interview & Usual care \\
\hline & & Hsieh 2012 & Hydrodistension + bladder training & Hydrodistension \\
\hline & & Kanter 2016 & $\begin{array}{l}\text { Mindfulness-based stress reduction + usual } \\
\text { care }\end{array}$ & Usual care \\
\hline & & Lee 2014 & E-health system & $\begin{array}{l}\text { Control (include treat- } \\
\text { ment) }\end{array}$ \\
\hline & & Lee 2016 & $\begin{array}{l}\text { Self-management telecare system (patient } \\
\text { education, mobile phone app, lifestyles) }\end{array}$ & Control (no detail) \\
\hline & & O'Reilly 2004 & $\begin{array}{l}\text { Transdermal laser stimulation of the posteri- } \\
\text { or tibial nerve }\end{array}$ & Sham \\
\hline \multirow[t]{2}{*}{ Physical therapy } & \multirow[t]{2}{*}{ Control } & FitzGerald 2009 & Myofascial physical therapy & $\begin{array}{l}\text { Global therapeutic mas- } \\
\text { sage }\end{array}$ \\
\hline & & FitzGerald 2012 & Pelvic floor myofascial physical therapy & $\begin{array}{l}\text { Global therapeutic mas- } \\
\text { sage }\end{array}$ \\
\hline
\end{tabular}


Table 2. Treatment category (by mode of action) for active interventions in the included studies (Continued)

$\begin{array}{lll}\text { Zakaria } 2016 & \text { TENS + } & \text { Sham TENS + physical } \\ & \text { physical therapy + medical care } & \text { therapy + medical care }\end{array}$

\section{Pharmacological vs control}

\begin{tabular}{|c|c|c|c|c|}
\hline \multirow[t]{2}{*}{ Amino acid } & \multirow[t]{2}{*}{ Control } & Cartledge 2000 & L-Arginine & Placebo \\
\hline & & Korting 1999 & L-Arginine & Placebo \\
\hline Antibiotics & Control & Warren 2000 & Antibiotic regimen & Placebo \\
\hline Anticholinergics & Control & Barbalias 2000 & Oxybutinin & Saline \\
\hline $\begin{array}{l}\text { Anticoagulants } \\
+ \text { local anaesthet- } \\
\text { ics }\end{array}$ & Control & Parsons 2012 & $\begin{array}{l}\text { Heparin + lidocaine + sodium bicarbonate in } \\
\text { water }\end{array}$ & $\begin{array}{l}\text { Sodium bicarbonate in } \\
\text { water }\end{array}$ \\
\hline Anticytokines & Control & Mirkin 2015 & Hyaluronic acid + anticytokine substance & Hyaluronic acid \\
\hline \multirow[t]{2}{*}{ Antidepressants } & \multirow[t]{2}{*}{ Control } & Foster 2010 & Amitriptyline + EBMP & Placebo + EBMP \\
\hline & & van Ophoven 2004 & Amitriptyline & Placebo \\
\hline Antihistamines & Control & Thilagarajah 2001 & Cimetidine & Placebo \\
\hline AQX-1125 & Control & $\begin{array}{l}\text { Leadership } 201 \text { Trial } \\
2016\end{array}$ & AQX-1125 & Placebo \\
\hline Buffer solutions & Control & Nguan 2005 & Acidic buffered solution & $\begin{array}{l}\text { Neutral buffered solu- } \\
\text { tion }\end{array}$ \\
\hline Caffeine & Control & Herati 2011 & Caffeine & Placebo \\
\hline \multirow{7}{*}{$\begin{array}{l}\text { Calcium channel } \\
\text { agonists }\end{array}$} & \multirow[t]{7}{*}{ Control } & Chen 2005 & RTX, 2 arms with varying dose & Placebo \\
\hline & & Ham 2012 & RTX + hydrodistension & Hydrodistension \\
\hline & & Kim 2012 & RTX + hydrodistension & Hydrodistension \\
\hline & & Lazzeri 1996 & Capsaicin & $\mathrm{NaCl}$ \\
\hline & & Lazzeri 2000 & RTX & $\mathrm{NaCl}$ \\
\hline & & Nickel 2012b & PD-0299685 & Placebo \\
\hline & & Payne 2005 & RTX, 3 arms with varying dose & Placebo \\
\hline \multirow{3}{*}{$\begin{array}{l}\text { Chondroitin sul- } \\
\text { fate }\end{array}$} & \multirow[t]{3}{*}{ Control } & Gulpinar 2013 & Sodium chondroitin sulfate + hyaluronic acid & Hyaluronic acid \\
\hline & & Nickel 2010 & Sodium chondroitin sulfate & $\mathrm{NaCl}$ \\
\hline & & Nickel 2012a & Sodium chondroitin sulfate & $\mathrm{NaCl}$ \\
\hline DMSO & Control & Perez-Marrero 1988 & DMSO & Saline \\
\hline
\end{tabular}


Table 2. Treatment category (by mode of action) for active interventions in the included studies (Continued)

\begin{tabular}{|c|c|c|c|c|}
\hline $\begin{array}{l}\text { Hyperbaric oxy- } \\
\text { gen }\end{array}$ & Control & van Ophoven 2006 & Hyperbaric oxygen & Placebo \\
\hline $\begin{array}{l}\text { Hydrogen-rich wa- } \\
\text { ter }\end{array}$ & Control & Matsumoto 2013 & Hydrogen-rich water & Placebo \\
\hline \multirow{10}{*}{$\begin{array}{l}\text { Immune modula- } \\
\text { tors }\end{array}$} & \multirow[t]{10}{*}{ Control } & Bosch 2014 & Adalimumab & Placebo \\
\hline & & Dimitrakov 2001 & Recombinant human nerve growth factor & Placebo \\
\hline & & Evans 2011 & Tanezumab & Placebo \\
\hline & & Irani 2004 & BCG & $\mathrm{NaCl}$ \\
\hline & & Mayer 2005 & Live Tice BCG & Saline \\
\hline & & Nickel 2016 & Tanezumab & Placebo \\
\hline & & Peters 1997 & Tice strain BCG & Saline \\
\hline & & Shirvan 2015 & Hydrodistension + curcumin & $\begin{array}{l}\text { Hydrodistension in nor- } \\
\text { mal saline }\end{array}$ \\
\hline & & Wang 2017a & Fulranumab & Placebo \\
\hline & & Yang 2011 & Mycophenolate mofetil & Placebo \\
\hline \multirow[t]{2}{*}{ Local anaesthetic } & \multirow[t]{2}{*}{ Control } & Nickel 2009 & PSD597 & Saline \\
\hline & & Nomiya 2017 & Heparin + lidocaine & Heparin \\
\hline \multirow[t]{2}{*}{ P2X3 antagonist } & \multirow[t]{2}{*}{ Control } & Hanno 2015 & AF-219 & Placebo \\
\hline & & Moldwin 2015 & AF-219 & Placebo \\
\hline $\begin{array}{l}\text { Parasympath- } \\
\text { omimetic } \\
\text { (+ urinary antisep- } \\
\text { tics) }\end{array}$ & Control & Souza 2012 & Cystex & Placebo \\
\hline PDE5 inhibitor & Control & Chen 2014 & Sildenafil & Placebo \\
\hline \multirow[t]{4}{*}{ PPS } & \multirow[t]{4}{*}{ Control } & Bade 1997 & PPS & Placebo \\
\hline & & Davis 2008 & Intravesical PPS + oral PPS & $\begin{array}{l}\text { Intravesical placebo + } \\
\text { oral PPS }\end{array}$ \\
\hline & & Mulholland 1990 & PPS & Placebo \\
\hline & & Nickel 2015 & PPS & Placebo \\
\hline
\end{tabular}

\section{Surgical vs control}

\begin{tabular}{|c|c|c|c|c|}
\hline $\begin{array}{l}\text { Neuromuscular } \\
\text { blockade }\end{array}$ & Control & Ahmadnia 2011 & Botulinum toxin $A$ & $\mathrm{NaCl}$ \\
\hline
\end{tabular}


Table 2. Treatment category (by mode of action) for active interventions in the included studies (Continued)

\begin{tabular}{|c|c|c|c|c|}
\hline & & Chuang 2017 & $\begin{array}{l}2 \text { arms: onabotulinumtoxinA (i) with lipo- } \\
\text { somes (lipotoxin) and (ii) in normal saline }\end{array}$ & Saline \\
\hline & & Gottsch 2011 & Botulinum toxin $\mathrm{A}$ & Saline \\
\hline & & Ismail 2016 & Botulinum toxin $\mathrm{A}$ & Saline \\
\hline & & Kuo 2009 & Botulinum toxin $A+$ hydrodistension & Hydrodistension \\
\hline & & Kuo 2016 & Botulinum toxin $A+$ hydrodistension & $\mathrm{NaCl}+\mathrm{Hydrodistension}$ \\
\hline & & Manning 2014 & Botulinum toxin $\mathrm{A}+$ hydrodistension & $\begin{array}{l}\text { Saline + hydrodisten- } \\
\text { sion }\end{array}$ \\
\hline & & Payne 2014 & Botulinum toxin $\mathrm{A}$ & Saline \\
\hline & & Pinto 2016 & Botulinum toxin $\mathrm{A}$ & Saline \\
\hline & & Yassin 2011 & Botulinum toxin $A+$ hydrodistension & $\mathrm{NaCl}+$ hydrodistension \\
\hline $\begin{array}{l}\text { Neuromuscular } \\
\text { blockade }\end{array}$ & Control & Mirkin 2012 & Incobotulinumtoxin A + DMSO & $\mathrm{NaCl}$ \\
\hline + DMSO & & & & \\
\hline
\end{tabular}

\section{Comparison of different treatments}

\begin{tabular}{|c|c|c|c|c|}
\hline $\begin{array}{l}\text { Behavioural ther- } \\
\text { apy }\end{array}$ & $\begin{array}{l}\text { Phys- } \\
\text { ical } \\
\text { therapy }\end{array}$ & Geirsson 1993 & Acupuncture & TENS \\
\hline $\begin{array}{l}\text { (Sodium) chon- } \\
\text { droitin sulfate }\end{array}$ & DMSO & De Ridder 2013 & Sodium chondroitin sulfate & DMSO \\
\hline Hyaluronic acid & DMSO & Singh 2003 & Hyaluronic acid & DMSO \\
\hline \multirow{2}{*}{$\begin{array}{l}\text { Immune modula- } \\
\text { tors }\end{array}$} & DMSO & Peeker 2000 & BCG & DMSO \\
\hline & & Sairanen 2009 & BCG & DMSO \\
\hline $\begin{array}{l}\text { (Sodium) chon- } \\
\text { droitin sulfate } \\
\text { + hyaluronic acid }\end{array}$ & DMSO & Cervigni 2014 & Sodium chondroitin sulfate + hyaluronic acid & DMSO \\
\hline $\begin{array}{l}\text { Anticoagulants } \\
+ \text { local anaesthet- } \\
\text { ics }\end{array}$ & \multicolumn{2}{|c|}{$\begin{array}{l}\text { Hyaluron- Lu } 2015 \\
\text { ic acid }\end{array}$} & Heparin + lidocaine & Hyaluronic acid \\
\hline $\begin{array}{l}\text { (Sodium) chon- } \\
\text { droitin sulfate }\end{array}$ & $\begin{array}{l}\text { Hyaluron- } \\
\text { ic acid }\end{array}$ & Gulpinar 2015 & Sodium chondroitin sulfate & Hyaluronic acid \\
\hline $\begin{array}{l}\text { Immune modula- } \\
\text { tors }\end{array}$ & PPS & Sairanen 2005 & Cyclosporin A & PPS \\
\hline $\begin{array}{l}\text { Immune modula- } \\
\text { tors }\end{array}$ & $\begin{array}{l}\text { Neuro- } \\
\text { mus- }\end{array}$ & Taha 2007 & BCG & Botulinum toxin $\mathrm{A}$ \\
\hline
\end{tabular}


Table 2. Treatment category (by mode of action) for active interventions in the included studies (Continued)

cular

block-

ade

\begin{tabular}{lllll}
\hline $\begin{array}{l}\text { Immune modula- } \\
\text { tor }\end{array}$ & $\begin{array}{l}\text { Fulgu- } \\
\text { ration }\end{array}$ & Oliver 2013 & Triamcinolone & Fulguration \\
\hline $\begin{array}{l}\text { Neuromuscular } \\
\text { blockade }\end{array}$ & $\begin{array}{l}\text { Hy- } \\
\text { drodis- } \\
\text { tension }\end{array}$ & Kasyan 2012 & Botulinum toxin A & Hydrodistension \\
\hline
\end{tabular}

\begin{tabular}{lllll}
\hline Fulguration & $\begin{array}{l}\text { Hy- } \\
\text { drodis- } \\
\text { tension }\end{array}$ & Kim 2015 & Fulguration & Hydrodistension \\
\hline Denervation & $\begin{array}{l}\text { Hy- } \\
\text { drodis- } \\
\text { tension }\end{array}$ & El-Hefnawy 2015 & Superior hypogastric plexus neurolysis & Hydrodistension \\
& & & & \\
\hline
\end{tabular}

\section{4-Arm trial}

\begin{tabular}{|c|c|c|c|c|c|}
\hline $\begin{array}{l}\text { Antihistamines } \\
\text { vs PPS } \\
\text { vs PPS + antihistamines } \\
\text { vs control }\end{array}$ & Sant 2003 & Hydroxyzine & PPS & $\begin{array}{l}\text { PPS + hy- } \\
\text { droxyzine }\end{array}$ & Placebo \\
\hline
\end{tabular}

BCG: bacillus Calmette-Guérin.

DMSO: dimethyl sulfoxide.

EBMP: educational and behavioural modification programme.

$\mathrm{NaCl}$ : sodium chloride.

PDE5: phosphodiesterase-5.

PPS: pentosan polysulfate.

RTX: resiniferatoxin.

TENS: transcutaneous electrical nerve stimulation.

\section{Table 3. List of interventions for which no studies were identified in the review}

\section{Treatment category Example of intervention}

\section{Pharmacological therapy (irrespective of route of administration)}

\begin{tabular}{ll}
\hline Analgesics & \\
\hline Antidepressants & $\cdot$ Doxepin \\
& $\cdot$ Desipramine \\
& $\cdot$ Duloxetine \\
\hline Immune modulators & $\cdot$ Azathioprine and chloroquine derivatives \\
& $\cdot$ Suplatast tosilate
\end{tabular}

\section{Methotrexate}

\section{Misoprostol}


Table 3. List of interventions for which no studies were identified in the review (Continued)

Nifedipine

Quercetin

\section{Surgical therapy}

Transurethral resection

Neuromodulation (implanted)

\begin{tabular}{ll}
\hline Denervation & Surgical denervation \\
$\cdot$ Cystolysis - peripheral denervation \\
$\cdot$ Sympathetic denervation \\
$\cdot$ Parasympathetic denervation \\
\hline Bowel surgery $\quad$ Bladder augmentation - cystoplasty \\
$\cdot$ Cystoplasty with supratrigonal resection \\
$\cdot$ Cystoplasty with subtrigonal cystectomy - orthotopic continent bladder augmentation \\
$\cdot$ Urinary diversion with or without total cystectomy and urethrectomy
\end{tabular}

Table 4. Results of the meta-analyses for proportion cured or improved

\begin{tabular}{|c|c|c|c|c|c|c|}
\hline \multirow[b]{2}{*}{ Treatment category } & \multirow[b]{2}{*}{$\begin{array}{l}\text { Inter- } \\
\text { ven- } \\
\text { tion }\end{array}$} & \multicolumn{2}{|c|}{ Network meta-analysis } & \multicolumn{3}{|c|}{ Pairwise meta-analyses } \\
\hline & & $\begin{array}{l}\text { No. } \\
\text { of tri- } \\
\text { als in } \\
\text { net- } \\
\text { work }\end{array}$ & $\begin{array}{l}\text { OR vs control (median ( } 95 \% \\
\text { CrI)) (random effects) }\end{array}$ & $\begin{array}{l}\text { No. } \\
\text { of tri- } \\
\text { als vs } \\
\text { con- } \\
\text { trol }\end{array}$ & $\begin{array}{l}\text { OR vs control }(95 \% \mathrm{Cl}) \\
\text { (random effects) }\end{array}$ & $\begin{array}{l}\text { GRADE } \\
\text { certain- } \\
\text { ty of evi- } \\
\text { dence }\end{array}$ \\
\hline Behavioural therapy & Con & 2 & 9.64 (1.13 to 99.38$)$ & 2 & 7.04 (1.57 to 31.61$)$ & Very low \\
\hline Physical therapy & Con & 2 & 6.78 (1.08 to 46.85$)$ & 2 & $4.77(2.00$ to 11.38$)$ & Very low \\
\hline Amino acid & Pharm & 1 & 3.36 (0.24 to 53.09$)$ & 1 & 3.07 (0.66 to 14.18$)$ & Low \\
\hline Local anaesthetics & Pharm & 2 & 1.94 (0.28 to 13.78$)$ & 2 & $2.20(0.84$ to 5.80$)$ & Very low \\
\hline Antibiotics & Pharm & 1 & 4.71 (0.36 to 63.5$)$ & 1 & 4.33 (1.09 to 17.17$)$ & Very low \\
\hline Antidepressants & Pharm & 2 & 5.91 (1.12 to 37.56$)$ & 2 & 7.02 (0.35 to 141.48$)$ & Very low \\
\hline Antihistamines & Pharm & 1 & $1.43(0.15$ to 14.01$)$ & 1 & 1.96 (0.49 to 7.87$)$ & Very low \\
\hline Calcium channel agonists & Pharm & 3 & 1.51 (0.38 to 6.22$)$ & 3 & 1.40 (0.57 to 3.43$)$ & Very low \\
\hline Chondroitin sulfate & Pharm & 3 & 3.82 (0.86 to 19.18$)$ & 2 & $1.70(0.85$ to 3.41$)$ & Very low \\
\hline DMSO & Pharm & 4 & 3.05 (0.55 to 16.58$)$ & 1 & 4.55 (0.77 to 26.84$)$ & Very low \\
\hline
\end{tabular}


Table 4. Results of the meta-analyses for proportion cured or improved (Continued)

\begin{tabular}{|c|c|c|c|c|c|c|}
\hline Hyaluronic acid & Pharm & 2 & $2.10(0.12$ to 44.26$)$ & 0 & $\mathrm{~N} / \mathrm{A}$ & Very low \\
\hline Hyperbaric oxygen & Pharm & 1 & $11.73(0.27$ to 8324.85$)$ & 1 & 5.53 (0.25 to 124.4$)$ & Very low \\
\hline Immune modulators & Pharm & 10 & 2.74 (1.16 to 6.57$)$ & 7 & 2.19 (1.24 to 3.89$)$ & Very low \\
\hline PDE5 inhibitor & Pharm & 1 & 24.53 (1.21 to 1255.14$)$ & 1 & $16.43(1.89,142.50)$ & Very low \\
\hline PPS & Pharm & 6 & 1.14 (0.40 to 3.35 ) & 5 & 1.41 (0.95 to 2.08 ) & Very low \\
\hline Neuromuscular blockade & Surg & 6 & $5.80(2.08$ to 18.30$)$ & 6 & 4.19 (1.44 to 12.25$)$ & Very low \\
\hline $\begin{array}{l}\text { Anticoagulants + local } \\
\text { anaesthetics }\end{array}$ & Comb & 1 & 0.93 (0.01 to 65.89$)$ & 0 & $\mathrm{~N} / \mathrm{A}$ & Very low \\
\hline PPS + antihistamines & Comb & 1 & 3.94 (0.42 to 37.37$)$ & 1 & 5.18 (1.34 to 20.06$)$ & Very low \\
\hline $\begin{array}{l}\text { Chondroitin sulfate + } \\
\text { hyaluronic acid }\end{array}$ & Comb & 1 & 7.04 (0.37 to 128.77$)$ & 0 & $\mathrm{~N} / \mathrm{A}$ & Very low \\
\hline
\end{tabular}

Credible intervals excluding 1 are highlighted in bold.

$\mathrm{Cl}$ : confidence interval.

Comb: combination therapy.

Con: conservative therapy.

Crl: credible interval.

DMSO: dimethyl sulfoxide.

N/A: not applicable.

OR: odds ratio.

PDE5: phosphodiesterase-5.

Pharm: pharmacological therapy.

PPS: pentosan polysulfate.

Surg: surgical therapy.

Table 5. Results of the meta-analyses for pain

\begin{tabular}{|c|c|c|c|c|c|c|}
\hline \multirow[b]{2}{*}{ Treatment category } & \multirow[b]{2}{*}{$\begin{array}{l}\text { Inter- } \\
\text { ven- } \\
\text { tion }\end{array}$} & \multicolumn{2}{|c|}{ Network meta-analysis } & \multicolumn{3}{|c|}{ Pairwise meta-analyses } \\
\hline & & $\begin{array}{l}\text { No. } \\
\text { of tri- } \\
\text { als in } \\
\text { net- } \\
\text { work }\end{array}$ & $\begin{array}{l}\text { Mean difference vs control } \\
\text { (median }(95 \% \mathrm{Crl})) \text { (random } \\
\text { effects) }\end{array}$ & $\begin{array}{l}\text { No. } \\
\text { of tri- } \\
\text { als vs } \\
\text { con- } \\
\text { trol }\end{array}$ & $\begin{array}{l}\text { Mean difference vs control } \\
(95 \% \mathrm{Cl}) \text { (random effects) }\end{array}$ & $\begin{array}{l}\text { GRADE } \\
\text { certain- } \\
\text { ty of ev- } \\
\text { idence }\end{array}$ \\
\hline Behavioural therapy & Con & 6 & $-0.60(-1.79$ to 0.62$)$ & 6 & $-1.50(-2.93$ to -0.06$)$ & Very low \\
\hline Physical therapy & Con & 2 & $-3.92(-5.80$ to -1.94$)$ & 2 & $-3.69(-9.90$ to 2.52$)$ & $\begin{array}{l}\text { Moder- } \\
\text { ate }\end{array}$ \\
\hline Local anaesthetics & Pharm & 2 & $-0.31(-2.58$ to 2.00$)$ & 2 & $-0.51(-1.93$ to 0.91$)$ & Very low \\
\hline Calcium channel agonists & Pharm & 6 & $-0.53(-1.72$ to 0.68$)$ & 6 & $-0.68(-0.94$ to -0.42$)$ & Very low \\
\hline Chondroitin sulfate & Pharm & 4 & $0.36(-1.31$ to 2.05$)$ & 3 & $0.30(-0.40$ to 1.00$)$ & Very low \\
\hline Hyperbaric oxygen & Pharm & 1 & $-2.45(-5.95$ to 1.04$)$ & 1 & $-2.45(-4.76$ to -0.15$)$ & Low \\
\hline
\end{tabular}


Table 5. Results of the meta-analyses for pain (Continued)

\begin{tabular}{|c|c|c|c|c|c|c|}
\hline Hydrogen-rich water & Pharm & 1 & $-0.20(-3.50$ to 3.12$)$ & 1 & $-0.20(-2.17$ to 1.77$)$ & Very low \\
\hline Immune modulators & Pharm & 8 & $-0.77(-1.81$ to 0.24$)$ & 7 & $-0.54(-1.27$ to 0.20$)$ & Low \\
\hline PDE5 inhibitor & Pharm & 1 & $-0.60(-3.77$ to 2.56$)$ & 1 & $-0.60(-2.30$ to 1.10$)$ & Very low \\
\hline Neuromuscular blockade & Surg & 6 & $-0.33(-1.71$ to 1.03$)$ & 5 & $-0.21(-1.01$ to 0.60$)$ & Very low \\
\hline Hydrodistension & Surg & 3 & $-0.01(-3.48$ to 3.44$)$ & 0 & $\mathrm{~N} / \mathrm{A}$ & Very low \\
\hline Fulguration & Surg & 1 & $-1.93(-6.53$ to 2.70$)$ & 0 & $\mathrm{~N} / \mathrm{A}$ & Very low \\
\hline Anticytokines & Pharm & 1 & $-1.20(-3.92$ to 1.51$)$ & 1 & $-1.20(-1.85$ to -0.55$)$ & Very low \\
\hline Denervation & Surg & 1 & $1.97(-2.44$ to 6.44$)$ & 0 & $\mathrm{~N} / \mathrm{A}$ & Very low \\
\hline AQX-1125 & Pharm & 1 & $-1.01(-3.83$ to 1.82$)$ & 1 & $-1.00(-2.03$ to 0.03$)$ & Very low \\
\hline $\begin{array}{l}\text { Neuromuscular blockade }+ \\
\text { DMSO }\end{array}$ & Comb & 1 & $-2.81(-5.87$ to 0.24$)$ & 1 & $-2.80(-4.36$ to -1.24$)$ & Low \\
\hline Antidepressants & Pharm & 2 & $-1.27(-3.25$ to 0.71$)$ & 2 & $-1.28(-3.31$ to 0.76$)$ & Low \\
\hline Antihistamines & Pharm & 1 & 0.65 (-1.96 to 3.27$)$ & 1 & $0.56(-0.44$ to 1.55$)$ & Very low \\
\hline Buffer solutions & Pharm & 1 & 0.23 (-3.89 to 4.33$)$ & 1 & $0.21(-2.94$ to 3.36$)$ & Very low \\
\hline DMSO & Pharm & 2 & $1.46(-1.22$ to 4.13$)$ & 0 & $\mathrm{~N} / \mathrm{A}$ & Very low \\
\hline $\mathrm{P} 2 \mathrm{X} 3$ antagonist & Pharm & 1 & $-1.20(-4.13$ to 1.73$)$ & 1 & $-1.20(-2.54$ to 0.14$)$ & Very low \\
\hline $\begin{array}{l}\text { Parasympathomimetic (+ } \\
\text { urinary antiseptics) }\end{array}$ & Pharm & 1 & $-2.75(-5.83$ to 0.34$)$ & 1 & $-2.76(-4.36$ to -1.16$)$ & Low \\
\hline PPS & Pharm & 4 & $0.42(-1.04$ to 1.91$)$ & 3 & $-0.03(-0.65$ to 0.60$)$ & Very low \\
\hline PPS + antihistamines & Comb & 1 & $-0.58(-3.20$ to 2.04$)$ & 1 & $-0.67(-1.70$ to 0.37$)$ & Very low \\
\hline $\begin{array}{l}\text { Chondroitin sulfate + } \\
\text { hyaluronic acid }\end{array}$ & Comb & 1 & $-0.05(-197.8$ to 195.2$)$ & 0 & $\mathrm{~N} / \mathrm{A}$ & Very low \\
\hline
\end{tabular}

\section{Treatments not part of the connected network}

\begin{tabular}{lllllll}
\hline Hyaluronic acid & Pharm & 1 & N/A & 0 & N/A & N/A \\
\hline $\begin{array}{l}\text { Anticoagulants + local } \\
\text { anaesthetics }\end{array}$ & Comb & 1 & N/A & 0 & N/A & N/A \\
\hline
\end{tabular}

Pain is measured on a 0 to 10 scale where 0 is no pain and 10 is maximum pain.

Credible intervals excluding zero are highlighted in bold.

$\mathrm{Cl}$ : confidence interval.

Comb: combination therapy.

Con: conservative therapy.

Crl: credible interval.

DMSO: dimethyl sulfoxide.

N/A: not applicable. 
OR: odds ratio.

PDE5: phosphodiesterase-5.

Pharm: pharmacological therapy.

PPS: pentosan polysulfate.

Surg: surgical therapy.

Table 6. Results of the meta-analyses for daytime frequency (number of daytime voids)

\begin{tabular}{|c|c|c|c|c|c|c|}
\hline \multirow[b]{2}{*}{ Treatment category } & \multirow[b]{2}{*}{$\begin{array}{l}\text { Inter- } \\
\text { ven- } \\
\text { tion }\end{array}$} & \multicolumn{2}{|c|}{ Network meta-analysis } & \multicolumn{3}{|c|}{ Pairwise meta-analyses } \\
\hline & & $\begin{array}{l}\text { No. } \\
\text { of tri- } \\
\text { als in } \\
\text { net- } \\
\text { work }\end{array}$ & $\begin{array}{l}\text { Mean difference vs con- } \\
\text { trol (median }(95 \% \mathrm{Crl}) \text { ) } \\
\text { (random effects) }\end{array}$ & $\begin{array}{l}\text { No. } \\
\text { of tri- } \\
\text { als vs } \\
\text { con- } \\
\text { trol }\end{array}$ & $\begin{array}{l}\text { Mean difference vs control } \\
(95 \% \mathrm{CI}) \text { (random effects) }\end{array}$ & $\begin{array}{l}\text { GRADE } \\
\text { certain- } \\
\text { ty of ev- } \\
\text { idence }\end{array}$ \\
\hline Behavioural therapy & Con & 1 & $-2.01(-6.44$ to 2.47$)$ & 1 & $-2.00(-3.41$ to -0.59$)$ & Very low \\
\hline Amino acid & Pharm & 1 & $4.14(-2.47$ to 10.80$)$ & 1 & $4.10(-1.18$ to 9.38$)$ & Low \\
\hline Local anaesthetics & Pharm & 1 & $0.35(-6.12$ to 6.69$)$ & 1 & $0.30(-4.67$ to 5.27$)$ & Very low \\
\hline Anticholinergics & Pharm & 1 & $-0.73(-6.34$ to 4.95$)$ & 1 & $-0.75(-4.62$ to 3.13$)$ & Very low \\
\hline Anticytokines & Pharm & 1 & $-4.69(-9.70$ to 0.29$)$ & 1 & $-4.70(-7.38$ to -2.02$)$ & Very low \\
\hline Calcium channel agonists & Pharm & 4 & $-0.79(-3.61$ to 2.23$)$ & 4 & $-1.09(-2.72$ to 0.55$)$ & Very low \\
\hline Chondroitin sulfate & Pharm & 2 & $0.05(-3.35$ to 3.46$)$ & 2 & $0.03(-1.44$ to 1.49$)$ & Very low \\
\hline Immune modulators & Pharm & 4 & $-1.95(-4.78$ to 0.73$)$ & 3 & $-0.82(-2.51$ to 0.88$)$ & Very low \\
\hline PDE5 inhibitor & Pharm & 1 & $-2.46(-7.54$ to 2.53$)$ & 1 & $-2.50(-5.32$ to 0.33$)$ & Very low \\
\hline PPS & Pharm & 2 & $-0.37(-5.00$ to 3.44$)$ & 1 & $-6.00(-10.34$ to -1.66$)$ & Very low \\
\hline Neuromuscular blockade & Surg & 5 & $-0.91(-3.24$ to 1.29$)$ & 5 & $-0.84(-2.28$ to 0.56$)$ & Very low \\
\hline $\begin{array}{l}\text { Neuromuscular blockade + } \\
\text { DMSO }\end{array}$ & Comb & 1 & $-8.97(-15.23$ to -2.81$)$ & 1 & $-9.00(-13.62$ to -4.38$)$ & $\begin{array}{l}\text { Moder- } \\
\text { ate }\end{array}$ \\
\hline Antidepressants & Pharm & 1 & $-2.41(-6.85$ to 2.05$)$ & 1 & $-2.40(-3.75$ to -1.05$)$ & Very low \\
\hline \multicolumn{7}{|c|}{ Treatments not part of the connected network } \\
\hline $\begin{array}{l}\text { Anticoagulants + local anaes- } \\
\text { thetics }\end{array}$ & Comb & 1 & N/A & 0 & N/A & N/A \\
\hline Hydrodistension & Surg & 1 & $\mathrm{~N} / \mathrm{A}$ & 0 & N/A & $\mathrm{N} / \mathrm{A}$ \\
\hline Hyaluronic acid & Pharm & 1 & $\mathrm{~N} / \mathrm{A}$ & 0 & N/A & $\mathrm{N} / \mathrm{A}$ \\
\hline Denervation & Surg & 1 & $\mathrm{~N} / \mathrm{A}$ & 0 & $\mathrm{~N} / \mathrm{A}$ & $\mathrm{N} / \mathrm{A}$ \\
\hline DMSO & Pharm & 1 & $\mathrm{~N} / \mathrm{A}$ & 0 & $\mathrm{~N} / \mathrm{A}$ & N/A \\
\hline $\begin{array}{l}\text { Chondroitin sulfate + } \\
\text { hyaluronic acid }\end{array}$ & Comb & 1 & $\mathrm{~N} / \mathrm{A}$ & 0 & $\mathrm{~N} / \mathrm{A}$ & $\mathrm{N} / \mathrm{A}$ \\
\hline
\end{tabular}


Credible intervals excluding zero are highlighted in bold.

$\mathrm{Cl}$ : confidence interval.

Comb: combination therapy.

Con: conservative therapy.

Crl: credible interval.

DMSO: dimethyl sulfoxide.

N/A: not applicable.

OR: odds ratio.

PDE5: phosphodiesterase-5.

Pharm: pharmacological therapy.

PPS: pentosan polysulfate.

Surg: surgical therapy.

Table 7. Results of the meta-analyses for nocturia (number of nighttime voids)

\begin{tabular}{|c|c|c|c|c|c|c|}
\hline \multirow[b]{2}{*}{ Treatment category } & \multirow[b]{2}{*}{$\begin{array}{l}\text { Inter- } \\
\text { ven- } \\
\text { tion }\end{array}$} & \multicolumn{2}{|c|}{ Network meta-analysis } & \multicolumn{3}{|c|}{ Pairwise meta-analyses } \\
\hline & & $\begin{array}{l}\text { No. } \\
\text { of tri- } \\
\text { als in } \\
\text { net- } \\
\text { work }\end{array}$ & $\begin{array}{l}\text { Mean difference vs control } \\
\text { (median }(95 \% \mathrm{Crl}) \text { ) (random } \\
\text { effects) }\end{array}$ & $\begin{array}{l}\text { No. } \\
\text { of tri- } \\
\text { als vs } \\
\text { con- } \\
\text { trol }\end{array}$ & $\begin{array}{l}\text { Mean difference vs control } \\
(95 \% \mathrm{Cl}) \text { (random effects) }\end{array}$ & $\begin{array}{l}\text { GRADE } \\
\text { certain- } \\
\text { ty of ev- } \\
\text { idence }\end{array}$ \\
\hline Behavioural therapy & Con & 1 & $-0.71(-3.21$ to 1.82$)$ & 1 & $-0.70(-1.26$ to -0.14$)$ & Very low \\
\hline Amino acid & Pharm & 1 & $0.12(-2.65$ to 2.87$)$ & 1 & $0.10(-1.29$ to 1.49$)$ & Low \\
\hline Local anaesthetics & Pharm & 1 & $0.29(-3.05$ to 3.67$)$ & 1 & $0.30(-2.14$ to 2.74$)$ & Very low \\
\hline $\begin{array}{l}\text { Calcium channel ago- } \\
\text { nists }\end{array}$ & Pharm & 3 & $-0.24(-2.04$ to 1.52$)$ & 3 & $-0.30(-0.99$ to 0.38$)$ & Very low \\
\hline Chondroitin sulfate & Pharm & 1 & $-0.01(-2.63$ to 2.65$)$ & 1 & $0.00(-1.10$ to 1.10$)$ & Very low \\
\hline PDE5 inhibitor & Pharm & 1 & $-1.40(-4.07$ to 1.22$)$ & 1 & $-1.40(-2.47$ to -0.33$)$ & Very low \\
\hline PPS & Pharm & 2 & $-1.20(-3.62$ to 1.28$)$ & 1 & $-2.20(-4.03$ to -0.37$)$ & Very low \\
\hline $\begin{array}{l}\text { Neuromuscular block- } \\
\text { ade }\end{array}$ & Surg & 4 & $-0.04(-1.35$ to 1.27$)$ & 4 & $-0.04(-0.84$ to 0.76$)$ & Very low \\
\hline Antidepressants & Pharm & 1 & $0.01(-2.53$ to 2.50$)$ & 1 & $0.00(-0.69$ to 0.69$)$ & Very low \\
\hline Immune modulators & Pharm & 2 & $-2.65(-5.04$ to 0.20$)$ & 1 & $-1.00(-3.63$ to 1.63$)$ & Low \\
\hline \multicolumn{7}{|c|}{ Treatments not part of the connected network } \\
\hline Denervation & Surg & 1 & $\mathrm{~N} / \mathrm{A}$ & 0 & $\mathrm{~N} / \mathrm{A}$ & $\mathrm{N} / \mathrm{A}$ \\
\hline Hydrodistension & Surg & 1 & $\mathrm{~N} / \mathrm{A}$ & 0 & N/A & $\mathrm{N} / \mathrm{A}$ \\
\hline
\end{tabular}

Credible intervals excluding zero are highlighted in bold.

$\mathrm{Cl}$ : confidence interval.

Con: conservative therapy.

Crl: credible interval.

N/A: not applicable.

PDE5: phosphodiesterase-5.

Pharm: pharmacological therapy. 
PPS: pentosan polysulfate.

Surg: surgical therapy.

Table 8. Results of the meta-analyses for ICSI (Interstitial Cystitis Symptom Index) score

\begin{tabular}{|c|c|c|c|c|c|}
\hline \multirow[b]{2}{*}{ Treatment category } & \multirow[b]{2}{*}{$\begin{array}{l}\text { Inter- } \\
\text { vention }\end{array}$} & \multicolumn{2}{|c|}{ Network meta-analysis } & \multicolumn{2}{|c|}{ Pairwise meta-analyses } \\
\hline & & $\begin{array}{l}\text { No. of } \\
\text { trials in } \\
\text { network }\end{array}$ & $\begin{array}{l}\text { Mean difference vs control } \\
\text { (median }(95 \% \mathrm{Crl}) \text { ) (random } \\
\text { effects) }\end{array}$ & $\begin{array}{l}\text { No. of } \\
\text { trials vs } \\
\text { control }\end{array}$ & $\begin{array}{l}\text { Mean difference vs control } \\
(95 \% \mathrm{CI}) \text { (random effects) }\end{array}$ \\
\hline Behavioural therapy & Con & 5 & $-0.89(-2.57$ to 0.81$)$ & 5 & $-0.94(-2.05$ to 0.18$)$ \\
\hline Physical therapy & Con & 1 & $-0.70(-4.07$ to 2.68$)$ & 1 & $-0.70(-2.61$ to 1.21$)$ \\
\hline Local anaesthetics & Pharm & 2 & $-1.25(-3.95$ to 1.44$)$ & 2 & $-1.30(-2.73$ to 0.13$)$ \\
\hline $\begin{array}{l}\text { Calcium channel ago- } \\
\text { nists }\end{array}$ & Pharm & 2 & $-1.25(-4.01$ to 1.49$)$ & 2 & $-1.22(-3.14$ to 0.70$)$ \\
\hline Chondroitin sulfate & Pharm & 4 & 0.34 (-1.63 to 2.32$)$ & 3 & $0.32(-0.84$ to 1.49$)$ \\
\hline Hydrogen-rich water & Pharm & 1 & $0.16(-4.1$ to 4.45$)$ & 1 & $0.20(-3.10$ to 3.50$)$ \\
\hline Immune modulators & Pharm & 5 & $-1.06(-2.87$ to 0.77$)$ & 3 & $-0.76(-1.65$ to 0.15$)$ \\
\hline PDE5 inhibitor & Pharm & 1 & $-6.02(-9.05$ to -2.93$)$ & 1 & $-6.00(-7.28$ to -4.72$)$ \\
\hline Neuromuscular blockade & Pharm & 5 & $-0.65(-2.49$ to 1.10$)$ & 4 & $-0.58(-1.96$ to 0.80$)$ \\
\hline Hydrodistension & Surg & 2 & $-1.26(-5.22$ to 2.62$)$ & 0 & $\mathrm{~N} / \mathrm{A}$ \\
\hline Denervation & Surg & 1 & $1.64(-3.41$ to 6.56$)$ & 0 & $\mathrm{~N} / \mathrm{A}$ \\
\hline Antidepressants & Surg & 1 & $-1.51(-4.47$ to 1.48$)$ & 1 & $-1.50(-2.48$ to -0.52$)$ \\
\hline Antihistamines & Pharm & 3 & $1.16(-1.95$ to 4.36$)$ & 1 & $1.00(-0.77$ to 2.77$)$ \\
\hline AQX-1125 & Pharm & 1 & $-2.39(-5.62$ to 0.80$)$ & 1 & $-2.40(-4.02$ to -0.78$)$ \\
\hline DMSO & Pharm & 1 & $1.02(-3.08$ to 5.20$)$ & 0 & $\mathrm{~N} / \mathrm{A}$ \\
\hline PPS & Pharm & 5 & $1.18(-1.10$ to 3.45$)$ & 1 & 0.60 (-1.15 to 2.35$)$ \\
\hline PPS + antihistamines & Comb & 3 & $-1.14(-4.31$ to 2.06$)$ & 1 & $-1.30(-3.09$ to 0.49$)$ \\
\hline
\end{tabular}

Credible intervals excluding zero are highlighted in bold.

$\mathrm{Cl}$ : confidence interval.

Comb: combination therapy.

Con: conservative therapy.

Crl: credible interval.

DMSO: dimethyl sulfoxide.

N/A: not applicable.

PDE5: phosphodiesterase-5.

Pharm: pharmacological therapy.

PPS: pentosan polysulfate.

Surg: surgical therapy. 
Table 9. Results of the meta-analyses for ICPI (Interstitial Cystitis Problem Index) score

\begin{tabular}{|c|c|c|c|c|c|}
\hline \multirow[b]{2}{*}{ Treatment category } & \multirow[b]{2}{*}{$\begin{array}{l}\text { Inter- } \\
\text { vention }\end{array}$} & \multicolumn{2}{|c|}{ Network meta-analysis } & \multicolumn{2}{|c|}{ Pairwise meta-analyses } \\
\hline & & $\begin{array}{l}\text { No. of } \\
\text { trials in } \\
\text { network }\end{array}$ & $\begin{array}{l}\text { Mean difference vs control } \\
\text { (median }(95 \% \mathrm{Crl}) \text { ) (random } \\
\text { effects) }\end{array}$ & $\begin{array}{l}\text { No. of } \\
\text { trials vs } \\
\text { control }\end{array}$ & $\begin{array}{l}\text { Mean difference vs control } \\
\text { ( } 95 \% \mathrm{Cl}) \text { (random effects) }\end{array}$ \\
\hline Behavioural therapy & Con & 4 & $0.31(-1.80$ to 2.38$)$ & 4 & $0.27(-2.08$ to 2.62$)$ \\
\hline Physical therapy & Con & 1 & $-1.40(-5.09$ to 2.33$)$ & 1 & $-1.40(-2.98$ to 0.18$)$ \\
\hline Local anaesthetics & Pharm & 2 & $-1.15(-4.09$ to 1.97$)$ & 2 & $-1.45(-2.84$ to -0.06$)$ \\
\hline $\begin{array}{l}\text { Calcium channel ago- } \\
\text { nists }\end{array}$ & Pharm & 1 & $-2.94(-7.41$ to 1.55$)$ & 1 & $-2.92(-5.93$ to 0.09$)$ \\
\hline Chondroitin sulfate & Pharm & 4 & $-0.18(-2.41$ to 2.09$)$ & 3 & $-0.19(-1.30$ to 0.92$)$ \\
\hline Hydrogen-rich water & Pharm & 1 & $-0.20(-4.36$ to 4.00$)$ & 1 & $-0.20(-2.73$ to 2.33$)$ \\
\hline Immune modulators & Pharm & 4 & $-0.59(-2.61$ to 1.54$)$ & 3 & $-0.07(-1.12$ to 0.98$)$ \\
\hline PDE5 inhibitor & Pharm & 1 & $-3.50(-7.71$ to 0.69$)$ & 1 & $-3.50(-6.05$ to -0.95$)$ \\
\hline Neuromuscular blockade & Surg & 6 & $-1.37(-3.28$ to 0.48$)$ & 5 & $-1.28(-2.61$ to 0.05$)$ \\
\hline Hydrodistension & Surg & 2 & $-1.87(-6.02$ to 2.25$)$ & 0 & $\mathrm{~N} / \mathrm{A}$ \\
\hline Denervation & Surg & 1 & $1.04(-4.39$ to 6.40$)$ & 0 & $\mathrm{~N} / \mathrm{A}$ \\
\hline Antidepressants & Pharm & 1 & $-1.28(-4.83$ to 2.25$)$ & 1 & $-1.30(-2.32$ to -0.28$)$ \\
\hline Antihistamines & Pharm & 1 & $1.63(-1.78$ to 5.31$)$ & 1 & $0.80(-0.63$ to 2.23$)$ \\
\hline AQX-1125 & Pharm & 1 & $-1.99(-5.72$ to 1.72$)$ & 1 & $-2.00(-3.55$ to -0.45$)$ \\
\hline DMSO & Pharm & 1 & $0.43(-4.22$ to 5.15$)$ & 0 & $\mathrm{~N} / \mathrm{A}$ \\
\hline PPS & Pharm & 2 & $2.66(-0.16$ to 5.59$)$ & 1 & 0.40 (-1.22 to 2.02$)$ \\
\hline PPS + antihistamines & Comb & 1 & $-0.27(-3.82$ to 3.50$)$ & 1 & $-1.10(-2.79$ to 0.59$)$ \\
\hline
\end{tabular}

Credible intervals excluding zero are highlighted in bold.

$\mathrm{Cl}$ : confidence interval.

Comb: combination therapy.

Con: conservative therapy.

Crl: credible interval.

DMSO: dimethyl sulfoxide.

N/A: not applicable.

PDE5: phosphodiesterase-5.

Pharm: pharmacological therapy.

PPS: pentosan polysulfate.

Surg: surgical therapy. 


\begin{tabular}{|c|c|c|c|c|c|c|c|c|}
\hline \multirow{2}{*}{$\begin{array}{l}\text { Treat- } \\
\text { ment } \\
\text { category } \\
1\end{array}$} & \multirow{2}{*}{$\begin{array}{l}\text { Treatment } \\
\text { category } 2\end{array}$} & \multirow[t]{2}{*}{ Study ID } & \multirow[t]{2}{*}{ Outcome } & \multirow{2}{*}{$\begin{array}{l}\text { Time } \\
\text { point } \\
\text { (month) }\end{array}$} & \multicolumn{2}{|c|}{ Intervention 1} & \multicolumn{2}{|c|}{ Intervention 2} \\
\hline & & & & & $\begin{array}{l}\text { Mean } \\
\text { (SD) }\end{array}$ & & Mean (SD) & $\mathbf{N}$ \\
\hline $\begin{array}{l}\text { Antide- } \\
\text { pressants }\end{array}$ & Control & $\begin{array}{l}\text { van } \\
\text { Ophoven } \\
2004\end{array}$ & $\begin{array}{l}\text { Functional bladder } \\
\text { volume }(\mathrm{mL}), \\
\text { change from baseline }\end{array}$ & 4 & $\begin{array}{l}19 \\
(54.62)\end{array}$ & 24 & $-7.7(47.5)$ & 24 \\
\hline $\begin{array}{l}\text { Calcium } \\
\text { channel } \\
\text { agonists }\end{array}$ & Control & Ham 2012 & $\begin{array}{l}\text { Functional bladder } \\
\text { capacity }(\mathrm{mL}), \\
\text { final value }\end{array}$ & 3 & $\begin{array}{l}222.9 \\
(36.9)\end{array}$ & 8 & $242(50.2)$ & 10 \\
\hline $\begin{array}{l}\text { Chon- } \\
\text { droitin sul- } \\
\text { fate } \\
+ \\
\text { hyaluronic } \\
\text { acid }\end{array}$ & DMSO & $\begin{array}{l}\text { Cervigni } \\
2014\end{array}$ & $\begin{array}{l}\text { Bladder capacity }(\mathrm{mL}) \text {, } \\
\text { change from baseline }\end{array}$ & 3 & $\begin{array}{l}38.07 \\
(71.53)\end{array}$ & 44 & $20.6(61.62)$ & 25 \\
\hline $\begin{array}{l}\text { Hyperbar- } \\
\text { ic oxygen }\end{array}$ & Control & $\begin{array}{l}\text { van } \\
\text { Ophoven } \\
2006\end{array}$ & $\begin{array}{l}\text { Functional bladder } \\
\text { capacity }(\mathrm{mL}), \\
\text { final value }\end{array}$ & 3 & $\begin{array}{l}147 \\
(49)\end{array}$ & 14 & $118(36)$ & 7 \\
\hline $\begin{array}{l}\text { Immune } \\
\text { modula- } \\
\text { tors }\end{array}$ & Control & Mayer 2005 & $\begin{array}{l}\text { Functional bladder } \\
\text { capacity }(\mathrm{mL}) \\
\text { change from baseline }\end{array}$ & 8.5 & $\begin{array}{l}-26 \\
(156)\end{array}$ & 109 & $-17(112)$ & 113 \\
\hline $\begin{array}{l}\text { Immune } \\
\text { modula- } \\
\text { tors }\end{array}$ & Control & Irani 2004 & $\begin{array}{l}\text { Maximum tolerable } \\
\text { bladder capacity }(\mathrm{mL}) \text {, } \\
\text { final value }\end{array}$ & 24 & $\begin{array}{l}240.5 \\
(93.7)\end{array}$ & 15 & $196.5(61.8)$ & 15 \\
\hline $\begin{array}{l}\text { Neuro- } \\
\text { muscular } \\
\text { blockade }\end{array}$ & Control & $\begin{array}{l}\text { Chuang } \\
2017\end{array}$ & $\begin{array}{l}\text { Functional bladder } \\
\text { capacity }(\mathrm{mL}) \text {, final value: } \\
\text { a. lipotoxin; } \\
\text { b. onabotulinumtoxinA }\end{array}$ & 1 & $\begin{array}{l}\text { a. } \\
307 \\
(110) \\
\text { b. } \\
315 \\
(118)\end{array}$ & $\begin{array}{l}\text { a. } 31 \\
\text { b. } 28\end{array}$ & 332 (169) & 31 \\
\hline & & Kuo 2016 & $\begin{array}{l}\text { Functional bladder } \\
\text { capacity (mL), final value }\end{array}$ & 2 & $\begin{array}{l}219.6 \\
(103.6)\end{array}$ & 40 & $189(99.4)$ & 20 \\
\hline
\end{tabular}




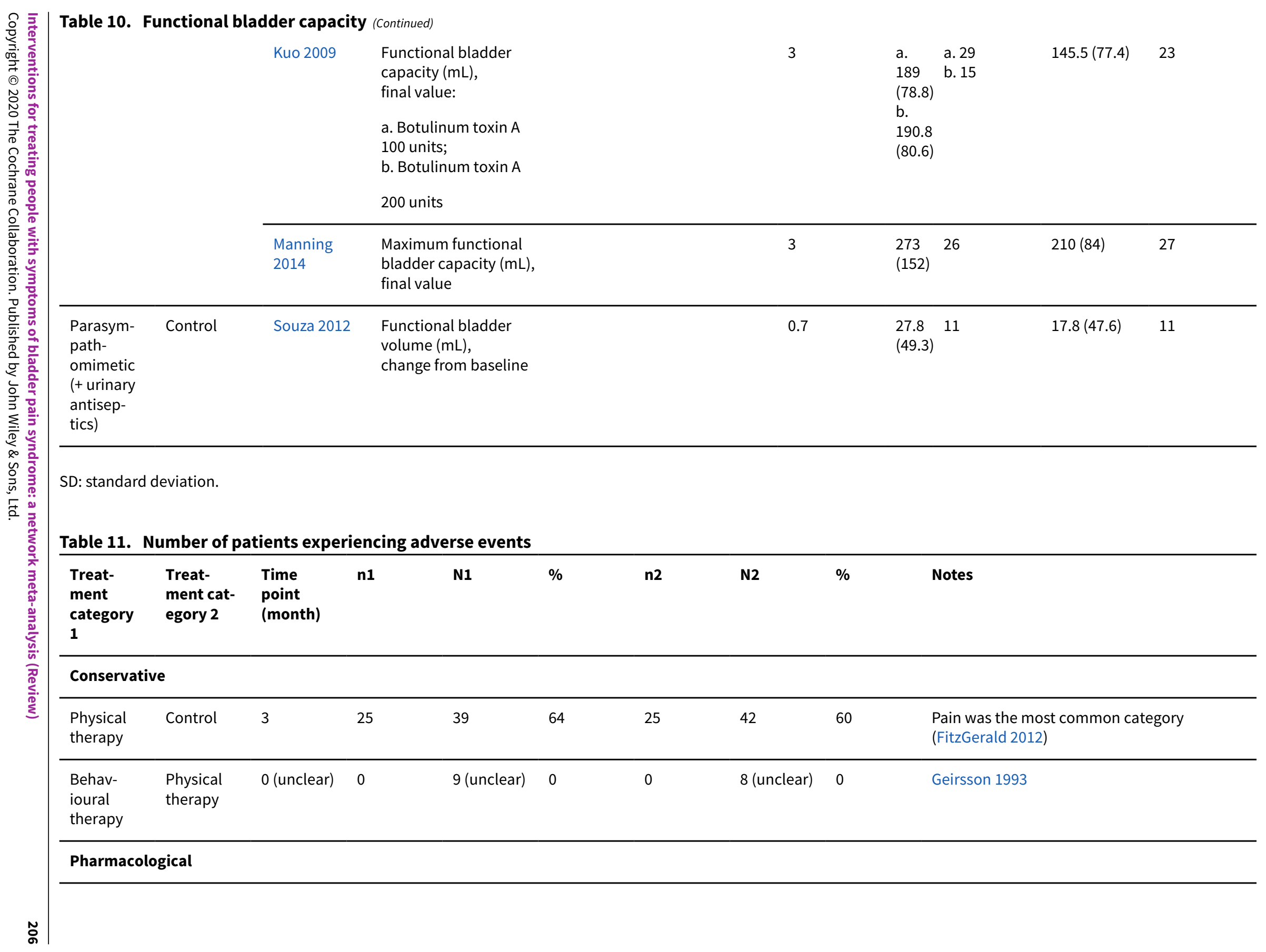




\begin{tabular}{|c|c|c|c|c|c|c|c|c|c|}
\hline $\begin{array}{l}\text { Amino } \\
\text { acid }\end{array}$ & Control & 3 & 12 & 21 & 57 & 12 & 25 & 48 & Korting 1999 \\
\hline Antibiotics & Control & 4.5 & 20 & 25 & 80 & 10 & 25 & 40 & $\begin{array}{l}\text { AEs included nausea and/or vomiting } 23 \text { vs } 6 \text {; } \\
\text { diarrhoea } 12 \text { vs } 2 \text {; headache } 5 \text { vs } 2 \text {; dizziness } 2 \\
\text { vs } 0 \text {; rash } 1 \text { vs } 3 \text {; vaginal symptoms } 3 \text { vs } 2 \text {; oth- } \\
\text { er } 5 \text { vs } 10 \text { (Warren 2000) }\end{array}$ \\
\hline $\begin{array}{l}\text { Anticoagu- } \\
\text { lants + } \\
\text { local } \\
\text { anaesthet- } \\
\text { ics }\end{array}$ & $\begin{array}{l}\text { Hyaluronic } \\
\text { acid }\end{array}$ & $\begin{array}{l}12 \text { (un- } \\
\text { clear) }\end{array}$ & 0 & 13 & 0 & 0 & 11 & 0 & Lu 2015 \\
\hline $\begin{array}{l}\text { Antide- } \\
\text { pressants }\end{array}$ & Control & 3 & 119 & 135 & 88 & 98 & 136 & 72 & $\begin{array}{l}\text { AEs included constitutional symptoms (pri- } \\
\text { marily fatigue, malaise) } 61 \text { vs } 42 \text {; dermatolog- } \\
\text { ical/skin } 9 \text { vs } 10 \text {; gastrointestinal (primarily } \\
\text { dry mouth, constipation) } 57 \text { vs } 32 \text {; infection, } \\
\text { fever } 9 \text { vs } 14 \text {; musculoskeletal } 7 \text { vs } 3 \text {; neuro- } \\
\text { logical (primarily dizziness, somnolence) } 45 \\
\text { vs } 29 \text {; ocular, visual } 3 \text { vs } 7 \text {; pain (primarily } \\
\text { headache) } 43 \text { vs } 48 \text {; pulmonary } 15 \text { vs } 13 \text {; re- } \\
\text { nal/genitourinary } 22 \text { vs } 10 \text { (Foster } 2010 \text { ) }\end{array}$ \\
\hline & & 4 & 22 & 24 & 92 & 5 & 24 & 21 & $\begin{array}{l}\text { AEs included mouth dryness } 19 \text { vs } 2 \text {; weight } \\
\text { gain } 15 \text { vs } 2 \text {; sedation } 9 \text { vs } 3 \text {; constipation } \\
11 \text { vs } 2 \text {; nausea/vertigo } 3 \text { vs } 3 \text {; blurred vi- } \\
\text { sion/diplopia } 4 \text { vs } 0 \text {; erectile dysfunction } 1 \\
\text { vs } 0 \text {. "A dry mouth was the most frequent } \\
\text { side effect in the amitriptyline group. No ad- } \\
\text { verse effects of grade } 3 \text { or higher were report- } \\
\text { ed" (van Ophoven 2004) }\end{array}$ \\
\hline AQX-1125 & Control & 1 & 19 & 37 & 51 & 25 & 32 & 78 & $\begin{array}{l}\text { Any treatment-emergent adverse events. } \\
\text { "The most frequently reported TEAEs (greater } \\
\text { than } 5 \% \text { ) and those that developed at a high- } \\
\text { er frequency in the AQX-1125 group were dys- } \\
\text { pepsia, gastroesophageal reflux disease and } \\
\text { sinusitis" (Leadership } 201 \text { Trial 2016) }\end{array}$ \\
\hline $\begin{array}{l}\text { Calcium } \\
\text { channel } \\
\text { agonists }\end{array}$ & Control & 3 & 16 & 18 & 89 & 3 & 4 & 75 & $\begin{array}{l}\text { AEs included pain during instillation, abdomi- } \\
\text { nal pain, cystitis, dizziness, pallor and urinary } \\
\text { tract disorders (number per event not report- } \\
\text { ed) (Chen 2005) }\end{array}$ \\
\hline
\end{tabular}




\begin{tabular}{|c|c|c|c|c|c|c|c|c|c|}
\hline & & 3 & $N / R$ & 8 & $\mathrm{~N} / \mathrm{A}$ & $N / R$ & 10 & $\mathrm{~N} / \mathrm{A}$ & $\begin{array}{l}\text { AEs included haematuria } 2 \text { vs } 0 \text {; bladder pain } \\
0 \text { vs } 1 \text {. "These side effects disappeared within } \\
2 \text { days" (Ham 2012) }\end{array}$ \\
\hline & & 6 & $N / R$ & 17 & $\mathrm{~N} / \mathrm{A}$ & $N / R$ & 18 & $\mathrm{~N} / \mathrm{A}$ & $\begin{array}{l}\text { AEs included pain during instillation: } 17 \text { vs } 15 \\
\text { (Lazzeri 1996) }\end{array}$ \\
\hline & & 3 & $N / R$ & 9 & $\mathrm{~N} / \mathrm{A}$ & $N / R$ & 9 & $\mathrm{~N} / \mathrm{A}$ & $\begin{array}{l}\text { AEs included pain during instillation: } 4 \text { vs } 0 \\
\text { (Lazzeri 2000) }\end{array}$ \\
\hline & & 1 & $N / R$ & 119 & N/A & $N / R$ & 44 & $\mathrm{~N} / \mathrm{A}$ & $\begin{array}{l}\text { AEs included pain during instillation: } 90 \text { vs } 23 \\
\text { (Payne 2005) }\end{array}$ \\
\hline $\begin{array}{l}\text { Chon- } \\
\text { droitin sul- } \\
\text { fate }\end{array}$ & Control & 3 & 22 & 33 & 67 & 28 & 32 & 88 & $\begin{array}{l}\text { AEs included gastrointestinal disorders } 0 \text { vs } 1 \text {; } \\
\text { nausea } 0 \text { vs } 1 \text {; infections and infestations } 0 \text { vs } \\
1 \text {; urethritis } 0 \text { vs } 1 \text {; renal and urinary disorders } \\
0 \text { vs } 1 \text {; urethral pain } 0 \text { vs } 1 \text {; reproductive sys- } \\
\text { tem and breast disorders } 1 \text { vs } 0 \text {; pelvic pain } 1 \\
\text { vs } 0 \text {; skin and subcutaneous tissue disorders } \\
0 \text { vs } 1 \text {; rash macular } 0 \text { vs } 1 \text {; urinary tract signs } \\
\text { and symptoms } 1 \text { vs } 1 \text {; dysuria } 1 \text { vs } 1 \text {. Most AEs } \\
\text { were reported as mild (Nickel 2010) }\end{array}$ \\
\hline & & 2.8 & 34 & 49 & 69 & 35 & 49 & 71 & $\begin{array}{l}\text { Treatment-related AEs occurred in } 3 \text { vs } 5 \text { par- } \\
\text { ticipants (Nickel 2012a) }\end{array}$ \\
\hline $\begin{array}{l}\text { Chon- } \\
\text { droitin } \\
\text { sulfate + } \\
\text { hyaluronic } \\
\text { acid }\end{array}$ & DMSO & 6 & 11 & 74 & 15 & 11 & 36 & 31 & $\begin{array}{l}\text { Treatment-related AEs were seen in } 1 \text { partic- } \\
\text { ipant in the 'chondroitin sulfate + hyaluron- } \\
\text { ic acid' group and } 8 \text { participants in the DMSO } \\
\text { group. The most common treatment-related } \\
\text { AEs were related to renal and urinary disor- } \\
\text { ders ( } 1 \text { vs } 8 \text { ), in particular, bladder irritation ( } 0 \\
\text { vs } 1 \text { ) or bladder pain ( } 1 \text { vs } 1 \text { ), cystitis ( } 0 \text { vs } 2 \text { ), } \\
\text { dysuria ( } 0 \text { vs } 4 \text { ) and strangury } 0 \text { vs } 1 \text { (Cervigni } \\
\text { 2014) }\end{array}$ \\
\hline $\begin{array}{l}\text { Hydro- } \\
\text { gen-rich } \\
\text { water }\end{array}$ & Control & 2 & 0 & 18 & 0 & 0 & 10 & 0 & Matsumoto 2013 \\
\hline $\begin{array}{l}\text { Immune } \\
\text { modula- } \\
\text { tors }\end{array}$ & Control & 4 & 23 & 29 & 79 & 18 & 20 & 90 & $\begin{array}{l}\text { AEs included UTI } 1 \text { vs } 2 \text {; voiding dysfunction } \\
\text { (retention) } 0 \text { vs } 0 . \text { "Headache was the most } \\
\text { frequently reported AE in the tanezumab } \\
\text { group }(20.6 \% \text { vs placebo } 16.7 \%) \text {. Paresthe- }\end{array}$ \\
\hline
\end{tabular}


sia (tanezumab 17.6\%, placebo 3.3\%) and hyperesthesia (tanezumab $8.8 \%$, placebo $0.0 \%$ ) were the most common AEs of abnormal peripheral sensation reported for tanezum-

ab. All of the abnormal peripheral sensation AEs were mild to moderate in severity, and most had resolved by the end of the study.

There were 3 patients on tanezumab and 2 on placebo who had a clinically significant worsening from baseline in the neurological examination" (Evans 2011)

\begin{tabular}{|c|c|c|c|c|c|c|c|}
\hline 8.5 & 123 & 129 & 95 & 126 & 132 & 95 & $\begin{array}{l}\text { AEs included allergy/immunology } 21 \text { vs } 19 ; \\
\text { cardiovascular, general } 7 \text { vs } 15 \text {; constitution- } \\
\text { al symptoms } 75 \text { vs } 67 \text {; fever } 5 \text { vs } 13 \text {; gastroin- } \\
\text { testinal } 70 \text { vs } 72 \text {; bladder symptoms } 101 \text { vs } \\
101 \text {; haematuria } 27 \text { vs } 45 \text {; infection, catheter } \\
\text { related } 1 \text { vs } 1 \text {; other infection } 16 \text { vs } 11 \text {; mus- } \\
\text { culoskeletal } 29 \text { vs } 23 \text {; neurological } 31 \text { vs } 25 \text {; } \\
\text { pain (pelvic) } 18 \text { vs } 26 \text {; pain (headache) } 17 \text { vs } \\
10 \text {; pain (arthralgias, myalgias } 31 \text { vs } 16 \text { ); pain } \\
\text { (other) } 39 \text { vs } 39 \text {; pulmonary } 35 \text { vs } 34 \text {; sexu- } \\
\text { al, reproductive } 15 \text { vs } 9 \text {; skin } 42 \text { vs } 38 \text { (Mayer } \\
2005 \text { ) }\end{array}$ \\
\hline 2 & 23 & 40 & 58 & 24 & 42 & 57 & $\begin{array}{l}\text { AEs occurring in } \geq 3 \text { patients in any treatment } \\
\text { included headache } 4 \text { vs } 4 \text {; arthralgia } 4 \text { vs } 4 \text {; } \\
\text { myalgia } 3 \text { vs } 0 \text {; hyperaesthesia } 3 \text { vs } 0 \text {; paraes- } \\
\text { thesia } 2 \text { vs } 3 \text {; UTI } 2 \text { vs } 1 \text {; pain in extremity } 2 \text { vs } \\
2 \text {; peripheral oedema } 2 \text { vs } 0 \text {; injection site re- } \\
\text { action } 2 \text { vs } 4 \text {; back pain } 1 \text { vs } 1 \text {; hypoaesthesia } \\
1 \text { vs } 1 \text {; nausea } 1 \text { vs } 0 \text {; fatigue } 1 \text { vs } 1 \text {; abdomi- } \\
\text { nal pain } 1 \text { vs } 0 \text {; bladder pain } 0 \text { vs } 0 \text {; dizziness } 0 \\
\text { vs } 0 \text {; urinary retention } 0 \text { vs } 0 \text {. AEs of abnormal } \\
\text { peripheral sensation included hyperaesthesia } \\
3 \text { vs } 0 \text {; paraesthesia } 2 \text { vs } 3 \text {; hypoaesthesia } 1 \text { vs } \\
1 \text {; allodynia } 1 \text { vs } 0 \text {; sensory disturbance } 1 \text { vs } 0 \text {; } \\
\text { burning sensation } 0 \text { vs } 0 \text {; decreased vibratory } \\
\text { sense } 0 \text { vs } 2 \text { (Nickel } 2016 \text { ) }\end{array}$ \\
\hline 6 & $\mathrm{~N} / \mathrm{R}$ & 17 & $\mathrm{~N} / \mathrm{A}$ & $\mathrm{N} / \mathrm{R}$ & 15 & $\mathrm{~N} / \mathrm{A}$ & $\begin{array}{l}\text { AEs included arthralgia } 3 \text { vs } 1 \text {; fatigue } 2 \text { vs } \\
0 \text {; low back pain } 3 \text { vs } 4 \text {; burning } 3 \text { vs } 5 \text {; nau- } \\
\text { sea } 1 \text { vs } 2 \text {; bronchitis } 1 \text { vs } 0 \text {; diarrhoea } 1 \text { vs } 2 \text {; } \\
\text { fever less than } 38.5^{\circ} \mathrm{C} 0 \text { vs } 1 \text {; incontinence } 1 \\
\text { vs } 1 \text {; urinary tract infection } 2 \text { vs } 1 \text {; rash } 0 \text { vs } 1 \text {; }\end{array}$ \\
\hline
\end{tabular}




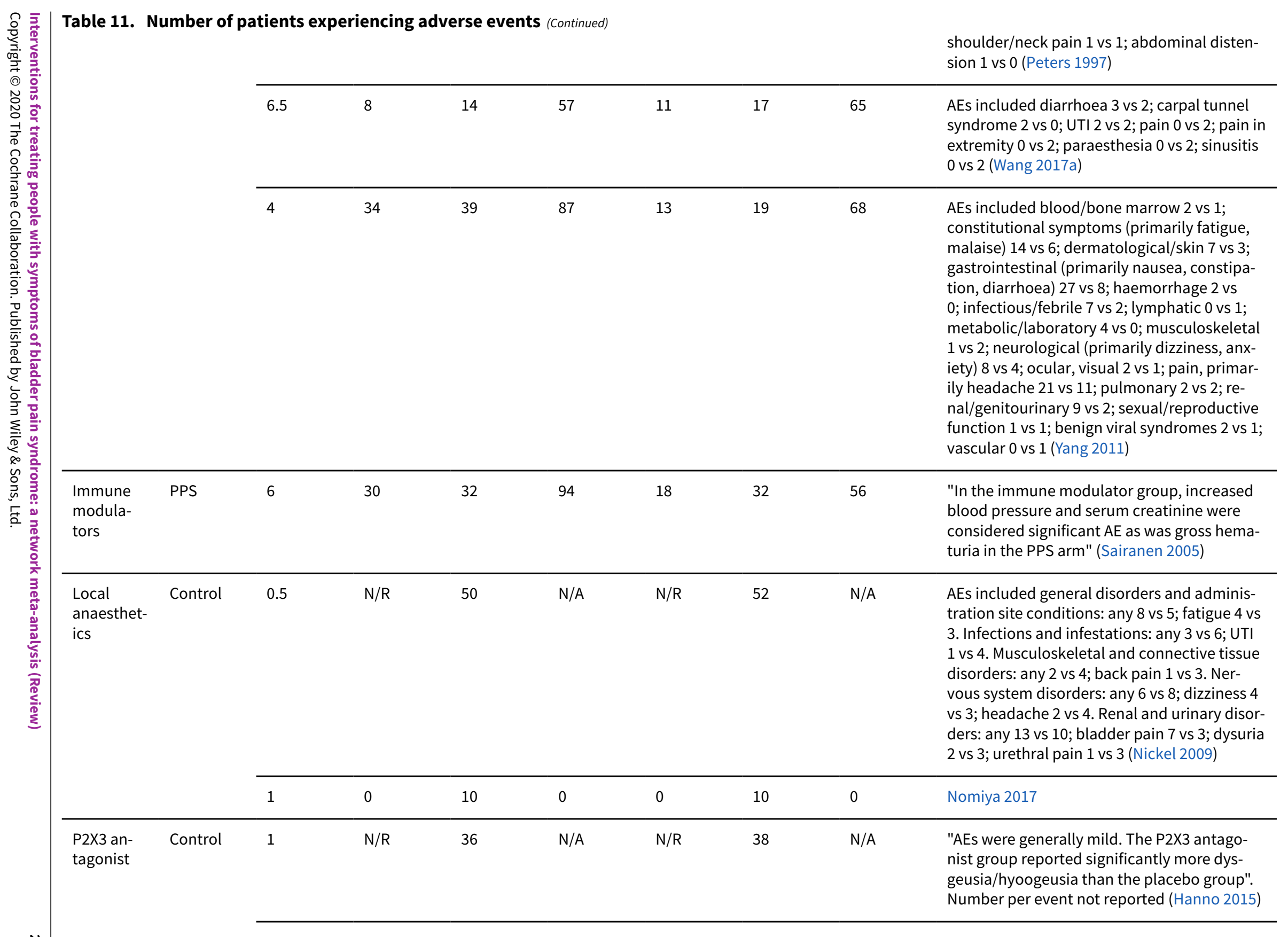




\begin{tabular}{|c|c|c|c|c|c|c|c|c|c|}
\hline & & 1 & $N / R$ & 36 & $\mathrm{~N} / \mathrm{A}$ & $N / R$ & 38 & $\mathrm{~N} / \mathrm{A}$ & $\begin{array}{l}\text { "AEs were generally mild. The most frequent- } \\
\text { ly reported AE in AF- } 219 \text { treated patients } \\
\text { (=P2X3 antagonist) was dysgeusia/hypogeusi- } \\
\text { a" (Moldwin 2015) }\end{array}$ \\
\hline $\begin{array}{l}\text { Parasym- } \\
\text { path- } \\
\text { omimetic } \\
\text { (+ urinary } \\
\text { antisep- } \\
\text { tics) }\end{array}$ & Control & 0.7 & 10 & 11 & 91 & 9 & 11 & 82 & $\begin{array}{l}\text { "Dry mouth was the most frequent side effect } \\
\text { in the Cystex group" (Souza 2012) }\end{array}$ \\
\hline $\begin{array}{l}\text { PDE5 in- } \\
\text { hibitor }\end{array}$ & Control & 6 & $N / R$ & 24 & $\mathrm{~N} / \mathrm{A}$ & $N / R$ & 24 & $\mathrm{~N} / \mathrm{A}$ & $\begin{array}{l}\text { AEs included mild headache in } 1 \text { and flushing } \\
\text { in } 4 \text { in the sildenafil group. "The symptoms } \\
\text { remitted after 2-4 days" (Chen 2014) }\end{array}$ \\
\hline \multirow[t]{3}{*}{ PPS } & \multirow[t]{3}{*}{ Control } & 4.5 & $N / R$ & 21 & N/A & $N / R$ & 20 & $\mathrm{~N} / \mathrm{A}$ & $\begin{array}{l}\text { AEs included UTI } 2 \text { vs } 0 \text {; headache } 14 \text { vs } 12 \text {; } \\
\text { bruise in arms due to blood draw } 11 \text { vs 11; } \\
\text { mild hair loss } 3 \text { vs } 1 \text { (Davis 2008) }\end{array}$ \\
\hline & & 3 & 3 & 54 & $6 \%$ & 7 & 56 & 13 & $\begin{array}{l}\text { AEs included headache } 1 \text { vs } 2 \text {; nausea } 1 \text { vs } \\
0 \text {; indigestion } 1 \text { vs } 0 \text {; increased perspiration } \\
1 \text { vs } 0 \text {; severe mood swings } 1 \text { vs } 0 \text {; suicidal } \\
\text { ideation } 1 \text { vs } 0 \text {; diarrhoea } 0 \text { vs } 2 \text {; explosive di- } \\
\text { arrhoea } 0 \text { vs } 1 \text {; severe joint pain } 0 \text { vs } 1 \text {; skin } \\
\text { rash on arms } 0 \text { vs } 1 \text {; itching } 0 \text { vs } 1 \text { (Mulholland } \\
\text { 1990) }\end{array}$ \\
\hline & & 6 & 205 & 251 & 82 & 96 & 118 & 81 & $\begin{array}{l}\text { AEs include bladder pain } 82 \text { vs } 38 \text {, nausea } 31 \\
\text { vs } 9 \text {, headache } 30 \text { vs } 16 \text {, nasopharyngitis } 21 \\
\text { vs } 2 \text {, diarrhoea } 19 \text { vs } 7 \text {, UTI } 18 \text { vs } 4 \text {, back pain } \\
12 \text { vs } 2 \text {, sinusitis } 12 \text { vs } 7 \text {, dizziness } 10 \text { vs } 3 \text {, in- } \\
\text { fluenza } 7 \text { vs } 6 \text { (Nickel 2015) }\end{array}$ \\
\hline \multicolumn{10}{|l|}{ Surgical } \\
\hline \multirow{2}{*}{$\begin{array}{l}\text { Neuro- } \\
\text { muscular } \\
\text { blockade }\end{array}$} & \multirow[t]{2}{*}{ Control } & 1 & $N / R$ & 59 & $\mathrm{~N} / \mathrm{A}$ & $N / R$ & 31 & $\mathrm{~N} / \mathrm{A}$ & $\begin{array}{l}\text { AEs included dysuria after treatment } 3 \text { vs } 1 \text {; } \\
\text { haematuria } 0 \text { vs } 0 ; \text { UTI } 0 \text { vs } 0 \text { (Chuang 2017) }\end{array}$ \\
\hline & & 3 & 0 & 9 & 0 & 0 & 11 & 0 & Gottsch 2011 \\
\hline
\end{tabular}




\begin{tabular}{|c|c|c|c|c|c|c|c|c|c|}
\hline & & $>6$ & $N / R$ & 44 & $\mathrm{~N} / \mathrm{A}$ & $N / R$ & 23 & $\mathrm{~N} / \mathrm{A}$ & $\begin{array}{l}\text { AEs included UTI } 3 \text { vs } 0 \text {; voiding dysfunction } \\
12 \text { vs } 0 \text {; haematuria } 2 \text { vs } 0 \text {; dysuria } 10 \text { vs } 1 \\
\text { (Kuo 2009) }\end{array}$ \\
\hline & & 2 & 20 & 40 & 50 & 1 & 20 & 5 & $\begin{array}{l}\text { AEs included UTI } 2 \text { vs } 0 \text {; voiding dysfunction } \\
\text { (retention) } 1 \text { vs } 0 \text {; dysuria } 16 \text { vs } 1 \text {; haematuria } \\
1 \text { vs } 0 \text { (Kuo 2016) }\end{array}$ \\
\hline & & 3 & $N / R$ & 26 & 0 & $N / R$ & 27 & $\%$ & AEs included UTI 7 vs 5 (Manning 2014) \\
\hline & & 6 (unclear) & $N / R$ & 14 & 0 & $\mathrm{~N} / \mathrm{R}$ & 2 & $\%$ & $\begin{array}{l}\text { AEs included voiding dysfunction (retention) } \\
5 \text { vs } 0 \text { (Payne 2014) }\end{array}$ \\
\hline & & 3 & $N / R$ & 10 & 0 & $\mathrm{~N} / \mathrm{R}$ & 9 & $\%$ & AEs included UTI 3 vs 2 (Pinto 2016) \\
\hline & & 6 & 0 & 18 & 0 & 0 & 10 & 0 & Yassin 2011 \\
\hline $\begin{array}{l}\text { Neuro- } \\
\text { muscular } \\
\text { blockade + } \\
\text { DMSO }\end{array}$ & Control & 0.2 & 0 & 15 & 0 & 0 & 8 & 0 & Mirkin 2012 \\
\hline $\begin{array}{l}\text { Neuro- } \\
\text { muscular } \\
\text { blockade }\end{array}$ & $\begin{array}{l}\text { Hydrodis- } \\
\text { tension }\end{array}$ & 3 & $N / R$ & 15 & $\mathrm{~N} / \mathrm{A}$ & $N / R$ & 17 & $\mathrm{~N} / \mathrm{A}$ & $\begin{array}{l}\text { AEs included upper urinary tract retention } 0 \\
\text { vs } 0 \text { (Kasyan 2012) }\end{array}$ \\
\hline $\begin{array}{l}\text { Denerva- } \\
\text { tion }\end{array}$ & $\begin{array}{l}\text { Hydrodis- } \\
\text { tension }\end{array}$ & 1 & $N / R$ & 12 & $\mathrm{~N} / \mathrm{A}$ & $N / R$ & 12 & $\mathrm{~N} / \mathrm{A}$ & $\begin{array}{l}\text { AEs included self-limited transient haema- } \\
\text { turia } 0 \text { vs } 1 \text {; left lower limb numbness } 1 \text { vs } 0 \text {; } \\
\text { lower back ache } 2 \text { vs } 0 \text { (El-Hefnawy 2015) }\end{array}$ \\
\hline $\begin{array}{l}\text { Hyperbar- } \\
\text { ic oxygen } \\
\text { (HBO) }\end{array}$ & Control & 3 & 4 & 12 & 33 & 1 & 7 & 14 & $\begin{array}{l}\text { "Four patients in the treatment arm reported } \\
\text { transient problems with accommodation dur- } \\
\text { ing treatment that were not further report- } \\
\text { ed at 3-month follow-up. One woman report- } \\
\text { ed mild eustachian tube dysfunction during } \\
\text { treatment sessions, resulting in a transient } \\
\text { hearing impairment within the chamber. The } \\
\text { events were solved by intense chewing of } \\
\text { some candy or gum, resulting in the open- } \\
\text { ing of the tube with subsequent pressure bal- } \\
\text { ance between the middle ear and the envi- } \\
\text { ronment. A decongestant nasal spray was oc- } \\
\text { casionally administered some minutes before } \\
\text { start of and/or during treatment. Oral med- }\end{array}$ \\
\hline
\end{tabular}




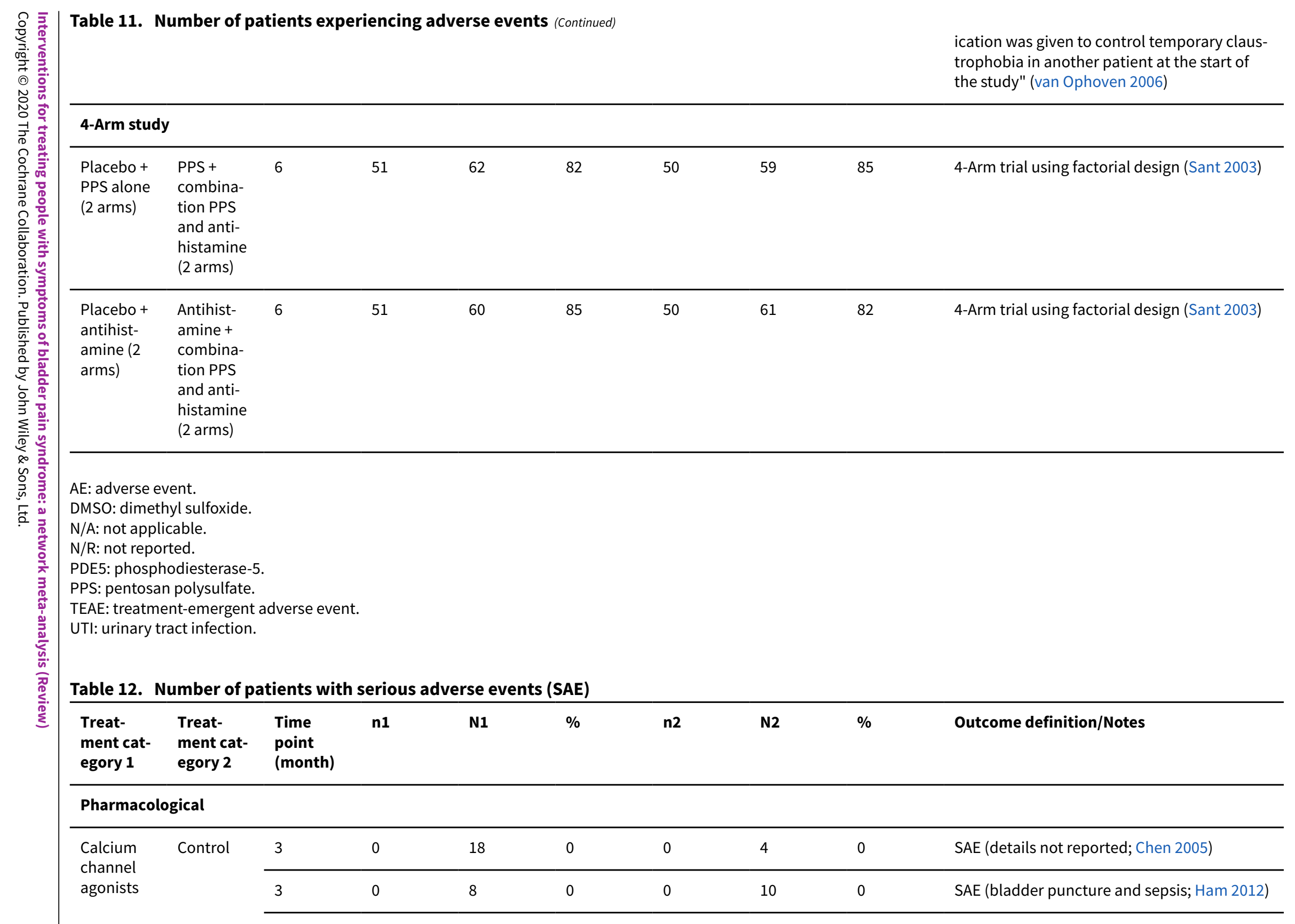




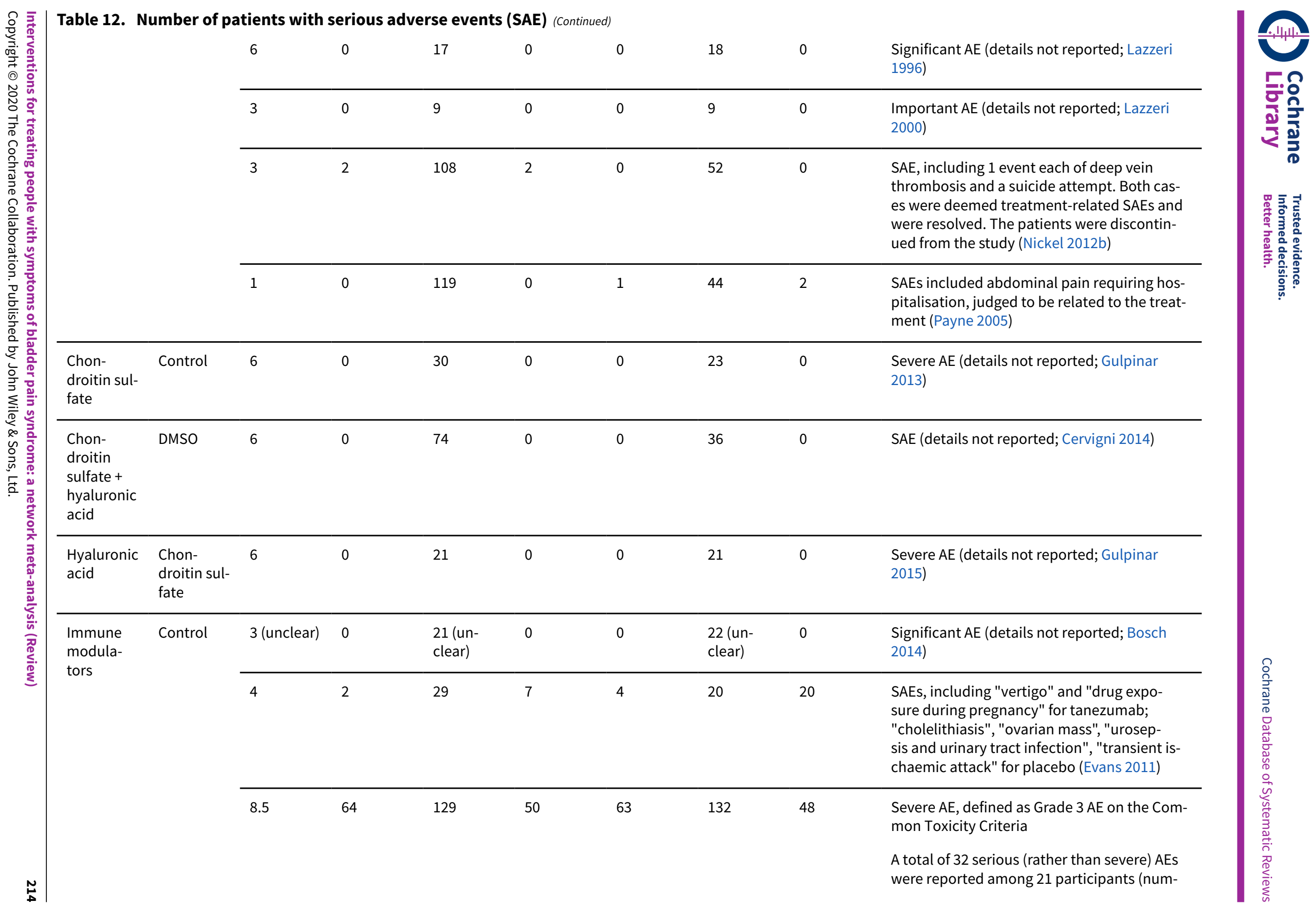




\begin{tabular}{|c|c|c|c|c|c|c|c|c|c|}
\hline & & & & & & & & & $\begin{array}{l}\text { ber in each group unclear), with } 2 \text { ascribed } \\
\text { to treatment (BCG hypersensitivity reaction } \\
\text { in } 1 \text { patient in the BCG group; prostatitis and } \\
\text { UTI in } 1 \text { patient in the placebo group) (Mayer } \\
\text { 2005) }\end{array}$ \\
\hline & & 2 & 1 & 40 & 3 & 0 & 42 & 0 & SAE (details not reported; Nickel 2016) \\
\hline $\begin{array}{l}\text { Local } \\
\text { anaesthet- } \\
\text { ics }\end{array}$ & Control & 0.5 & 4 & 50 & 8 & 5 & 52 & 10 & $\begin{array}{l}\text { Severe AE. The most common event was } \\
\text { bladder pain, which usually resolved within a } \\
\text { day of instillation (Nickel 2009) }\end{array}$ \\
\hline P2X3 an- & Control & 1 & 0 & 36 & 0 & 0 & 38 & 0 & SAE (details not reported; Hanno 2015) \\
\hline & & 1 & 0 & 36 & 0 & 0 & 38 & 0 & SAE (details not reported; Moldwin 2015) \\
\hline $\begin{array}{l}\text { PDE5 in- } \\
\text { hibitor }\end{array}$ & Control & 6 & 0 & 24 & 0 & 0 & 24 & 0 & SAE (details not reported; Chen 2014) \\
\hline PPS & Control & 6 & 4 & 251 & 2 & 4 & 118 & 3 & $\begin{array}{l}\text { SAEs, including } 1 \text { event each of abdominal } \\
\text { pain, anxiety, chest pain, gastroesophageal } \\
\text { reflux disease, pyrexia, renal mass and uri- } \\
\text { nary tract infection in the PPS group; } 1 \text { event } \\
\text { each of cholelithiasis, cholesterolosis, homi- } \\
\text { cidal ideation and urinary retention in the } \\
\text { placebo group (Nickel 2015) }\end{array}$ \\
\hline Surgical & & & & & & & & & \\
\hline Neuro- & Control & 1 & 0 & 61 & 0 & 0 & 31 & 0 & Treatment-related SAE (Chuang 2017) \\
\hline blockade & & 2 & 0 & 15 & 0 & 0 & 15 & 0 & Major AE (details not reported; Ismail 2016) \\
\hline & & 6 (unclear) & 0 & 14 & 0 & 0 & 2 & 0 & SAE (details not reported; Payne 2014) \\
\hline $\begin{array}{l}\text { Denerva- } \\
\text { tion }\end{array}$ & $\begin{array}{l}\text { Hydrodis- } \\
\text { tension }\end{array}$ & 1 & 0 & 12 & 0 & 0 & 12 & 0 & SAE (details not reported; El-Hefnawy 2015) \\
\hline
\end{tabular}

$A E$ : adverse event

BCG: bacille Calmette-Guérin

DMSO: dimethyl sulfoxide.

N/A: not applicable.

点

N/R: not reported. 

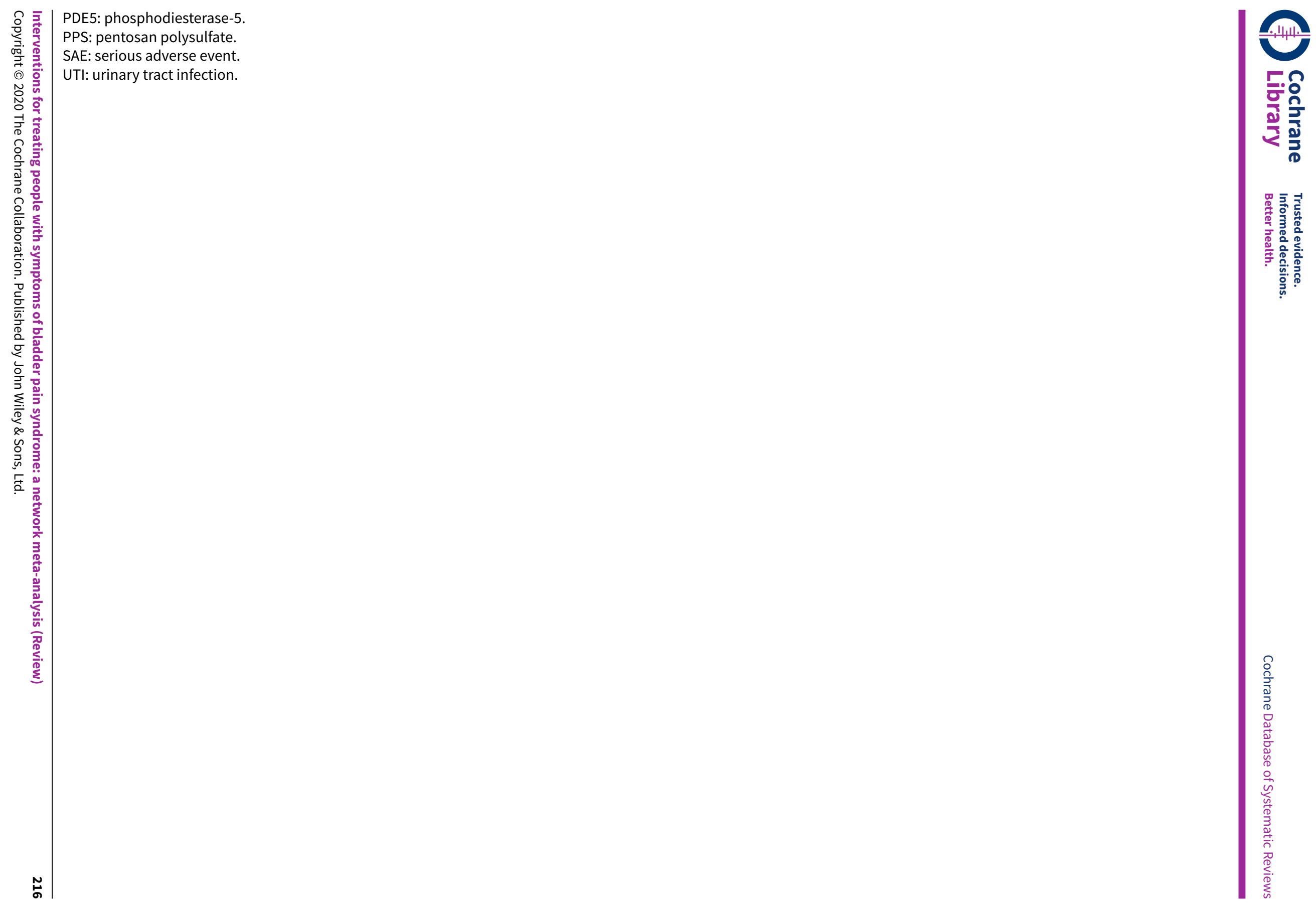


\section{A P PEN DICES}

\section{Appendix 1. Cochrane Incontinence Specialised Register - search terms}

We searched the Cochrane Incontinence Specialised Register using the following search terms:

DESIGN.CCT* or DESIGN.RCT*

AND

\section{TOPIC.URINE.INTERSTITIAL CYSTITIS.}

All searches were of the 'Keyword' field in EndNote 2018.

Please note: the UK Clinical Research Network Portfolio was replaced by UK Clinical Trials Gateway, which in turn has been replaced by Be Part of Research. At 11 July 2019, the site is still in development and is available at https://bepartofresearch.nihr.ac.uk/

\section{H I S T O R Y}

Protocol first published: Issue 5, 2019

Review first published: Issue 7, 2020

\section{CONTRIBUTIONS OFAUTHORS}

MI: designed and wrote the protocol; conducted risk of bias assessment, data extraction and data checking; and drafted the methods and results section.

NS: designed and wrote the protocol; contributed to data extraction and data checking; conducted all statistical analyses; contributed to interpretation and presentation of results; and drafted methods and results sections.

JO: conceived, designed and wrote the protocol; provided expert advice; conducted study screening and selection, risk of bias assessment and data extraction; and contributed to interpretation of results.

AF: conceived, designed and wrote the protocol; provided expert advice; conducted study screening and selection, risk of bias assessment and data extraction; and contributed to interpretation of results.

SW: designed and wrote the protocol; conducted literature searches and compiled the reference list of the review; led study screening and selection; conducted risk of bias assessment; and drafted sections of the report related to the search strategies and search results.

YD: contributed to protocol development; conducted data extraction; and drafted the background section.

MB: designed and wrote the protocol; contributed to study screening and selection; interpreted data; and provided expert advice on review methods.

\section{DECLARATIONSOF INTEREST}

MI: none known.

NS: none known.

JO: none known.

AF: received money from Astellas towards travel to the IUGA Conference in 2016; this had no impact on this current work.

SW: serves as Cochrane Information Specialist for Cochrane Incontinence, whose single largest funder is the UK National Institute for Health Research (NIHR).

YD: none known.

MB: none known.

This work was supported by a grant from the NIHR Systematic Reviews Programme (project number 16/59/01), which was paid to the University of Aberdeen.

\section{SOURCES OF SUPPORT}

\section{Internal sources}

- No sources of support supplied

\section{External sources}

- Chief Scientist Office of the Scottish Government Health and Social Care Directorates, UK

The Health Services Research Unit is core-funded by the Chief Scientist Office of the Scottish Government Health and Social Care Directorates. The views expressed in this report are those of the authors and not necessarily those of the Chief Scientist Office of the Scottish Government Health Directorates or of the NIHR PHR Programme. Any errors are the responsibility of the authors. 
- National Institute for Health Research (NIHR), UK

This review was commissioned by the NIHR Systematic Reviews Programme as project number 16/59/01.

- National Institute for Health Research (NIHR), UK

This project was supported by the National Institute for Health Research, via Cochrane Infrastructure funding to Cochrane Incontinence. The views and opinions expressed therein are those of the authors and do not necessarily reflect those of the Evidence Synthesis Programme, the NIHR, NHS or the Department of Health and Social Care.

\section{DIFFERENCES BETWEEN PROTOCOL AND REVIEW}

Methods used for the GRADE assessment of evidence certainty and the 'Summary of findings' table were amended after the review commenced. These include the use of CINeMA software, modification of the 'Risk of bias' assessment to make it outcome specific and specification of minimal clinically important differences for primary outcomes. 